\title{
DNA barcoding, phylogeny and systematics of Golden-backed frogs (Hylarana, Ranidae) of the Western Ghats-Sri Lanka biodiversity hotspot, with the description of seven new species
}

\author{
S.D. Biju ${ }^{1,4}$, Sonali Garg ${ }^{1}$, Stephen Mahony ${ }^{1,2}$, Nayana Wijayathilaka ${ }^{3}$, Gayani Senevirathne ${ }^{3}$, Madhava Meegaskum- \\ bura $^{3}$ \\ ${ }^{1}$ Systematics Lab, Department of Environmental Studies, University of Delhi, Delhi 110 007, India \\ ${ }^{2}$ School of Biology and Environmental Science, UCD Science Centre (West), University College Dublin, Belfield, \\ Dublin 4, Ireland \\ ${ }^{3}$ Evolutionary Ecology and Systematics Lab, Faculty of Science \& Postgraduate Institute of Science, University of \\ Peradeniya, Sri Lanka \\ ${ }^{4}$ E-mail:sdbiju@es.du.ac.in
}

Key words: Amphibia, cryptic species, endemism, integrative taxonomy, lectotypification, multiple gene barcoding, neotypification, taxonomic revision

\begin{abstract}
A systematic revision of the genus Hylarana in the Western Ghats-Sri Lanka biodiversity hotspot is presented. Species delineation in Hylarana is complicated due to a lack of distinct colour differences or striking morphological characters, leading to potential misidentification. We conducted extensive surveys throughout the Western Ghats-Sri Lanka biodiversity hotspot and performed multiple gene (16S, COI and Cytb) barcoding using 103 samples collected from cultivated land and natural habitats. Genetic distance comparisons and Neighbor Joining trees indicated the presence of at least 14 candidate species in the region, supported by taxa groupings for all three genetic markers. Utilising a combination of molecular and morphological data, we describe seven new species, doubling the number of Hylarana species previously known from this region. We further demonstrate that $H$. temporalis, which was originally described from Sri Lanka, was misidentified with the Western Ghats endemic species for nearly 100 years. Conversely, $H$. aurantiaca was originally described from the Western Ghats and misidentified in Sri Lanka. Our study confirms that the distribution of $H$. temporalis is restricted to Sri Lanka, while $H$. aurantiaca is endemic to the Western Ghats, and that there are no shared Hylarana species between the two regions. Hylarana flavescens, $H$. intermedius and $H$. montanus, previously considered synonyms of $H$. temporalis are confirmed as valid species. Hylarana bhagmandlensis is removed from the synonymy of $H$. aurantiaca and placed as a junior subjective synonym of $H$. montanus. To establish nomenclatural stability, H. flavescens, $H$. malabarica and $H$.temporalis are lectotypified and $H$. intermedius is neotypified. Detailed descriptions, diagnosis, morphological and genetic comparisons, illustrations and data on distribution and natural history are provided for all species. Phylogenetic analyses based on three mitochondrial markers (16S, COI and Cytb) and a fragment of the nuclear Rag1 gene, show complete endemism of the Western Ghats-Sri Lankan species. Four major groups in this region are identified as: $1-$ the Hylarana aurantiaca group, endemic to the Western Ghats; 2 - the Hylarana flavescens group, endemic to the Western
\end{abstract}

Ghats; 3 - the Hylarana temporalis group, endemic to Sri Lanka; and 4 - the Hylarana malabarica group from Sri Lanka and India. The discovery of numerous morphologically cryptic Hylarana species in this region further emphasizes the benefits of utilizing an integrative taxonomic approach for uncovering hidden diversity and highlighting local endemism in the Western Ghats-Sri Lanka biodiversity hotspot.

\section{Contents}

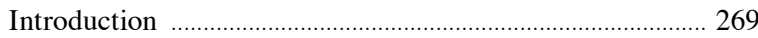

Material and methods ............................................................... 271

Field survey and specimen collection ............................. 271

DNA extraction, PCR and sequencing ............................ 271

DNA barcoding analysis ..................................................... 274

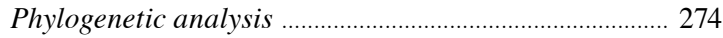

Morphology and recognition of new species .................. 274

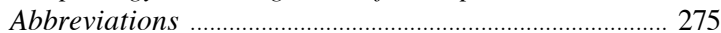

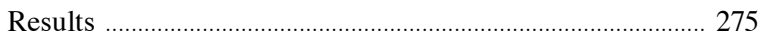

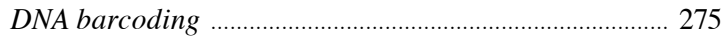

Morphological recognition of species ............................. 279

Phylogenetic analysis ....................................................... 279

Generic level taxonomy ....................................................... 280

Species level taxonomy and endemism ............................ 281

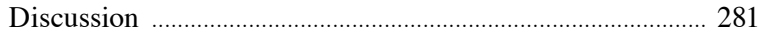

Acknowledgements ............................................................... 282

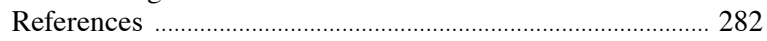

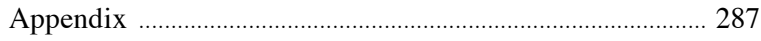

\section{Introduction}

The Western Ghats and Sri Lanka together form one of the 34 global biodiversity hotspots with extraordinary amphibian diversity and high levels of endemism (Myers et al., 2000; Meegaskumbura et al., 2002; 
Bossuyt et al., 2004; Mittermeier et al., 2004), but this region still remains poorly understood with regard to the species level identifications in many of its extant amphibians (Biju, 2001; Meegaskumbura et al., 2002). However, recent herpetological studies involving several lineages in the Western Ghats and Sri Lanka have resulted in the discovery of many previously undescribed species of frogs (e.g. Pethiyagoda and Manamendra-Arachchi, 1998; Biju, 2001; Biju and Bossuyt, 2003, 2005a, b, c, 2006, 2009; Biju et al., 2007, 2008a, 2009, 2010, 2011, 2014; Meegaskumbura et al., 2002, 2010; Meegaskumbura and Manamendra-Arachchi, 2005, 2011; Zachariah et al., 2011; Abraham et al., 2013). Despite being one of the largest genera of the cosmopolitan anuran family Ranidae (Frost, 2014), Hylarana Tschudi, 1838, has not been subjected to any rigorous systematic analyses and presently has only four known species from the entire Western Ghats-Sri Lanka biodiversity hotspot, which spans an area of more than $227600 \mathrm{~km}^{2}$.

Globally, the genus Hylarana contains 84 nominal species distributed on three continents (Frost, 2014), among which several are widely distributed (Bain et al., 2003; Frost et al., 2006). Two such species are $H$. aurantiaca (Boulenger, 1904) and H.temporalis (Günther, 1864), which are known as widely distributed species both in the Western Ghats and Sri Lanka (e.g. Daniel and Sekar, 1989; Dutta and ManamendraArachchi, 1996; Dutta, 1997; Chanda, 2002; Daniels, 2005; De Silva, 2009). The taxonomy of these commonly occuring species is confusing and unstable (Biju, 2001; Biju et al., 2004a, b). Moreover, unlike the other genera from this region, Hylarana is the only widespread genus for which no new taxa have been described for the past 77 years.

Günther (1864) described Hylorana [sic] temporalis from 'Ceylon' (= Sri Lanka) and this species was subsequently reported from the entire Western Ghats (e.g. Boulenger, 1920; Inger et al., 1985; Daniel and Sekar, 1989; Dutta and Manamendra-Arachchi, 1996; Dutta, 1997; Chanda, 2002; Daniels, 2005). On the other hand, a relatively smaller species, Rana aurantiaca was described by Boulenger (1904) from 'near Trivandrum, Travancore [Kerala]', southern India, and later reported to occur in Sri Lanka (e.g. Dutta and Manamendra-Arachchi, 1996; Dutta, 1997; De Silva, 2009). Hylarana temporalis and $H$. aurantiaca have not been studied in any great detail from across their ranges and many of the systematists working on amphibians of the Western Ghats and Sri Lanka continue to treat similar looking species from both regions as same (e.g.
Boulenger, 1920; Kirtisinghe, 1957; Inger et al., 1985; Daniel and Sekar, 1989; Dutta and ManamendraArachchi, 1996; Dutta, 1997; Chanda, 2002; Daniels, 2005; Pethiyagoda et al., 2006; De Silva, 2009; Ukuwela, 2009; Bopage et al., 2011; Reshmy et al., 2011).

Phylogenetic relationships of taxa currently contained in the genus Hylarana still remain unresolved at both species and generic level (Chen et al., 2005; Matsui et al., 2005; Bossuyt et al., 2006; Che et al., 2007; Gawor et al., 2009; Inger et al., 2009). Within the geographical region of interest to our study, $\mathrm{Hy}$ drophylax Fitzinger, 1843 and Sylvirana Dubois, 1992 are currently placed in the synonymy of Hylarana (Che et al., 2007). At species level Hylarana aurantiaca contains Rana (Hylorana) bhagmandlensis Rao, 1922 as a synonym (by Dubois, 1992), while Hylarana temporalis contains three synonyms: Rana flavescens Jerdon 1853, Rana (Hylorana) gracilis montanus Rao, 1922 and Rana (Hylorana) intermedius Rao, 1937

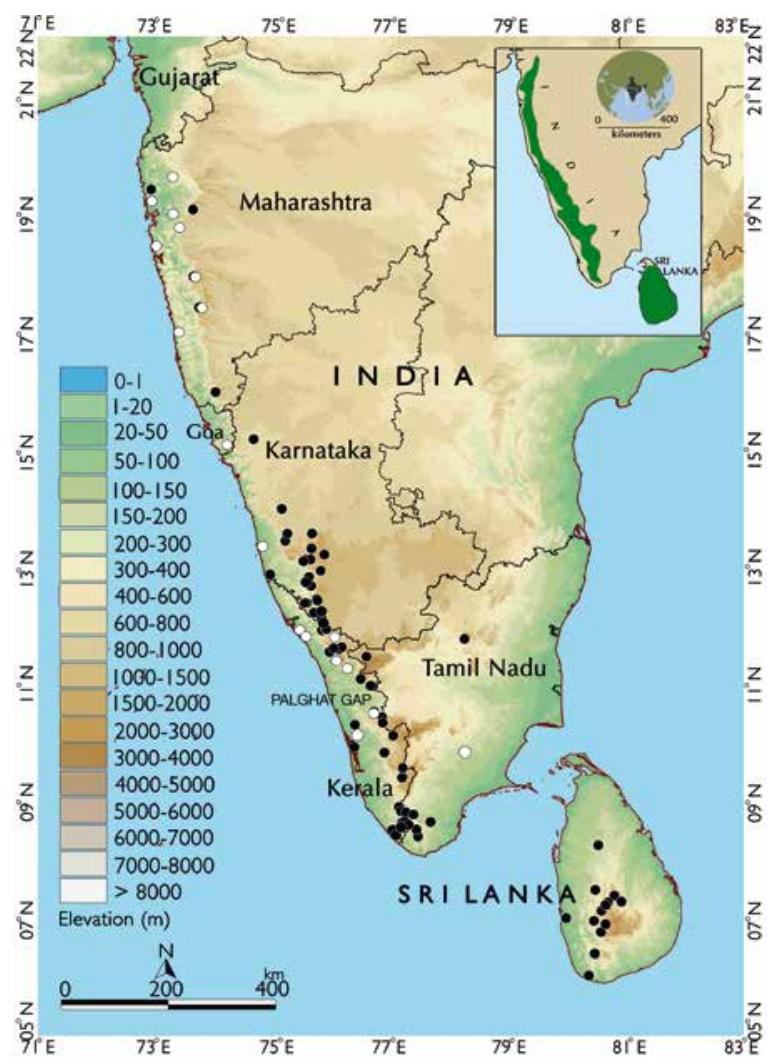

Fig. 1. Study area, the Western Ghats-Sri Lanka Global biodiversity hotspot and distribution of the genus Hylarana. Closed circles indicate the present study collections and open circles indicate specimens studied from museums. Coordinates are provided in Table 1. 
(placed by Boulenger, 1882; Dutta, 1997; Dubois, 1992, respectively). However, no molecular phylogenetic justification is available for these placements.

A few studies have concentrated on other aspects of Hylarana in South and Southeast Asia. Several tadpoles of Hylarana species have been studied in some detail (e.g. Grosjean, 2005; Gawor et al., 2009; Bortamuli et al., 2010), especially emphasising on the reproductive ecology, and the external and buccal morphology typically for a single Gosner stage (between stages 27 and 39). Most of the studies on Hylarana tadpole development and ecology have been on the Indian $H$. temporalis (e.g. Girish and Saidapur, 1999; Hiragond and Saidapur, 1999; Hiragond and Saidapur, 2001; Veeranagoudar et al., 2004a, b). Though it is well known that carefully studied larval amphibian characters are invaluable for systematic studies (Haas, 1996, 1997; Maglia et al., 2001; Grosjean, 2005), the paucity of lineages analysed so far is not sufficient for this information to be useful in a systematics context involving Western Ghats-Sri Lanka biodiversity hotspot members. The genus Hylarana has also recently attracted the attention of scientists for new antimicrobial peptides that have been isolated from the skin of several species (e.g. Conlon et al., 2008a, b; Al-Ghaferi et al., 2009; Wang et al., 2009), including H. temporalis from India (Reshmy et al., 2010, 2011).

Currently, no exhaustive systematics studies have been undertaken to understand the diversity of this group in the Western Ghats-Sri Lanka biodiversity hotspot. Our study uses concordant evidence based on molecular barcoding, morphology and molecular phylogenetic analyses to investigate the following questions: Are there independent evolutionary lineages that need to be recognized as significant taxonomic units within this region? What are the distribution ranges of these lineages? Are Hylarana temporalis and H. aurantiaca single widely distributed species, or do they represent morphologically cryptic species complexes? To address these questions we sampled Hylarana species from throughout the Western Ghats-Sri Lanka biodiversity hotspot, and generated new morphological and molecular data to understand lineage diversity in this group.

\section{Material and methods}

\section{Field survey and specimen collection}

The study includes 103 Hylarana tissue vouchers sampled from throughout the Western Ghats and Sri Lanka during field trips from 2002-2013. An attempt was made to obtain unbiased partitions of genetic diversity by sampling randomly from 70 and 15 locations in the Western Ghats and Sri Lanka, respectively. The study also includes five tissue samples collected from Central and Northeast India. Adult specimens were collected at night, mostly by locating calling males, and sometimes by opportunistic surveys during both day and night. Live frogs were photographed in the wild, with a few exceptions in captivity. Animals were euthanised in MS-222 (Tricaine methane sulphonate), fixed in 4\% formalin for two days and transferred to $70 \%$ ethanol after washing under running water. Before fixation in formalin, a portion of the thigh muscle or liver was taken and preserved in absolute ethanol for subsequent molecular analyses. Tissue samples were stored at $-20^{\circ} \mathrm{C}$ in the Systematics Lab, University of Delhi (SDBDU) for Indian species, and the Department of Zoology, University of Peradeniya (DZ) for Sri Lankan species. Type specimens from India are deposited in the Bombay Natural History Society Museum (BNHS) and specimens from Sri Lanka in the Department of Zoology, University of Peradeniya (DZ). Sampling localities and geographical range per species are given in Table 1 and Fig. 1, respectively. A Garmin 76CSx was used to record GPS coordinates in the field.

\section{DNA extraction, PCR and sequencing}

Genomic DNA was extracted from ethanol-preserved muscle or liver tissue samples from 108 specimens, using standard extraction protocol (Sambrook et al., 1989) or a Qiagen DNA extraction kit following manufacturer's protocol. Three mitochondrial (mt) genes: $\approx 540$ bp segment of $16 \mathrm{~S}$ rRNA $(16 \mathrm{~S}), \approx 580 \mathrm{bp}$ segment of Cytochrome $\mathrm{b}$ (Cytb) and $\approx 650 \mathrm{bp}$ segment of Cytochrome oxidase subunit I (COI) genes were PCR-amplified from 108 samples, and one nuclear (nu) gene, $\approx$ 555 bp segment of Rag1 was PCR-amplified from 36 samples representing all species groups. Primers used in the study follow Simon et al. (1994), Bossuyt and Milinkovitch (2000), Che et al. (2012) and Biju and Bossuyt (2003), respectively. Sequences were generated on both strands using a BigDye Terminator v3.1 Cycle Sequencing Kit and an ABI 3730 automated DNA sequencer (Applied Biosystems). Sequence data was checked and assembled in ChromasPro v1.34 (Technelysium Pty Ltd.). MEGA 5.0 (Tamura et al., 2011) was used to edit sequences, create alignment by ClustalW analysis and to manually optimise the dataset. Newly generated sequences were submitted to 
Table 1. Collection localities of Hylarana species of the Western Ghats-Sri Lanka biodiversity hotspot discussed in the text. Localities are arranged by state. ${ }^{1}$ Specimens not used in morphometric studies but identity confirmed from molecular evidence, ${ }^{2}$ Specimens studied from museum collections, ${ }^{3}$ Specimens studied from museum collections but not used in morphometric measurements.

\begin{tabular}{llc}
\hline Locality & $\begin{array}{l}\text { Altitude } \\
(\text { meters })\end{array}$ & $\begin{array}{c}\text { Coordinates } \\
\text { Latitude }\left({ }^{\circ} \mathrm{N}\right) \text { Longitude }\left({ }^{\circ} \mathrm{E}\right)\end{array}$ \\
\hline
\end{tabular}

INDIA

\section{Tamil Nadu}

\begin{tabular}{|c|c|c|c|c|c|}
\hline Dindigul district & Manalur, Palni hills & 118 & 9,859 & 78,216 & H. malabarica ${ }^{3}$ \\
\hline Kanyakumari district & Glenback estate, Kiriparai & 450 & 8,419 & 77,418 & H. sreeni \\
\hline \multirow[t]{2}{*}{ Nilgiris district } & Naduvattam & 1908 & 11,473 & 76,548 & H.flavescens \\
\hline & Yercaud, Shevaroy hills & 1439 & 11,775 & 78,209 & H. sreeni ${ }^{1}$ \\
\hline \multirow[t]{2}{*}{ Tirunelveli district } & Kakkachi 1 & 1266 & 8,536 & 77,395 & H. magna ${ }^{1}$ \\
\hline & Kakkachi 2 & 1200 & 8,667 & 77,633 & H. magna 1 \\
\hline
\end{tabular}

\section{Kerala}

\begin{tabular}{|c|c|c|c|c|c|}
\hline \multirow[t]{2}{*}{ Ernakulam district } & Kadavanthra & 5 & 9,969 & 76,307 & H. urbis \\
\hline & Tripunithura & 11 & 9,936 & 76,340 & H. urbis \\
\hline \multirow[t]{4}{*}{ Idukki district } & Kadalar estate, Munnar & 1421 & 10,133 & 76,999 & H. sreeni ${ }^{1}$ \\
\hline & Poomala & 119 & 9,844 & 76,851 & H. doni \\
\hline & Thekkady 1 & 936 & 9,573 & 77,159 & H. doni \\
\hline & Thekkady 2 & 924 & 9,584 & 77,162 & H. sreeni \\
\hline \multirow[t]{5}{*}{ Kannur district } & Aralam WLS 1 & 66 & 11,922 & 75,791 & H. indica ${ }^{1}$ \\
\hline & Aralam WLS 2 & 461 & 11,941 & 75,866 & H. indica ${ }^{1}$ \\
\hline & Aralam WLS, Meenmutty & 358 & 11,938 & 75,857 & H. indica ${ }^{1}$ \\
\hline & Cannanore (= Kannur) & 21 & 11,875 & 75,370 & H. malabarica ${ }^{3}$ \\
\hline & Tellicherry (= Thalassery) & 12 & 11,752 & 75,492 & H. malabarica ${ }^{3}$ \\
\hline Kasaragod district & Edanad & 16 & 10,140 & 76,395 & H. malabarica ${ }^{2}$ \\
\hline \multirow[t]{2}{*}{ Kollam district } & Kattilappara, Shendurney WLS & 130 & 8,918 & 77,095 & H. aurantiaca ${ }^{1}$ \\
\hline & Pandimotta, Shendurney WLS & 1222 & 8,827 & 77,217 & H. sreeni, H. magna \\
\hline \multirow[t]{2}{*}{ Kozhikode district } & Kakkayam, Calicut & 752 & 11,554 & 75,920 & H. intermedius \\
\hline & Pullurampara & 55 & 11,405 & 76,038 & H. malabarica ${ }^{3}$ \\
\hline \multirow{2}{*}{ Malappuram district } & Kadakkattupara & 30 & 11,134 & 75,879 & H. urbis ${ }^{1}$ \\
\hline & Nilambur & 40 & 11,272 & 76,224 & H. malabarica ${ }^{3}$ \\
\hline \multirow[t]{8}{*}{ Palakkad district } & Nelliyampathy, Kaikatti & 965 & 10,537 & 76,676 & H. sreeni \\
\hline & Nelliyampathy, Kesavapara & 923 & 10,524 & 76,667 & H. doni \\
\hline & Nelliyampathy, Padagiri & 922 & 10,525 & 76,672 & H. doni \\
\hline & Parambikulam TR 1 & 544 & 10,445 & 76,813 & H. doni \\
\hline & Parambikulam TR 2 & 955 & 10,352 & 76,822 & H. doni, H. sreeni \\
\hline & Sairandhri, Silent Valley & 962 & 11,095 & 76,451 & H.flavescens \\
\hline & Siruvani, Kuddam & 758 & 10,970 & 76,655 & H. sreeni \\
\hline & Siruvani, Singappara & 856 & 10,979 & 76,615 & H. sreeni, H. flavescens ${ }^{1}$ \\
\hline \multirow[t]{2}{*}{ Pathanamthitta district } & Gavi 1 & 1210 & 9,430 & 77,166 & H. doni \\
\hline & Gavi 2 & 1107 & 9,417 & 77,151 & H. sreeni \\
\hline Thiruvananthapuram & Athirimala & 1425 & 8,793 & 77,342 & H. magna \\
\hline \multirow{9}{*}{ district } & Attyar, Agasthyamala & 605 & 8,634 & 77,209 & H. magna ${ }^{1}$ \\
\hline & Chathankod, Thekal & 127 & 8,658 & 77,153 & H. aurantiaca \\
\hline & Chathankod 1 & 116 & 8,661 & 77,153 & H. doni, H. sreeni \\
\hline & Chathankod 2 & 140 & 8,659 & 77,149 & H. aurantiaca, H. doni \\
\hline & Kallar, Ponmudi & 180 & 8,849 & 77,132 & H. aurantiaca ${ }^{1}$ \\
\hline & Karamana & 18 & 8,478 & 76,968 & H. aurantiaca \\
\hline & Palode & 150 & 8,633 & 77,15 & H. doni ${ }^{1}$ \\
\hline & Pandipath & 1340 & 8,675 & 77,197 & H. magna ${ }^{1}$ \\
\hline & Vellayani & 23 & 8,431 & 77,000 & H. aurantiaca \\
\hline \multirow[t]{2}{*}{ Thrissur district } & Meladoor & 150 & 10,317 & 76,35 & H. urbis, H. malabarica \\
\hline & Mannuthy & 40 & 10,524 & 76,294 & H. malabarica \\
\hline \multirow[t]{4}{*}{ Wayanad district } & Kalpetta & 950 & 11,6 & 76,083 & H. intermedius \\
\hline & Mananthavady (= Mānantoddy) & 766 & 11,807 & 76,010 & H. malabarica ${ }^{3}$ \\
\hline & Settukunnu & 823 & 11,617 & 75,991 & H. flavescens \\
\hline & Suganthagiri & 1300 & 11,636 & 76,127 & H. indica \\
\hline
\end{tabular}

\section{Karnataka}

Chikmagalur district

Bygoor
Charmadi Ghats

\section{2}

929

$\begin{array}{ll}13,311 & 75,613 \\ 13,118 & 75,510\end{array}$

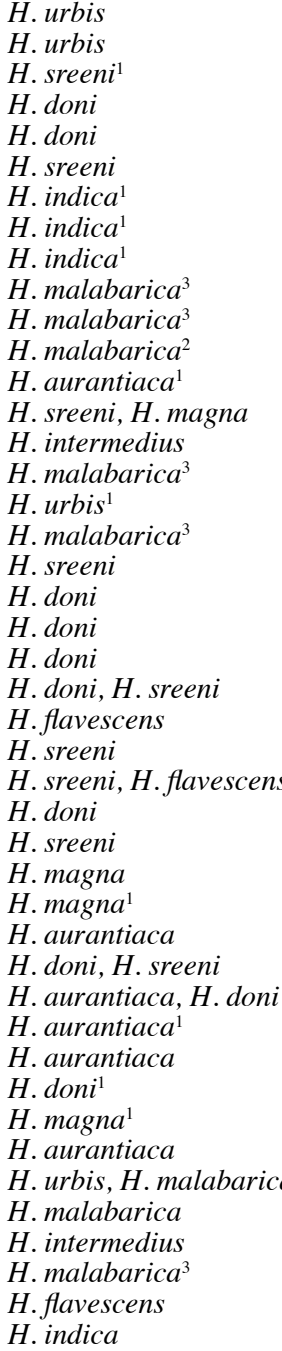

H. urbis

urbis

H. doni

$H$. indica $^{1}$

indica ${ }^{1}$

H. malabarica ${ }^{3}$

H. aurantiaca ${ }^{1}$

sreeni, H. magna

H. urbis

H. doni

$H$. flavescens

H. doni

H. magna

. aurantiaca

H. aurantiaca, H. doni

H. doni ${ }^{1}$

H. magna

aurantiaca

$H$. malabarica

malabarica

$H$. indica 


$\begin{array}{ll} & \text { Mudigere } \\ & \text { Muthodi-Kemmanagundi } \\ \text { Dakshin Kannada district } & \text { Adyar, Mangalore } \\ & \text { Gundia } \\ & \text { Gundia-Subramanya } \\ \text { Hemphan district } & \text { Kottigehara 1 } \\ & \text { Kottigehara 2 } \\ & \text { Sakleshpur } \\ & \text { Bhagamandala } \\ \text { Kodagu district } & \text { Madikeri 1 } \\ & \text { Madikeri 2 } \\ & \text { Thalakaveri } \\ & \text { Wattakolli, Coorg } \\ & \text { Yavakapady, Coorg } \\ \text { Shimoga district } & \text { Jog falls } \\ & \text { Kachigebailu } \\ \text { Udupi district } & \text { Someshwar } \\ \text { Uttara Kannada district } & \text { Dandeli }\end{array}$

$\begin{array}{rll}862 & 13,125 & 75,597 \\ 1100 & 13,565 & 75,623 \\ 8 & 12,868 & 74,913 \\ 129 & 12,828 & 75,572 \\ 122 & 12,677 & 75,609 \\ 649 & 12,8566 & 75,696 \\ 798 & 13,208 & 75,832 \\ 796 & 13,095 & 75,477 \\ 948 & 12,936 & 75,770 \\ 889 & 12,386 & 75,534 \\ 1102 & 12,453 & 75,703 \\ 1145 & 12,429 & 75,715 \\ 1183 & 12,386 & 75,503 \\ 675 & 12,127 & 75,786 \\ 1176 & 12,220 & 75,656 \\ 600 & 13,442 & 75,170 \\ 639 & 13,984 & 75,110 \\ & & \\ 100 & 13,563 & 75,205 \\ 494 & 15,167 & 74,632\end{array}$

H. indica ${ }^{1}$

H. montanus

$H$. intermedius

H. indica

H. indica

H. indica ${ }^{1}$

H. montanus

H. montanus

$H$. intermedius

$H$. intermedius ${ }^{1}, H$. montanus

$H$. intermedius

H. indica ${ }^{1}$

$H$. intermedius ${ }^{1}, H$. montanus

$H$. intermedius

H. montanus

$H$. intermedius

$H$. intermedius,

H. malabarica haplogroup ${ }^{1}$

$H$. indica ${ }^{1}$

H. indica

\begin{tabular}{|c|c|c|c|c|c|}
\hline \multicolumn{6}{|l|}{ Goa } \\
\hline Goa district & Goa & 193 & 15,068 & 74,181 & H. malabarica haplogroup $1^{3}$ \\
\hline \multicolumn{6}{|l|}{ Maharashtra } \\
\hline Mumbai district & Kanheri Caves & 180 & 19,208 & 72,906 & H. malabarica haplogroup $1^{3}$ \\
\hline \multirow[t]{2}{*}{ Pune district } & Bhimashankar & 972 & 19,068 & 73,605 & H. malabarica haplogroup $1^{1,3}$ \\
\hline & Khandala & 541 & 18,760 & 73,374 & H. malabarica haplogroup $1^{3}$ \\
\hline \multirow[t]{2}{*}{ Raigad district } & Matheran & 840 & 18,990 & 73,269 & H. malabarica haplogroup $1^{3}$ \\
\hline & Phansad WLS & 221 & 18,455 & 72,926 & H. malabarica haplogroup $1^{3}$ \\
\hline Ratnagiri district & Ratnagiri & 9 & 16,983 & 73,3 & $\begin{array}{l}\text { H. } \text { caesari }^{1} \text {, } \\
\text { H. malabarica haplogroup } 1^{3}\end{array}$ \\
\hline \multirow[t]{4}{*}{ Satara district } & Humbarli, Koyna & 827 & 17,403 & 73,737 & H. caesari \\
\hline & Koyna Nagar & 746 & 17,4 & 73,76 & $\begin{array}{l}\text { H. } \text { caesari }^{2} \text {, } \\
\text { H. malabarica haplogroup } 1^{3}\end{array}$ \\
\hline & Mahabaleshwar & 1307 & 17,922 & 73,642 & H. caesari $^{2}$ \\
\hline & Mahabaleshwar, Dhobi's fall & 1188 & 17,919 & 73,652 & H. caesari ${ }^{3}$ \\
\hline Sindhudurg district & Amboli & 733 & 15,969 & 73,988 & $\begin{array}{l}\text { H. } \text { caesari }^{1} \text {, } \\
\text { H. malabarica haplogroup } 1\end{array}$ \\
\hline Thane district & $\begin{array}{l}\text { Tansa WLS } \\
\text { Tungareshwar WLS }\end{array}$ & $\begin{array}{r}170 \\
77\end{array}$ & $\begin{array}{l}19,620 \\
19,409\end{array}$ & $\begin{array}{l}73,262 \\
72,894\end{array}$ & $\begin{array}{l}\text { H. malabarica haplogroup } 1^{3} \\
H . \text { malabarica haplogroup } 1^{3}\end{array}$ \\
\hline
\end{tabular}

\section{SRI LANKA}

\begin{tabular}{|c|c|c|c|c|c|}
\hline Anuradhapura district & Nachchaduwa & 126 & 8,271 & 80,478 & H. gracilis \\
\hline Galle district & Hiyare & 121 & 6,059 & 80,316 & H. gracilis \\
\hline Gampaha district & Ganemulla & 28 & 7,033 & 79,931 & H. gracilis \\
\hline \multirow[t]{5}{*}{ Kandy district } & Panwila & 930 & 7,416 & 80,749 & H. temporalis \\
\hline & Peradeniya, Kevunkahata Ela & 731 & 7,246 & 80,615 & H. temporalis \\
\hline & Peradeniya, Sarasavi Oya & 506 & 7,255 & 80,600 & H. gracilis, H. temporalis \\
\hline & Udadumbara & 914 & 7,312 & 80,869 & H. temporalis \\
\hline & Udawatta Kele & 591 & 7,299 & 80,640 & H. gracilis \\
\hline \multirow[t]{2}{*}{ Kegalle district } & Hemmathagama & 448 & 7,160 & 80,533 & H. temporalis \\
\hline & Kithulgala & 119 & 6,986 & 80,403 & H. temporalis ${ }^{1}$ \\
\hline Kurunegala district & Karawaddana & 114 & 7,512 & 80,427 & H. gracilis \\
\hline \multirow{2}{*}{ Nuwara Eliya district } & Kotagala & 1250 & 6,929 & 80,603 & H. gracilis \\
\hline & $\begin{array}{l}\text { Morey estate, Sri Pada } \\
\text { (Adam's peak) }\end{array}$ & 1424 & 6,795 & 80,523 & H. temporalis \\
\hline \multirow[t]{2}{*}{ Ratnapura district } & Kudawa, Sinharaja 1 & 446 & 6,431 & 80,416 & H. temporalis \\
\hline & Kudawa, Sinharaja 2 & 517 & 6,417 & 80,423 & H. serendipi \\
\hline \multicolumn{6}{|l|}{ Colonial locations } \\
\hline & $\begin{array}{l}\text { 'Travancore' } \\
\text { 'Malabar' } \\
\text { 'Mysore' } \\
\text { 'Ceylon' }\end{array}$ & & & & $\begin{array}{l}\text { H. } \text { aurantiaca }^{2} \\
\text { H. } \text { flavescens }^{2}, H . \text { malabarica }^{2} \\
\text { H. } \text { montanus }^{2} \\
\text { H. } \text { temporalis }^{2}\end{array}$ \\
\hline
\end{tabular}


GenBank under accession numbers KM068907KM069261. Sequences used from GenBank are provided in Table S1.

\section{DNA barcoding analysis}

Three independent mtDNA datasets (16S, COI and Cytb) were created in MEGA 5.0 (Tamura et al., 2011) utilising sequences from 103 Western Ghats and Sri Lankan specimens. The datasets contained: 504 characters for $16 \mathrm{~S}$ rRNA, and 579 and 580 characters for protein coding COI and Cytb, respectively. For each dataset, a Neighbor Joining tree was constructed using the Kimura 2-parameter (K2P) distance model. Clinotarsus curtipes (Jerdon, 1853) was used as outgroup, since it is a closely related ranid to the genus Hylarana (Roelant et al., 2004; Frost et al., 2006; Che et al., 2007). Uncorrected pairwise genetic distances were computed as implemented in PAUP* $4.0 \mathrm{~b} 10$ (Swofford, 2002). Based on taxon grouping in Neighbor Joining trees, data matrices were constructed for a total of 7745 pairwise comparisons from 16S (85), COI (90) and Cytb (97) sequences, to verify species delineation, understand intra and interspecific variation, and geographical range of each species. Identical haplotypes among the sequences were excluded from genetic distance calculations. Taxonomic haplotypes were selected based on sequence divergence and morphometric analysis (see 'Morphology and recognition of new species'). Genetic distance values were calculated between individuals or populations of recognised species, and between closely related species. These were plotted independently for three molecular markers to graphically analyse the overlap between maximum intraspecific and minimium interspecific pairwise distance values (Meyer and Paulay, 2005).

\section{Phylogenetic analysis}

A combined dataset of $2208 \mathrm{bp}$ for 46 taxa was assembled from mitochondrial 16S (512 bp), COI (579 bp) and Cytb (558 bp), and nuclear Rag1 (559 bp) sequences of 30 selected haplotypes representative of species from the Western Ghats-Sri Lanka region, one additional sample from Central India, four from Northeast India, and nine representative Southeast Asian taxa from GenBank. The tree was rooted using Lankanectes corrugatus (Peters, 1863) as an additional outgroup. Phylogenetic relationships were reconstructed using Maximum Likelihood and Bayesian analyses in PAUP* $4.0 \mathrm{~b} 10$ (Swofford, 2002). For phylogeny inference by likelihood method, an appropriate model was determined by implementing Akaike Information Criterion in ModelTest 3.5 (Posada and Crandall, 1998). GTR $+\mathrm{I}+\mathrm{G}$ was estimated as the best model and ML searches were executed using the substitution model with the following parameters: Rate matrix: $\mathrm{R}(\mathrm{G}-\mathrm{T})=$ $1, \mathrm{R}(\mathrm{C}-\mathrm{T})=19.840, \mathrm{R}(\mathrm{C}-\mathrm{G})=0.837, \mathrm{R}(\mathrm{A}-\mathrm{T})=3.236$, $R(A-G)=15.643, R(A, B, C)=2.120$; Nucleotide frequency: $\mathrm{A}=0.293, \mathrm{C}=0.276, \mathrm{G}=0.147, \mathrm{~T}=0.284$; Rate variation: shape parameter for gamma distributed rate variation among sites (alpha) $=0.630$; proportion of invariable sites $=0.522$. Bayesian inference as implemented in MrBayes (Huelsenbeck and Ronquist, 2001) was used to generate a phylogenetic hypothesis of relationships among the taxa, and to estimate a general time reversible model of sequence evolution with gamma-distributed rate variation among sites and a proportion of invariant sites $(\mathrm{GTR}+\mathrm{I}+\mathrm{G})$. Four MetropolisCoupled Markov Chain Monte Carlo (MCMCMC) chains were run for 500,000 generations and the summed likelihood of the four chains reached burn-in time by 100,000 generations. We used the frequency of clades in trees that were sampled every 100 generations from the last 250,000 generations as estimates of the posterior probabilities of those clades (Huelsenbeck et al., 2001). Uniform priors were used throughout and branch lengths, topology, and nucleotide substitution parameters were unconstrained. To evaluate clade stability, we implemented a Bootstrap Analysis in a Maximum Parsimony Bootstrap framework (1000 replicates, random stepwise addition with 100 repetitions).

\section{Morphology and recognition of new species}

Our study adopted an integrative approach in recognising species based on molecular and morphological data. The candidate species were compared with all available types, and with recently collected specimens from the type localities for species whose type series have been lost or destroyed. For convenience of discussion, Hylarana species were grouped as small (25-40 $\mathrm{mm})$, medium $(41-70 \mathrm{~mm})$ and large (71-95 mm). Sex and maturity were determined by examining gonads through a small lateral or ventral incision. Only mature (adult) animals were used for morphological analysis, species comparisons and as type series. Identity of sub-adult specimens was confirmed through molecular analysis allowing inclusion of their collection localities in the distribution of respective species.

Measurements and associated terminology follow Biju et al. (2011); webbing formula follows Savage and 
Heyer (1967) as modified by Myers and Duellman (1982). The amount of webbing relative to subarticular tubercles is described by numbering the tubercles 1-3, starting from the toe discs. The term shank is used here to refer to the part of the leg containing the tibia, and thigh is used for the part containing the femur. Measurements of all specimens were taken by SDB (with the exception of the type series of Hylarana aurantiaca, $H$. temporalis and $H$. montanus by SM), using a digital slide-caliper, or a binocular microscope with a micrometre ocular, to the nearest $0.1 \mathrm{~mm}$. All measurements provided in the taxonomy section are in millimetres. Range, average and standard deviation used in the 'comparison' section without mentioning the sex are for males. Abbreviations: SVL (snout-vent length), HW (head width, at the angle of the jaws), HL (head length, from the rear of the mandible to the tip of the snout), MN (distance from the rear of the mandible to the nostril), MFE (distance from the rear of the mandible to the anterior orbital border), MBE (distance from the rear of the mandible to the posterior orbital border), SL (snout length, from the tip of the snout to the anterior orbital border), EL (eye length, horizontal distance between the bony orbital borders), IUE (inter upper eyelid width, shortest distance between the upper eyelids), UEW (maximum upper eyelid width), IFE (internal front of the eyes, shortest distance between the anterior orbital borders), IBE (internal back of the eyes, shortest distance between the posterior orbital borders), FAL (forearm length, from the flexed elbow to the base of the outer palmar tubercle), HAL (hand length, from the base of the outer palmar tubercle to the tip of the third finger), SHL (shank length), TL (thigh length), FOL (foot length, from the base of the inner metatarsal tubercle to the tip of the fourth toe), TFOL (distance from the heel to the tip of the fourth toe), FD (disc width of finger), FW (width of finger, measured at the base of the disc), TD (disc width of toe), TW (width of toe, measured at the base of the disc), digit number is represented by roman numerals I-V.

\section{Abbreviations}

For museums and frequently used terms, abbreviations are as follows: BNHS (Bombay Natural History Society, Bombay, India), DU (University of Delhi, Delhi, India), MNHN (Muséum National d'Histoire Naturelle, Paris), NHM (Natural History Museum, formerly British Museum (Natural History)), BMNH, (British Museum (Natural History), London, United Kingdom),
ZSIC (Zoological Survey of India, Kolkata, India), SDB (S.D. Biju), SG (Sonali Garg), MM (Madhava Meegaskumbura), NW (Nayana Wijayathilaka) and SM (Stephen Mahony). In the Material studied section and Table 2 the following abbreviations after specimen numbers refer to: (HT) holotype, (PT) paratype, (LT) lectotype, (PLT) paralectotype, (RS) referred specimen and (TT) topotype.

\section{Results}

\section{DNA barcoding}

Neighbor Joining (NJ) trees for 16S (Fig. 2), COI and Cytb (not shown) were created for species delineation and to help elucidate species geographic ranges. The three molecular markers produced identical taxa groupings and similar tree topologies.

Here, we discuss our results with respect to only the 16S NJ tree (Fig. 2) since the topology was in agreement with our deeper phylogenetic analyses, and because analysis based on this gene showed a more conservative approach to species delineation. Within the in-group taxa, there were 15 major clades corresponding to four valid Hylarana species: H. aurantiaca (clade 1), H. temporalis (clade 12), H. gracilis (clade 13) and $H$. malabarica (clade 14); three named species currently considered as synonyms: $H$. intermedius (clade 2), H. flavescens (clade 9) and H. montanus (clade 10); and between seven (clades 3-8 and 11) to eight (clades 3-8, 11 and 14a) unnamed species. We herein describe these as - Hylarana doni sp. nov., Hylarana urbis sp. nov., Hylarana sreeni sp. nov., Hylarana indica sp. nov., Hylarana caesari sp. nov., Hylarana magna sp. nov. and Hylarana serendipi sp. nov., respectively (Appendix) and clade 14a is referred to as Hylarana malabarica haplogroup 1. For further discussion see 'Morphological recognition of species'.

Genetic distance comparisons (Tables S2, S3) showed maximum intraspecific uncorrected pairwise distance of $1.5 \%$ (for $16 \mathrm{~S}$ ) and $3.6 \%$ (for COI) for Hylarana sreeni (clade 5). For Cytb, maximum intraspecific distance of $6.2 \%$ was observed for $\mathrm{H}$. indica (clade 6) and $6.1 \%$ for $H$. sreeni. With respect to closely related species, the minimum interspecific uncorrected pairwise divergence was $16 \mathrm{~S}: 2.0 \%$ between $H$. indica and $H$. sreeni, COI: $4.3 \%$ between $H$. sreeni and $H$. indica, Cytb: $8.0 \%$ between $H$. intermedius and H. doni. An analysis of the barcode gap showed no overlap between the maximum intraspecific pairwise 


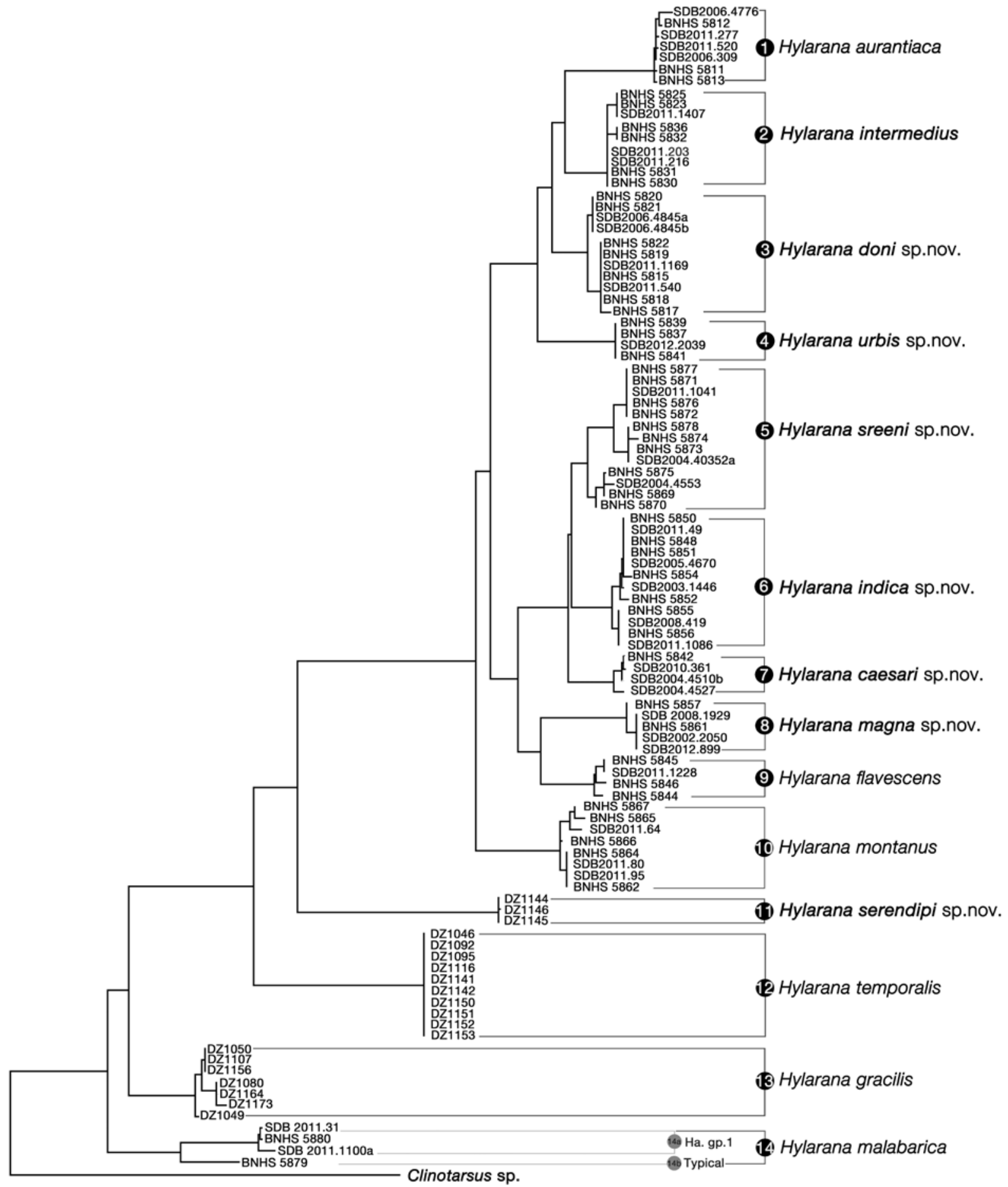

0.005 substitutions/site

Fig. 2. Neighbour Joining tree of Kimura-2-parameter (K2P) distances based on mtDNA 16S for 102 Hylarana samples from the Western Ghats-Sri Lanka biodiversity hotspot. Collection numbers are presented in Table S1. 


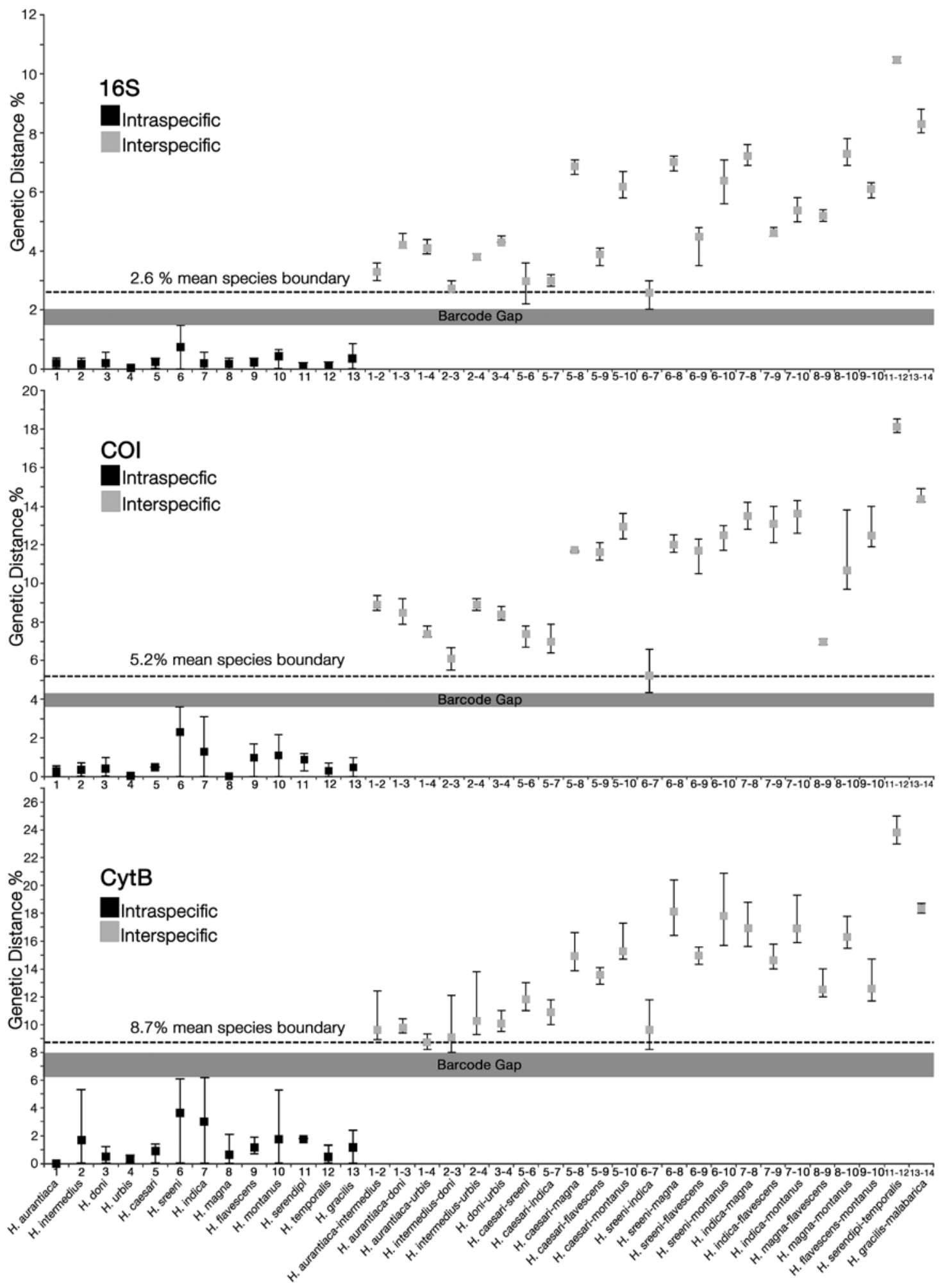

Fig. 3. Comparison of mean, minimum and maximum uncorrected pairwise intraspecific values for 13 species, and interspecific values for 23 species pairs. Mean threshold values for species delineation are represented for three mitochondrial markers: $16 \mathrm{~S}$ showing $2.6 \%$, COI showing 5.2\% and Cytb showing 8.7\%. For intra and interspecific comparisons, see Tables S2 and S3. 


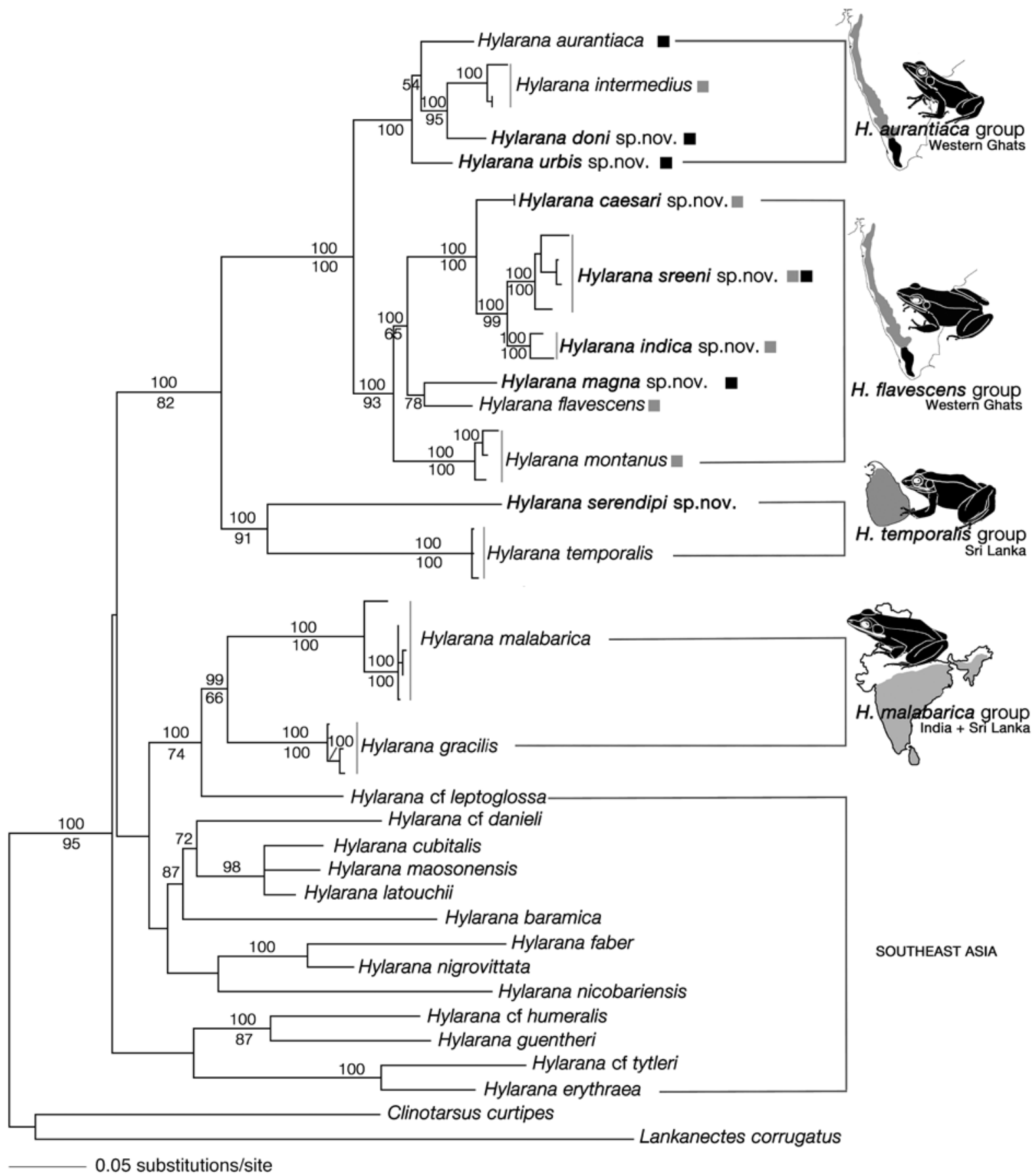

Fig. 4. Maximum Likelihood tree for 46 taxa, including 30 selected haplotypes from the Western Ghats-Sri Lanka biodiversity hotspot, five Hylarana species from Northeast and Central India, nine Hylarana species from Southeast Asia, and two outgroup taxa. Numbers above and below the nodes indicate Bayesian Posterior Probabilities and Maximum Parsimony Boostrap values $>50$, respectively. Squares indicate the species distribution - black squares represent species found south of Palghat Gap, grey squares represent species found north of Palghat Gap. 
distance within species and the minimum interspecific divergence between species (Fig. 3). The observed mean threshold values of sequence divergence for species delineation were: $2.6 \%$ for $16 \mathrm{~S}, 5.2 \%$ for COI and $8.7 \%$ for Cytb. A high level of genetic variation was observed between H. malabarica typical and H. malabarica haplogroup 1 (clades 14a-b) (Fig. 2). Though there was considerable sequence divergence with an average of $3.7 \%$ for $16 \mathrm{~S}$, the COI and Cytb sequence divergences (3.2\% and $6.2 \%$ respectively) were lower than the threshold values observed for other species pairs. Maximum divergence in our dataset was observed within the $H y$ larana temporalis group of Sri Lanka, with mean values of $10.5 \%$ (16S), 18.1\% (COI) and 23.8\% (Cytb) between the species $H$. serendipi and H. temporalis.

Overall, not only were our results concordant for all the three molecular markers but also in agreement with earlier studies that have proposed 3\% and 4-8\% as threshold values for $16 \mathrm{~S}$ and COI, respectively (Fouquet et al., 2007a; Smith et al., 2008). Only two of the recognised species pairs showed slightly lower mean sequence divergence values for $16 \mathrm{~S}(2.7 \%$ between Hylarana intermedius- $H$. doni, and $2.5 \%$ between $H$. indica-H. sreeni). However, morphologically these represented well-supported distinct lineages. For Cytb, the overall threshold value was slightly lower than the values shown by certain other studies (Kotaki et al., 2010; Hasan et al., 2012). However, there are not many comparable studies available for amphibian barcoding based on Cytb, and since species delineation based on Cytb sequences was in agreement with the other two molecular markers in the present study, an $8.7 \%$ threshold value for Cytb seems realistic. For detailed genetic comparisons, see the 'Genetic divergence' section of each species in the Appendix.

Our barcoding results, in the light of taxonomic interpretations, showed remarkable patterns of species level distribution. All of the Western Ghats and Sri Lankan taxa formed distinct clades. The Western Ghats groups showed north-south distribution trends among different species, while the Sri Lankan species showed a dry zone-wet zone (again essentially a north-south) distribution trend (Fig. 1). Hylarana malabarica (India) and H. gracilis (Sri Lanka), both with wider distributions, formed the basal clades to all of the remaining Western Ghats-Sri Lankan clades (Fig. 2).

\section{Morphological recognition of species}

A detailed comparison of morphological data along with molecular evidence provides greater confidence in the identification of 14 taxonomic haplotypes (Figs 2, 4), and facilitates a comprehensive taxonomic revision of Hylarana from the Western Ghats-Sri Lanka biodiversity hotspot. Morphological examination of available types, museum specimens and our recent collections, indicate seven new species in the genus Hylarana, all of which are endemic to the Western Ghats-Sri Lanka biodiversity hotspot. Furthermore, the study of new collections of three 'lost' species: Rana (Hylarana) gracilis montanus Rao, 1922, Rana flavescens Jerdon, 1853 and Rana (Hylorana) intermedius Rao, 1937 from their type localities 'Bhagamandla', 'Malabar' and 'Sakleshpur', respectively, conclude that these are valid species. Rana (Hylorana) bhagmandlensis Rao, 1922 is considered as junior subjective synonym of Hylarana monta$n u s$, based on detailed comparison of type specimens and original descriptions. Detailed taxonomic accounts and the descriptions of the new species are provided in the Appendix, and illustrated in Figs 5-25.

Our data is insufficient to provide a conclusive taxonomic resolution to the status of Hylarana malabarica haplogroup 1 from the northern Western Ghats, which on the basis of the molecular data appeared to represent a lineage divergent from the typical form, from the southern Western Ghats. The available specimen collection of both the typical and haplogroup forms was, however, inadequate from the entire range of this species to enable detailed morphological comparisons. Our preliminary results indicate that $H$. malabarica typical and $H$. malabarica haplogroup 1 are very similar morphologically and therefore we recognise that further work is required to assess the taxonomic status of these populations.

\section{Phylogenetic analysis}

The results of our phylogenetic analysis allow us to investigate evolutionary relationships among all nominal species within the Western Ghats-Sri Lanka biodiversity hotspot, and with the Southeast Asian taxa by extending the geographical range of our dataset.

The Maximum Likelihood tree (Fig. 4) depicts four major clades, which are highly resolved, with various associated distribution patterns within the Western Ghats-Sri Lanka biodiversity hotspot: the Hylarana aurantiaca and Hylarana flavescens groups are restricted to the Western Ghats; the Hylarana temporalis group is found only in Sri Lanka; the Hylarana malabarica group has a wide distribution in India and Sri Lanka, along with Hylarana cf. leptoglossa from Northeast India (Fig. 4). 
The other Southeast Asian taxa, including Hylarana nigrovittata - type species of the genus Sylvirana (Dubois, 1992), were found to be basal to the abovementioned Western Ghats and Sri Lankan groups. However these associations were not strongly supported, probably due to insufficient taxon sampling to resolve these relationships. The clade containing Hylarana erythraea (type species of the genus Hylarana) formed the most basal split with strong support. Though some relationships among the Southeast Asian taxa remained unresolved due to poor data sampling from outside the study area, most branches in our trees were well supported and the overall topology was in agreement with earlier studies (Che et al., 2007; Pyron and Wiens, 2011).

Seen in the context of Che et al. (2007) and Pyron and Wiens (2011) our results suggest that most of the Western Ghats-Sri Lankan congeners form an endemic radiation (Fig. 4). This includes the Hylarana aurantiaca and $H$. flavescens groups from India, and the $H$. temporalis group from Sri Lanka. The H. malabarica group which has one species each from India and Sri Lanka, forms a well-supported clade with South East Asian H. cf. leptoglossa. Given that previously recognized generic level taxa (Sylvirana and Hydrophylax) included in our study form sister clades at the base of the phylogeny, further taxonomic focus is needed to ascertain if the endemic Western Ghats-Sri Lankan radiation warrants a higher level taxonomic status.

Three (out of four) Northeast Indian taxa nested with Southeast Asian species rather than the species from the Western Ghats, except Hylarana cf. leptoglossa, which was closely related to the Hylarana malabarica group (Fig. 4). This group also contained the single sample from Central India (SDBDU 2011.596), which nested with the Hylarana malabarica haplogroup 1 . The identity of this sub-adult specimen could not be confirmed morphologically. Our results suggest that among the Western Ghats-Sri Lankan groups, the Hylarana malabarica group is more closely related to the Southeast Asian taxa. This is also evident from the distribution of species in the subgenus Hydrophylax (Dubois, 1992), whose taxonomic status remains unresolved (Che et al., 2007). Though our sampling is insufficient to comment on the dispersal and distribution of Hylarana throughout its range, the results of our study provide the first molecular evidence for the diversity and distribution of Hylarana species across the Western Ghats and Sri Lankan biogeographical region, and may assist future studies to resolve the existing uncertainty about taxonomic positions of taxa contained in the genus Hylarana.

\section{Generic level taxonomy}

Our study provides an opportunity to discuss the taxonomic history of two named, but currently synonymised group level taxa within the genus Hylarana (sensu lato).

Hydrophylax Fitzinger, 1843: We report sequences from the type species of Hydrophylax (H. malabarica from 'Malabar' India). Our molecular phylogenetic analysis suggests monophyly of the proposed Hylarana malabarica group (containing $H$. malabarica and H. gracilis) (Fig. 4), along with morphological support (Figs 5, 6). Hylarana cf. leptoglossa, a species closely related to the $H$. malabarica group, is shown to have distinct finger and toe tips demonstrating that digit tip morphology may not be taxonomically significant for delineating putative generic level taxa like Hydrophylax, as previously suggested (Dubois, 1992). Further morphological and molecular evidence incorporating more samples from the H. malabarica group, as well as closely related members like 'Hylarana leptoglos$s a$ ' and Amnirana would be required to completely resolve the taxonomic status of Hydrophylax. For detailed taxonomic history see generic level taxonomy in the appendix.

Sylvirana Dubois, 1992: Our study does not provide conclusive evidence to address the generic status of Sylvirana, but suggests an interesting biogeographical pattern to understand the dispersal of members of the genus Hylarana. The well-supported sister relationship between the Hylarana malabarica group and $H$. cf. leptoglossa, a species which was previously regarded as Sylvirana leptoglossa (Dubois, 1992; Frost et al. 2006), indicates that if Sylvirana is considered as a genus, it would include members from throughout much of India and Sri Lanka, as well as Southeast Asia, thus partially supporting the assertions of some studies (e.g. Dubois, 1992, 2005; Frost et al., 2006; Fei et al., 2010). However, this mixed clade is a sequential sister group to the well-supported and phylogenetically distinct Western Ghats-Sri Lankan endemic radiation (H. aurantiaca, $H$. flavescens and $H$. temporalis groups). The phylogenetic position of this clade relative to its sister congeners, suggests that the Western Ghats-Sri Lankan endemic radiation came into being through an India-Sri Lanka dispersal event from Southeast Asia through Northeast India. 


\section{Species level taxonomy and endemism}

The detailed morphological and molecular evidences from our study successfully resolved many taxonomic ambiguities and distribution limits of several nominal taxa in the genus Hylarana. These include species that have long been misidentified, or are currently considered as synonyms. Confirmed endemicity of $H$. aurantiaca and $H$. temporalis based on our results is interesting given that these two species have been known for more than 100 years (H. aurantiaca), up to nearly 150 years $(H$. temporalis). While $H$. aurantiaca is endemic to the vicinity of its type locality in the Western Ghats, H. temporalis is endemic to Sri Lanka. The small-sized Hylarana in Sri Lanka belong to a previously unnamed species $H$. serendipi and 'Hylarana temporalis' populations from India comprise of a complex of two named $(H$. flavescens and $H$. monta$n u s)$ and four previously unnamed species (H. caesari, $H$. indica, $H$. magna and $H$. sreeni). Hylarana flavescens, $H$. intermedius and $H$. montanus are resurrected from the synonymy of H.temporalis and considered as valid species. Rana (Hylorana) bhagmandlensis is removed from the synonymy of $H$. aurantiaca, and regarded as a junior subjective synonym of $H$. montanus. In the interest of nomenclatural stability, Rana flavescens, Rana malabarica and Hylorana temporalis are lectotypified, and a neotype is designated for Rana (Hylorana) intermedius. Hylarana malabarica, which was originally described from the southern Western Ghats is suggested to possibly represent at least two genetically distinct morphologically cryptic species. For taxonomic remarks on all Hylarana species of the Western Ghats and Sri Lanka, see individual species accounts in the Appendix.

Our data suggests that many species have a narrow latitudinal range, especially $H$. temporalis and $H$. aurantiaca, which were previously considered as the most widely distributed taxa. The consensus of all our analyses is a trichotomy of four major lineages within the study area: 1 - the Hylarana aurantiaca group, is one that gave rise to a clade of species mostly restricted to south of the Palghat Gap, except for the distribution of H.intermedius which is only found north of the Palghat Gap (Fig. 10); 2 - the Hylarana flavescens group, is widely distributed along the entire Western Ghats, but has restricted distribution ranges at species level. Hylarana sreeni is the only species found both north and south of the Palghat gap. Hylarana magna is restricted to the Agasthyamala hill range south of the Palghat gap, while $H$. flavescens, $H$. indica and $H$. montanus are only found north of the gap. Furthermore, $H$. caesari is restricted to the northern Western Ghats of Maharashtra (Fig. 14). 3 - the Hylarana temporalis group is a radiation endemic to Sri Lanka. Hylarana temporalis is widely distributed on the island and occurs both at mid elevation (up to about 900 meters) and in the wet zones of Sri Lanka. This group also contains a previously unnamed species, $H$. serendipi, which is endemic to, and found sympatrically with H.temporalis in the wet zone of Sinharaja World Heritage Site, Sri Lanka (Fig. 20). 4 - the Hylarana malabarica group forms a distinct, well supported clade containing one peninsular Indian (H. malabarica) and one Sri Lankan (H. gracilis) species (Fig. 24). Though $H$. malabarica is considered to be widely distributed, our study finds genetic segregation between the populations found in northern (Hylarana malabarica haplogroup 1) and southern parts of the Western Ghats. Based on molecular evidence, we confirm the extended occurrence of Hylarana malabarica haplogroup 1 populations from the northern Western Ghats, east to Madhya Pradesh state. Hylarana gracilis is the most widely occurring among Sri Lankan Hylarana species, which is endemic to Sri Lanka and found from sea level to $1250 \mathrm{~m}$ elevation.

\section{Discussion}

Hylarana is one of the most widely distributed genera in Ranidae and it is also the most specious among the Ranids. As currently defined, Hylarana contains 84 species that are distributed in two broad and disjunct regions - Tropical Africa and Tropical Asia (Sri Lanka, India, southeastern Nepal, across southern China [including Taiwan], and south through Indochina, and almost the entire Indo-Australian Archipelago to northern Australia) (Frost, 2014). The distribution patterns specifically for Hylarana species in the Western Ghats-Sri Lanka biodiversity hotspot have not been studied before. Bossuyt et al. (2004) had used several vertebrate and invertebrate groups having various life history characteristics, to show that despite many land bridge connections over the last 50,000 years before present, only limited faunal exchange has taken place between the Western Ghats and Sri Lanka, thus giving rise to a pattern of clade level endemicity, and contradicting the pre-existing understanding that the two regions have numerous shared species. Our studies on Hylarana corroborate these biogeographic patterns and further bolster the notion that the Western Ghats 
and Sri Lanka both contain highly distinct and diverse endemic fauna.

The status of African Hylarana is still under debate and the taxonomy and systematics of the Asian and Australian groups is still unresolved (Gawor et al., 2009). Several studies have attempted to resolve the systematics of Ranidae and dealt superficially with Hylarana (Chen et al., 2005; Bossuyt et al., 2006; Frost et al., 2006; Che et al., 2007). However, most of the previous works were based on limited samples and a widely distributed genus like Hylarana requires a detailed phylogenetic study, with extensive taxon sampling across its geographic range, to aid in the resolution of systematic positions for all taxanomic clades. The present work is the most comprehensive study available with regards to molecular and morphological data for the Hylarana of the Western Ghats-Sri Lanka biodiversity hotspot, and may play an important role in the further resolution of Hylarana systematics.

Better sampling efforts in a study are essential to accurately determine the distribution ranges of species and also contribute to the recognition of unidentified cryptic species (Bickford et al., 2007). Sometimes the use of molecular data allows the recognition of potential operational taxonomic unites within morphologically cryptic species groups (e.g. Meegaskumbura et al., 2002; Vieites et al., 2009; Funk et al., 2011). The results of our study show that some cryptic species can be identified by careful morphological examination, e.g. Hylarana temporalis of Sri Lanka can be distinguished from the similar Indian Hylarana species, by the presence of a supratympanic ridge. In several other morphologically conserved species groups, where species identification can be a very difficult task (e.g. Kuramato et al., 2007; Biju et al., 2009; Biju et al., 2011), molecular data has proved to be extremely useful and has gained fast acceptance as a taxonomic tool (e.g. Meegaskumbura and Manamendra-Arachchi, 2005; Fouquet et al., 2007b; Biju and Bossuyt, 2009; Vieites et al., 2009; Kamei et al., 2013).

Recent advances in amphibian taxonomy have revealed that many widespread amphibian 'species' represent morphologically cryptic species groups (e.g. Bain et al., 2003; Stuart et al., 2006; Elmer et al., 2007; Biju and Bossuyt, 2009; Inger et al., 2009; Vieites et al., 2009; McLeod, 2010; Arntzen et al., 2013). Discovering morphologically cryptic species, and redefining their distribution ranges is an important step for the design and implementation of conservation action plans (Bickford et al., 2007; McLeod, 2010). Hylarana malabarica, $H$. 'temporalis', and $H$. 'aurantiaca' are currently considered as Least Concern (Biju et al., 2004a, b, c) owing to previous misconceptions that they have widespread distributions in India, with no major threats. Our taxonomic review highlights that these species have a considerably more restricted geographic range, and therefore require immediate conservation reassessments. In a scenario where forests across South and Southeast Asia, and particularly in the Western Ghats and Sri Lanka, are increasingly threatened by human pressure (Gunawardene et al., 2007; Bain et al., 2008; Biju et al., 2008b), a complex of species each with a small geographic distribution may be much more susceptible to habitat degradation and related threats. Therefore, revisiting threat categorisations and identifying priority species within Indian-Sri Lankan Hylarana is essential based on the new and redefined species distributions provided in this study.

\section{Acknowledgements}

This research was supported by grant to SDB from CEPF 'Project 55918/2009', USA; DU/DST '2009/868', Government of India; DBT 'BT/PR7833/NDB/51/153/2006', Government of India and MoEF '23/3/2007-RE', Government of India. SDB is thankful to Muséum National d'Histoire Naturelle, Department of Systematics and Evolution, France for two-month study visit fellowship in 2002 to study the type specimen of Hylarana malabarica. The state Forest Departments of Kerala, Tamil Nadu, Karnataka and Maharashtra kindly gave study permits to SDB and are greatly appreciated for their support. SG was supported by fellowship from University of Delhi under the University Teaching Assistantship (UTA) Scheme 2010/56562. MM thanks National Research Council \#11-124 and past and present EES-Lab members, permission for research from Department of Wildlife Conservation Sri Lanka and Forest Department Sri Lanka. Authors thank two anonymous reviewers for their comments and suggestions on the manuscript; KV Gururaja for preparation of maps; Mr Rajesh for Hylarana urbis collection from Kadakkattupara, V Sandeep for Hylarana urbis collection from Tripunithura; C Sengupta and past and present Systematics Lab members for support and companionship in field; A Thomas for lab support; B Clarke, M Wilkinson and D Gower (NHM), A Dubois and A Ohler (MNHN), G Ramakrishna and K Deuti (ZSI) and AR Rahmani and RV Khot (BNHS) and for providing support to SDB and/or SM during museum study visits.

\section{References}

Abraham RK, Pyron RA, Ansil BR, Zachariah A, Zachariah A. 2013. Two novel genera and one new species of treefrog (Anura: Rhacophoridae) highlight cryptic diversity in the Western Ghats of India. Zootaxa 3640: 177-189. 
Al-Ghaferi N, Kolodziejek J, Nowotny N, Coquet L, Jouenne T, Leprince J, Vaudry H, King JD, Conlon JM. 2009. Antimicrobial peptides from the skin secretions of the South-East Asian frog Hylarana erythraea (Ranidae). Peptides 31: 548554.

Arntzen JW, McAtear J, Recuero E, Ziermann JM, Ohler A, van Alphen J, Martínez-Solano I. 2013. Morphological and genetic differentiation of Bufo toads: two cryptic species in western Europe (Anura, Bufonidae). Contributions to Zoology 82: 147-169.

Bain RH, Lathrop A, Murphy RW, Orlov NL, Ho CT. 2003. Cryptic species of a cascade frog from Southeast Asia: taxonomic revisions and descriptions of six new species. American Museum Novitates 3417: 1-60.

Bain RH, Biju SD, Brown R, Das I, Diesmos A, Dutta S, Gower D, Inger R, Iskandar D, Kaneko Y, Lau MWN, Meegaskumbura M, Ohler A, Papenfuss T, Pethiyagoda R, Stuart B, Wilkinson M, Xie Feng. 2008. Amphibians of the Indomalayan Realm. Pp. 74-79 in: Stuart SN, Hoffmann M, Chanson, JS, Cox, NA, Berridge RJ, Ramani P, Young BE, eds, Threatened Amphibians of the World. Lynx Editions, Barcelona, Spain.

Bickford D, Lohman DJ, Sodhi NS, Ng PKL, Meier R, Winker K, Ingram KK, Das I. 2007. Cryptic species as a window on diversity and conservation. Trends in Ecology \& Evolution 22: 148-155.

Biju SD. 2001. A synopsis to the frog fauna of the Western Ghats, India. ISBC - Occasional Publication 1: 1-24.

Biju SD, Bossuyt F. 2003. New frog family from India reveals an ancient biogeographical link with the Seychelles. Nature 425: 711-714.

Biju SD, Manamendra-Arachchi K, Dutta SK, Inger RF, de Silva A. 2004a. Hylarana aurantiaca in: IUCN 2014. IUCN Red List of Threatened Species. Version 2014.1. <www.iucnredlist.org>. Downloaded on 5 January 2014.

Biju SD, Manamendra-Arachchi K, Dutta SK, Inger, RF, de Silva A. 2004b. Hylarana temporalis In: IUCN 2014. IUCN Red List of Threatened Species. Version 2014.1. <www.iucnredlist.org >. Downloaded on 5 January 2014.

Biju SD, Dutta SK, Inger, RF. 2004c. Hylarana malabarica In: IUCN 2014. IUCN Red List of Threatened Species. Version 2014.1. <www.iucnredlist.org >. Downloaded on 5 January 2014.

Biju SD, Bossuyt F. 2005a. New Species of Philautus (Anura: Ranidae, Rhacophorinae) from Ponmudi Hill in the Western Ghats of India. Journal of herpetology 39: 349-353.

Biju SD, Bossuyt F. 2005b. A new species of frog (Ranidae, Rhacophorinae, Philautus) from the rainforest canopy in the Western Ghats. Current Science 88: 175-178.

Biju SD, Bossuyt F. 2005c. Two new Philautus (Anura: Ranidae: Rhacophorinae) from Ponmudi Hill in the Western Ghats of India. Copeia 2005: 29-37.

Biju SD, Bossuyt F. 2006. Two new species of Philautus (Anura, Ranidae, Rhacophorinae) from the Western Ghats, India. Amphibia-Reptilia 27: 1-9.

Biju SD, Bossuyt F. 2009. Systematics and phylogeny of Philautus Gistel, 1848 (Anura, Rhacophoridae) in the Western Ghats of India, with descriptions of 12 new species. Zoological Journal of the Linnean Society 155: 374-444.

Biju SD, Van Bocxlaer I, Giri VB, Roelants K, Nagaraju J, Bossuyt F. 2007. A new nightfrog, Nyctibatrachus minimus sp. nov. (Anura: Nyctibatrachidae): The smallest frog from India. Current Science 93: 854-858.

Biju SD, Roelants K, Bossuyt F. 2008a. Phylogenetic position of the montane treefrog Polypedates variabilis Jerdon, 1853 (Anura: Rhacophoridae), and description of a related species. Organisms Diversity \& Evolution 8: 267-276.

Biju SD, Kamei R, Bhatta G, Giri V, Cox N, Das I, Bossuyt F. 2008b. Diversity and conservation status of the Western Ghats amphibians. Pp. 80-82 in: Stuart SN, Hoffmann M, Chanson, JS, Cox, NA, Berridge RJ, Ramani P, Young BE, eds., Threatened Amphibians of the World. Lynx Editions, Barcelona, Spain.

Biju SD, Van Bocxlaer I, Giri VB, Loader SP, Bossuyt F. 2009. Two new endemic genera and a new species of toad (Anura: Bufonidae) from the Western Ghats of India. BMC research notes 2: 241.

Biju SD, Shouche Y, Dubois A, Dutta SK, Bossuyt F. 2010. A ground-dwelling rhacophorid frog from the highest mountain peak of the Western Ghats of India. Current Science 98: 1199-1125.

Biju SD, Bocxlaer I, Mahony S, Dinesh KP, Radhakrishnan C, Zachariah A, Giri V, Bossuyt F. 2011. A taxonomic review of the Night Frog genus Nyctibatrachus Boulenger, 1882 in the Western Ghats, India (Anura: Nyctibatrachidae) with description of twelve new species. Zootaxa 3029: 1-96.

Biju SD, Garg S, Gururaja KV, Shouche Y, Walujkar SA. 2014. DNA barcoding reveals unprecedented diversity in Dancing Frogs of India (Micrixalidae, Micrixalus): a taxonomic revision with description of 14 new species. Ceylon Journal of Science (Biological Sciences) 43: 1-87.

Bopage MM, Wewalwala K, Krvavac M, Jovanovic O, Safarek G, Pushpamal V. 2011. Species diversity and threat status of amphibians in the Kanneliya Forest, lowland Sri Lanka. Salamandra 47: 173-177.

Bossuyt F, Milinkovitch MC. 2000. Convergent adaptive radiations in Madagascan and Asian ranid frogs reveal covariation between larval and adult traits. Proceedings of the $\mathrm{Na}$ tional Academy of Sciences USA 97: 6585-6590.

Bossuyt F, Meegaskumbura M, Beenaerts N, Gower DJ, Pethiyagoda R, Roelants K, Mannaert A, Wilkinson M, Bahir MM, Manamendra-Arachchi K, Ng PKL, Schneider CJ, Oommen OV, Milinkovitch MC. 2004. Local endemism within the Western Ghats-Sri Lanka biodiversity hotspot. Science 306: 479-481.

Bossuyt F, Brown RM, Hillis DM, Cannatella DC, Milinkovitch MC. 2006. Phylogeny and biogeography of cosmopolitan frog radiation: Late Cretaceous diversification resulted in continent-scale endemism in the family Ranidae. Systematic Biology 55: 579-594.

Boulenger GA. 1882. Catalogue of the Batrachia Salientia s. Ecaudata in the Collection of the British Museum, Second Edition. British Museum (Natural History), Taylor and Francis, London.

Boulenger GA. 1904. Descriptions of three new frogs from southern India and Ceylon. Journal of the Bombay Natural History Society 15: 430-431.

Boulenger GA. 1920. A monograph of the South Asian, Papuan, Melanesian and Australian frogs of the genus Rana. Records of the Indian Museum 20: 1-226.

Bortamuli T, Bordoloi S, Ohler A, Grosjean S. 2010. External morphology, buccopharyngeal anatomy and development 
rate of the tadpoles of two Asian Ranidae (Amphibia: Anura), Hylarana humeralis (Boulenger, 1887) and Hylarana leptoglossa (Cope, 1868). Journal of Natural History 44: 421-445.

Chanda SK, Das I, Dubois A. 2001 [2000]. Catalogue of amphibian types in the collection of the Zoological Survey of India. Hamadryad 25: 100-128.

Chanda SK. 2002. Hand book - Indian Amphibians. Zoological Survey of India, Calcutta.

Chari VK. 1962. A description of the hitherto undescribed tadpole of, and some field notes on the Fungoid Frog Rana malabarica (Bibr.). Journal of the Bombay Natural History Society 59: 71-76.

Che J, Pang J, Zhao H, Wu GF, Zhao EM, Zhang YP. 2007. Phylogeny of Raninae (Anura: Ranidae) inferred from mitochondrial and nuclear sequences. Molecular Phylogenetics and Evolution 43: 1-13.

Che J, Chen HM, Yang JX, Jin JQ, Jiang K, Yuan ZY, Murphy RW, Zhang YP. 2012. Universal COI primers for DNA barcoding amphibians. Molecular Ecology Resources 12: 247258.

Chen L, Murphy RW, Lathrop A, Ngo A, Orlov NL, Ho CT, Somorjai ILM. 2005. Taxonomic chaos in Asian ranid frogs: an initial phylogenetic resolution. Herpetological Journal 15: 231-243.

Conlon JM, Power GJ, Abdel-Wahab YHA, Flatt PR, Jiansheng H, Coquet L, Leprince J, Jouenne T, Vaudry H. 2008a. A potent, non-toxic insulin-releasing peptide isolated from an extract of the skin of the Asian frog, Hylarana guntheri (Anura: Ranidae). Regulatory Peptides 29: 151-153.

Conlon JM, Kolodziejek J, Nowotny N, Leprince J, Vaudry H, Coquet L, Jouenne T, King JD. 2008b. Characterization of antimicrobial peptides from the skin secretions of the Malaysian frogs, Odorrana hosii and Hylarana picturata (Anura:Ranidae). Toxicon 52: 465-473.

Daniel JC, Sekar AG. 1989. Field guide to the Amphibians of western India. IV. Journal of the Bombay Natural History Society 86: 194-202.

Daniels RJR. 2005. Amphibians of Peninsular India. Universities Press (India), Hyderabad.

De Silva A. 2009. Amphibians of Sri Lanka: A Photographic Guide to Common Frogs, Toads and Caecilians. Published by the author, Colombo.

Du Preez LH, Carruthers VC. 2009. A Complete Guide to the Frogs of Southern Africa. Struik Nature, Cape Town.

Dubois A. 1984. Note preliminaire sur le groupe de Rana limnocharis Gravenhorst, 1829 (Amphibiens, Anoures). Alytes 3: $143-159$

Dubois A. 1992. Notes sur la classification des Ranidae (Amphibiens anoures). Bulletin Mensuel de la Société Linnéenne de Lyon 61: 305-352.

Dubois A. 2005. Amphibia Mundi. 1.1. An ergotaxonomy of recent amphibians. Alytes 23: 1-24.

Dutta SK. 1990. Rana bhagmandlensis: a junior synonym of Rana aurantiaca Boulenger (Anura: Ranidae). Journal of the Bombay Natural History Society 87: 310.

Dutta SK. 1997. Amphibians of India and Sri Lanka (Checklist and Bibliography). Odyssey Publishing House, Bhubaneswar.

Dutta SK, Manamendra-Arachchi K. 1996. The Amphibian fauna of Sri Lanka. Wildlife Heritage Trust of Sri Lanka, Colombo.
Elmer KR, Dávila JA, Lougheed SC. 2007. Cryptic diversity and deep divergence in an upper Amazonian Leaflitter Frog, Eleutherodactylus ockendeni. BMC Evolutionary Biology 7: 247.

Fei L, Ye C, Jiang J. 2010. Phylogenetic systematics of Ranidae. Herpetologica Sinica 12: 1-43.

Fitzinger LJFJ. 1843. Systema Reptilium. Fasciculus Primus. Wien: Braumüller et Seidel.

Fouquet A, Gilles A, Vences M, Marty C, Blance M, Gemmel NJ. 2007a. Underestimation of species richness in neotropical frogs revealed by mtDNA analysis. PLOS ONE 2: e1109.

Fouquet A, Vences M, Salducci MD, Meyer A, Marty C, Blanc M, Gilles A. 2007b. Revealing cryptic diversity using molecular phylogenetics and phylogeography in frogs of the Scinax ruber and Rhinella margaritifera species groups. Molecular Phylogenetics and Evolution 43: 567-582.

Frank N, Ramus E. 1995. Complete Guide to Scientific and Common Names of Amphibians and Reptiles of the World. N. G. Publishing Inc., Pottsville, Pennsylvania.

Frost DR. 2014. Amphibian Species of the World: an Online Reference. Version 6.0 (20 February 2014). Electronic Database accessible at http://research.amnh.org/herpetology/ amphibia/index.html. American Museum of Natural History, New York, USA.

Frost DR, Grant T, Faivovich J, Bain RH, Haas A, Haddad CFB, Rafael O. De Sa et al. 2006. The amphibian tree of life. Bulletin of the American Museum of Natural History 297: 1-291.

Funk WC, Caminer M, Ron SR. 2011. High levels of cryptic species diversity uncovered in Amazonian frogs. Proceedings of the Royal Society B 279: 1806-1814.

Gawor A, Hendrix A, Vences M, Bohme W, Ziegler T. 2009. Larval morphology in four species of Hylarana from Vietnam and Thailand with comments on the taxonomy of $H$. nigrovittata sensu latu (Anura: Ranidae). Zootaxa 2051: $1-25$.

Girish S, Saidapur SK. 1999. The effects of density and kinship on growth and metamorphosis of the bronzed frog (Rana temporalis) tadpoles. Acta ethologica 2: 61-66.

Grandison AGC, Senanayake FR. 1966. Redescription of Rana (Hylarana) aurantiaca Boulenger (Amphibia: Ranidae). Annals \& Magazine of Natural History 13: 419-421.

Gravenhorst JLC. 1829. Deliciae Musei Zoologici Vratislaviensis. Fasciculus primus. Chelonios et Batrachia. Leopold Voss, Leipzig.

Grosjean S. 2005. The choice of external morphological characters and developmental stages for tadpole-based anuran taxonomy: a case study in Rana (Sylvirana) nigrovittata (Blyth, 1855) (Amphibia, Anura, Ranidae). Contributions to Zoology 74: 1-22.

Guibé J. 1950 [1948]. Catalogue des Types d'Amphibiens du Muséum National d'Histoire Naturelle. Imprimerie Nationale, Paris.

Gunatilleke CVS, Gunatilleke IAUN. 1985. Phytosociology of Sinharaja - A contribution to rain forest conservation in Sri Lanka. Biological Conservation 31: 21-40.

Gunawardene NR, Daniels AED, Gunatilleke IAUN, Gunatilleke CVS, Karunakaran PV, Nayak KG, Prasad S, Puyravaud P, Ramesh BR, Subramanian KA, Vasanthy, G. 2007. A brief overview of the Western Ghats-Sri Lanka biodiversity hotspot. Current Science 93: 1567-1572. 
Günther ACLG. 1859 [1858]. Catalogue of the Batrachia Salientia in the Collection of the British Museum. Taylor and Francis, London.

Günther ACLG. 1864. The Reptiles of British India. Ray Society by R. Hardwicke. London.

Haas A. 1996. Non-feeding and feeding tadpoles in hemiphractine frogs: larval head morphology, heterochrony, and systematics of Flectonotus goeldii (Amphibia: Anura: Hylidae). Journal of Zoological Systematics and Evolutionary Research 34: 163-171.

Haas A. 1997. The larval hyobranchial apparatus of discoglossoid frogs: its structure and bearing on the systematics of Anura (Amphibia: Anura). Journal of Zoological Systematics and Evolutionary Research 35: 179-197.

Hasan M, Islam MM, Khan MMR, Alam MS, Kurabayashi A, Igawa T, Kuaramoto M, Sumida M. 2012. Cryptic anuran biodiversity in Bangladesh revealed by mitochondrial $16 \mathrm{~S}$ rRNA gene sequences. Zoological Science 29: 162-172.

Hiragond NC, Saidapur SK. 1999. Description of tadpoles of Rana temporalis from South India. Current Science 76: 442-446.

Hiragond NC, Saidapur SK. 2001. Microhabitat choice of tadpoles of seven anuran species. Current Herpetology 20: 51-60.

Huelsenbeck JP, Ronquist F. 2001. MrBayes: Bayesian inference of phylogeny. Bioinformatics 17: 754-755.

Huelsenbeck JP, Ronquist F, Nielsen R, Bollback JP. 2001. Bayesian inference of phylogeny and its impact on evolutionary biology. Science 294: 2310-2314.

Jerdon TC. 1853. Catalogue of reptiles inhabiting the Peninsula of India. Journal of the Asiatic Society of Bengal 22: 522534.

Inger RF, Shaffer HB, Koshy M, Bakde R. 1985 [1984]. A report on a collection of amphibians and reptiles from the Ponmudi, Kerala, South India. Journal of the Bombay Natural History Society 81: 551-570.

Inger RF, Stuart BL, Iskandar DT. 2009. Systematics of a widespread Southeast Asian frog, Rana chalconota (Amphibia: Anura: Ranidae). Zoological Journal of the Linnean Society 155: 123-147.

Kamei RG, Gower DJ, Wilkinson M, Biju SD. 2013. Systematics of the caecilian family Chikilidae (Amphibia: Gymnophiona) with the description of three new species of Chikila from northeast India. Zootaxa 3666: 401-435.

Kirtisinghe P. 1957. The Amphibia of Ceylon. Published by the author, Colombo.

Kotaki M, Kurabayashi A, Matsui M, Kuramoto M, Djong TH, Sumida M. 2010. Molecular phylogeny of the diversified frogs of genus Fejervarya (Anura: Dicroglossidae). Zoological Science 27: 386-395.

Maglia AM, Pugener LA, Trueb L. 2001. Comparative development of anurans: using phylogeny to understand ontogeny. American Zoologist 41: 538-551.

Matsui M, Shimada T, Ota H, Tomoko TU. 2005. Multiple invasions of the Ryukyu Archipelago by Oriental frogs of the subgenus Odorrana with phylogenetic reassessment of the related subgenera of the genus Rana. Molecular Phylogenetics and Evolution 37: 733-742.

McLeod DS. 2010. Of least concern? Systematics of a cryptic species complex: Limnonectes kuhlii (Amphibia: Anura: Dicroglossidae). Molecular Phylogenetics and Evolution 56: 991-1000.
Meegaskumbura M, Bossuyt F, Pethiyagoda R, ManamendraArachchi K, Bahir M, Milinkovitch MC, Schneider CJ. 2002. Sri Lanka: an amphibian hotspot. Science 298: 379.

Meegaskumbura M, Manamendra-Arachchi K. 2005. Description of eight new species of shrub frogs (Ranidae: Rhacophorinae: Philautus) from Sri Lanka. Pp. 305-338 in: Yeo DCJ, Ng PKL, Pethiyagoda R, eds., Contributions to biodiversity exploration and research in Sri Lanka. The Raffles Bulletin of Zoology Suppl. No. 12. Singapore.

Meegaskumbura M, Meegaskumbura S, Bowatte G, Manamendra-Arachchi K, Pethiyagoda R, Hanken J, Schneider CJ. 2010. Taruga (Anura: Rhacophoridae), a new genus of foamnesting tree frogs endemic to Sri Lanka. Ceylon Journal of Science (Biological Sciences) 39: 75-94.

Meegaskumbura M, Manamendra-Arachchi K. 2011. Two new species of shrub frogs (Rhacophoridae: Pseudophilautus) from Sri Lanka. Zootaxa 2747: 1-18.

Meyer CP, Paulay G. 2005. DNA barcoding: error rates based on comprehensive sampling. PLoS biology 3: 2229-2238.

Mittermeier RA, Robles Gil P, Hoffmann M, Pilgrim JD, Brooks TM, Mittermeier CG, Fonseca GAB da. 2004. Hotspots Revisited: Earth's Biologically Richest and Most Endangered Ecoregions. CEMEX, Mexico City.

Myers CW, Duellman WE. 1982. A New Species of Hyla from Cerro Colorado, and other tree frog records and geographical notes from western Panama. American Museum novitates 2752: 1-32.

Myers N, Mittermier RA, Mittermier CG, Fonescaand da GAB, Kent J. 2000. Biodiversity hotspots for conservation priorities. Nature 403: 853-858.

Padhye A, Anushree J, Manawa D, Neelesh D. 2012. Population variations in the fungoid frog Hylarana malabarica (Anura: Ranidae) from northern Western Ghats of India. Journal of Threatened Taxa 4: 2343-2352.

Peters WCH. 1863. Über eine neue Schlangen-Gattung, Styporhynchus, und verschiedene andere Amphibien des zoologischen Museum. Monatsberichte der Königlichen Preussische Akademie des Wissenschaften zu Berlin 1863: 399-413.

Pethiyagoda R, Manamendra-Arachchi K. 1998. Evaluating Sri Lanka's amphibian diversity. Occasional Papers of the Wildlife Heritage Trust 2: 1-12.

Pethiyagoda R, Manamendra-Arachchi K, Bahir MM, Meegaskumbura M. 2006. Sri Lankan amphibians: diversity, uniqueness and conservation. Pp. 65-69 in: Bambaradeniya CNB, ed., The Fauna of Sri Lanka: Status of Taxonomy, Research and Conservation. The World Conservation Union Sri Lanka \& Government of Sri Lanka, Colombo.

Posada D, Crandall KA. 1998. MODELTEST: testing the model of DNA substitution. Bioinformatics 14: 817-818.

Pyron RA, Wiens JJ. 2011. A large-scale phylogeny of amphibia including over 2800 species, and a revised classification of extant frogs, salamanders, and caecilians. Molecular Phylogenetics and Evolution 61: 543-583.

Rao CRN. 1922. Notes on Batrachia. Journal of the Bombay Natural History Society 28: 439-447.

Rao CRN. 1937. On some new forms of Batrachia from S. India. Proceedings of the Indian Academy of Sciences, Section B 6: 387-427.

Reshmy V, Preeji V, Parvin A, Santhoshkumar K, George S. 2010. Molecular cloning of a novel bradykinin-related 
peptide from the skin of Indian bronzed frog Hylarana temporalis. Genomics Insights 3: 23-28.

Reshmy V, Preeji V, Parvin A, Santhoshkumar K, George, S. 2011. Three novel antimicrobial peptides from the skin of the Indian bronzed frog Hylarana temporalis (Anura: Ranidae). Journal of Peptide Science 17: 342-347.

Roelants K, Jiang J, Bossuyt F. 2004. Endemic ranid (Amphibia: Anura) genera in southern mountain ranges of the Indian subcontinent represent ancient frog lineages: evidence from molecular data. Molecular Phylogenetics and Evolution 31: 730-740. http://dx.doi.org/10.1016/j.ympev.2003.09.011

Sambrook J, Fritsch EF, Maniatis T. 1989. Molecular Cloning: A Laboratory Manual. Cold Spring Harbor Laboratory press, Cold Spring Harbor, NY.

Savage JM, Heyer WR. 1967. Variation and distribution in the tree-frog genus Phyllomedusa in Costa Rica, Central America: With 6 figures. Studies on Neotropical Fauna and Environment 2: 111-131.

Simon C, Frati F, Beckenbach A, Crespi B, Liu H, Flook P. 1994. Evolution, weighting and phylogenetic utility of mitochondrial gene sequences and a compilation of conserved polymerase chain reaction primers. Annals of the Entomological Society of America 87: 651-701.

Smith MA, Poyarkov NA Jr., Hebert PDN. 2008. CO1 DNA barcoding amphibians: take the chance, meet the challenge. Molecular Ecology Resources 8: 235-246.

Swofford DL. 2002. PAUP*: Phylogenetic Analysis Using Parsimony (* and other methods), Version 4.0b10. Sinauer, Sunderland.

Stuart BL, Inger RF, Voris HK. 2006. High level of cryptic species diversity revealed by sympatric lineages of Southeast Asian forest frogs. Biology Letters 2: 470-474.

Tamura K, Peterson D, Peterson N, Stecher G, Nei M, Kumar S. 2011. MEGA5: Molecular Evolutionary Genetics Analysis using maximum likelihood, evolutionary distance, and maximum parsimony methods. Molecular Biology and Evolution 28: 2731-2739. http://dx.doi.org/10.1093/molbev/msr121
Tschudi JJv. 1838. Classification der Batrachier mit Berücksichtigung der fossilen Thiere dieser Abtheilung der Reptilien. Petitpierre, Neuchâtel.

Ukuwela KDB. 2009. Description of the tadpole of Hylarana aurantiaca (Anura: Ranidae) from Sri Lanka. Zootaxa 2016: 67-68.

Veeranagoudar DK, Shanbhag BA, Saidapur SK. 2004a. Foraging behaviour in tadpoles of the bronze frog Rana temporalis: Experimental evidence for the ideal free distribution. Journal of Biosciences 29: 201-207.

Veeranagoudar DK, Shanbhag BA, Saidapur SK. 2004b. Mechanism of food detection in the tadpoles of the bronze frog Rana temporalis. Acta Ethologica 7: 37-41.

Vieites DR, Wollenberg KC, Andreone F, Köhler J, Glaw F, Vences M. 2009. Vast underestimation of Madagascar's biodiversity evidenced by an integrative amphibian inventory. Proceedings of the National Academy of Sciences 106: 8267-8272.

Wang H, Lu Y, Zhang X, Hu Y, Yu H, Liu J, Sun J. 2009. The novel antimicrobial peptides from skin of Chinese broadfolded frog, Hylarana latouchii (Anura: Ranidae). Peptides 30: 273-282.

Wiens JJ, Sukumaran J, Pyron RA, Brown RM. 2009. Evolutionary and biogeographic origins of high tropical diversity in Old World frogs (Ranidae). Evolution 63: 1217-1231.

Zachariah A, Dinesh KP, Kunhikrishnan E, Das S, Raju DV, Radhakrishnan C, Palot MJ, Kalesh S. 2011. Nine new species of frogs of the genus Raorchestes (Amphibia: Anura: Rhacophoridae) from southern Western Ghats, India. Biosystematica 5 : 25-48.

Received: 7 March 2014

Revised and accepted: 7 July 2014

Published online: 29 October 2014

Editor: J.W. Arntzen

\section{Online supplementary information (SI)}

S1. List of sequences used in the study for intra and interspecific pairwise comparisons, barcoding and molecular phylogeny of Hylarana species.

$S 2$. Uncorrected intraspecific pairwise $p$-distances within Hylarana species from Western Ghats-Sri Lanka biodiversity hotspot. The table gives mean and standard deviation values over all pairwise comparisons among individuals or populations of a species, and minimum and maximum values are recorded. $N$ is the number of sequences. The original $p$-distances are shown as percentages.

S3. Uncorrected interspecific pairwise $p$-distances between closely related Hylarana species of Western Ghats-Sri Lanka biodiversity hotspot. The table gives mean and standard deviation values over all pairwise comparisons of individuals sequenced from the two species being compared. Minimum and maximum values are recorded. $N$ is the number of pairwise comparisons. The original $p$-distances are shown as percentages. 


\section{Appendix}

In this section we provide taxonomic accounts for all Hylarana species from the Western Ghats-Sri Lanka biodiversity hotspot, including the formal description of seven new species. Species are discussed in four major groups - Hylarana aurantiaca group, Hylarana flavescens group, Hylarana temporalis group and Hylarana malabarica group; identified in the present study based on their phylogenetic positions (Fig. 4) supported by morphological characters. Morphological and genetic comparisons for each species are provided for only closely related members within the species groups. The genetic divergence section for each species discusses both intraspecific variation within species and interspecific divergence between closely related species.

Family Ranidae Rafinesque, 1814

Genus Hylarana Tschudi, 1838

Hylarana Tschudi, 1838. Classification der Batrachier mit Berücksichtigung der fossilen Thiere dieser Abtheilung der Reptilien [Neuchâtel]: Petitpierre. 37. Type species: Hyla erythraea Schlegel, 1827, by monotypy.

Limnodytes Duméril and Bibron, 1841. Erpétologie Genérale ou Histoire Naturelle Complète des Reptiles. Volume 8 [Paris]: Librarie Encyclopedique de Roret. 8: 510. Substitute name for Hylarana Tschudi, 1838.

Hydrophylax Fitzinger, 1843. Systema Reptilium. Fasciculus Primus [Wien]: Braumüller et Seidel: 31. Type species: Rana malabarica Tschudi, 1838, by original designation.

Zoodioctes Gistel, 1848. Naturgeschichte des Thierreichs für höhere Schulen [Stuttgart]: Hoffmann. xi. Substitute name for Hylarana Tschudi, 1838.

Tenuirana Fei, Ye, and Huang, 1990. [Key to Chinese Amphibians] [Chongqing, China]: Publishing House for Scientific and Technological Literature. [In Chinese]: 139 Type species: Rana taipehensis Van Denburgh, 1909, by original designation.

Amnirana Dubois, 1992. Notes sur la classification des Ranidae (Amphibiens Anoures). Bulletin Mensuel de la Société Linnéenne de Lyon 61: 324. Type species: Rana amnicola Perret, 1977, by original designation.

Papurana Dubois, 1992. Notes sur la classification des Ranidae (Amphibiens Anoures). Bulletin Mensuel de la Société Linnéenne de Lyon 61: 325. Type species: Rana papua Lesson, 1830, by original designation.

Pulchrana Dubois, 1992. Notes sur la classification des Ranidae (Amphibiens Anoures). Bulletin Mensuel de la Société Linnéenne de Lyon 61: 326. Type species: Polypedates signatus Günther, 1872, by original designation.

Sylvirana Dubois, 1992. Notes sur la classification des Ranidae (Amphibiens Anoures). Bulletin Mensuel de la Société Linnéenne de Lyon 61: 326. Type species: Lymnodytes nigrovittatus Blyth, 1855, by original designation.

Chalcorana Dubois, 1992. Notes sur la classification des Ranidae (Amphibiens Anoures). Bulletin Mensuel de la Société Linnéenne de Lyon 61: 326. Type species: Hyla chalconota Schlegel, 1837, by original designation.

Tylerana Dubois, 1992. Notes sur la classification des Ranidae (Amphibiens Anoures). Bulletin Mensuel de la Société Linnéenne de Lyon 61: 329. Type species: Rana jimiensis Tyler, 1963, by original designation.

Boulengerana Fei, Ye, and Jiang, 2010. Phylogenetic systematics of Ranidae. Herpetologica Sinica/ Liang qi pa xing dong wu xue yan jiu 12: 21. Type species: Rana guentheri Boulenger, 1882.

Common name. Golden-backed frogs (Du Preez and Carruthers, 2009).

Etymology. The name Hylarana is composed of two words, Hyla which is New Latin and derived from the Greek 'hyle' meaning wood or forest, and the Latin word 'rana' meaning frog. It is unclear whether the name was coined to mean its literal sense (wood frog), or whether it was to point to a group of frogs similar to the genus Rana, which had toe pads reminiscent of frogs of the genus Hyla.

Distribution. Widely distributed in two broadly disjunct regions - tropical Africa, from Senegal to Eritrea, Ethiopia and Somalia south to Mozambique; tropical Asia, from Sri Lanka, India, Nepal, southern China (including Taiwan and Hainan), through the Indo-Australian Archipelago to the Philippines, New Guinea and northern Australia (Gawor et al., 2009; Frost, 2014).

Salient morphological characters of the Western Ghats-Sri Lankan Hylarana. Small to large-sized frogs, male SVL 27-85 mm, female SVL 38-92 mm; nostrils oval with flap of skin; tympanum distinct; pineal ocellus present; vomerine teeth present; supratympanic fold absent; webbing absent on fingers; webbing 


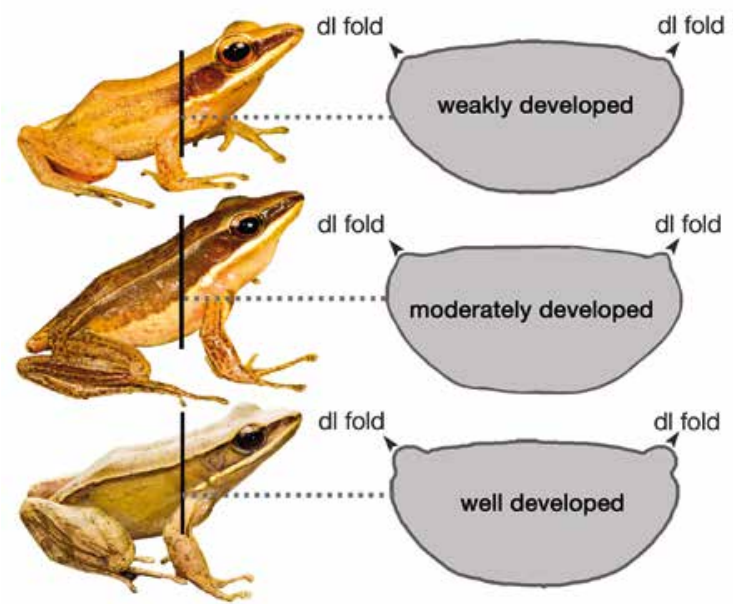

Fig. 5. Schematic illustration showing the dorsolateral folds (dl fold), that stretch from posterior corner of the eye to the vent in the genus Hylarana from Western Ghats-Sri Lanka biodiversity hotspot. Top to bottom are: weakly developed dorsolateral fold (H. aurantiaca, H. urbis); moderately developed dorsolateral fold ( $H$. doni, $H$. intermedius, $H$. malabarica, $H$. serendipi); well developed dorsolateral fold $(H$. caesari, $H$. flavescens, $H$. gracilis, $H$. indica, H. magna, $H$. montanus, $H$. sreeni, $H$. temporalis).

present on toes; shagreened, granular or horny spinular skin; distinct rictal gland posterior to corner of mouth; weakly or well developed humeral glands on males; presence of dorsolateral skin folds.

\section{Generic level taxonomic confusions}

Hydrophylax: This genus was described by Fitzinger (1843) to accommodate Rana malabarica (Tschudi, 1838), but was later synonymised with Rana by Günther (1859). Dubois (1992) resurrected Hydrophylax as a subgenus (subsection), for this taxon [Rana (Hydrophylax) malabarica] based on finger and toe tip morphology. It was later recognised as a genus based on further morphological and molecular evidence (Frost et al., 2006). However, Che et al. (2007) synonymised Hydrophylax with the genus Hylarana, based on molecular evidence. Interestingly most of the recent studies (Frost et al., 2006; Che et al., 2007; Bossuyt et al., 2006; Matsui et al., 2005) did not use the type species of this genus, while a few others that use Hylarana 'malabarica' did not sample a population from within the type locality (Wiens et al., 2009; Pyron and Wiens, 2011).

Sylvirana: Dubois (1992) proposed this as a new subgenus, which was redefined and considered as a

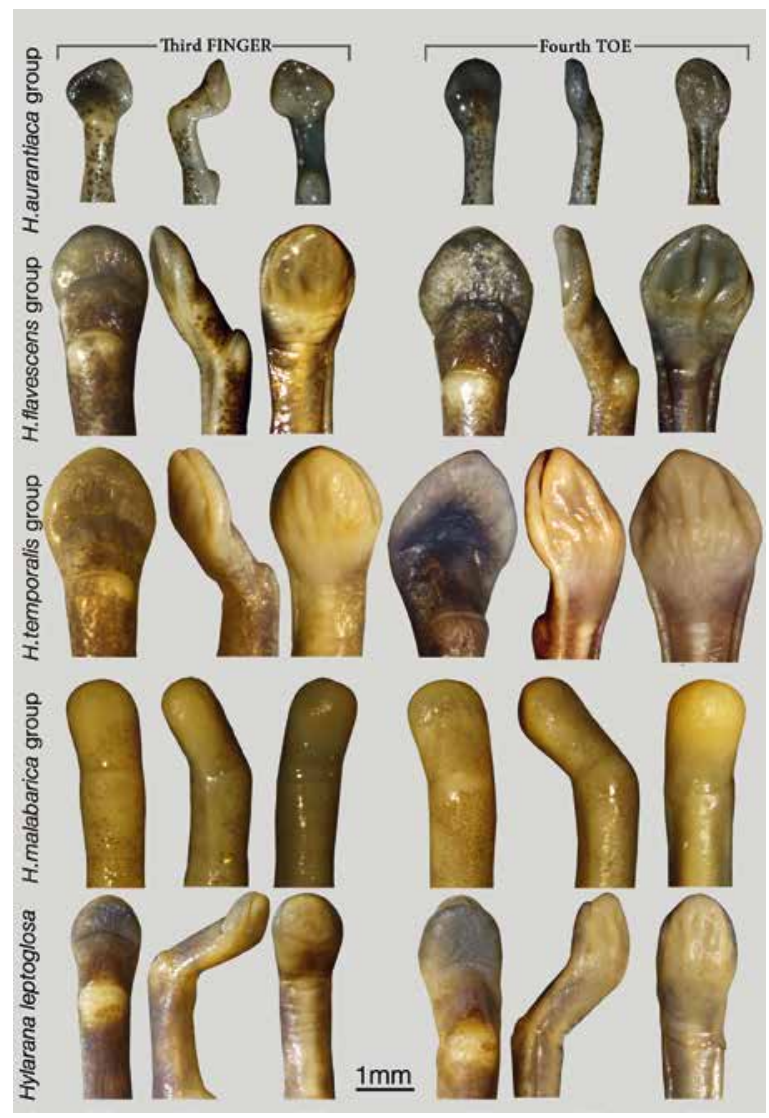

Fig. 6. The structure and shape of third finger and fourth toe tips in Hylarana species representing four groups from the Western Ghats-Sri Lanka biodiversity hotspot - Hylarana aurantiaca group (SDBDU 2011.520), Hylarana flavescens group (SDBDU 2011.860), Hylarana temporalis group (DZ 1046) and Hylarana malabarica group (BNHS 5879); and Hylarana cf. leptoglossa (SDBDU 2007.93) from Northeast India. From left to right: third finger - dorsal view, lateral view, ventral view; fourth toe - dorsal view, lateral view, ventral view.

genus by Frost et al. (2006). Bossuyt et al. (2006) demonstrated that Hylarana is embedded within a paraphyletic Sylvirana, and subsequently Che et al. (2007) synonymised Sylvirana with Hylarana.

\section{Taxonomic accounts and descriptions of new species}

Hylarana aurantiaca group. This group can be distinguished from other Hylarana groups by the following suite of characters: small to medium-sized adult (male, SVL 27-44 mm; female, SVL 37-50 mm), body slender; dorsolateral folds weakly or moderately developed (Fig. 5); finger and toe discs dorsoventrally compressed and obtusely pointed (Fig. 6); fourth toe web- 
bing does not extend beyond the second subarticular tubercle on the inside; endemic to the southern Western Ghats. In a phylogenetic framework, the Hylarana aurantiaca group can be characterised as the most inclusive clade that contains a Western Ghats radiation (Hylarana aurantiaca, Hylarana intermedius $+\mathrm{Hy}$ larana doni sp. nov., Hylarana urbis sp. nov.), but none of the other clades within the Western Ghats or Sri Lankan radiations of Hylarana (Fig. 4).

Hylarana aurantiaca (Boulenger, 1904)

Boulenger's Golden-backed frog

(Figs 7a-c, 8a-c, 9a, 10; Tables 1-2)

Original name and description. Rana aurantiaca Boulenger 1904. Description of three new frogs from southern India and Ceylon, Journal of Bombay Natural History Society, 15: 430. Holotype. By monotypy, NHM 1947.2.2.92 (ex BMNH 1903.9.26.1), an adult female, collected by K.S. Ferguson. Type locality. "near Trivandrum, Travancore [Kerala]', Thiruvananthapuram dist., Kerala state, India. Current status of specific name. Valid name, as Hylarana aurantiaca (Boulenger, 1904).

Referred specimens. BNHS 5809 and SDBDU 2011.520, two adult males, Chathankod, Thekal, Thiruvananthapuram dist., collected by SDB and Systematics Lab team, 10 August 2011; BNHS 5810-5811 and SDBDU 2001.795, three adult males, Chathankod, Thiruvananthapuram dist., collected by SDB, 23 October 2001; BNHS 5812, an adult male, Chathankod, Thiruvananthapuram dist., collected by SDB, 23 May 2006; SDBDU 2006.4776, an adult male, Karamana, Thiruvananthapuram dist., collected by SDB, 8 July 2006; BNHS 5813 and SDBDU 2012.1894, two adult males, Vellayani, Thiruvananthapuram dist., collected by SDB and SG, 30 January 2012; SDBDU 2006.309, a sub-adult, Kallar, Ponmudi, Thiruvananthapuram dist., collected by SDB, 24 May 2006; SDBDU 2011.277, a sub-adult, Kattilappara, Shendurney WLS, Kollam dist., collected by SDB and Systematics Lab team, 12 September 2011.

Comments. Holotype is moderately dehydrated (Fig. $7 \mathrm{a}-\mathrm{b}$ ) and many of the measurements of hand and feet cannot be reliably made to provide a comprehensive description. The present collection from 'Trivandrum' (= Thiruvananthapuram) is comparable to the holotype and hence, for a more accurate description of this species, we provide a complete description based on a topotype BNHS 5809.

Comparison. Hylarana aurantiaca could be confused with Hylarana doni sp. nov., Hylarana intermedius and Hylarana urbis sp. nov. in the Hylarana aurantiaca group, due to its small adult size. However, H. $a u$ rantiaca differs from $H$. doni and $H$. intermedius by its smaller adult male snout-vent size, SVL 27.1-31.7 mm, $N=9$ (vs. SVL $38.0-43.1 \mathrm{~mm}, N=12$, H. doni; SVL 33.0-41.6 mm, $N=14, H$. intermedius), toes thin (Figs 8b, e, h) with weakly developed subarticular tubercles (vs. thick with well developed subarticular tubercles in both species), third toe webbing not extending up to the disc on the outside (vs. up to the disc in both species). Furthermore, H. aurantiaca differs from $H$. doni by its dorsal skin shagreened (vs. granular), dorsolateral folds weakly developed (vs. moderately developed), forearm without granular projections (vs. ventral side of forearm, having a straight line of granular projections from the base of finger IV to the elbow); differs from $H$. urbis by its interorbital space equal to the upper eyelid width, IUE $2.5 \pm 0.2 \mathrm{~mm}$, UEW $2.5 \pm$ $0.2 \mathrm{~mm}, N=9$ (vs. wider IUE $2.9 \pm 0.2 \mathrm{~mm}$, UEW 1.9 $\pm 0.1 \mathrm{~mm}, N=5$ ), relatively more webbing between toes $\mathrm{I} 1^{1 / 3}-2 \mathrm{III} 1^{+}-2^{+} \mathrm{IIII} 1^{1 / 2}-3 \mathrm{IV} 21 / 2^{-}-1^{1 /} \mathrm{V}$ (vs. less $\mathrm{I} 2^{-}-2^{+} \mathrm{III} 1^{3 /} / 4^{-}$ $2^{3} /{ }_{4} \mathrm{III} 2-3 \mathrm{IV} 3-1 \frac{3}{4} \mathrm{~V}$ ) (Figs $\left.8 \mathrm{~b}-\mathrm{c}, \mathrm{k}-\mathrm{l}\right)$.

Genetic divergence. Intraspecific genetic variation within populations of Hylarana aurantiaca was $0.2 \pm$ $0.1 \%$ (range $0-0.4 \%, N=5$ ) for $16 \mathrm{~S}, 0.1 \pm 0.1 \%$ (range $0-0.4 \%, N=6)$ for COI, and zero $(N=7)$ for Cytb. Based on phylogenetic position, $H$. aurantiaca is closely related to the members of Hylarana aurantiaca group (Fig. 4); differs from $H$. doni by mean genetic divergence of $4.2 \pm 0.1 \%$ (range $4.1-4.6 \%, N=40$ ) for $16 \mathrm{~S}, 8.5 \pm 0.3 \%$ (range $7.9-9.2 \%, N=63$ ) for COI, and $9.8 \pm 0.3 \%$ (range 9.4-10.4\%, $N=50$ ) for Cytb; from $H$. intermedius by mean genetic divergence of $3.3 \pm 0.2 \%($ range $3.0-3.6 \%, N=45$ ) for $16 \mathrm{~S}, 8.9 \pm 0.2 \%$ (range $8.6-9.4 \%, N=63$ ) for COI, and $9.6 \pm 0.9 \%$ (range $8.9-12.4 \%, N=45$ ) for Cytb; from $H$. urbis by mean genetic divergence of $4.1 \pm 0.2 \%$ (range 3.9$4.4 \%, N=15$ ) for $16 \mathrm{~S}, 7.4 \pm 0.2 \%$ (range $7.3-7.8 \%, N=$ 21) for COI, and $8.7 \pm 0.4 \%$ (range $8.2-9.3 \%, N=15$ ) for Cytb (Tables S2-S3).

Redescription of holotype (Figs 7a-b). Small-sized, slender adult female (SVL 37.9). Head small (HW 10.4, HL 13.2, IFE 5.9, IBE 7.8), longer than wide, slightly concave above; snout rounded (due to poor 


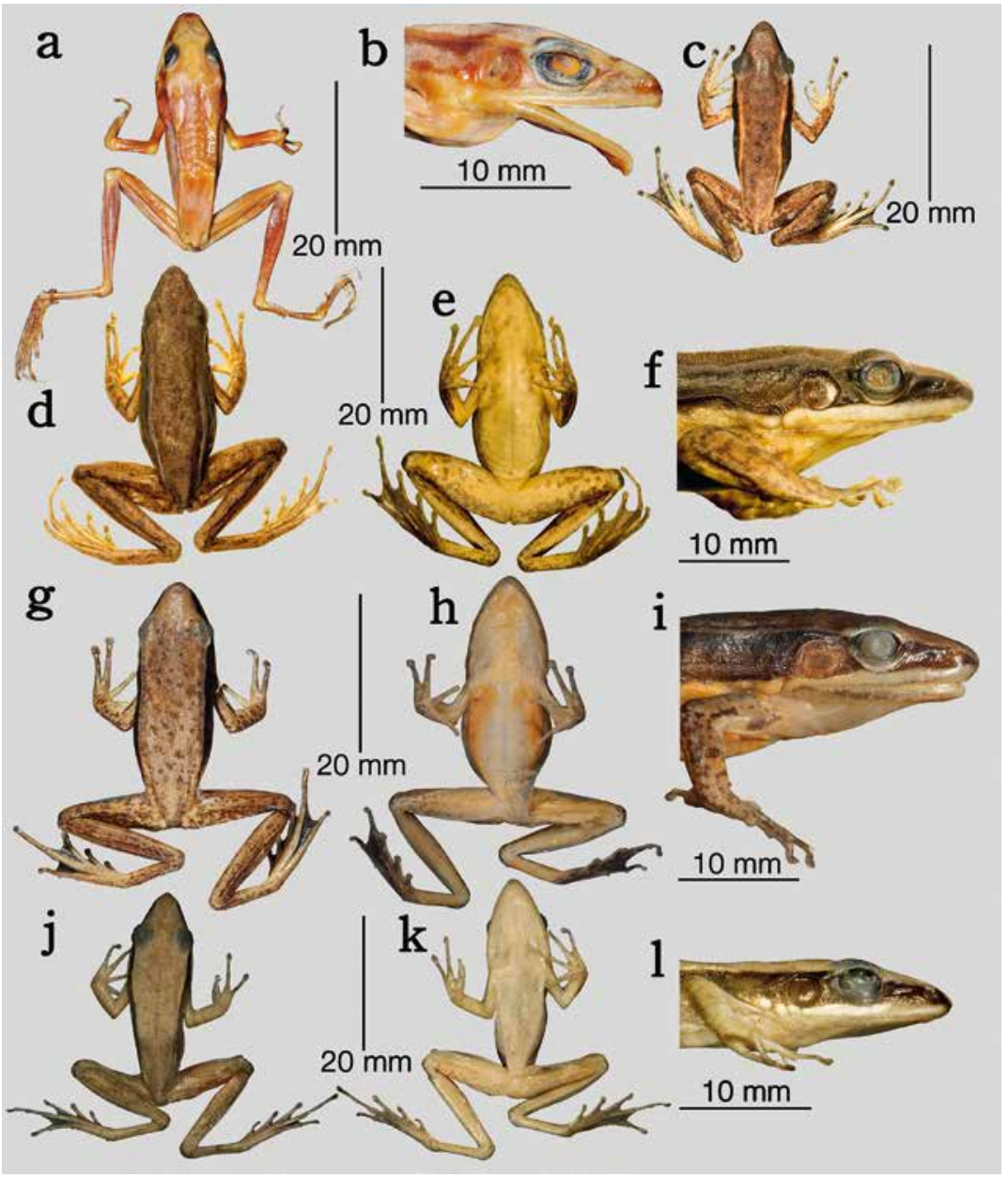

Fig. 7a-l. Dorsal view, ventral view, and lateral view of head of the Hylarana aurantiaca group in preservation: a. dorsal view and b. lateral view of head, holotype of Rana aurantiaca (= Hylarana aurantiaca) (NHM 1947.2.2.92 [ex BMNH 1903.9.26.1]); c. topotype of $H$. aurantiaca (BNHS 5809); d-f. holotype of $H$. doni (BNHS 5814): d. dorsal view, e. ventral view, f. lateral view of head; g-i. neotype of $H$. intermedius (BNHS 5823): g. dorsal view, h. ventral view, i. lateral view of head; j-l. holotype of $H$. urbis (BNHS 5837): $\mathrm{j}$. dorsal view, $\mathrm{k}$. ventral view, 1. lateral view of head. preservation) in lateral view, its length (SL 5.6) longer than horizontal diameter of eye (EL 4.2); loreal region acute and concave with rounded canthus rostralis; interorbital space slightly concave, wider (IUE 3.7) than upper eyelid (UEW 2.0) and internarial distance (IN 3.3); nostril oval with flap of skin laterally, closer to tip of snout (NS 2.0) than eye (EN 4.1); tympanum (TYD 2.3 ) $54 \%$ of eye diameter (EL 4.2); vomerine ridge present but weak, bearing numerous small teeth, with an angle of $45^{\circ}$ to body axis, closer to choanae than each other, shorter than the distance between them; tongue moderately large, emarginated, bearing no medium lingual process. Forelimbs moderately long and thin; forelimb (FAL 7.9) shorter than hand length (HAL 9.3); fingers long and rounded with lateral fringes, finger lengths not obtainable due to damage, tip of all intact fingers with discs, with lateroventral groove, slightly wider than finger width (not measured due to specimen desiccation); subarticular tubercles promi- nent, oval, single, all present; palmar and supernumerary tubercles all indistinct. Hindlimbs relatively long and thin, thigh length (TL 16.9) shorter than shank (SHL 20.0); relative digit lengths $\mathrm{I}<\mathrm{II}<\mathrm{III}=\mathrm{V}<\mathrm{IV}$; tips of all toes obtusely pointed with small discs possessing lateroventral grooves (not measured due to specimen desiccation); webbing present (not measured due to specimen desiccation and damage); dermal ridge along toe V present; subarticular tubercles prominent, oval, all present; inner and outer metatarsal tubercles and supernumerary tubercles indistinct (due to desiccated state of specimen).

None of the skin characters can be reliably determined due to poor preservation of the specimen.

Description of topotype, male, BNHS 5809 (Figs 7c, 8a-c). Small-sized, moderately slender adult male (SVL 31.7). Head small (HW 9.2, HL 12.9, IFE 5.6, IBE 7.6), longer than wide, flat above; snout subovoid 
in dorsal and ventral view, rounded in lateral view, protruding, its length (SL 5.9) longer than horizontal diameter of eye (EL 4.0); loreal region vertical and concave with rounded canthus rostralis; interorbital space flat, equal (IUE 3.0) to upper eyelid (UEW 3.0) and narrower than internarial distance (IN 3.1); distance between back of eyes (IBE 7.6) slightly more than 1.3 times the distance between front of eyes (IFE 5.6); nostril closer to tip of snout (NS 2.0) than eye (EN 2.8); tympanum (TYD 2.8) 70\% of eye diameter (EL 4.0); tympanum-eye distance (TYE 0.6); pineal ocellus present, between anterior border of eyes; vomerine ridge present, bearing small teeth, with an angle of $45^{\circ}$ to body axis, as close to choanae as to each other, tongue moderately large, emarginated. Forelimbs short and thin; forelimb (FAL 5.5) shorter than hand length (HAL 8.6); fingers short, finger length formula I=II $<\mathrm{IV}<\mathrm{III}$, tip of all fingers with obtusely pointed discs, with lateroventral groove, moderately expanded relative to finger width $\left(\mathrm{FD}_{\mathrm{I}} 0.7, \mathrm{FW}_{\mathrm{I}}\right.$ $0.5 ; \mathrm{FD}_{\text {II }} 0.8, \mathrm{FW}_{\text {II }} 0.6 ; \mathrm{FD}_{\text {III }} 1.0, \mathrm{FW}_{\text {III }} 0.4 ; \mathrm{FD}_{\text {IV }} 1.1$, $\mathrm{FW}_{\text {IV }}$ 0.5); dermal fringe present; subarticular tubercles not prominent, oval, single, all present; two oval distinct palmar tubercles weakly developed; a distinct supernumerary tubercle on base of each finger. Hindlimbs relatively long and thin, thigh length (TL 13.0) shorter than shank (SHL 15.0), and foot (FOL 14.4); relative digit lengths $\mathrm{I}<\mathrm{II}<\mathrm{III}<\mathrm{V}<\mathrm{IV}$; tips of all toes with small obtusely pointed discs possessing lateroventral grooves, moderately expanded relative to toe width $\left(\mathrm{TD}_{\mathrm{I}} 0.8, \mathrm{TW}_{\mathrm{I}} 0.6 ; \mathrm{TD}_{\mathrm{II}} 0.8, \mathrm{TW}_{\mathrm{II}} 0.5 ; \mathrm{TD}_{\mathrm{III}}\right.$ $\left.0.9, \mathrm{TW}_{\mathrm{III}} 0.5 ; \mathrm{TD}_{\mathrm{IV}} 0.7, \mathrm{TW}_{\mathrm{IV}} 0.5 ; \mathrm{TD}_{\mathrm{V}} 0.8, \mathrm{TW}_{\mathrm{V}} 0.5\right)$; webbing present, moderate: $\mathrm{I}^{1} \frac{1}{3}-2 \mathrm{II} 1^{+}-2^{+} \mathrm{III} 1^{1} / 2_{2}-3 \mathrm{IV} 2^{1} / 2^{-}$ $1 \frac{1}{4} \mathrm{~V}$; dermal ridge along toe $\mathrm{V}$ present, subarticular tubercles prominent, oval, all present; inner metatarsal tubercle distinct and rather short, outer metatarsal tubercle rounded, prominent; supernumerary tubercles absent, tarsal tubercle absent.

Skin of snout, between eyes, side of head and anterior part of dorsum finely shagreened; posterior part of back and upper part of flank finely glandular; dorsolateral folds that extend from the posterior corner of the eye to the entire body length on both sides, weakly developed (Figs 5, 7c); dorsal part of forelimb without glandular warts; thigh, tibia and tarsus with weakly developed glandular warts; distinct rictal gland posterior to corner of mouth; flat weakly developed humeral glands.

Colour in preservation (Figs 7c, 8a-b). Dorsal parts greyish-brown, lower flank light grey with black speckles; tympanic area dark grey; upper lip with white stripe continuing through rictal gland to above arm insertion; dorsolateral folds light grey; forelimbs, dorsal parts of thigh, shank and foot light greyishbrown with grey spots, and weakly formed crossbands; throat and margin of throat greyish-white with black flecks; chest and belly greyish-white; ventral parts of thigh, tibia and foot greyish-white with black spots; webbing dark grey with minute specks. Colour in life (SDBDU 2006.4776) (Fig. 9a). Dorsal parts light brown, lower flank greyish-brown with black specks, tympanic area reddish-grey; upper lip with white stripe continuing through rictal gland to above arm insertion; dorsolateral folds light brown; forelimbs, dorsal parts of thigh, shank and foot light brown with grey spots; margin of throat white with black flecks; chest and belly off-white, ventral parts of thigh, tibia and foot greyish-white with black spots; webbing dark grey with minute specks; iris reddish-brown.

Variation. See Table 2 for morphometric data from nine adult males and an adult female (holotype). SDBDU 2012.1894: dorsum finely granular; SDBDU 2011.520, SDBDU 2006.4776, SDBDU 2001.795 and BNHS 5810: dorsum light brown with minute dark spots and without scattered granular projections; BNHS 5811-5812: dorsum with scattered granular projections; SDBDU 2001.795: tympanic region light grey.

Secondary sexual characters. Males: Single ovalshaped nuptial pad on finger I present, cream-coloured; vocal sac not visible externally on lower jaw (internal vocal slits present); humeral gland weakly developed, positioned laterally on the preaxial side of the upper forelimb.

Distribution. Known only from two districts of the southern Western Ghats, south of Palghat Gap - Thiruvananthapuram and Kollam districts in the state of Kerala (Fig. 10, Table 1).

Habitat and natural history. This species was collected either from disturbed habitats adjacent to secondary forests (BNHS 5809), or wayside temporary ponds surrounded by vegetation (SDBDU 2006.4776) below $180 \mathrm{~m}$ asl. Animals were found both in temporary (SDBDU 2006.4776) and permanent water bodies (BNHS 5809-5811, SDBDU 2011.520, SDBDU 2001. 795), but none were found in fast flowing streams. BNHS 5810-5811 were collected from leaves about 


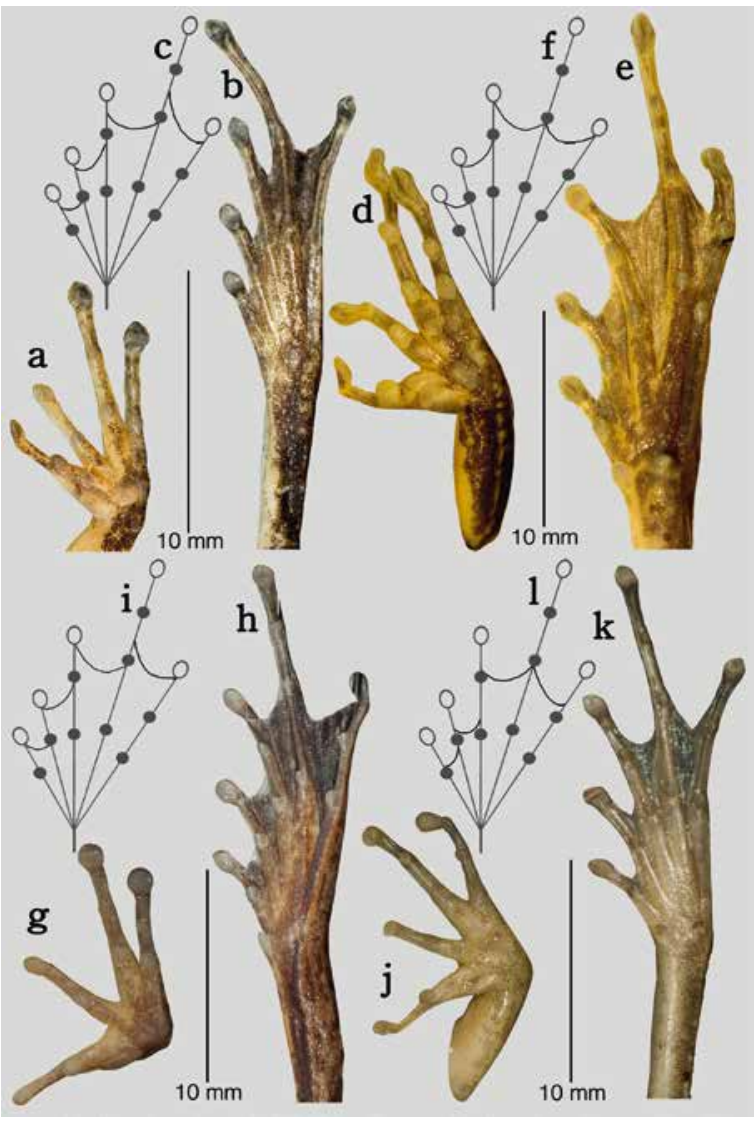

Fig. 8a-l. Ventral view of hand and foot, and schematic illustration of webbing on feet of the Hylarana aurantiaca group in preservation: a-c. topotype of $H$. aurantiaca (BNHS 5809): a. ventral view of hand, b. ventral view of foot, c. schematic illustration of webbing on feet; d-f. holotype of $H$. doni (BNHS 5814): d. ventral view of hand, e. ventral view of foot, f. schematic illustration of webbing on feet; g-i. neotype of $H$. intermedius (BNHS 5823): $\mathrm{g}$. ventral view of hand, $\mathrm{h}$. ventral view of foot, i. schematic illustration of webbing on feet; $j-1$. holotype of H. urbis (BNHS 5837): j. ventral view of hand, k. ventral view of foot, 1. schematic illustration of webbing on feet.

one meter above the ground close to a water body, whereas BNHS 5809 was collected along a stream, where over 30 aggressively calling males were observed. During the dry season this species was not found at any of these sites, however, immediately after a few monsoon showers, aggregating males called continuously just after sunset to approximately 22:00 h.

Remarks. Small-sized Hylarana species from Sri Lanka have long been misidentified as H. aurantiaca (e.g. Grandison and Senanayake, 1966; Dutta and Manamendra-Arachchi, 1996; Dutta, 1997; Pethiyagoda et al., 2006; De Silva, 2009; Ukuwela, 2009; Bopage et al.,
2011). Biju (2001) first raised doubts about the occurrence of this taxon in Sri Lanka and suggested careful comparison of Sri Lankan and south Indian populations. Subsequently, Biju et al. (2004a) suggested that the Sri Lankan populations belong to an undescribed species that requires further scientific validation.

We sampled some commonly misidentified smallsized 'Hylarana aurantiaca' populations from the wet zone of Sri Lanka, and reveal that these are either variants of $\mathrm{H}$. gracilis or populations belonging to an altogether new species, described herein as Hylarana serendipi sp. nov. Populations from Galle and Udawatta Kele (Ampitya), which include earlier records of $\mathrm{Hy}$ larana aurantiaca (Dutta and Manamendra-Arachchi, 1996; Dutta, 1997; Ukuwela, 2009; Bopage et al. 2011) belong to $H$. gracilis, whereas populations from Kudawa in Sinharaja forest (Dutta and ManamendraArachchi, 1996) and the adjacent Kanneliya forest reserve (Grandison and Senanayake, 1966) belong to the new species $H$. serendipi. Furthermore, the size of ' $H$. aurantiaca' reported by previous authors (14.6-62.6 $\mathrm{mm}$ ) is far too variable, and clearly includes misidentifications of adults and/or immature specimens of other species (i.e., adult male $H$. aurantiaca sensu stricto have SVL 27.1-31.7 $\mathrm{mm}$ ).

Hylarana doni sp. nov.

Don's Golden-backed frog

(Figs 7d-f, 8d-f, 9b-c, 10; Tables 1-2)

Holotype. BNHS 5814, an adult male, Padagiri, Nelliyampathy, Palakkad dist., Kerala state, India, collected by SDB and SG, 15 October 2011.

Paratypes. BNHS 5815, an adult male, collected along with holotype; BNHS 5816, an adult male and BNHS 5817, an adult female, Poomala, Idukki dist., collected by SDB and Systematics Lab team, 21 April 2012; BNHS 5818, an adult male, Parambikulam tiger reserve, Palakkad dist., collected by SDB and Systematics Lab team, 11 August 2011; BNHS 5819, an adult male, Thekkady, Idukki dist., collected by SDB, 23 July 2005; BNHS 5820, an adult male, Chathankod, Thiruvananthapuram dist., collected by SDB, 23 May 2006; BNHS 5821, an adult male, Chathankod, Thiruvananthapuram dist., collected by SDB and Systematics Lab team, 11 September 2011; BNHS 5822, an adult male, Gavi, Pathanamthitta dist., collected by SDB, 10 June 2007.

Referred specimens. SDBDU 2011.540, an adult male, Parambikulam tiger reserve, Palakkad dist., 
collected by SDB and Systematics Lab team, $11 \mathrm{Au}-$ gust 2011; SDBDU 2011.265, an adult male, Chathankod, Thiruvananthapuram dist., collected by SDB and Systematics Lab team, 11 September 2011; SDBDU 2011.1169, an adult male, Kesavapara, Nelliyampathy, Palakkad dist., collected by SDB and SG, 14 October 2011; SDBDU 2006.4824, an adult male, Gavi, Pathanamthitta dist., collected by SDB, 10 June 2007; SDBDU 2006.4845a, a sub-adult, Palode, Thiruvananthapuram dist., collected by SDB, 6 October 2006.

Comparison. Hylarana doni sp. nov. could not be confused with Hylarana aurantiaca, Hylarana intermedius and H. urbis sp. nov. within the Hylarana aurantiaca group due to its relatively large adult male snoutvent size, SVL 38.0-43.1 mm, $N=12$ (vs. SVL 27.1$31.7 \mathrm{~mm}, N=9, H$. aurantiaca, SVL $33.0-41.6 \mathrm{~mm}, N$ $=14, H$. intermedius, SVL 30.1-34.3 mm, $N=5, H$. urbis) and ventral side of the forearm with a straight line of granular projections from the base of finger IV to the elbow (vs. absent in all three species) (Figs 8b, e, $\mathrm{h}, \mathrm{k}$ ). Furthermore, $H$. doni differs from $H$. intermedi$u s$ by its shank longer than foot length, male SHL 21.7 $\pm 1.3 \mathrm{~mm}$, FOL $19.8 \pm 1.0 \mathrm{~mm}, N=12$ (vs. equal, male SHL $17.9 \pm 0.9 \mathrm{~mm}$, FOL $17.9 \pm 0.9 \mathrm{~mm}, N=14)$ and fourth toe webbing not extending beyond the second subarticular tubercle on the outside (vs. well beyond); differs from $H$. urbis by its dorsolateral folds moderately developed (vs. weakly developed), granular dorsal skin (vs. shagreened) and relatively more webbing I1-2II1-2+III1-3IV3-1V (vs. less I2-2+III/3/4-23/4III-$3 \mathrm{IV} 3-1{ }^{3} / \mathrm{V}$ ) (Figs 8e-f, k-1). See Hylarana aurantiaca for comparison with that species.

Genetic divergence. Intraspecific genetic variation within Hylarana doni was $0.2 \pm 0.2 \%$ (range $0-0.6 \%$, $N=8$ ) for $16 \mathrm{~S}, 0.4 \pm 0.3 \%$ (range $0-1.0 \%, N=9$ ) for COI and $0.5 \pm 0.5 \%$ (range $0-1.2 \%, N=10$ ) for Cytb. Based on phylogenetic position, $H$. doni is closely related to the members of Hylarana aurantiaca group (Fig. 4); differs from $H$. intermedius by mean genetic divergence of $2.7 \pm 0.1 \%$ (range $2.6-3.0 \%, N=72$ ) for $16 \mathrm{~S}, 6.1 \pm 0.3 \%$ (range $5.5-6.7 \%, N=81$ ) for COI, and $9.1 \pm 0.1 \%$ (range $8.0-12.1 \%, N=90$ ) for Cytb; differs from $H$. urbis by mean genetic divergence of $4.3 \pm$ $0.1 \%$ (range $4.3-4.5 \%, N=24$ ) for $16 \mathrm{~S}, 8.4 \pm 0.2 \%$ (range $8.1-8.8 \%, N=27$ ) for COI, and $10.1 \pm 0.6 \%$ (range $9.5-11 \%, N=30$ ) for Cytb (Tables S2-S3). See Hylarana aurantiaca for comparison with that species.
Description of holotype (Figs 7d-f, 8d-f). Small-sized, slender adult male (SVL 42.0). Head small (HW 11.8, HL 15.6, IFE 7.9, IBE 10.1), longer than wide, flat above; snout sub-elliptical in dorsal and ventral view, rounded in lateral view, protruding, its length (SL 7.8) longer than horizontal diameter of eye (EL 4.0); loreal region vertical and concave with rounded canthus rostralis; interorbital space flat, wider (IUE 4.2) than upper eyelid (UEW 2.8) and internarial distance (IN 3.8); distance between back of eye (IBE 10.1) 1.3 times the distance between front of eye (IFE 7.9); nostril oval, closer to tip of snout (NS 2.3) than eye (EN 4.0); tympanum (TYD 3.7) 93\% of eye diameter (EL 4.0); tympanum-eye distance (TYE 1.0); pineal ocellus present, between anterior border of eyes; vomerine ridges present, bearing small teeth, with an angle of $45^{\circ}$ to body axis, as close to choanae as to each other; tongue moderately large, emarginated. Forelimbs moderately short and strong; forelimb (FAL 8.5) shorter than hand length (HAL 12.6); fingers short, finger length formula I=II $<$ IV $<$ III; tips of all fingers with obtusely pointed discs, with lateroventral groove, moderately wide compared to finger width $\left(\mathrm{FD}_{\mathrm{I}} 1.0, \mathrm{FW}_{\mathrm{I}} 0.6 ; \mathrm{FD}_{\mathrm{II}} 1.1, \mathrm{FW}_{\mathrm{II}}\right.$ $0.4 ; \mathrm{FD}_{\text {III }} 1.6, \mathrm{FW}_{\text {III }} 0.6 ; \mathrm{FD}_{\text {IV }} 1.5, \mathrm{FW}_{\text {IV }} 0.7$ ); dermal fringe present, subarticular tubercles prominent, oval, single, all present; two distinct oval palmar tubercles weakly developed; a distinct supernumerary tubercle on base of each finger. Hindlimbs relatively long and strong, thigh length (TL 19.8) shorter than shank (SHL 24.2), and foot (FOL 21.3); relative digit lengths $\mathrm{I}<\mathrm{II}<\mathrm{III}<\mathrm{V}<\mathrm{IV}$; tips of all toes with small pointed discs possessing lateroventral grooves, rather wide compared to toe width $\left(\mathrm{TD}_{\mathrm{I}} 1.1, \mathrm{TW}_{\mathrm{I}} 0.5 ; \mathrm{TD}_{\text {II }} 1.3, \mathrm{TW}_{\text {II }}\right.$ $0.5 ; \mathrm{TD}_{\text {III }} 1.2, \mathrm{TW}_{\text {III }} 0.5 ; \mathrm{TD}_{\text {IV }} 1.3, \mathrm{TW}_{\text {IV }} 0.6 ; \mathrm{TD}_{\mathrm{V}} 1.2$, $\mathrm{TW}_{\mathrm{V}} 0.5$ ); webbing present, moderate: I1-2II1-2+III13IV3-1V; weakly developed dermal ridge along toe $\mathrm{V}$ present; subarticular tubercles prominent, oval, all present; inner metatarsal tubercle distinct and moderately short, outer metatarsal tubercle rounded, prominent.

Skin of snout, between eyes, side of head and anterior part of dorsum granular; posterior part of back and upper part of flanks shagreened; lower part of flanks smooth; dorsolateral folds that extend from the posterior corner of the eye to the entire body length on both sides, moderately developed (Figs 5, 7d, f); dorsal part of forelimb smooth; thigh, tibia and tarsus granular with weakly developed warts in longitudinal lines bearing horny spinules; distinct rictal gland posterior to corner of mouth; flat indistinct humeral glands; ventral side of forearm having a straight line of granular projections from base of finger IV to elbow (Fig. 8d); 

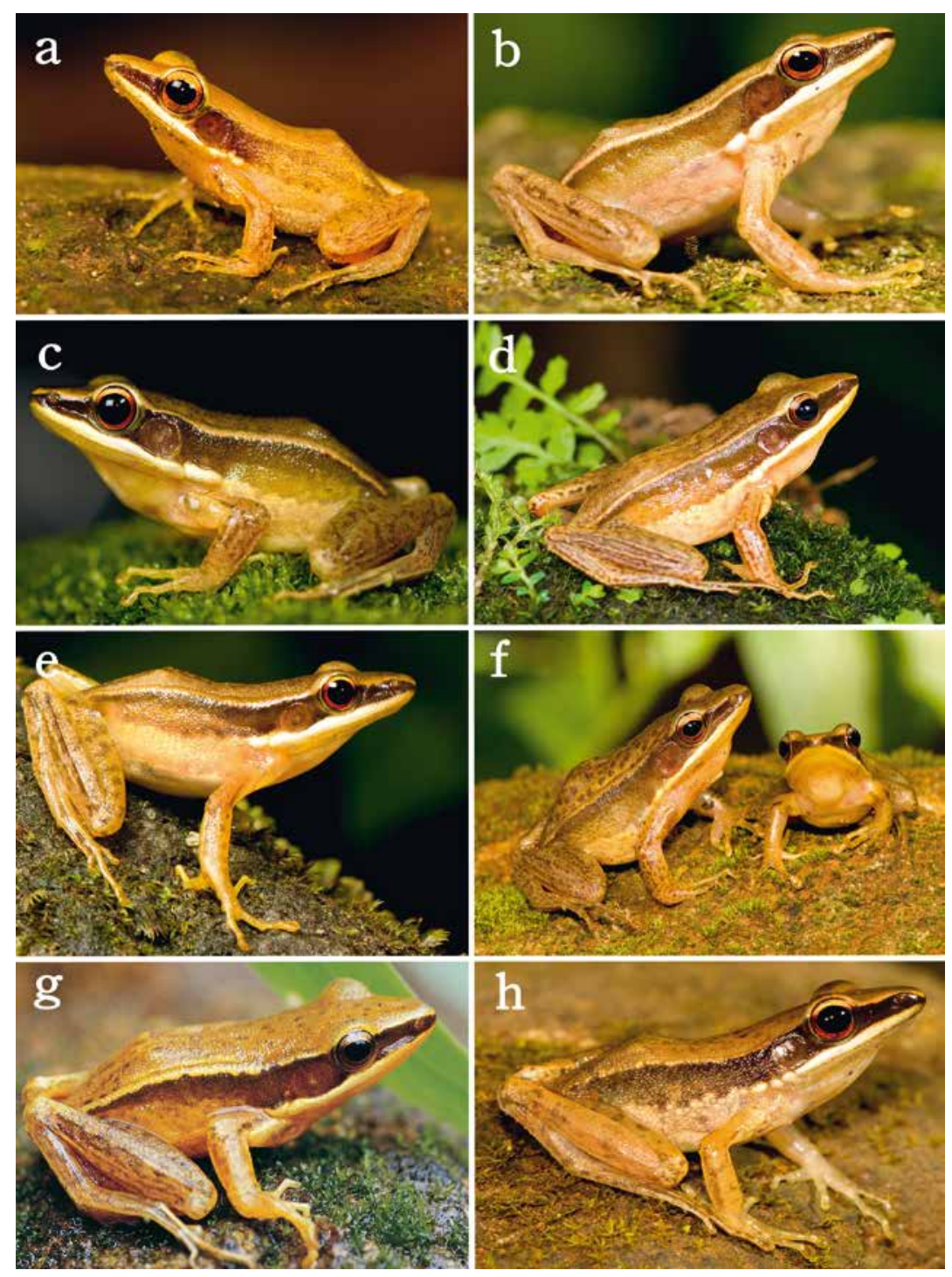

Fig. 9a-h. Hylarana aurantiaca group in life: a. H. aurantiaca, dorsolateral view of referred specimen (SDBDU 2006.4776, male), from Karamana, Thiruvananthapuram; b-c. H. doni, b. dorsolateral view of holotype (BNHS 5814, male), from Padagiri, Nelliyampathy, c. dorsolateral view of paratype (BNHS 5818, male), from Parambikulam; d-g. H. intermedius, d. dorsolateral view of neotype (BNHS 5823, male), from Sakleshpur, e. dorsolateral view of referred specimen (BNHS 5829, male), from Adyar, Mangalore, f. dorsolateral view (on left, BNHS 5830, male) and front view (on right, SDBDU 2012.2224, male) of referred specimens from Madikeri, g. dorsolateral view of referred specimen, (BNHS 5832, male), from Kalpetta; h. H. urbis, dorsolateral view of holotype (BNHS 5837, male), from Kadavanthra (Photos: SD Biju). weakly developed granular projections from base of toe $\mathrm{V}$ to knee (Fig. 8e).

Colour in preservation (Figs 7d-f). Dorsal parts greyish-brown with dark speckles; lower flanks light grey with black speckles; tympanic areas dark grey; upper lips with white stripe continuing through rictal gland to above arm insertion; dorsolateral folds light grey; forelimbs, dorsal surface of thighs, tibia and feet light greyish-brown with grey spots and weakly developed cross-bands, posterior part of thighs light grey with dark greyish-brown reticulations; throat and margin of throat, chest and belly greyish-white with black flecks; ventral parts of thighs, tibia and feet greyish-white with black spots; webbing dark grey with minute specks. Colour in life (Fig. 9b). Dorsum uniform greyish-brown with black specks; tympanum and surrounding areas light brown; upper lips with greyishwhite stripe continuing through rictal gland to above arm insertion; iris reddish-brown with golden specks with dark patches on either side; flanks light yellowishgrey; limbs dorsally greyish-brown with light brown cross-bands; feet and webbing dark grey; throat and margin of throat, chest and belly greyish-white with prominent black flecks.

Variation. See Table 2 for morphometric data from 12 adult males and one adult female. BNHS 5815: posterior 
part of thigh light grey with dark brown reticulations; SDBDU 2011.540: side of head with horny spinules, posterior part of thigh light grey with light brown reticulations; BNHS 5822: anterior and posterior part of back prominently granular, loreal and tympanic region darker brown, posterior part of thigh light grey with dark brown reticulations; BNHS 5819: anterior and posterior part of back prominently granular with very prominent dark spots, posterior part of thigh light grey with dark brown reticulations; BNHS 5820: anterior and posterior part of back prominently granular with very prominent dark spots; BNHS 5817: posterior part of thigh without reticulation, with dark spots on light grey background; BNHS 5821, SDBDU 2006.4824 and SDBDU 2011.1169: anterior and posterior part of back prominently granular with very prominent dark spots, posterior part of thigh light grey with dark brown reticulations; BNHS 5821: ventral surface (lower part of belly) granular; BNHS 5818: anterior and posterior part of back prominently granular with very prominent dark spots; SDBDU 2011.265: anterior and posterior part of back prominently granular with very prominent dark spots, posterior parts of thigh with dark spots on light grey background rather than reticulations, anterior part of flanks granular, ventral side (lower part of belly) slightly granular.

Secondary sexual characters. Males: Single ovalshaped nuptial pad on finger I present, cream-coloured; two vocal sacs faintly visible externally on the posterior lateral side of the throat; humeral gland weakly developed, positioned laterally on the preaxial side of the upper forelimb. Females: ova white, pigmented on pole (diameter 1.2-1.7 mm, $N=20$ ).

Etymology. This species is named after Dr. Don R. Church, in appreciation for his contribution to global amphibian conservation initiatives, especially for his tremendous support in formulating the Western Ghats Network of Protected Areas for Threatened Amphibians (WNPATA) for Western Ghats amphibian conservation. The species name doni is a noun in the genitive case.

Distribution. Hylarana doni is known only from the Western Ghats state of Kerala, with its distribution restricted to south of the Palghat Gap. The present study found this species in Palakkad dist. (Padagiri, Nelliyampathy; Kesavapara, Nelliyampathy; Parambikulam Tiger Reserve), Ernakulam dist. (Poomala and Thekkady), Pathanamthitta dist. (Gavi) and
Thiruvananthapuram dist. (Chathankod and Palode) (Fig. 10, Table 1).

Habitat and natural history. The primary habitat of this species is broadly regarded as open secondary and primary forest. Specimens are reported from elevations of 116 to $1210 \mathrm{~m}$ asl. Hylarana doni was found to be relatively abundant at all of its collection localities. Animals are located in both disturbed agricultural areas (Poomala and Chathankod) and undisturbed forest habitats (Nelliyampathy, Parambikulam and Thekkady). BNHS 5818 and SDBDU 2011.540 were collected from leaf litter on the forest floor; BNHS 5821 and SDBDU 2011.265 from temporary water bodies near a small stream. The majority of specimens were found actively calling, and collected between 18:3019:30 h.

Hylarana intermedius (Rao, 1937)

Rao's intermediate Golden-backed frog

(Figs 7g-i, 8g-i, 9d-g, 10; Tables 1-2)

Original name and description. Rana (Hylorana) intermedius Rao, 1937. On some new forms of Batrachia from s. India, Proceedings of Indian Academy of Science, Series B, 6: 394. Neotype. By present designation, BNHS 5823, an adult male, SVL $39.2 \mathrm{~mm}$, collected by SDB and SG, 1 October 2012 from Sakleshpur. Type locality. Sakleshpur, Hassan dist., 'Mysore' (current Karnataka) state, India. Current status of specific name. Valid name, as Hylarana intermedius (Rao, 1937).

Referred specimens. SDBDU 2012.2209, an adult male, Sakleshpur, Hassan dist., collected by SDB and SG, 1 October 2012; BNHS 5824, an adult male, Bhagamandala, Kodagu dist., collected by SDB and team, 13 June 2011; BNHS 5825, an adult male, Kachigebailu, Shimoga dist., 10 June 2011; BNHS 5826-5828 and SDBDU 2003.40190, four adult males, Jog falls, Shimoga dist., collected by SDB, 26 June 2003; BNHS 5829, an adult male, Adyar, Mangalore, Dakshin Kannada dist., collected by SDB and team, 24 October 2011; BNHS 5830 and SDBDU 2012.2224, two adult males, Madikeri, Kodagu dist., collected by SDB and SG, 2 October 2012; BNHS 5831, an adult male, Wattakolli, Coorg, Kodagu dist., collected by SDB and team, 15 June 2011; BNHS 5832, an adult male, Kalpetta, Wayanad dist., collected by SDB, 17 August 2007; BNHS 5833-5835 and SDBDU 2002.580, four adult females, Kalpetta, Wayanad dist., collected by 
SDB, 20 July 2002; BNHS 5836, an adult male, Kakkayam, Kozhikode dist., collected by SDB and Systematics Lab team, 25 May 2010; SDBDU 2011.203, a sub-adult, Bhagamandala, Kodagu dist., collected by SDB and team, 13 June 2011; SDBDU 2011.216, a subadult, Thalakaveri, Kodagu dist., collected by SDB and team, 14 June 2011; SDBDU 2011.1407, sub-adult, Adyar, Mangalore, Dakshin Kannada dist., collected by SDB and team, 24 October 2011.

Comments. Rao (1937) described Rana (Hylorana) intermedius from 'Saklespur, Hassan District, Mysore State' based on one specimen '(total length $43 \mathrm{~mm}$ )', deposited in Central College, Bangalore. The original name bearing type of this species is lost (Dubois, 1984; SDB personal observation). This nominal taxon was considered a junior subjective synonym of H.temporalis by Dubois (1992); a decision concurred by subsequent authors (e.g. Dutta, 1997; Dutta and Manamendra-Arachchi, 1996). Rao (1937) mentions 'the size and proportions of the head' and 'relative size of the tympanum and the eye' as a justification to consider this taxa as a new species, without any comparison with other known species. Our collections from the type locality correspond to the general body size and degree of webbing between the toes of Rana (Hylorana) intermedius, as described in the original description (Rao, 1937, 'figures 3 and 3a', plate XXII). The primary inconsistency between recent collections and the original description was in the relative measurements, but we consider these differences to be a matter of size variation. For nomenclatural stability, we formally designate BNHS 5823 as the neotype for this taxon and elevate Hylarana intermedius to the status of a valid species.

Comparison. Hylarana intermedius could be confused with Hylarana aurantiaca, Hylarana doni sp. nov. and Hylarana urbis sp. nov. in the Hylarana aurantiaca group, due to its small adult size. However $H$. intermedius differs from all other members in this group by its shank equal to foot length, male SHL 17.9 $\pm 0.9 \mathrm{~mm}$, FOL $17.9 \pm 0.9 \mathrm{~mm}, N=14$ (vs. longer, SHL $14.7 \pm 0.6 \mathrm{~mm}$, FOL $14.2 \pm 0.5 \mathrm{~mm}, N=9$, H. auranti $a c a$; SHL $21.7 \pm 1.3 \mathrm{~mm}$, FOL $19.8 \pm 1.0 \mathrm{~mm}, N=12$, H. doni; vs. shorter, SHL $15.9 \pm 1.0 \mathrm{~mm}$, FOL $16.3 \pm$ $1.6 \mathrm{~mm}, N=5, H$. urbis). More specifically differs from $H$. doni by its small adult male snout-vent size, SVL 33.0-41.6 mm, $N=14$ (vs. SVL 38.0-43.1 mm, $N$ $=12$ ), fingers and toes thin (Figs 8d-e, g-h) with weakly developed subarticular tubercles (vs. thick with well

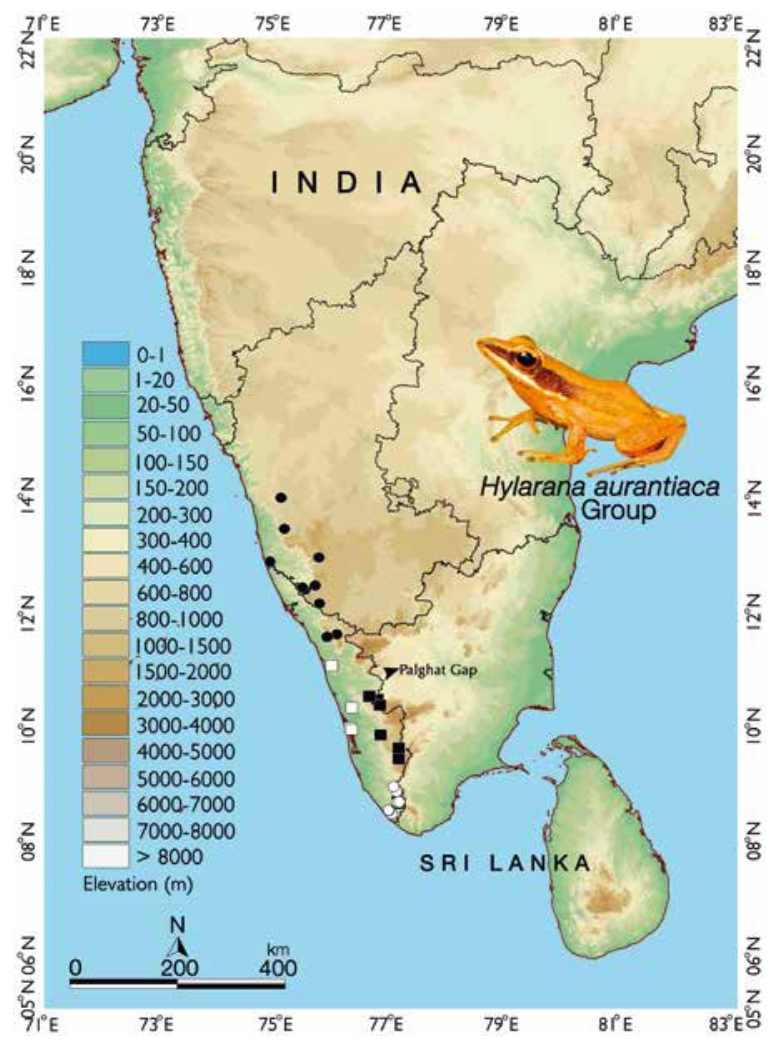

Fig. 10. Geographic distribution of four species of the Hylarana aurantiaca group in the Western Ghats. Open circle = Hylarana aurantiaca, closed circle $=$ Hylarana intermedius, closed square = Hylarana doni, open square $=$ Hylarana urbis. Coordinates are provided in Table 1.

developed subarticular tubercles), dorsal skin shagreened (vs. granular), dorsolateral folds weakly developed (vs. moderately developed). Furthermore, H. intermedius differs from $H$. doni by its webbing extending beyond the second subarticular tubercle on the outside of toe IV (vs. up to the second subarticular tubercle), ventral side of forearm without granular projections (vs. ventral side of forearm, having a straight line of granular projections from the base of finger IV to the elbow); differs from $H$. urbis by its relatively more webbing I1-2II1-2III1-3IV2 $2 /{ }_{3}-1 \mathrm{~V}$ (vs. less I2$2^{+} \mathrm{III}^{3} /{ }_{4}-2^{3} /{ }_{4} \mathrm{III} 2-3 \mathrm{IV} 3-1^{3} /{ }_{4}$ ) (Figs $8 \mathrm{~h}-\mathrm{I}, \mathrm{k}-\mathrm{l}$ ).

Genetic divergence. Intraspecific genetic variation within Hylarana intermedius was $0.2 \pm 0.1 \%$ (range $0-0.4 \%, N=9$ ) for $16 \mathrm{~S}, 0.4 \pm 0.3 \%$ (range $0-0.7 \%, N=$ 9) for COI and $1.7 \pm 1.8 \%$ (range $0-5.3 \%, N=9$ ) for Cytb. Based on phylogenetic position, $H$. intermedius is closely related to the members of Hylarana aurantiaca group (Fig. 4); differs from $H$. urbis by mean ge- 
netic divergence of $3.8 \pm 0.1 \%$ (range 3.7-3.9\%, $N=27$ ) for $16 \mathrm{~S}, 8.9 \pm 0.2 \%$ (range $8.6-9.2 \%, N=27$ ) for COI, and $10.3 \pm 1.3 \%$ (range 9.3-13.8\%, $N=27$ ) for Cytb (Tables S2-S3). See Hylarana aurantiaca and H. doni for comparison with those species.

Description of neotype (Figs 7g-i, 8g-i). Small-sized, slender adult female (SVL 39.2). Head small (HW 10.6, HL 14.6, IFE 6.7, IBE 8.9), longer than wide, slightly concave above; snout subovoid in dorsal and ventral view, rounded in lateral view, protruding, its length (SL 6.5) longer than horizontal diameter of eye (EL 3.8); loreal region acute and concave with rounded canthus rostralis; interorbital space slightly concave, wider (IUE 3.5) than upper eyelid (UEW 2.6) and equal to internarial distance (IN 3.5); nostril oval with flap of skin laterally, closer to tip of snout (NS 1.8) than eye (EN 3.5); tympanum (TYD 3.5) $92 \%$ of eye diameter (EL 3.8); vomerine ridge present but weak, bearing numerous small teeth, with an angle of $40^{\circ}$ to body axis, closer to choanae than each other, shorter than the distance between them; tongue moderately large, emarginated, bearing no medium lingual process. Forelimbs moderately long and thin; forelimb (FAL 6.8) shorter than hand length (HAL 11.5); fingers short, finger length formula $\mathrm{I}=\mathrm{II}<\mathrm{IV}<\mathrm{III}$; tips of all fingers with obtusely pointed discs, with lateroventral groove, moderately wide compared to finger width $\left(\mathrm{FD}_{\mathrm{I}} 0.7, \mathrm{FW}_{\mathrm{I}} 0.4 ; \mathrm{FD}_{\mathrm{II}} 0.8, \mathrm{FW}_{\mathrm{II}} 0.5 ; \mathrm{FD}_{\text {III }} 1.3, \mathrm{FW}_{\text {III }}\right.$ $\left.0.5 ; \mathrm{FD}_{\mathrm{IV}} 1.2, \mathrm{FW}_{\mathrm{IV}} 0.4\right)$; dermal fringe present, subarticular tubercles prominent, oval, single, all present; two distinct oval palmar tubercles weakly developed; a distinct supernumerary tubercle on base of each finger. Hindlimbs relatively long and thick, thigh length (TL 16.3) shorter than shank (SHL 19.7), and foot (FOL 19.8); relative digit lengths $\mathrm{I}<\mathrm{II}<\mathrm{III}<\mathrm{V}<\mathrm{IV}$; tips of all toes with small pointed discs possessing lateroventral grooves, rather wide compared to toe width $\left(\mathrm{TD}_{\mathrm{I}} 0.8\right.$, $\mathrm{TW}_{\text {I }} 0.3 ; \mathrm{TD}_{\text {II }} 1.0, \mathrm{TW}_{\text {II }} 0.5 ; \mathrm{TD}_{\text {III }} 1.0, \mathrm{TW}_{\text {III }} 0.5 ; \mathrm{TD}_{\text {IV }}$ $1.0, \mathrm{TW}_{\mathrm{IV}} 0.4 ; \mathrm{TD}_{\mathrm{V}} 0.8, \mathrm{TW}_{\mathrm{V}} 0.4$ ); webbing present, moderate: I1-2II1-2III1-3IV2 $2 /{ }_{3}-1 \mathrm{~V}$; weakly developed dermal ridge along toe $\mathrm{V}$ present; subarticular tubercles prominent, oval, all present; inner metatarsal tubercle distinct and moderately short, outer metatarsal tubercle rounded, prominent.

Skin of snout, between eyes, side of head and anterior part of dorsum sparsely granular; posterior part of back, upper and lower part of flanks shagreened; dorsolateral folds that extend from the posterior corner of the eye to the entire body length on both sides, moderately developed (Figs 5, 7g, i); dorsal part of forelimb sha- greened; thigh shagreened to sparsely granular; tibia and tarsus sparsely granular with weakly developed warts in longitudinal lines; distinct rictal gland posterior to corner of mouth; flat indistinct humeral glands.

Colour in preservation (Figs 7g-i). Dorsal parts greyish-brown with light brown irregular spots, lower flank light grey; tympanic area dark brownish-grey; upper lip with white stripe continuing through rictal gland to above arm insertion; dorsolateral folds light grey; forelimbs, dorsal part of thigh, shank and foot light grey with irregular light brown spots; throat and margin of throat greyish-white; chest and belly greyish-white; ventral parts of thigh, tibia and foot greyish-white with minute black spots; webbing light grey with minute specks. Colour in life (Fig. 9d). Dorsal parts light golden brown with irregular light brown spots; lower flank greyish-brown with black speckles; tympanic area reddish-brown; upper lip with light yellow stripe continuing through rictal gland to above arm insertion; dorsolateral folds light brown; forelimbs, dorsal part of thigh, shank and foot light brown with grey spots; margin of throat white; chest and belly off-white, ventral parts of thigh, tibia and foot greyish-white with minute black spots; webbing dark grey with minute specks; iris reddish-brown.

Variation. See Table 5 for morphometric data from 14 adult males and four females. BNHS 5836: with more prominently granular dorsum; BNHS 5831, BNHS 5826-5827: dorsum uniform light brown without spots.

Secondary sexual characters. Males: Single ovalshaped nuptial pad on finger I present, greyish-white coloured; vocal sac not visible externally on lower jaw (internal vocal slits present); humeral gland weakly developed, positioned laterally on the preaxial side of the upper forelimb. Females (BNHS 5833): ova white, pigmented on pole (diameter $0.7-1.0 \mathrm{~mm}, N=20$ ).

Distribution. This species is endemic to the Western Ghats and its distribution is restricted to north of the Palghat Gap. It is widely distributed in Karnataka and adjoining regions of Kerala, predominently at elevations between $600-1183 \mathrm{~m}$ asl, but also as low as $8 \mathrm{~m}$ asl at Adyar (Mangalore). In the present study, we collected this species from Sakleshpur (Hassan dist.), Bhagamandala, Madikeri and Wattakolli (Kodagu dist.), Kachigebailu and Jog falls (Shimoga dist.) and in lowland areas of Adyar, Mangalore (Dakshin Kannada dist.) in Karnataka state, and Kalpetta (Wayanad 
dist.) and Kakkayam (Kozhikode dist.) in the northern parts of Kerala state. (Fig. 10, Table 1).

Habitat and natural history. This species was collected either from disturbed habitats adjacent to secondary forest (Kachgebailu, Jog falls, Wattakolli, Kalpetta and Kakkayam), or wayside temporary ponds surrounded by vegetation (Saklespur, Madikeri and Adyar, Mangalore). Animals were found both in temporary and permanent water bodies but none were found in fast flowing streams. Specimens from the type locality (BNHS 5823 and SDBDU 2012.2209) were collected from vegetation surrounding a water body in a cultivated field. Kalpetta populations were found either in cultivated fields (BNHS 5832 and SDBDU 2002.580), or secondary forest near urban areas (BNHS 5833-5835). BNHS 5831 and BNHS 5835 were collected from leaves up to one meter above the ground, near a water body. During daytime animals were found on leaf litter close to water bodies. BNHS 5827-5828 were collected from a bush overhanging a stream, at a height of ca. $1.5 \mathrm{~m}$.

Hylarana urbis sp. nov.

Urban Golden-backed frog

(Figs 7j-1, 8j-1, 9h, 10; Tables 1-2)

Holotype. BNHS 5837, an adult male, Kadavanthra, Ernakulam dist., Kerala state, India, collected by SDB and SG, 12 April 2012.

Paratypes. BNHS 5838, an adult male and BNHS 5839, an adult female, collected along with holotype; BNHS 5840, an adult male, Tripunithura, Ernakulam dist., collected by SDB and team, 27 April 2012; BNHS 5841, an adult male, Meladoor, Thrissur dist., collected by SDB, 7 July 2003.

Referred specimens. SDBDU 2003.40230, an adult male, Meladoor, Thrissur dist., collected by SDB, 7 July 2003; SDBDU 2012.2039, a sub-adult, Kadakkattupara, Malappuram dist., collected by SDB and SG, 25 April 2012.

Comparison. Hylarana urbis sp. nov. could be confused with Hylarana aurantiaca, Hylarana intermedius and Hylarana doni sp. nov. within the Hylarana aurantiaca group due to its small adult size. However, $H$. urbis differs from $H$. doni and $H$. intermedius by the combination of small adult male snout-vent size, SVL 30.1-34.3 mm, $N=5$ (vs. SVL 38.0-34.1 mm, $N=$ 12, H. doni; SVL 33.0-41.6 mm, $N=14$, H. interme- dius) and weakly developed dorsolateral fold (vs. moderately developed in both species) (Figs 7d, g, j); differs from all other members of the Hylarana aurantiaca group by its shank shorter than foot length, male SHL $15.9 \pm 1.0 \mathrm{~mm}$, FOL $16.3 \pm 1.6 \mathrm{~mm}, N=5$ (vs. longer, SHL $14.7 \pm 0.6 \mathrm{~mm}$, FOL $14.2 \pm 0.5 \mathrm{~mm}, N=9$, $H$. aurantiaca; SHL $21.7 \pm 1.3 \mathrm{~mm}$, FOL $19.8 \pm 1.0$ $\mathrm{mm}, N=12, H$. doni; vs. equal, SHL $17.9 \pm 0.9 \mathrm{~mm}$, FOL $17.9 \pm 0.9 \mathrm{~mm}, N=14, H$. intermedius) and relatively less webbing between toes I2-2+ $\mathrm{II}^{3} /{ }^{3}-2^{3} /{ }_{4} \mathrm{III} 2^{-}$$3 \mathrm{IV} 3-1^{3 / 4} \mathrm{~V}$ (vs. more in other three species, $\mathrm{I}^{1 / 1} 3_{3}-2 \mathrm{II}^{+}$$2+\mathrm{III} 1 \frac{1}{2}-3 \mathrm{IV} 2 \frac{1}{2}-1^{1 / 1} / \mathrm{V}$ in $H$. aurantiaca, I1-2II1-2+III13IV3-1V in H. doni, I1-2II1-2III1-3IV2 $2 /{ }_{3}-1 \mathrm{~V}$ in $H$. intermedius) (Figs 8b-c, e-f, h-i, k-1). For more differences with Hylarana aurantiaca, H. doni, H. intermedius see 'Comparison' of those species.

Genetic divergence. Intraspecific genetic variation within Hylarana urbis was zero $(N=3)$ for $16 \mathrm{~S}, 0.1 \pm$ $0.1 \%$ (range $0-0.2 \%, N=3$ ) for COI, and $0.4 \pm 0.3 \%$ (range $0-0.6 \%, N=3$ ) for Cytb (Tables S2). Based on phylogenetic position, $H$. urbis is a member of the $H y$ larana aurantiaca group (Fig. 4). See Hylarana aurantiaca, $H$. doni and $H$. intermedius for comparison with those species.

Description of holotype (Figs 7j-1, 8j-1). Small-sized, moderately slender adult male, (SVL 30.1). Head small (HW 8.5, HL 10.3, IFE 5.6, IBE 7.3), longer than wide, flat above; snout sub-elliptical in dorsal and ventral view, rounded in lateral view, protruding, its length (SL 5.6) longer than horizontal diameter of eye (EL 3.2); loreal region vertical and flat with rounded canthus rostralis; interorbital space flat, wider (IUE 2.8) than upper eyelid (UEW 1.9) and subequal to internarial distance (IN 3.0); distance between front of eye (IFE 5.6) 1.3 times of distance between back of eye (IBE 7.3); nostril oval, closer to tip of snout (NS 1.4) than eye (EN 2.6); tympanum (TYD 2.5) 78\% of eye diameter (EL 3.2); tympanum-eye distance (TYE 0.9); pineal ocellus present, between anterior border of eyes; vomerine ridge present, bearing small teeth, with an angle of $45^{\circ}$ to body axis, as close to choanae as to each other; tongue moderately large, emarginated. Forelimbs moderately short and thin; forelimb (FAL 5.3) shorter than hand length (HAL 8.7); fingers short, finger length formula $\mathrm{I}=\mathrm{I} \mathrm{I}<\mathrm{IV}<\mathrm{III}$, tips of all fingers with obtusely pointed discs, with lateroventral groove, moderately wide compared to finger width $\left(\mathrm{FD}_{\mathrm{I}} 0.5\right.$, $\mathrm{FW}_{\mathrm{I}} 0.4 ; \mathrm{FD}_{\text {II }} 0.7, \mathrm{FW}_{\text {II }} 0.4 ; \mathrm{FD}_{\text {III }} 0.8, \mathrm{FW}_{\text {III }} 0.3 ; \mathrm{FD}_{\text {IV }}$ $0.9, \mathrm{FW}_{\mathrm{IV}} 0.6$ ); subarticular tubercles prominent, oval, 
single, all present; prepollex distinct, oval; two oval distinct palmar tubercles; a distinct supernumerary tubercle on base of each finger. Hindlimbs relatively long and thin; thigh length (TL 13.0) shorter than shank (SHL 15.9), and foot (FOL 16.1); relative digit lengths $\mathrm{I}<\mathrm{II}<\mathrm{III}<\mathrm{V}<\mathrm{IV}$; tips of all toes with small obtusely pointed discs possessing lateroventral grooves, rather wide compared to toe width $\left(\mathrm{TD}_{\mathrm{I}} 0.3, \mathrm{TW}_{\mathrm{I}} 0.2 ; \mathrm{TD}_{\mathrm{II}}\right.$ $0.7, \mathrm{TW}_{\text {II }} 0.4 ; \mathrm{TD}_{\text {III }} 0.7, \mathrm{TW}_{\text {III }} 0.3 ; \mathrm{TD}_{\text {IV }} 0.7, \mathrm{TW}_{\text {IV }} 0.3$; $\mathrm{TD}_{\mathrm{V}}$ 10.6, $\mathrm{TW}_{\mathrm{V}} 0.3$ ); webbing present, moderate: $\mathrm{I}^{2}-$ $2^{+} \mathrm{II}^{3} /{ }_{4}-2^{3} /{ }_{4} \mathrm{III} 2-3 \mathrm{IV} 3-13 / 4 \mathrm{~V}$; dermal ridge along toe $\mathrm{V}$ present; subarticular tubercles prominent, oval, all present; inner metatarsal tubercle distinct and moderately short, outer metatarsal tubercle rounded, prominent.

Skin of snout, between eyes, side of head and anterior part of dorsum shagreened, posterior part of back and upper part of flanks shagreened with scattered glandular projections; lower part of flanks rather smooth; dorsolateral folds that extend from the posterior corner of the eye to the entire body length on both sides, weakly developed (Figs 5, 7j, 1); dorsal part of forelimb without smooth; thigh, tibia and tarsus shagreened with scattered glandular projections; distinct rictal gland posterior to corner of mouth (Fig. 7l).

Colour in preservation (Figs $7 \mathrm{j}-1$ ). Dorsal parts light grey, lower flanks light grey with black speckles; tympanic area light grey; upper lips with white stripe continuing through rictal gland to above arm insertion; dorsolateral folds light grey; forelimbs, dorsal surface of thighs, tibia and feet light grey with minute black spots and weakly formed cross-bands; throat and margin of throat greyish-white with black flecks; chest and belly greyish-white; ventral parts of thighs, tibia and feet greyish-white with black spots; webbing dark grey with minute specks. Colour in life (Fig. 9h). Dorsum uniform greyish-brown; tympanum and surrounding areas dark brown; upper lips with white stripe continuing through rictal gland to above arm insertion; iris reddish-brown in lower half and golden brown in upper half; flanks light grey; limbs dorsally light greyishbrown with light brown cross-bands; throat and margin of throat, chest and belly greyish-white with minute black spots; feet and webbing dark grey.

Variation. See Table 2 for morphometric data from five adult males and an adult female. BNHS 5838: dorsum blackish-brown in preservation (brownish-black in life).

Secondary sexual characters. Males: Single ovalshaped nuptial pad on finger I present, cream-coloured; two vocal sacs faintly visible externally on the posterior lateral side of the throat; humeral gland weakly developed, positioned laterally on the preaxial side of the upper forelimb. Females (BNHS 5839): ova immature.

Etymology. The species epithet is a noun in apposition, therefore invariable, derived from a Latin phrase ' $u r$ bis' meaning urban or city, referring to the species inhabiting mainly urban areas.

Distribution. This species is known only from Kadavanthra and Tripunithura (Ernakulam dist.), Kadakkattupara (Malappuram dist.), and Meladoor (Thrissur dist.) in Kerala state, southern Western Ghats (Fig. 10, Table 1).

Habitat and natural history. The primary habitat of this species is broadly regarded as open wayside water bodies in urban areas, below $150 \mathrm{~m}$ asl. The holotype and paratypes were found near an open pond with overhanging vegetation; BNHS 5841 and SDBDU 2003.40230 were found calling from vegetation close to paddy fields at around 17:30 $\mathrm{h}$.

Hylarana flavescens group. This group can be distinguished by the following suite of characters: medium to large-sized adult (male, SVL 43-85 $\mathrm{mm}$; female, SVL 58-92 mm), body robust; dorsolateral folds well developed (Fig. 5); finger and toe discs dorsoventrally compressed and obtusely pointed (Fig. 6); fourth toe webbing extends up to the first subarticular tubercle on the outside; endemic to the Western Ghats. In a phylogenetic framework, Hylarana flavescens group can be characterised as the most inclusive clade that contains a Western Ghats radiation (Hylarana caesari sp. nov., H. flavescens, Hylarana indica sp. nov., Hylarana magna sp. nov., H. montanus and Hylarana sreeni sp. nov.), but none of the other Western Ghats or Sri Lankan clades of Hylarana (Fig. 4).

Hylarana caesari sp. nov.

Maharashtra Golden-backed frog

(Figs 11a-c, 12a-c, 13a, 14; Tables 1-2)

Holotype. BNHS 5842, an adult male, Humbarli, Koyna, Satara dist., Maharashtra state, India, collected by SDB, 13 July 2004.

Paratypes. BNHS 5843, an adult female, collected by SDB and Systematics Lab team, 20 August 2010; 


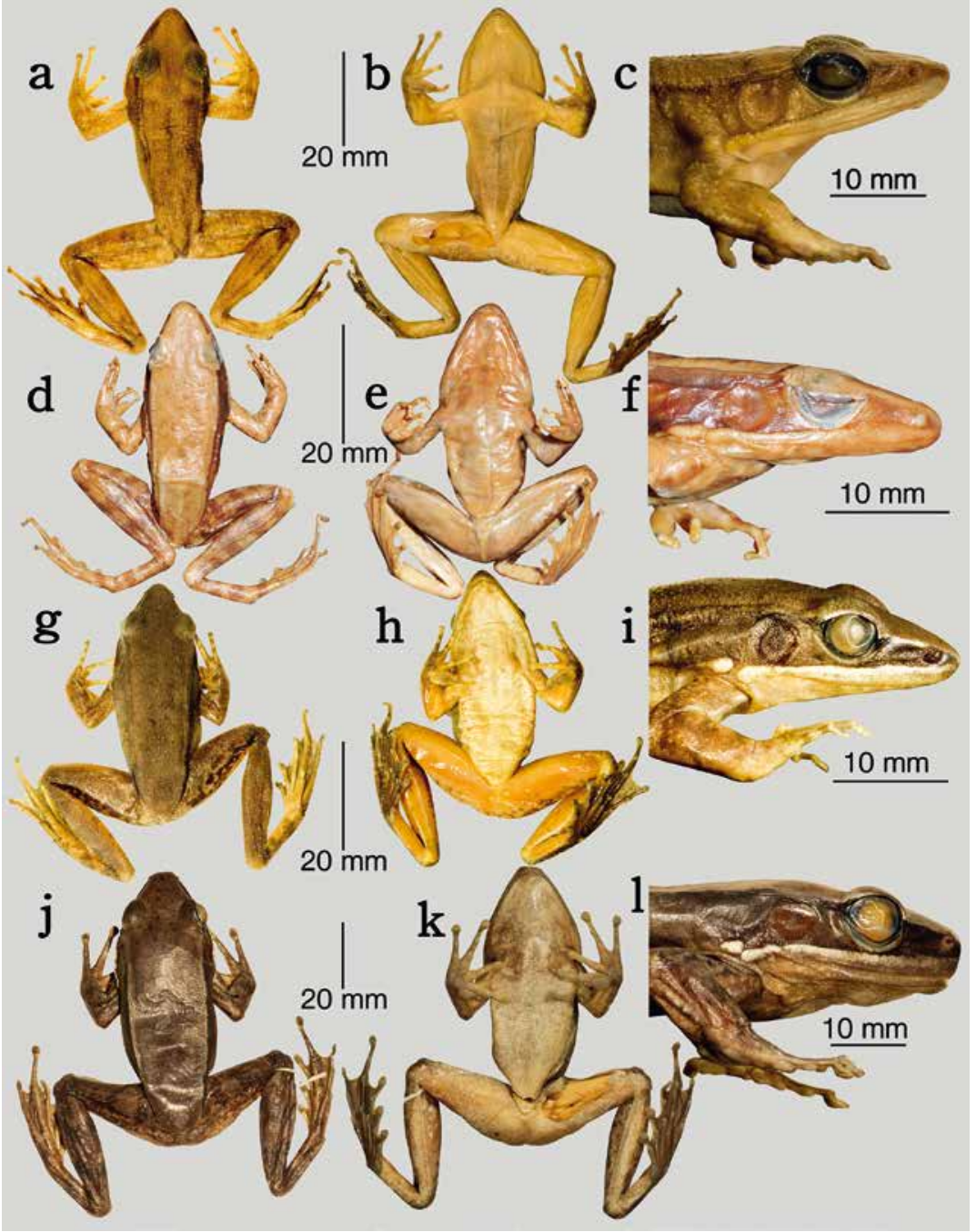

Fig. 11a-l. Dorsal view, ventral view, and lateral view of head of the Hylarana flavescens group in preservation: a-c. holotype of $H$. caesari (BNHS 5842): a. dorsal view, b. ventral view, c. lateral view of head; d-f. lectotype of Rana flavescens (= Hylarana flavescens) (ZSIC 2777): d. dorsal view, e. ventral view, f. lateral view of head; g-i. holotype of $H$. indica (BNHS 5847): g. dorsal view, h. ventral view, $i$. lateral view of head; $j-1$. holotype of $H$. magna (BNHS 5857): j. dorsal view, $\mathrm{k}$. ventral view, 1. lateral view of head.
BNHS 2996-2997, two adult males, Koyna, Satara dist., collected by AG Sekar and VM Hegde, $17 \mathrm{Au}-$ gust 1995; BNHS 1349 and BNHS 1353, two adult males, Mahabaleshwar, Satara dist., collected by $\mathrm{H}$. Abdulali, 31 October 1954.

Referred specimens. SDBDU 2010.368, an adult female, Humbarli, Koyna, Satara dist., collected by SDB and Systematics Lab team, 20 August 2010; SDBDU 2010.361, a sub-adult female, Humbarli, Koyna, Satara dist., collected by SDB and Systematics Lab team, 20 August 2010; SDBDU 2004.4510b, a sub-adult male, Humbarli, Koyna, Satara dist., collected by SDB, 13 July 2004; SDBDU 2004.4525 and SDBDU 2004.4527, two sub-adult males, Amboli, Sindhudurg dist., collected by SDB, 15 July 2004.
Comparison. Hylarana caesari sp. nov. could be confused with Hylarana flavescens, Hylarana indica sp. nov., Hylarana magna sp. nov., Hylarana montanus, Hylarana sreeni sp. nov. in the Hylarana flavescens group, due to its overall adult size. However, H. caesari differs from all other members in this group by its snout sub-elliptically pointed in dorsal (Fig. 11a) and dermal fringe along toe $\mathrm{V}$ well developed from tip of toe to heel, with glandular projections ending with sharp spinules in males (Fig. 12b); more specifically it differs from $H$. flavescens and $H$. sreeni by its second toe webbing well beyond the first subarticular tubercle on the inside (vs. up to first subarticular tubercle, in both species), dorsal skin granular (vs. shagreened to sparsely granular in both species); more specifically it 
differs from $H$. sreeni by its interorbital space wider than the upper eyelid width, IUE $5.1 \pm 0.4 \mathrm{~mm}$, UEW $3.5 \pm 0.2 \mathrm{~mm}$, male, $N=5$ (vs. subequal, IUE $4.1 \pm 0.5$ $\mathrm{mm}$, UEW $4.0 \pm 0.4 \mathrm{~mm}, N=7$ ); differs from $H$. indica by its tympanum diameter smaller than horizontal diameter of eye, TYD $3.9 \pm 0.4 \mathrm{~mm}$, EL $5.6 \pm 0.5$ $\mathrm{mm}$, male, $N=5$ (vs. equals to horizontal diameter of eye, TYD $5.3 \pm 0.6 \mathrm{~mm}$, EL $5.3 \pm 0.6 \mathrm{~mm}, N=10$ ); thigh shorter than foot length on males, TL $21.0 \pm 1.7$ $\mathrm{mm}$, FOL $23.3 \pm 0.9 \mathrm{~mm}, N=5$ (vs. equal on males, TL $26.7 \pm 2.3 \mathrm{~mm}$, FOL $26.7 \pm 2.2 \mathrm{~mm}, N=10)$, dorsal skin granular (vs. shagreened to sparsely granular); differs from H. magna and H. montanus by its smaller adult size, male SVL 46.1-50.1 mm, $N=5$; female SVL $58.0-59.7 \mathrm{~mm}, N=2$ (vs. male SVL $84.5 \mathrm{~mm}, N=1$, female SVL 78.7-91.8 mm, $N=4$ in H. magna; male SVL 54.0-65.0 mm, $N=8$, female SVL 65.6-74.5 mm, $N=3$ in $H$. montanus), snout sub-elliptically pointed in dorsal and ventral view (vs. nearly truncate in $H$. magna, rounded to truncate in $H$. montanus), dorsal skin granular (vs. shagreened in H. magna, shagreened to sparsely granular in $H$. montanus); individually differs from $H$. montanus by its thigh shorter than foot length, TL $21.0 \pm 1.7 \mathrm{~mm}$, FOL $23.3 \pm 0.9 \mathrm{~mm}$, male, $N=5$ (vs. equal, TL $30.0 \pm 1.6 \mathrm{~mm}$, FOL $30.0 \pm 1.6$ $\mathrm{mm}$, male, $N=8)$.

Genetic divergence. Intraspecific genetic variation within populations of Hylarana caesari was $0.3 \pm$ $0.2 \%$ (range $0-0.4 \%, N=3$ ) for $16 \mathrm{~S}, 0.5 \%(N=2)$ for COI and $0.9 \pm 0.7 \%$ (range $0-1.4 \%, N=3$ ) for Cytb. Based on phylogenetic position, H. caesari is closely related to the members of the Hylarana flavescens group (Fig. 4); differs from $H$. sreeni by mean genetic divergence of $3.0 \pm 0.4 \%$ (range 2.2-3.6\%, $N=48$ ) for $16 \mathrm{~S}, 7.4 \pm 0.3 \%$ (range $6.7-7.8 \%, N=42$ ) for COI, and $11.8 \pm 0.5 \%$ (range $11.0-13.0 \%, N=42$ ) for Cytb; differs from $\mathrm{H}$. indica by mean genetic divergence of 3.0 $\pm 0.1 \%$ (range $2.8-3.2 \%, N=36$ ) for $16 \mathrm{~S}, 7.0 \pm 0.4 \%$ (range $6.4-7.9 \%, N=20$ ) for COI, and $10.9 \pm 0.5 \%$ (range $10.0-11.8 \%, N=33$ ) for Cytb; differs from $H$. magna by mean genetic divergence of $6.9 \pm 0.1 \%$ (range $6.6-7.1 \%, N=16$ ) for $16 \mathrm{~S}, 11.7 \pm 0.1 \%$ (range $11.6-11.7 \%, N=8$ ) for COI, and $14.9 \pm 0.8 \%$ (range $13.9-16.6 \%, N=15$ ) for Cytb; differs from $H$. flavescens by mean genetic divergence of $3.9 \pm 0.2 \%$ (range $3.5-4.1 \%, N=8$ ) for $16 \mathrm{~S}, 11.6 \pm 0.3 \%$ (range 11.2$12.1 \%, N=8$ ) for COI, and $13.6 \pm 0.4 \%$ (range 12.9$14.1 \%, N=12$ ) for Cytb; differs from $H$. montanus by mean genetic divergence of $6.2 \pm 0.2 \%$ (range 5.8$6.7 \%, N=28$ ) for $16 \mathrm{~S}, 12.9 \pm 0.4 \%$ (range $12.3-13.6 \%$,
$N=14$ ) for COI, and $15.3 \pm 0.8 \%$ (range $14.7-17.3 \%, N$ $=21)$ for Cytb (Tables S2-S3).

Description of holotype (Figs 11a-c, 12a-c). Mediumsized, robust species, adult male (SVL 50.1). Head small (HW 16.8, HL 20.2, IFE 8.9, IBE 12.4), longer than wide, flat above; snout sub-elliptically pointed in dorsal and ventral view, rounded in lateral view, slightly protruding, its length (SL 8.3) longer than horizontal diameter of eye (EL 5.4); loreal region acute and concave with rounded canthus rostralis; interorbital space flat, wider than (IUE 4.5) upper eyelid (UEW 3.8) and shorter than internarial distance (IN 5.1); distance between back of eye (IBE 12.4) 1.4 times the distance between front of eye (IFE 8.9); nostril oval with flap of skin laterally, closer to tip of snout (NS 2.6) than eye (EN 3.6); tympanum (TYD 4.6) $85 \%$ of eye diameter (EL 5.4); tympanum-eye distance (TYE 1.6); pineal ocellus present, between anterior border of eye; vomerine ridge present, bearing small teeth, with an angle of $45^{\circ}$ to body axis, as close to choanae as to each other; tongue moderately large, emarginated. Forelimbs moderately short and thin; forelimb (FAL 8.7) shorter than hand length (HAL 13.5); fingers long, finger length formula $\mathrm{I}=\mathrm{II}<\mathrm{IV}<\mathrm{III}$, finger tips dorsoventrally compressed, with obtusely pointed discs and lateroventral grooves, moderately wide compared to finger width $\left(\mathrm{FD}_{\mathrm{I}} 1.2, \mathrm{FW}_{\mathrm{I}} 0.5 ; \mathrm{FD}_{\mathrm{II}} 1.3, \mathrm{FW}_{\mathrm{II}} 0.5 ; \mathrm{FD}_{\mathrm{III}} 1.5\right.$, $\mathrm{FW}_{\text {III }} 0.5 ; \mathrm{FD}_{\text {IV }} 1.5, \mathrm{FW}_{\text {IV }} 0.5$ ); dermal fringe present; subarticular tubercles prominent, oval, single, all present; one oval and one elongated distinct palmar tubercles moderately developed; a distinct supernumerary tubercle at base of each finger. Hindlimbs relatively long and thin; thigh length (TL 22.4) shorter than shank (SHL 25.5), and foot (FOL 24.0); relative digit lengths $\mathrm{I}<\mathrm{II}<\mathrm{III}=\mathrm{V}<\mathrm{IV}$; toe tips dorsoventrally compressed, with obtusely pointed discs and lateroventral grooves, rather wide compared to toe width $\left(\mathrm{TD}_{\mathrm{I}} 1.6\right.$, $\mathrm{TW}_{\mathrm{I}} 0.4 ; \mathrm{TD}_{\text {II }} 1.5, \mathrm{TW}_{\text {II }} 0.5 ; \mathrm{TD}_{\text {III }} 1.8, \mathrm{TW}_{\text {III }} 0.5 ; \mathrm{TD}_{\text {IV }}$ 1.7, $\mathrm{TW}_{\mathrm{IV}} 0.6 ; \mathrm{TD}_{\mathrm{V}} 1.5, \mathrm{TW}_{\mathrm{V}} 0.5$ ); webbing present, rather medium: I1-1 $1 / 2 \mathrm{II} 1-2 \mathrm{III} 1-2 \mathrm{IV} 2-1 \mathrm{~V}$; dermal ridge along toe $\mathrm{V}$ present; subarticular tubercles rather prominent, oval, all present; inner metatarsal tubercles distinct and rather short; outer metatarsal tubercles rounded, prominent.

Skin of snout and between eyes shagreened; sides of head shagreened to sparsely granular; upper eyelids granular; anterior and posterior part of dorsum granular; upper and lower part of flanks rather shagreened with few scattered glandular projection with horny spinules; dorsolateral folds that extend from the posterior 


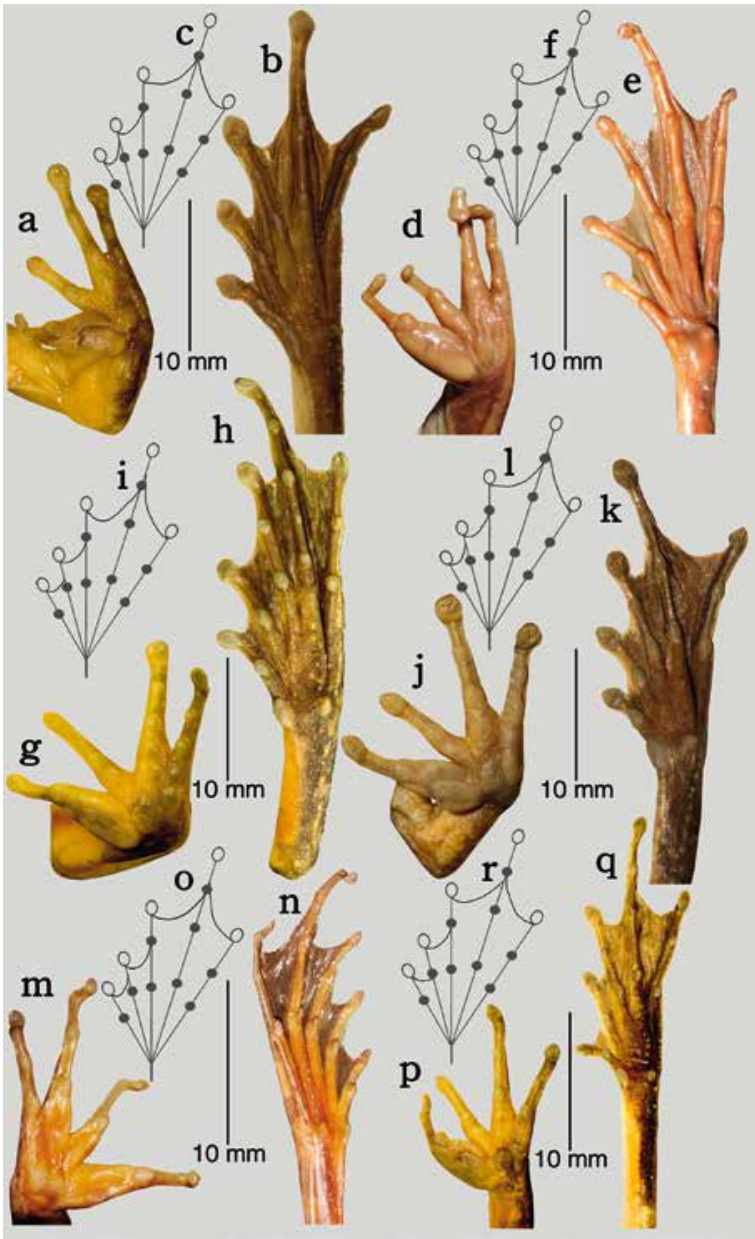

Fig. 12a-r. Ventral view of hand and foot, and schematic illustration of webbing on feet of the Hylarana flavescens group in preservation: a-c. holotype of $H$. caesari (BNHS 5842): a. ventral view of hand, b. ventral view of foot, c. schematic illustration of webbing on feet; d-f. lectotype of Rana flavescens (= Hylarana flavescens) (ZSIC 2777): d. ventral view of hand, e. ventral view of foot, $\mathrm{f}$. schematic illustration of webbing on feet; g-i. holotype of $H$. indica (BNHS 5847): g. ventral view of hand, h. ventral view of foot, i. schematic illustration of webbing on feet; j-1. holotype of $H$. magna (BNHS 5857): j. ventral view of hand, $\mathrm{k}$. ventral view of foot, 1 . schematic illustration of webbing on feet; m-o. holotype of Rana (Hylorana) gracilis montanus (= Hylarana montanus) $($ NHM 1947.2.2.66 [ex BMNH 1921.1.20.6]): $\mathrm{m}$. ventral view of hand, $n$. ventral view of foot, o. schematic illustration of webbing on feet; p-r. holotype of H. sreeni (BNHS 5869): p. ventral view of hand, q. ventral view of foot, r. schematic illustration of webbing on feet.

corner of the eye to the entire body length on both sides, well developed (Figs 5, 11a, c) with glandular projections with horny spinules; dorsal parts of forelimb shagreened to sparsely granular; thigh sparsely granular; tibia and tarsus shagreened with scattered granular projections; toe $\mathrm{V}$ with dermal fringe from the base of $\mathrm{V}$ toe to knee, with prominent spinular projections; distinct rictal gland posterior to corner of mouth; distinct humeral glands; ventral part of throat smooth; anterior and posterior part of belly shagreened; posterior part of thigh granular (Fig. 11a).

Colour in preservation (Figs 11a-c). Dorsal surface light brown; lower flank light grey with minute black speckles; tympanic area light grey; upper lips with white stripe continuing through rictal gland to above arm insertion; dorsolateral folds dark grey; forelimbs, dorsal parts of thigh, tibia and foot straw coloured; anterior parts of thigh straw coloured with grey patches and weakly formed cross-bands; throat and margin of throat light straw coloured; chest and belly straw coloured; ventral parts of thigh and tibia light greyishwhite; foot and webbing dark grey with minute specks. Colour in life (Fig. 13a). Dorsal parts light orangishbrown; lower flank greyish-brown with minute black spots; tympanic area brown; upper lips with creamywhite stripe continuing through rictal gland to above arm insertion; dorsolateral folds light brown; forelimbs light reddish-brown; dorsal parts of thigh, tibia and foot light brown with grey spots and weakly formed cross-bands; throat and margin of throat white; chest and belly off-white; ventral parts of thigh, tibia and foot greyish-white with black spots; webbing dark grey with minute specks; iris reddish-brown.

Variation. See Table 2 for morphometric data from five adult males and two adult females. SDBDU 2010.368: dorsum dark greyish-brown; thigh, tarsus and tibia with more prominent cross-bands; loreal and tympanic region dark brown in colour.

Secondary sexual characters. Males: Single ovalshaped nuptial pad on finger I present, cream-coloured; two vocal sacs visible externally on the posterior lateral side of the throat; humeral glands weakly developed, positioned laterally on the preaxial side of the upper forelimb. Females (SDBDU 2010.368): ova immature.

Etymology. This species is named after Dr. Caesar Sengupta, in appreciation of his support towards amphibian conservation initiatives, especially for his contribution and active participation in creating awareness about the Lost Amphibians of India (LAI) initiative. The species name caesari is a noun in the genitive case. 
Distribution. This species is endemic to Maharashtra state in the northern Western Ghats and known only from two districts - Satara dist. (Koyna and Mahabaleshwar) and Sindhudurg dist. (Amboli). This species is likely to be more widespread in the Western Ghats of Maharashtra (Fig. 14, Table 1).

Habitat and natural history. We observed Hylarana caesari only at Humbarli in Koyna, and Amboli, where individuals were found on rock surfaces emerging from fast flowing streams, in secondary forests.

Hylarana flavescens (Jerdon, 1853)

Yellowish Golden-backed frog

(Figs 11d-f, 12d-f, 13b-c, 14; Tables 1-2)

Original name and description. Rana flavescens Jerdon, 1853. Catalogue of reptiles inhabiting the Peninsula of India, Journal of the Asiatic Society of Bengal, 22: 531. Lectotype. By present designation, ZSIC 2777, an adult male, SVL $45.2 \mathrm{~mm}$. Type locality. 'found frequenting mountain stream in the forest only' by implication in south India, but in the specimen catalogue written as 'Malabar'. Current status of specific name. Valid name, as Hylarana flavescens (Jerdon, 1853).

Referred specimens. SDBDU 2011.860, an adult male and BNHS 5844, an adult female, Settukunnu, Wayanad dist., collected by SDB, 15 August 2011; BNHS 5845, an adult male, Sairandhri, Silent valley, Palakkad dist., collected by SDB and SG, 18 September 2011; BNHS 5846, an adult male, Naduvattam, Nilgiris dist., collected by SDB and Systematics Lab team, 24 July 2008; SDBDU 2011.1228, a sub-adult, Siruvani, Singappara, Palakkad dist., collected by SDB and Systematics Lab team, 16 October 2011.

Comments. This species is the second oldest Hylarana species recorded from the Western Ghats of India, 160 years ago (Jerdon, 1853). Boulenger (1882) tentatively considered this species as a subjective synonym of Rana temporalis. However, Rana (Hylarana) flavescens was never used as a senior synonym of Hylorana temporalis (Frost, 2014).

In our study, we examined the type specimens currently available in ZSIC and collected topotypes to evaluate this taxon morphologically and genetically. According to Chanda et al. (2001), there are eight syntypes, ZSIC 2776-2778, ZSI 4298-4301, and ZSI 10248 , from 'S. India' in the ZSIC. The present study found ZSIC 2777 (male, SVL $45.2 \mathrm{~mm}$ ) and ZSIC
2778 (male, SVL $54.2 \mathrm{~mm}$ ) from 'Malabar, T.C. Jerdon' dated 1870; ZSIC 4298 (male, SVL $49.1 \mathrm{~mm}$ ), ZSIC 4299 (male, SVL $56.5 \mathrm{~mm}$ ), and ZSIC 4300 (male, SVL $52.0 \mathrm{~mm}$ ) from Coonoor, Nilgiris, collected by F. Day dated 1880; ZSIC 10248 (male, SVL 60.6 $\mathrm{mm}$ ), from Coonoor, Nilgiris, collected by Beddome dated 1880. We consider only Jerdon's specimens as true 'syntypes', since the collections of Day and Beddome are dated 1880 , and there is no clarity as to whether these were available to Jerdon at the time of the species description in 1853. One of Jerdon's specimens ZSIC 2776 could not be located during recent visits to the ZSIC, and so is probably lost. Therefore we consider only two specimens (ZSIC 2777, ZSIC 2778), collected by T.C. Jerdon from Malabar in 1853 , and deposited at ZSIC in 1870, as true syntypes.

Our results also provide evidence for this species to be considered as a distinct taxon and we elevate Rana flavescens (Jerdon, 1853) from the synonymy of $\mathrm{Hyl}$ orana temporalis. In order to stabilize the nomenclatural status of this species and to remove further confusion, we herein designate one of the syntypes (ZSIC 2777) as the lectotype for Rana flavescens.

Comparison. Hylarana flavescens could be confused with Hylarana caesari sp. nov., Hylarana indica sp. nov., Hylarana magna sp. nov., Hylarana montanus and Hylarana sreeni sp. nov. in the Hylarana flavescens group, due to its overall adult size. However, $H$. flavescens differs from all other members of this group by its third toe webbing well below the first subarticular tubercle on the inside (vs. up to the first subarticular tubercle); more specifically differs from $H$. indica and $H$. sreeni by its snout rounded in dorsal and ventral view (Figs 11d-e, g-h, 15h-i) (vs. sub-elliptical in both species); individually differs from $H$. indica by its dorsal skin shagreened to sparsely granular (vs. granular), tympanum diameter smaller to horizontal diameter of eye, TYD $4.0 \pm 0.8 \mathrm{~mm}$, EL $5.7 \pm 0.7 \mathrm{~mm}$, male, $N=4$ (vs. equals to horizontal diameter of eye, TYD $5.3 \pm$ $0.6 \mathrm{~mm}$, EL $5.3 \pm 0.6 \mathrm{~mm}, N=10$ ), thigh shorter than foot length, TL $24.3 \pm 3.5 \mathrm{~mm}$, FOL $26.3 \pm 3.2 \mathrm{~mm}$, male, $N=4$ (vs. equal, TL $26.7 \pm 2.3 \mathrm{~mm}$, FOL $26.7 \pm$ $2.2 \mathrm{~mm}$, male, $N=10$ ); differs from $H$. sreeni by its interorbital space wider than the upper eyelid width, IUE $5.2 \pm 0.6 \mathrm{~mm}$, UEW $3.7 \pm 0.4 \mathrm{~mm}$, male, $N=4$ (vs. subequal, IUE $4.1 \pm 0.5 \mathrm{~mm}$, UEW $4.0 \pm 0.4 \mathrm{~mm}, N=$ 7); differs from $H$. magna and $H$. montanus by its small adult snout-vent size, male SVL 45.2-59.5 mm, $N$ $=4$, female SVL $75.5 \mathrm{~mm}, N=1$ (vs. large, male SVL $84.5 \mathrm{~mm}, N=1$; female SVL 78.7-91.8 mm, $N=4$ in $H$. 

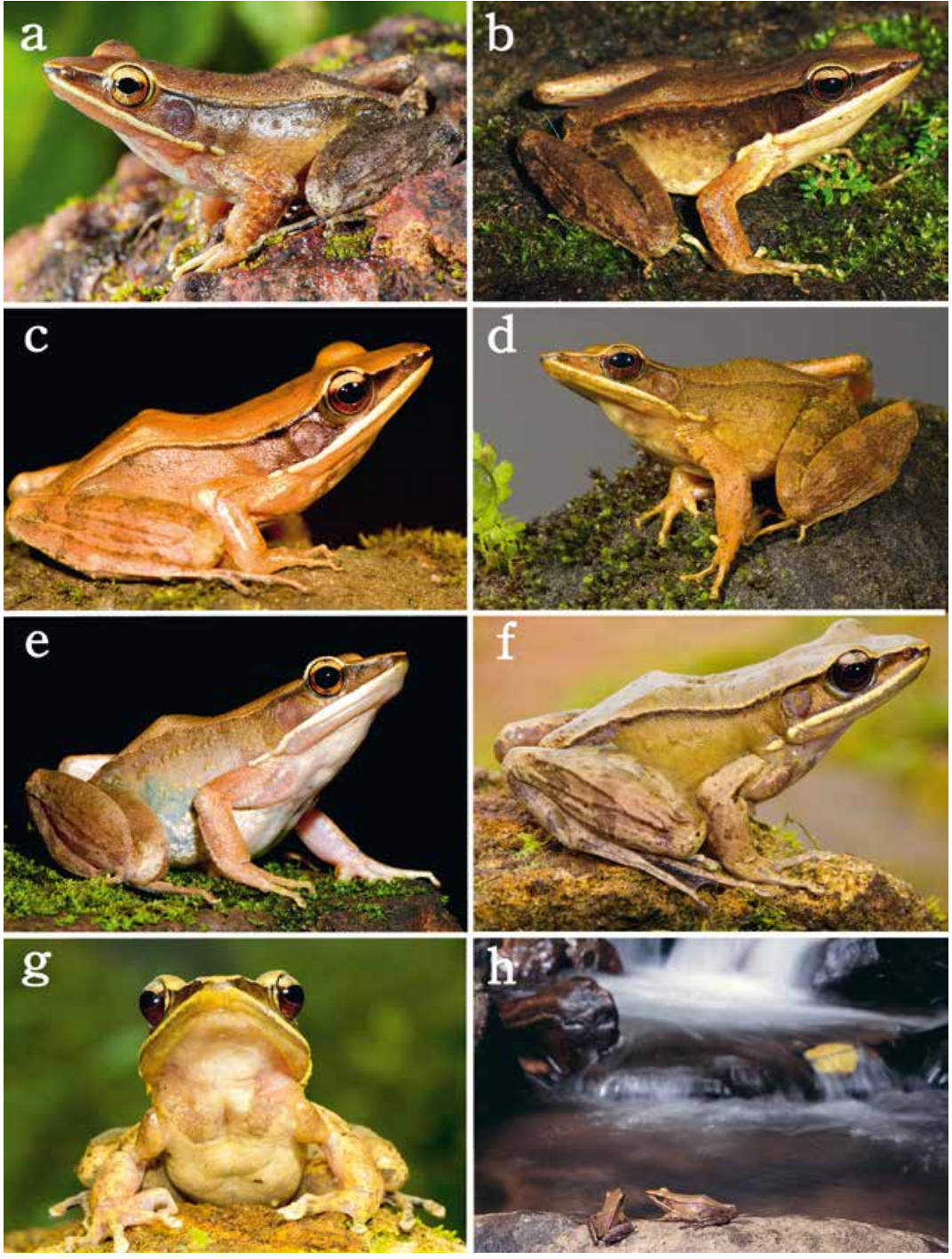

Fig. 13a-h. Hylarana flavescens group in life: a. H. caesari, dorsolateral view of holotype (BNHS 5842, male) from Humbarli, Koyna, Satara; b-c. H. flavescens, b. dorsolateral view of referred specimen (SDBDU 2011.860, male), from Settukunnu, Wayanad, c. dorsolateral view of referred specimen (BNHS 5845, male), from Silent Valley, Palakkad; d-e. H. indica, d. dorsolateral view of holotype (BNHS 5847, male), from Charmadi Ghats, Chikmagalur, e. dorsolateral view of paratype (BNHS 5854, female), from Dandeli, Uttara Kannada; f-h. H. magna, f. dorsolateral view, g. front view of holotype (BNHS 5857, male), from Pandimotta, Kollam, h. dorsal view (on left, male, not collected) and dorsolateral view of paratype (on right, BNHS 5858, female), from Athirimala, Thiruvananthapuram (Photos: SD Biju). magna; male SVL 54.0-65.0 mm, $N=8$; female SVL 65.6-74.5 mm, $N=3$ in H.montanus), snout rounded in dorsal and ventral view (vs. nearly truncate in H. mag$n a$; rounded to truncate in $H$. montanus); individually differs from H. magna by its dorsal skin shagreened to sparsely granular (vs. shagreened); differs from $H$. montanus by its thigh shorter than foot length, TL 24.3 $\pm 3.5 \mathrm{~mm}$, FOL $26.3 \pm 3.2 \mathrm{~mm}$, male, $N=4$ (vs. equal, TL $30.0 \pm 1.6 \mathrm{~mm}$, FOL $30.0 \pm 1.6 \mathrm{~mm}$, male, $N=8$ ). See Hylarana caesari for comparison with that species.

Genetic divergence. Intraspecific genetic variation within populations of Hylarana flavescens was $0.3 \pm$ $0.2 \%$ (range $0-0.4 \%, N=4$ ) for $16 \mathrm{~S}, 1.0 \pm 0.7 \%$ (range
$0-1.7 \%, N=4$ ) for COI and $1.2 \pm 0.5 \%$ (range $0.7-1.9 \%$, $N=4$ ) for Cytb. Based on phylogenetic position, $H$. flavescens is closely related to the members of Hylarana flavescens group (Fig. 4); differs from $H$. indica by mean genetic divergence of $4.6 \pm 0.1 \%$ (range 4.5 $4.8 \%, N=36$ ) for $16 \mathrm{~S}, 13.1 \pm 0.6 \%$ (range $12.1-14.0 \%$, $N=44$ ) for COI and $14.6 \pm 0.5 \%$ (range $14.0-15.8 \%, N$ = 44) for Cytb; from H. magna by $5.2 \pm 0.1 \%$ (range $5.0-5.4 \%, N=16$ ) for $16 \mathrm{~S}, 7.0 \pm 0.1 \%$ f (range 6.9-7.1\%, $N=16$ ) for COI and $12.5 \pm 0.8 \%$ (range $12.0-14.0 \%, N$ $=20$ ) for Cytb; from H. montanus by $6.1 \pm 0.2 \%$ (range $5.8-6.3 \%, N=28$ ) for $16 \mathrm{~S}, 12.5 \pm 0.5 \%$ (range 11.9$14.0 \%, N=28$ ) for COI and $12.6 \pm 0.8 \%$ (range 11.7$14.7 \%, N=28$ ) for Cytb; from $H$. sreeni by $4.5 \pm 0.4 \%$ (range $3.5-4.8 \%, N=48$ ) for $16 \mathrm{~S}, 11.7 \pm 0.4 \%$ (range 
$10.5-12.3 \%, N=48$ ) for COI and $15.0 \pm 0.3 \%$ (range $14.3-15.6 \%, N=56$ ) for Cytb (Tables S2-S3).

Description of lectotype (Figs 11d-f, 12d-f). Mediumsized, robust species, adult male (SVL 45.2). Head large (HW 14.1, HL 17.2, IFE 7.6, IBE 11.3), longer than wide, flat above; snout rounded in dorsal and ventral view, rounde in lateral view, protruding, its length (SL 7.3) longer than horizontal diameter of eye (EL 6.2); loreal region acute and concave with angular canthus rostralis; interorbital space flat, wider (IUE 5.0) than upper eyelid (UEW 3.4) and wider than internarial distance (IN 4.4); distance between back of eye (IBE 11.3) 1.5 times the distance between front of eye (IFE 7.6); nostril oval with flap of skin laterally, closer to tip of snout (NS 3.5) than eye (EN 4.3); tympanum (TYD 3.7) $60 \%$ of eye diameter (EL 6.2); tympanumeye distance (TYE 1.2); pineal ocellus present, between anterior border of eye; vomerine ridge present, bearing numerous small teeth, with an angle of $45^{\circ}$ to body axis, as close to choanae as to each other, longer than distance between them; tongue moderately large, emarginated, bearing no medium lingual process. Forelimbs moderately long and thick; forelimb (FAL 9.4) shorter than hand length (HAL 12.8); fingers rounded with lateral fringes, finger length formula $\mathrm{II}=\mathrm{I}<\mathrm{IV}<\mathrm{III}$, finger tips with obtusely pointed discs and dorsoventrally compressed, with lateroventral groove, moderately wide compared to finger width $\left(\mathrm{FD}_{\mathrm{I}} 1.1, \mathrm{FW}_{\mathrm{I}} 0.5 ; \mathrm{FD}_{\text {II }} 1.0, \mathrm{FW}_{\text {II }} 0.6 ; \mathrm{FD}_{\text {III }} 1.5, \mathrm{FW}_{\text {III }}\right.$ $\left.0.5 ; \mathrm{FD}_{\mathrm{IV}} 1.8, \mathrm{FW}_{\mathrm{IV}} 0.7\right)$; subarticular tubercles prominent, oval, single, all present; prepollex distinct, oval, two oval distinct palmar tubercles; a distinct supernumerary tubercle on base of each finger. Hindlimbs relatively long; thigh length (TL 22.2) shorter than shank (SHL 24.9), and foot (FOL 24.7); relative digit lengths $\mathrm{I}<\mathrm{II}<\mathrm{III}<\mathrm{V}<\mathrm{IV}$; toe tips with obtusely pointed discs and dorsoventrally compressed, with lateroventral grooves, rather wide compared to toe width $\left(\mathrm{TD}_{\mathrm{I}}\right.$ $1.1, \mathrm{TW}_{\mathrm{I}} 0.5 ; \mathrm{TD}_{\mathrm{II}} 1.4, \mathrm{TW}_{\mathrm{II}} 0.5 ; \mathrm{TD}_{\text {III }} 1.3, \mathrm{TW}_{\text {III }} 0.5$; $\left.\mathrm{TD}_{\mathrm{IV}} 1.3, \mathrm{TW}_{\mathrm{IV}} 0.4 ; \mathrm{TD}_{\mathrm{V}} 0.9, \mathrm{TW}_{\mathrm{V}} 0.5\right)$; webbing present, rather large: I1-2-II1-2 $1 / 4 \mathrm{III} 1-2^{1} /{ }_{3} \mathrm{IV} 2-1 \mathrm{~V}$; dermal ridge along toe $\mathrm{V}$ absent, subarticular tubercles prominent, oval, all present; inner metatarsal tubercle distinct and rather short; outer metatarsal tubercle rounded, prominent; supernumerary tubercles absent, tarsal tubercles absent.

Skin of snout, between eyes, side of head shagreened; anterior and posterior part of dorsum shagreened and sparsely granular; flanks shagreened with prominently scattered granules; dorsolateral folds that extend from the posterior corner of the eye to the entire body length on both sides, well developed (Figs 5, $11 \mathrm{~d}, \mathrm{f}$ ); dorsal part of forelimb shagreened; thigh, tibia and tarsus shagreened and sparsely granular; distinct rictal gland posterior to corner of mouth; flat indistinct humeral glands (Fig. 12f).

Colour in preservation (Figs 11d-f). Dorsal parts reddish-brown; flank light greyish-brown; tympanic area grey; upper lip with greyish-white stripe continuing through rictal gland to above arm insertion; forelimbs, dorsal parts of thigh, tibia and foot greyish-brown; throat and margin of throat light greyish-brown; chest and belly greyish-white; ventral parts of thigh, tibia and foot greyish-white with grey patches; webbing reddishgrey. Colour in life (SDBDU 2011.860) (Fig. 13b). Dorsal parts golden brown; lower flank light brown, upper flank brown; tympanic area brown; upper lip with yellowish-white stripe continuing through rictal gland to above arm insertion; forelimbs, dorsal parts of thigh, tibia and foot brown, with darker brown cross-bands weakly formed; throat and margin of throat yellowishwhite; chest and belly off-white; ventral parts of thigh, tibia and foot greyish-white with black spots; webbing dark grey with minute specks; iris, lower half reddish brown and upper half golden brown.

Variation. See Table 2 for morphometric data from four adult males and an adult female. SDBDU 2011.860: dorsal skin shagreened to sparsely granular, dorsum dark greyish-brown, ventral surface uniform light grey with minute black spots, ventral surface of arm margins dark brown, posterior part of thigh with slight reticulations; BNHS 5845: dorsal skin shagreened, dorsum uniform light brown, sides of hands and legs shagreened; BNHS 5846: dorsum light greyish-brown with scattered spots.

Secondary sexual characters. Males: Single oval shaped nuptial pad on finger I present, cream-coloured; two vocal sacs faintly visible externally as loose skin on the posterior lateral side of the throat; humeral gland weakly developed, positioned laterally on the preaxial side of the upper forelimb. Females (BNHS 5844): ova white, pigmented on pole (diameter 1.3-1.6 mm, $N=20$ ).

Distribution. This species is known only from the southern Western Ghats states of Kerala and Tamil Nadu. In this study, the species was collected from the districts of Wayanad (Settukunnu) and Palakkad (Sairandhri, Silent Valley; Siruvani, Singappara), in 


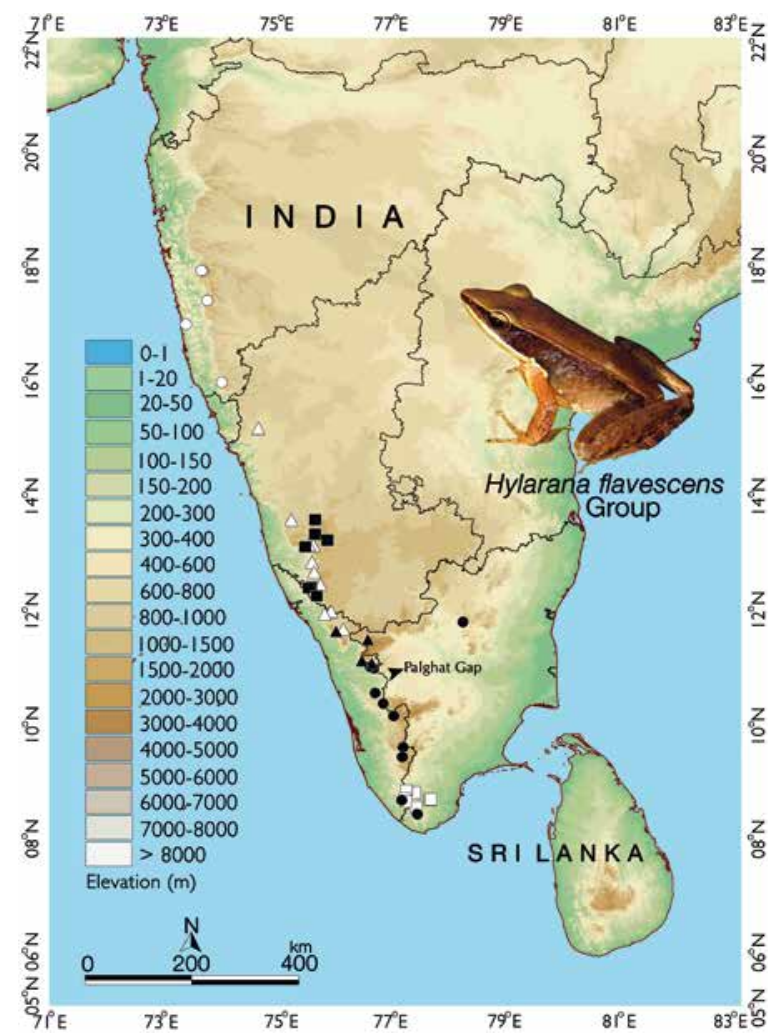

Fig. 14. Geographic distribution of six species of the Hylarana flavescens group in the Western Ghats. Closed circle $=$ Hylarana sreeni, open circle $=$ Hylarana caesari, , closed square $=H y$ larana montanus, open square = Hylarana magna, closed triangle $=$ Hylarana flavescens, open triangle $=$ Hylarana indica . Coordinates are provided in Table 1.

Kerala, and the Nilgiris district (Naduvattam) in Tamil Nadu, at elevations between 800-1900 m asl (Fig. 14, Table 1).

Habitat and natural history. This species is widely distributed both in secondary and primary forests. We collected Hylarana flavescens from streams in closed canopy evergreen forest (BNHS 5845), highly disturbed secondary forest (BNHS 5846), and habitats close to cultivated land (SDBDU 2011.860).

Hylarana indica sp. nov.

Indian Golden-backed frog

(Figs 11g-i, 12g-i, 13d-e, 14; Tables 1-2)

Holotype. BNHS 5847, an adult male, Charmadi Ghats, Chikmagalur dist., Karnataka state, India, collected by SDB and SG, 23 October 2011.
Paratypes. BNHS 5848, an adult male, collected along with holotype; BNHS 5849, an adult male, Gundia-Subramanya, Dakshin Kannada dist., collected by SDB, 2 October 2005; BNHS 5850, an adult male, Gundia, Dakshin Kannada dist., collected by SDB and team, 6 November 2010; BNHS 5851, an adult male, Mudigere, Chikmagalur dist., collected by SDB and SG, 28 September 2012; BNHS 5852-5853, two adult males, Someshwar, Udupi dist., collected by SDB, 3 October 2005; BNHS 5854, an adult female, Dandeli, Uttara Kannada dist., collected by SDB and team, 20 October 2011; BNHS 5855, an adult male, Meenmutty, Aralam, Kannur dist., collected by SDB, 5 June 2008; BNHS 5856, an adult female, Suganthagiri, Wayanad dist., collected by SDB, 15 October 2005.

Referred specimens. SDBDU 2005.4670, an adult male, Gundia-Subramanya, Dakshin Kannada dist., collected by SDB, 2 October 2005; SDBDU 2005.4699, an adult male, Someshwar, Udupi dist., collected by SDB, 3 October 2005; SDBDU 2011.1086, an adult female, Aralam, Kannur dist., collected by SDB and Systematics lab team, 25 September 2011; SDBDU 2008.419, Aralam, a sub-adult, Kannur dist., collected by SDB, 5 June 2008; SDBDU 2011.49, a sub-adult, Kempholey, Hassan dist., collected by SDB and team, 11 June 2011.

Comparison. Hylarana indica sp. nov. could be confused with Hylarana caesari sp. nov., Hylarana flavescens, Hylarana magna sp. nov., Hylarana montanus and Hylarana sreeni sp. nov. in the Hylarana flavescens group, due to its overall adult size. However, $H$. indica differs from H. magna and H. montanus by its smaller adult snout-vent size, male SVL $45.8-58.6 \mathrm{~mm}$, $N=10$; female SVL 66.0-74.3 mm, $N=3$ (vs. male SVL $84.5 \mathrm{~mm}, N=1$, female SVL 78.7-91.8 mm, $N=$ 4 in H. magna; male SVL 54.0-65.0 mm, $N=8$, female SVL 65.6-74.5 mm, $N=3$ in H. montanus), snout subelliptical in dorsal and ventral view (vs. nearly truncate in $H$. magna; rounded to truncate in $H$. montanus), tympanum diameter equal to horizontal diameter of eye, TYD $5.3 \pm 0.6 \mathrm{~mm}$, EL $5.3 \pm 0.6 \mathrm{~mm}$, male, $N=$ 10 (vs. smaller to horizontal diameter of eye in both species, TYD $6.5 \mathrm{~mm}$, EL $8.1 \mathrm{~mm}$, male, $N=1$ in $H$. magna; TYD $5.2 \pm 0.4 \mathrm{~mm}$, EL $6.4 \pm 0.4 \mathrm{~mm}$, male, $N$ $=8$ in H. montanus), and dorsal skin granular (vs. shagreened in H. magna; shagreened to sparsely granular in $H$. montanus); more specifically differs from $H$. magna by its thigh equal to foot length, TL $26.7 \pm 2.3$ $\mathrm{mm}$, FOL $26.7 \pm 2.2 \mathrm{~mm}$, male, $N=10$ (vs. shorter, TL $41.0 \mathrm{~mm}$, FOL $42.7 \mathrm{~mm}$, male, $N=1$ ); differs from $H$. 
sreeni by its interorbital space wider than the upper eyelid width, IUE $5.1 \pm 0.7 \mathrm{~mm}$, UEW $4.0 \pm 0.4 \mathrm{~mm}$, male, $N=10$ (vs. subequal, IUE $4.1 \pm 0.5 \mathrm{~mm}$, UEW $4.0 \pm 0.4 \mathrm{~mm}, N=7$ ), tympanum diameter equal to horizontal diameter of eye, TYD $5.3 \pm 0.6 \mathrm{~mm}$, EL 5.3 $\pm 0.6 \mathrm{~mm}$, male, $N=10$ (vs. smaller to horizontal diameter of eye, TYD $4.4 \pm 0.3 \mathrm{~mm}$, EL $5.6 \pm 0.4 \mathrm{~mm}$, male, $N=7$ ), second toe webbing above the first subarticular tubercle on the inside (vs. just below the first subarticular tubercle on inside of toe two), dorsal skin granular (vs. shagreened to sparsely granular). For differences with Hylarana caesari and H. flavescens and see 'Comparison' of those species.

Genetic divergence. Intraspecific genetic variation within populations of Hylarana indica was $0.2 \pm 0.2 \%$ (range $0-0.6 \%, N=9$ ) for $16 \mathrm{~S}, 1.3 \pm 1.0 \%$ (range $0-3.1 \%, N=11$ ) for COI and $3.0 \pm 2.3 \%$ (range $0-6.2 \%$, $N=11)$ for Cytb. Based on phylogenetic position, $H$. indica is closely related to the members of Hylarana flavescens group (Fig. 4); differs from H. magna by 7.2 $\pm 0.2 \%$ (range $6.9-7.6 \%, N=36$ ) for $16 \mathrm{~S}, 13.5 \pm 0.4 \%$ (range $12.8-14.2 \%, N=44$ ) for COI and $16.9 \pm 0.7 \%$ (range 15.6-18.8\%, $N=55$ ) for Cytb; from H. montanus by $5.4 \pm 0.2 \%$ (range $5.0-5.8 \%, N=63$ ) for $16 \mathrm{~S}$, $13.6 \pm 0.5 \%$ (range $12.6-14.3 \%, N=70$ ) for COI and $16.9 \pm 0.9 \%$ (range $15.9-19.3 \%, N=88$ ) for Cytb; from $H$. sreeni by $2.6 \pm 0.3 \%$ (range $2.0-3.0 \%, N=108$ ) for $16 \mathrm{~S}, 5.2 \pm 0.6 \%$ (range $4.3-6.6 \%, N=132$ ) for COI and $9.6 \pm 0.9 \%$ (range $8.2-11.8 \%, N=154$ ) for Cytb (Tables S2-S3).

Description of holotype (Figs 11g-i, 12g-i). Mediumsized, robust species, adult male (SVL 46.6). Head small (HW 15.0, HL 19.5, IFE 8.0, IBE 12.3), longer than wide, flat above; snout sub-elliptical in dorsal and ventral view, rounded in lateral view, protruding, its length (SL 8.2) longer than horizontal diameter of eye (EL 4.5); loreal region acute and concave with rounded canthus rostralis; interorbital space flat, wider than (IUE 4.5) upper eyelid (UEW 3.6) and equal to internarial distance (IN 4.5); distance between back of eye (IBE 12.3) 1.5 times the distance between front of eye (IFE 8.0); nostril oval with flap of skin laterally, closer to tip of snout (NS 2.9) than eye (EN 4.3); tympanum (TYD 4.6) nearly equal to eye diameter (EL 4.5); tympanum-eye distance (TYE 1.5); pineal ocellus present, between anterior border of eye; vomerine ridge present, bearing small teeth, with an angle of $45^{\circ}$ to body axis, as close to choanae as to each other; tongue moderately large, emarginated. Forelimbs moderately short and thin; forelimb (FAL 9.0) shorter than hand length (HAL 12.9); fingers long, finger length formula $\mathrm{II}<\mathrm{I}<\mathrm{IV}<\mathrm{III}$, finger tips with obtusely pointed discs and dorsoventrally compressed, with lateroventral grooves, moderately wide compared to finger width $\left(\mathrm{FD}_{\mathrm{I}} 0.9, \mathrm{FW}_{\mathrm{I}} 0.5 ; \mathrm{FD}_{\text {II }} 0.9, \mathrm{FW}_{\text {II }} 0.4 ; \mathrm{FD}_{\text {III }} 1.1, \mathrm{FW}_{\text {III }}\right.$ $0.5 ; \mathrm{FD}_{\mathrm{IV}} 1.2, \mathrm{FW}_{\mathrm{IV}} 0.5$ ); dermal fringe present; subarticular tubercles prominent, oval, single, all present; two oval distinct palmar tubercles moderately developed; a distinct supernumerary tubercle at base of each finger. Hindlimbs relatively long and thin; thigh length (TL 24.2) shorter than shank (SHL 26.7), and almost equal to foot (FOL 24.1); relative digit lengths $\mathrm{I}<\mathrm{II}<\mathrm{III}=\mathrm{V}<\mathrm{IV}$; toe tips with obtusely pointed discs and dorsoventrally compressed, with lateroventral grooves, rather wide compared to toe width $\left(\mathrm{TD}_{\mathrm{I}} 1.0\right.$, $\mathrm{TW}_{\mathrm{I}} 0.5 ; \mathrm{TD}_{\text {II }} 1.4, \mathrm{TW}_{\text {II }} 0.5 ; \mathrm{TD}_{\text {III }} 1.4, \mathrm{TW}_{\text {III }} 0.4 ; \mathrm{TD}_{\text {IV }}$ 1.4, $\left.\mathrm{TW}_{\mathrm{IV}} 0.5 ; \mathrm{TD}_{\mathrm{V}} 1.3, \mathrm{TW}_{\mathrm{V}} 0.4\right)$; webbing present, rather medium: I1-1 $1 /{ }_{3} \mathrm{II} 1-2 \mathrm{III} 1-2 \mathrm{IV} 1^{2} /{ }_{3}-1 \mathrm{~V}$; dermal ridge along toe $\mathrm{V}$ present; subarticular tubercles rather prominent, oval, all present; inner metatarsal tubercles distinct and rather short; outer metatarsal tubercles rounded, rather prominent.

Skin of snout and between eyes shagreened and sparsely granular; side of head shagreened to sparsely granular; upper eyelids granular; anterior and posterior part of dorsum granular; upper and lower parts of flanks rather shagreened with few scattered glandular projections; dorsolateral folds that extend from the posterior corner of the eye to the entire body length on both sides, well developed (Figs 5, 11g, i); dorsal part of forelimb shagreened to sparsely granular; thigh sparsely granular; tibia and tarsus granular; anal region prominently granular; toe $\mathrm{V}$ with dermal fringe from the base of $\mathrm{V}$ toe to knee; distinct rictal gland posterior to corner of mouth; distinct humeral glands; ventral part of throat smooth; anterior part of belly shagreened, posterior part of belly shagreened; posterior part of thigh granular.

Colour in preservation (Figs 11g-i). Dorsal surface greyish-brown, lower flank light grey; tympanic area brown, tympanum dark brown; upper lip with greyishwhite stripe continuing through rictal gland to above arm insertion; forelimbs, dorsal parts of thigh, tibia and foot greyish-brown with faint cross-bands, anterior part of thigh reticulated with light greyish-brown patches on dark grey background; throat and margin of throat greyish-white; chest and belly greyish-white; ventral parts of thigh, tibia and foot greyish-white with scattered black spots; webbing dark grey with minute 


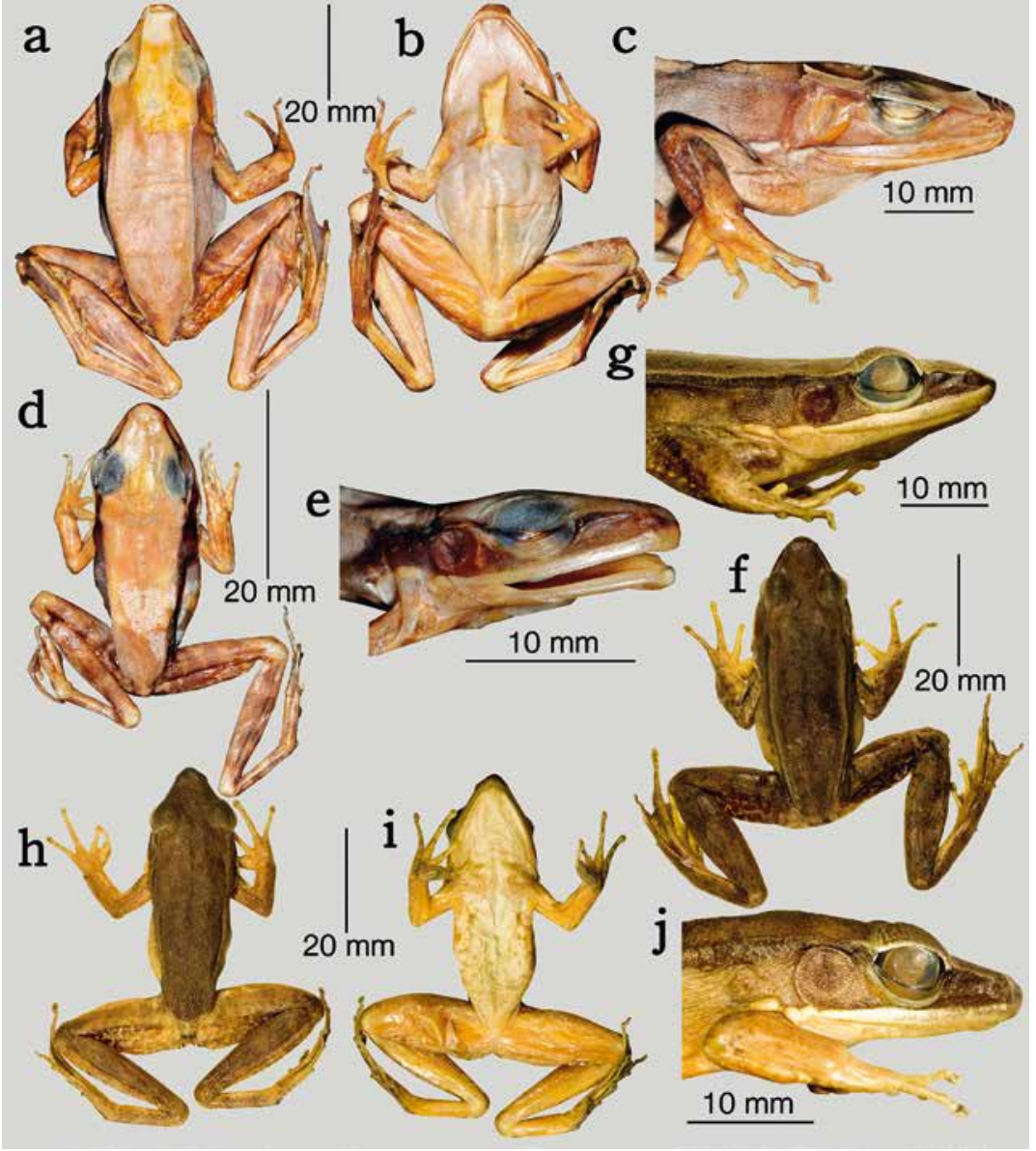

Fig. 15a-j. Dorsal view, ventral view, and lateral view of head of the Hylarana flavescens group in preservation: a-c. holotype of Rana (Hylorana) gracilis montanus (= Hylarana montanus) (NHM 1947.2.2.66 [ex BMNH 1921.1.20.6]): a. dorsal view, b. ventral view, c. lateral view of head; d-e. holotype of Rana (Hylorana) bhagmandlensis (NHM 1947.2.2.12 [ex BMNH 1921.1.20.1]): d. dorsal view, e. lateral view of head; $f$-g. referred specimen of Hylarana montanus (BNHS 5862): f. dorsal view, g. lateral view of head; h-j. holotype of $H$. sreeni (BNHS 5869): h. dorsal view, i. ventral view, j. lateral view of head. specks. Colour in life (Fig. 13d). Dorsal parts bronze coloured; lower flank light brown; tympanic area light greyish-brown, tympanum light brown; upper lip with yellowish-white stripe continuing through rictal gland to above arm insertion; forelimbs, dorsal parts of thigh, tibia and foot light yellowish-brown; anterior part of thigh reticulated with light yellowish-brown patches on light grey background; throat and margin of throat greyish-white; chest and belly greyish-white; ventral parts of thigh, tibia and foot greyish-white with scattered black spots; webbing dark grey with minute specks.

Variation. See Table 2 for morphometric data from 10 adult males and three adult females. BNHS 5850: dorsum with few scattered large dark brown spots; BNHS 5848, BNHS 5852 and SDBDU 2005.4670: dorsum more prominently spinular; SDBDU 2005.4699: forelimbs with prominent dark brown cross-bands on light brown background; BNHS 5854: anterior and posteri- or parts of flank with prominent glandular projections; BNHS 5856: anterior part of dorsum shagreened and posterior part shagreened to sparsely granular; SDBDU 2011.1086: dorsum dark brown, ventral side greyish-white with minute black spots, throat and chest with more prominent black spots.

Secondary sexual characters. Males: Single oval shaped nuptial pad on finger I present, cream-coloured; two vocal sacs faintly visible externally as loose skin on the posterior lateral side of the throat; humeral gland weakly developed, positioned laterally on the preaxial side of the upper forelimb. Females (SDBDU 2011.1086): ova white, pigmented on pole (diameter $1.2-1.6 \mathrm{~mm}, N=20$ ).

Etymology. This species is named after its country of origin, India; derived from a Latin phrase 'indica' meaning 'of India' - to highlight that this species is endemic to India, and not representative of Hylarana 
temporalis sensu stricto, a species endemic to Sri Lan$\mathrm{ka}$, with which until now, it has been extensively, but wrongly considered as conspecific.

Distribution. Hylarana indica is one of the most widely distributed species of Hylarana in the Western Ghats state of Karnataka and adjoining regions in Kerala, at elevations between $60-1145 \mathrm{~m}$ asl. This species is so far reported only from regions north of Palghat Gap: Charmadi Ghats, Gundia, Gundia-Subramanya, Mudigere, Someshwar, Kempholey, and Dandeli in Karnataka, and Aralam and Suganthagiri in Kerala (Fig. 14, Table 1).

Habitat and natural history. This species is predominantly found in secondary and primary forest habitats (Charmadi Ghats, Gundia, Gundia-Subramanya, Kempholey, Someshwar, Madikeri, Aralam, Suganthagiri), however two populations were collected near wetlands adjacent to forest areas (Mudigere, Dandeli). Animals were found associated with perennial fast flowing streams, usually perched on rocks emerging from or on the banks of the streams. During the breeding season, egg laying was observed in shallow peripheral parts of the streams.

Hylarana magna sp. nov.

Large Golden-backed frog

(Figs 11j-1, 12j-1, 13f-h, 14; Tables 1-2)

Holotype. BNHS 5857, an adult male, Pandimotta, Shendurney WLS, Thiruvananthapuram dist., Kerala state, India, collected by SDB and Systematics Lab team, 13 September 2011.

Paratypes. BNHS 5858-5861, four adult females, Athirimala, Thiruvananthapuram dist., Kerala State, collected by SDB, 16 May 2002.

Referred specimens. SDBDU 2002.2050, a subadult female, collected by SDB, 30 August 2002, and SDBDU 2008.1929, a sub-adult female, collected by SDB, 16 November 2008, from Kakkachi, Tirunelveli dist.; SDBDU 2012.899, a sub-adult male, from Pandipath, Thiruvananthapuram dist., collected by SDB and team, 21 September 2012.

Comparison. Hylarana magna sp. nov. could not be confused with any taxa within the Hylarana flavescens group, due to its large adult size, male SVL 84.5 $\mathrm{mm}, N=1$; female SVL 78.7-91.8 mm, $N=4$ (vs. male SVL 43.2-50.1 mm, $N=5$, female SVL 58.0-59.7 mm,
$N=2$ in $H$. caesari; male SVL 45.2-59.5 mm, $N=4$, female SVL $75.5 \mathrm{~mm}, N=1$ in $H$. flavescens; male SVL 45.8-58.6 mm, $N=10$, female SVL 66.0-74.3 $\mathrm{mm}, N=3$ in $H$. indica; male SVL 54.0-65.0 $\mathrm{mm}, N=$ 8, female SVL 65.6-74.5 mm, $N=3$ in H. montanus; male SVL 44.0-52.4 mm, $N=7$, female SVL 64.8-80.1 $\mathrm{mm}, N=6$ in $H$. sreeni), snout nearly truncate in dorsal and ventral view (vs. sub-elliptically pointed in H.caesari, rounded in $H$. flavescens, sub-elliptical in $H$. indica and $H$. sreeni, rounded to truncate in $H$. montanus) (Figs 11a-b, d-e, g-h, j-k, 15a-b, h-i) and shagreened dorsal skin (vs. granular in $H$. caesari and $H$. indica, shagreened to sparsely granular in $H$. flavescens, $H$. montanus and $H$. sreeni); more specifically differs from $H$. montanus by its thigh shorter to foot length, TL $41.0 \mathrm{~mm}$, FOL $42.7 \mathrm{~mm}$, male, $N=1$ (vs. equal, TL $30.0 \pm 1.6 \mathrm{~mm}$, FOL $30.0 \pm 1.6 \mathrm{~mm}$, male, $N$ = 8); differs from $H$. sreeni by its second toe webbing above the first subarticular tubercle on the inside (vs. just below the first subartcluar tubercle), interorbital space wider than the upper eyelid width, IUE $9.7 \mathrm{~mm}$, UEW $6.1 \mathrm{~mm}$, male, $N=1$ (vs. subequal, IUE $4.1 \pm 0.5$ $\mathrm{mm}$, UEW $4.0 \pm 0.4 \mathrm{~mm}, N=7$ ). For differences with Hylarana caesari, $H$. flavescens and $H$. indica see 'Comparison' of those species.

Genetic divergence. Intraspecific genetic variation within populations of Hylarana magna was $0.2 \pm 0.1 \%$ (range $0-0.4 \%, N=4$ ) for $16 \mathrm{~S}$, zero $(N=4)$ for $\mathrm{COI}$ and $0.7 \pm 0.8 \%$ (range $0-2.1 \%, N=5$ ) for Cytb. Based on phylogenetic position, H. magna is closely related to the members of Hylarana flavescens group (Fig. 4); differs from $H$. montanus by mean interspecific divergence of $7.3 \pm 0.3 \%$ (range $6.9-7.8 \%, N=28$ ) for $16 \mathrm{~S}$, $10.7 \pm 1.3 \%$ (range $9.7-13.8 \%, N=28$ ) for COI and 16.3 $\pm 0.7 \%$ (range $15.5-17.8 \%, N=40$ ) for Cytb; differs from $H$. sreeni by mean interspecific divergence of 7.0 $\pm 0.1 \%$ (range $6.7-7.2 \%, N=48$ ) for $16 \mathrm{~S}, 12.0 \pm 0.3 \%$ (range $11.6-12.5 \%, N=48$ ) for COI and $18.1 \pm 0.9 \%$ (range 16.4-20.4\%, $N=70$ ) for Cytb (Tables S2-S3). See Hylarana caesari, $H$. flavescens and $H$. indica for comparison with those species.

Description of holotype (Figs 11j-1, 12j-1). Large-sized, robust species, adult male (SVL 84.5). Head moderately large (HW 30.1, HL 32.8, IFE 15.1, IBE 21.9), longer than wide, flat above; snout nearly truncate in dorsal, ventral and lateral view, protruding, its length (SL 12.4) longer than horizontal diameter of eye (EL 8.1); loreal region acute and concave, canthus rostralis rounded; interorbital space flat, wider (IUE 9.7) than 

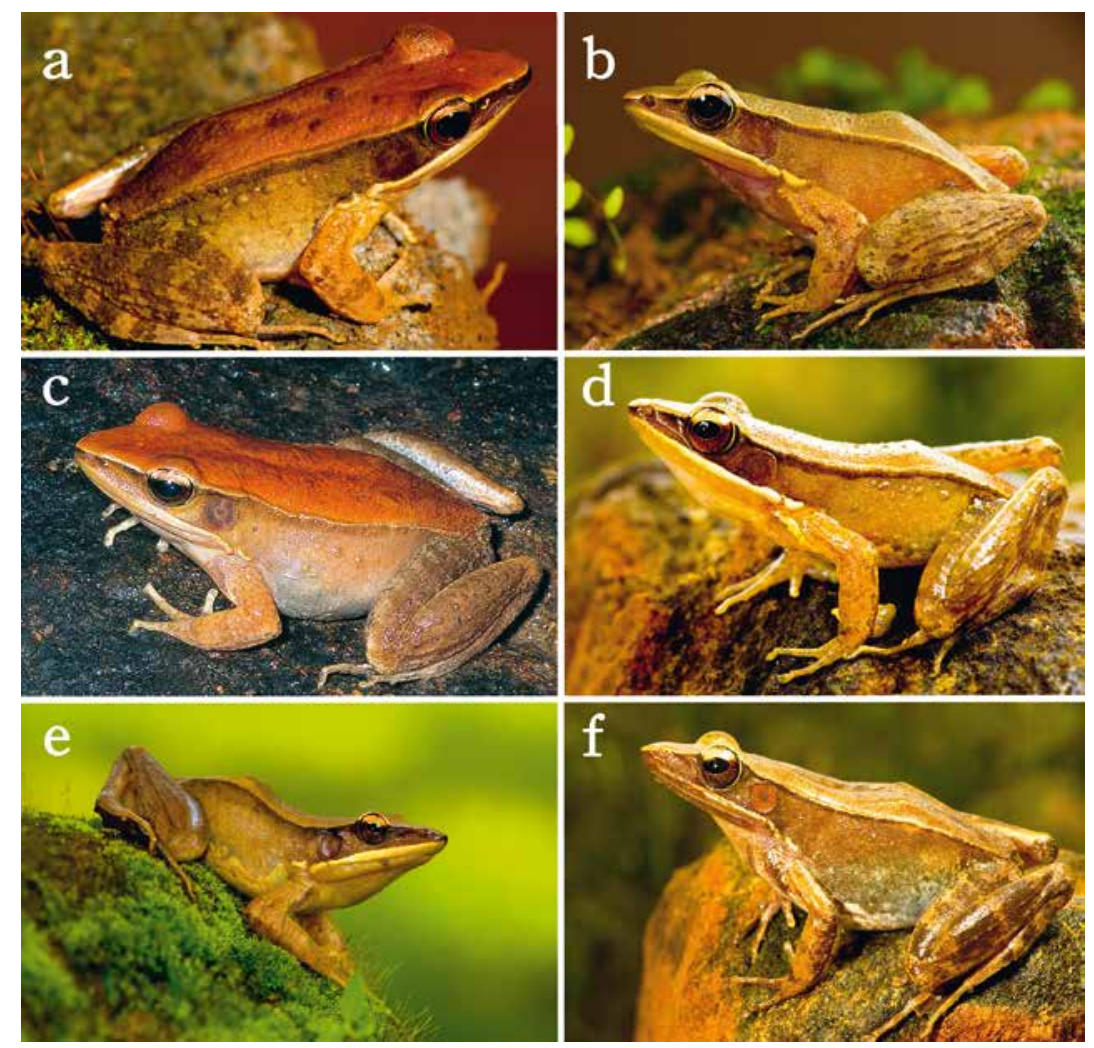

Fig. 16a-f. Hylarana flavescens group in life: a-c. H. montanus, a. dorsolateral view of referred specimen (BNHS 5867, male), from Kottigehara, Hassan, b. dorsolateral view of referred specimen (BNHS 5862), from Bhagamandala, Hassan, c. dorsolateral view of referred specimen (BNHS 5868, female), from Kottigehara, Hassan; d-f. H. sreeni, d. dorsolateral view of holotype (BNHS 5869, male), from Siruvani, Kuddam, Palakkad, e. dorsolateral view of paratype (BNHS 5876, female), from Parambikulam, Palakkad, f. dorsolateral view of paratype (BNHS 5875, female), from Siruvani, Singappara, Palakkad (Photos: SD Biju). upper eyelid (UEW 6.1) and internarial distance (IN 8.2); distance between back of eyes (IBE 21.9) slightly more than 1.4 times the distance between front of eyes (IFE 15.1); nostril closer to tip of snout (NS 3.7) than eye (EN 7.3); tympanum (TYD 6.5) $80 \%$ of eye diameter (EL 8.1); tympanum-eye distance (TYE 4.4); pineal ocellus present, between anterior border of eyes; vomerine ridges present, bearing numerous small teeth, with an angle of $45^{\circ}$ to body axis, as close to choanae as to each other; tongue moderately large, emarginated. Forelimbs short and thick; forelimb (FAL 16.1) shorter than hand length (HAL 22.5); fingers long, finger length formula $\mathrm{II}<\mathrm{I}<\mathrm{IV}<\mathrm{III}$, finger tips with obtusely pointed discs and dorsoventrally compressed, with lateroventral groove, moderately wide compared to finger width $\left(\mathrm{FD}_{\mathrm{I}} 2.7, \mathrm{FW}_{\mathrm{I}} 1.0 ; \mathrm{FD}_{\mathrm{II}}\right.$ $2.4, \mathrm{FW}_{\text {II }} 10.9 ; \mathrm{FD}_{\text {III }} 3.0, \mathrm{FW}_{\text {III }} 0.9 ; \mathrm{FD}_{\mathrm{IV}} 3.0, \mathrm{FW}_{\text {IV }}$ 1.0); dermal fringe present; subarticular tubercles rather prominent, oval, single, all present; two oval distinct palmar tubercles weakly developed; distinct supernumerary tubercles present on base of each finger. Hindlimbs relatively long; thigh length (TL 41.0) shorter than shank (SHL 43.5), and foot (FOL 42.7); relative digit lengths $\mathrm{I}<\mathrm{II}<\mathrm{III}<\mathrm{V}<\mathrm{IV}$; toe tips with obtusely pointed discs and dorsoventrally compressed, with lateroventral grooves, rather wide compared to toe width $\left(\mathrm{TD}_{\mathrm{I}} 2.6, \mathrm{TW}_{\mathrm{I}} 0.7 ; \mathrm{TD}_{\mathrm{II}} 2.7, \mathrm{TW}_{\mathrm{II}} 0.9 ; \mathrm{TD}_{\text {III }}\right.$ $\left.2.9, \mathrm{TW}_{\text {III }} 0.9 ; \mathrm{TD}_{\mathrm{IV}} 3.1, \mathrm{TW}_{\mathrm{IV}} 0.9 ; \mathrm{TD}_{\mathrm{V}} 2.7, \mathrm{TW}_{\mathrm{V}} 0.1\right)$; webbing present, rather medium: I1-1/1/2II1-2III12IV2-1V; dermal ridge along toe $\mathrm{V}$ present; subarticular tubercles rather prominent, oval, all present; inner metatarsal tubercles distinct and rather short; outer metatarsal tubercles rounded, rather prominent; supernumerary tubercles absent; tarsal tubercles absent.

Skin of snout, between eyes, sides of head and anterior part of dorsum shagreened; posterior part of back and upper part of flanks shagreened; dorsolateral folds that extend from posterior corner of eye to the entire body length on both sides, well developed (Figs 5, 11j, l); dorsal part of forelimbs without glandular warts; thighs, tibia and tarsus with weakly developed glandular warts; distinct rictal gland posterior to corner of mouth; flat weakly developed humeral glands; ventral parts of throat and belly smooth; anterior and posterior part of belly shagreened; posterior part of thigh granular. 
Colour in preservation (Figs 11j-1). Dorsal surfaces greyish-brown with scattered blackish spots; lower flanks light grey with black speckles; tympanic area dark grey; upper lip with white stripe continuing through rictal gland to above arm insertion; dorsolateral folds light grey; forelimbs, dorsal parts of thigh, tibia and foot light greyish-brown with grey spots, cross-bands are weakly formed; throat and margin of throat greyish-white with black flecks; chest and belly greyish-white; ventral surface of thighs, tibia and feet greyish-white with black spots; webbing dark grey with minute specks. Colour in life (Figs 13f-g). Dorsal parts light brown with grey spots; lower flanks bronze coloured; tympanic area reddish-grey; upper lip with white stripe continuing through rictal gland to above arm insertion; forelimbs, dorsal surface of thighs, tibia and feet light brown with grey spots, cross-bands are weakly formed; throat and margin of throat white with black flecks; chest and belly off-white; ventral surface of thighs, tibia and feet grey-white with black spots; webbing dark grey with minute specks; iris lower half dark brown and upper half golden brown.

Variation. See Table 2 for morphometric data from one adult male and four adult females. BNHS 5858: dorsal skin shagreened and sparsely granular, throat and chest with minute specks, posterior surface of thighs mottled; BNHS 5860: ventral surface of thighs sparsely granular.

Secondary sexual characters. Males: Single oval shaped nuptial pad on finger I present, cream-coloured; two vocal sacs faintly visible externally as loose skin on the posterior lateral side of the throat; humeral gland weakly developed, positioned laterally on the preaxial side of the upper forelimb. Females (BNHS 5859): ova white, pigmented on pole (diameter 1.7-2.1 $\mathrm{mm}, N=30$ ).

Etymology. The species epithet is derived from the Latin word 'magna' meaning 'large', which refers to the large body size of the new species, when compared with congeners from the Western Ghats-Sri Lanka biodiversity hotspot.

Distribution. This species is known only from four localities in the Agasthyamala hills (Pandimotta, Athirimala, Attyar, Pandipath) in the southern Western Ghats of Kerala state, and adjoining regions (Kakkachi) of Tamil Nadu state, between 600-1425 m asl. The distribution of H. magna is restricted to south of the Palghat Gap (Fig. 14, Table 1).
Habitat and natural history. This species was only found in evergreen forests. BNHS 5857 and SDBDU 2012.899: collected from the banks of a flowing stream in a closed canopy forest; BNHS 5858-5861: collected from emergent boulders in a fast flowing stream inside primary forest. During the dry season this species was commonly observed on stream banks, or amongst vegetation near forest streams, whereas during the monsoon (June-September), males were located on emergent boulders in these streams. After sunset they continued to call until around 21:00 h.

Hylarana montanus (Rao, 1922)

Mountain Golden-backed frog

(Figs 12m-o, 14, 15a-g, 16a-c; Tables 1-2)

Original name and description. Rana (Hylorana) gracilis montanus Rao, 1922. Notes on Batrachia, Journal of Bombay Natural History Society, 28: 439. Holotype. By monotypy, NHM 1947.2.2.66 (ex BMNH 1921.1.20.6), an adult female, collected by C.R. Narayan Rao. Type locality. 'Hill forests of Bhagamandla, Coorg', Karnataka state, India. Current status of specific name. Valid name, as Hylarana montanus (Rao, 1922). Synonym. Rana (Hylorana) bhagmandlensis Rao, 1922, previously in synonymy of Hylarana aurantiaca (Boulenger, 1904).

Referred specimens. NHM 1947.2.29.43 (ex BMNH 1921.1.20.7), an adult female, 'Mysore', Karnataka state, collected by C.R. Narayan Rao; BNHS 5862 and SDBDU 2011.95, two adult males, Bhagamandala, Kodagu dist., collected by SDB and team, 13 June 2011; BNHS 5863, an adult male, Thalakaveri, Kodagu dist., collected by SDB and team, 14 June 2011; BNHS 5864, an adult male, Yavakapady, Coorg, Kodagu dist., collected by SDB and team, 13 June 2011; BNHS 5865 and SDBDU 2011.513, two adult males, Bygoor, Chikmagalur dist., collected by SDB and team, 28 July 2011; BNHS 5866, an adult male, Muthodi-Kemmanagundi, Chikmagalur dist., collected by SDB 3 July 2003; BNHS 5867, an adult male, Kottigehara, Hassan dist., collected by SDB, 17 November 2010; and BNHS 5868, an adult female, Kottigehara, Hassan dist., collected by SDB, 2 August 2002; SDBDU 2011.64, a sub-adult, Kottigehara, Hassan dist., collected by SDB, 11 June 2011; SDBDU 2011.80, a sub-adult, Yavakapady, Coorg, Kodagu dist., collected by SDB and team, 13 June 2011; NHM 1947.2.2.12 (ex BMNH 1921.1.20.1), as holotype of Rana (Hylorana) bhagmandlensis Rao, 1922, Bhagamandala, Coorg, collected by C.R. Narayan Rao. 
Comments. Parker (1938) first questioned the identity of this taxon in his handwritten notes in the NHM catalogue, which states ' $R$. gracilis montanus to be conspecific with R.temporalis' (Dutta, 1997 and SDB personal observation). Dutta (1997) synonymised Rana (Hylorana) gracilis montanus with Rana (Hylarana) temporalis without any taxonomic discussion. Informed by morphological and molecular evidence from the present study, we resurrect this taxon from synonymy.

Rao (1922) described a new taxon Rana bhagmandlensis in the subgenus 'Hylorana' from 'water courses in the forest of Bhagamandla, Coorg'. In the original description, Rao (1922) mentioned two specimens 'No 1 (type) presented to the British and No. 2 to the Indian Museum'. The holotype, NHM 1947.2.2.12 (ex BMNH 1921.1.20.1), a sub-adult female specimen (Figs 15d-e) is currently present in the NHM, however we failed to locate the second specimen deposited in the Indian Museum (Zoological Survey of India). Dutta (1990) erroneously designated NHM 1947.2.2.12 (ex BMNH 1921.1.20.1) as the lectotype and formally synonymised Rana bhagmandlensis with Hylarana aurantiaca (Boulenger, 1904). Dubois (1992) rejected this synonymy without any discussion.

Rao (1922) did not provide any diagnostic characters for Rana bhagmandlensis in the original description, apart from a note by Miss Procter who examined the type and states '... possibly a new species. They agree well with the description of $R$. aurantiaca in Dr Boulenger's monograph, but they are not same. ......R. $a u$ rantiaca is much more elongate in habitat [habitus?], length of head going $3^{1 /} / 4$ in total length as against $2 \frac{1}{2}$ '. We studied the type specimens and original descriptions of Rana bhagmandlensis and Hylarana auranti$a c a$, and find the former to differ from the latter by its moderately robust body (vs. slender) and snout nearly truncate in dorsal view (vs. rounded). In fact, Rana (= Hylarana) bhagmandlensis does not match any members of the Hylarana aurantiaca group due to its moderately robust body, which has been found to be a reliable character to distinguish the members of the $\mathrm{Hy}$ larana aurantiaca group from other Hylarana groups in the Western Ghats-Sri Lanka biodiversity hotspot.

Our recent collections from the type locality of Rana (= Hylarana) bhagmandlensis, 'Bhagamandla, Coorg', yielded two distinct populations in a molecular phylogenetic framework - one that nested with $\mathrm{Hy}$ larana montanus, and the other with $H$. intermedius. While H. intermedius was described from Sakleshpur (Rao 1937), H. montanus was described from the same locality (and altitude) as Rana bhagmandlensis (Rao, 1922). We presume that the two taxa were described differently in the same publication by Rao (1922) mainly based on size differences; smaller specimen, a sub-adult ('from tip of snout to vent $30 \mathrm{~mm}$ ') described as Rana (Hylorana) bhagmandlensis, and the larger specimen, an adult female (SVL 'snout to vent 75.6') as Rana (Hylorana) gracilis montanus. We compared the type and original description of $R$. bhagmandlensis with Hylarana intermedius and H. montanus and observe that the overall body plan and morphological characters are comparable with the latter species, which belongs to the proposed Hylarana flavescens group. Since the holotype of Rana bhagmandlensis is an immature specimen, we do not provide a detailed redescription of this specimen.

On the basis of the above evidence, we consider Rana (Hylorana) bhagmandlensis Rao, 1922 (pp. 441) to be a junior subjective synonym of Rana (Hylorana) gracilis montanus Rao, 1922 (pp. 439) (= Hylarana montanus).

Comparison. Hylarana montanus could be confused with Hylarana caesari sp. nov., Hylarana flavescens, Hylarana indica sp. nov., Hylarana magna sp. nov. and Hylarana sreeni sp. nov. in the Hylarana flavescens group, due to its overall adult size. However, $H$. montanus differs from $H$. sreeni by its snout rounded to truncate (vs. sub-elliptical), second toe webbing extending beyond the first subarticular tubercle on the inside (vs. up to the first subarticular tubercle) (Figs 12o, r), interorbital space wider than the upper eyelid width, IUE $6.0 \pm 0.3 \mathrm{~mm}$, UEW $4.4 \pm 0.3 \mathrm{~mm}$, male, $N$ $=8$ (vs. subequal, IUE $4.1 \pm 0.5 \mathrm{~mm}$, UEW $4.0 \pm 0.4$ $\mathrm{mm}, N=7)$. For differences with Hylarana caesari, $H$. flavescens, H. indica and H. magna see 'Comparison' of those species.

Genetic divergence. Intraspecific genetic variation within populations of Hylarana montanus was $0.5 \pm$ $0.2 \%$ (range $0-0.7 \%, N=7$ ) for $16 \mathrm{~S}, 1.1 \pm 0.6 \%$ (range $0-2.2 \%, N=7$ ) for COI and $1.8 \pm 1.4 \%$ (range $0-5.3 \%$, $N=8$ ) for Cytb. Based on phylogenetic position, $H$. montanus is closely related to the members of Hylarana flavescens group (Fig. 4); differs from $H$. sreeni by mean genetic divergence of $6.4 \pm 0.4 \%$ (range 5.6-7.1\%, $N=84$ ) for $16 \mathrm{~S}, 12.5 \pm 0.3 \%$ (range $11.7-13.0 \%, N=$ 84) for COI and $17.8 \pm 1.3 \%$ (range $15.7-20.9 \%, N=$ 112) for Cytb (Tables S2-S3). See Hylarana caesari, $H$. flavescens, $H$. indica and $H$. magna for comparison with those species. 
Redescription of holotype (Figs 12m-o, 15a-c). Medium-sized, robust species, adult female (SVL 74.3). Head moderately large (HW 25.4, HL 29.5, IFE 13.9, IBE 18.6), longer than wide, flat above; snout rounded to nearly truncate in dorsal, ventral and lateral view, protruding, its length (SL 11.4) longer than horizontal diameter of eye (EL 9.4); loreal region acute and concave with angular canthus rostralis; interorbital space flat, wider (IUE 6.9) than upper eyelid (UEW 5.5) and narrower than internarial distance (IN 7.2); nostril oval with flap of skin laterally, closer to tip of snout (NS 4.9) than eye (EN 7.3); tympanum (TYD 6.1) 65\% of eye diameter (EL 9.4); tympanum-eye distance (TYE 2.8); pineal ocellus present; vomerine ridge present, bearing numerous small teeth, with an angle of $45^{\circ}$ to body axis, slightly closer to choanae than each other, longer than distance between them; tongue moderately large, emarginated, bearing no median lingual process. Forelimbs moderately short and thin; forelimb (FAL 15.6) shorter than hand length (HAL 22.0); fingers with weakly developed lateral fringes, finger length formula $\mathrm{II}<\mathrm{I}<\mathrm{IV}<\mathrm{III}$, finger tips with obtusely pointed discs and dorsoventrally compressed, with lateroventral groove, moderately wide compared to finger width $\left(\mathrm{FD}_{\mathrm{I}} 1.5\right.$, $\mathrm{FW}_{\mathrm{I}} 1.2 ; \mathrm{FD}_{\mathrm{II}} 1.4, \mathrm{FW}_{\mathrm{II}} 1.2 ; \mathrm{FD}_{\text {III }} 1.6, \mathrm{FW}_{\mathrm{III}} 1.2 ; \mathrm{FD}_{\mathrm{IV}} 1.5$, $\mathrm{FW}_{\mathrm{IV}}$ 1.2); subarticular tubercles very prominent, oval, single, all present; prepollex distinct, oval, two oval distinct palmar tubercles; supernumerary tubercles indistinct (Fig. 12m). Hindlimbs relatively long and thin; thigh length (TL 40.0) shorter than shank (SHL 44.5), and longer than foot (FOL 39.8); relative digit lengths $\mathrm{I}<\mathrm{II}<\mathrm{III}<\mathrm{V}<\mathrm{IV}$; toe tips with obtusely pointed discs and dorsoventrally compressed, with lateroventral grooves, rather wide compared to toe width $\left(\mathrm{TD}_{\mathrm{I}} 1.5, \mathrm{TW}_{\mathrm{I}} 1.3\right.$; $\mathrm{TD}_{\text {II }} 1.7, \mathrm{TW}_{\text {II }} 1.3 ; \mathrm{TD}_{\text {III }} 1.7, \mathrm{TW}_{\text {III }} 1.3 ; \mathrm{TD}_{\text {IV }} 1.8, \mathrm{TW}_{\text {IV }}$ $\left.1.2 ; \mathrm{TD}_{\mathrm{v}} 1.3, \mathrm{TW}_{\mathrm{v}} 1.2\right)$; webbing moderate; $\mathrm{I} 1-1 \frac{1}{2} \mathrm{II} 1-$ 2III1-2IV2-1V; dermal ridge along toe $\mathrm{V}$ weak; subarticular tubercles prominent, oval, all present; inner metatarsal tubercles ovoid and rather short; outer metatarsal tubercles rounded, prominent; supernumerary tubercles absent; tarsal tubercles absent.

Skin of dorsum, lateral sides of head and limbs covered with small granules; all ventral surfaces smooth and tympanum smooth; dorsolateral folds that extend from the posterior corner of the eye to the entire body length on both sides, well developed (Figs 5, 15a, c); supratympanic ridge absent; rictal gland present at the corner of the mouth; humeral glands absent.

Colour in preservation (Figs 15a-c). Dorsal surface yellowish-brown; lower flank light greyish-brown; tympanic area and tympanum light brown; upper lip light grey with white stripe continuing through rictal gland to above arm insertion; forelimbs, dorsal parts of thigh, tibia and foot light greyish-brown with dark grey cross-bands; anterior part of thigh reticulated with light yellowish-brown patches on brown background; throat and margin of throat greyish-white; chest and belly greyish-white; ventral parts of thigh, tibia and foot light brown; webbing dark grey with minute specks.

Due to slight dehydration and slight damage of the holotype (Figs 15a-c), we provide a brief description of a male specimen (BNHS 5862) from the type locality. It is also appropriate to describe a male specimen for uniform comparison with other male specimen descriptions in this study.

Description of topotype, male, BNHS 5862 (Figs 15fg). Medium-sized, robust species, adult male (SVL 59.6). Head rather large (HW 20.2, HL 23.1, IFE 10.6, IBE 15.2), longer than wide, flat above; snout rounded to truncate in dorsal, ventral and lateral view, protruding, its length (SL 9.3) longer than horizontal diameter of eye (EL 6.6); interorbital space flat, wider (IUE 6.1) than upper eyelid (UEW 4.3) and internarial distance (IN 5.6); distance between back of eye (IBE 15.2) more than 1.4 times the distance between front of eye (IFE 10.6); nostril closer to tip of snout, (NS 3.6) than eye (EN 5.1); tympanum (TYD 4.5) 68\% of eye diameter (EL 6.6); pineal ocellus present, between anterior border of eye. Forelimbs thick; forelimb (FAL 12.4) shorter than hand length (HAL 16.6); fingers thick, finger length formula II $<\mathrm{I}<\mathrm{IV}<\mathrm{III}$, finger tips with obtusely pointed discs and dorsoventrally compressed, with lateroventral groove, moderately wide compared to finger width $\left(\mathrm{FD}_{\mathrm{I}} 1.5, \mathrm{FW}_{\mathrm{I}} 0.6 ; \mathrm{FD}_{\text {II }} 1.6, \mathrm{FW}_{\mathrm{II}} 0.7 ; \mathrm{FD}_{\text {III }}\right.$ $\left.1.8, \mathrm{FW}_{\text {III }} 0.6 ; \mathrm{FD}_{\text {IV }} 1.5, \mathrm{FW}_{\text {IV }} 0.4\right)$. Hindlimbs relatively long and thin; thigh length (TL 31.9) shorter than shank (SHL 33.1), and longer to foot (FOL 30.9); relative digit lengths $\mathrm{I}<\mathrm{I} I<\mathrm{III}<\mathrm{V}<\mathrm{IV}$; toe tips with obtusely pointed discs and dorsoventrally compressed, with lateroventral grooves, rather wide compared to toe width $\left(\mathrm{TD}_{\mathrm{I}} 1.4, \mathrm{TW}_{\mathrm{I}} 0.6 ; \mathrm{TD}_{\mathrm{II}} 1.3, \mathrm{TW}_{\mathrm{II}} 0.6 ; \mathrm{TD}_{\text {III }} 1.7, \mathrm{TW}_{\text {III }}\right.$ $\left.0.5 ; \mathrm{TD}_{\mathrm{IV}} 1.4, \mathrm{TW}_{\mathrm{IV}} 0.5 ; \mathrm{TD}_{\mathrm{V}} 1.3, \mathrm{TW}_{\mathrm{V}} 0.5\right)$; webbing present, rather medium: I1-1 $1 / 2 \mathrm{II} 1-2 \mathrm{III} 1-2 \mathrm{IV} 2-1 \mathrm{~V}$; subarticular tubercles prominent, oval, all present; inner metatarsal tubercles distinct and rather short; outer metatarsal tubercles rounded, rather prominent; supernumerary tubercles absent.

Skin of snout and between eyes shagreened to sparsely granular; sides of head shagreened with spinular 


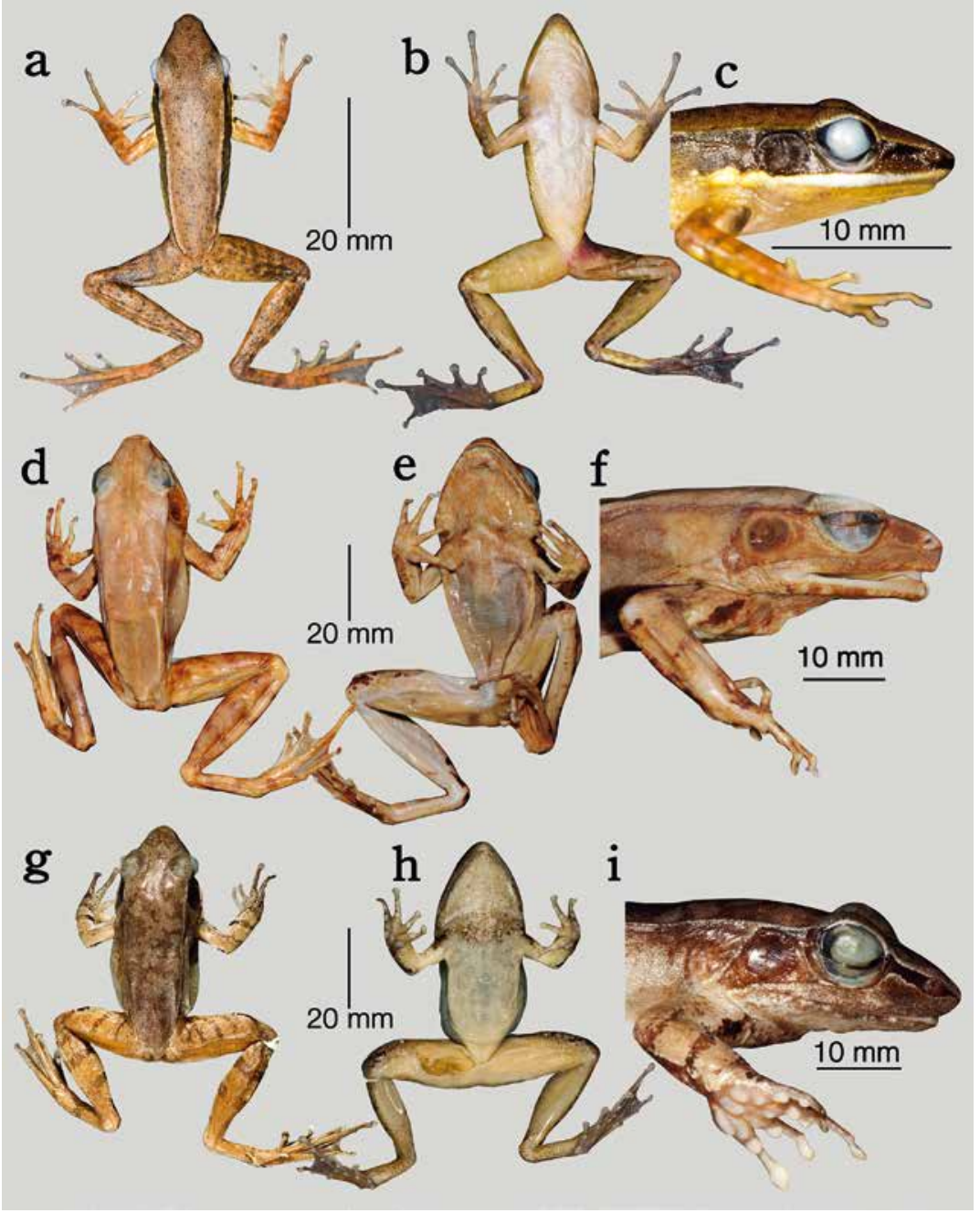

Fig. 17a-i. Dorsal view, ventral view, and lateral view of head of the Hylarana temporalis group in preservation: a-c. holotype of $H$. serendipi (DZ 1247): a. dorsal view, b. ventral view, c. lateral view of head; d-f. lectotype of Hylorana temporalis (NHM 1947.2.3.5 [ex BMNH 53.7.19.11]): d. dorsal view, e. ventral view, f. lateral view of head; g-i. referred specimen of Hylarana temporalis (DZ 1046): g. dorsal view, h. ventral view, i. lateral view of head. projections; upper eyelids granular with spinular projections; dorsolateral folds that extend from the posterior corner of the eye to the entire body length on both sides, well developed with horny spinules; anterior part of dorsum granular, posterior part of dorsum prominently granular (Figs 5, 15f-g); distinct rictal gland posterior to corner of mouth with marginal horny spinules; humeral glands weakly developed; flank shagreened with scattered granular; dorsal parts of forelimb shagreened with horny spinules; thigh, tibia and tarsus with glandular warts and horny spinules.

Colour in preservation (Figs 15f-g). Dorsal parts dark greyish-brown; flanks light grey; tympanic area dark grey; upper lip with light greyish-brown stripe continuing through rictal gland to above arm insertion; fore- limbs, dorsal parts of thigh, tibia and foot dark grey; throat and margin of throat greyish-white; chest and belly greyish-white; ventral parts of thigh, tibia and foot greyish-white; webbing dark grey; anterior part of the thigh with light brown reticulations on dark grey background, cross-bands faintly visible. Colour in life (Fig. 16b). Dorsal parts bronze coloured; lower flanks light bronze, lower and upper parts of flank bronze; tympanic area golden brown; upper lip with yellowishwhite stripe continuing through rictal gland to above arm insertion; forelimbs, dorsal part of thigh, tibia and foot light brown with grey spots, cross-bands are weakly formed; throat and margin of throat yellowishwhite; chest and belly off-white; ventral parts of thigh, tibia and foot greyish-white; webbing dark grey with minute specks; iris lower half dark brown and upper half golden brown. 
Variation. See Table 2 for morphometric data from eight adult males and three adult females including holotype. BNHS 5867: dorsum dark reddish-brown with scattered grey spots in life, turned light grey in preservation, posterior part of back granular, flanks glandular; BNHS 5868: dorsum light red in life, turned light grey in preservation, posterior part of dorsal skin prominently granular.

Secondary sexual characters. Males (BNHS 5862): Single oval shaped nuptial pad on finger I present, cream-coloured; two vocal sacs faintly visible externally as loose skin on the posterior lateral side of the throat; humeral gland weakly developed, positioned laterally on the preaxial side of the upper forelimb. Females (NHM 1947.2.2.66): ova white, pigmented on pole (diameter 1.3-1.9 mm, $N=14$ ).

Distribution. This species is widely distributed in the Western Ghats of Karnataka state. In the present study, we collected Hylarana montanus from Bygoor and Muthodi-Kemmanagundi (Chikmagalur dist.); Kottigehara (Hassan dist.); Coorg, Bhagamandala, and Thalakaveri (Kodagu dist.), at elevations between 800 $1200 \mathrm{~m}$ asl. (Fig. 14, Table 1).

Habitat and natural history. This species was found both in primary and secondary forests. BNHS 5862 and SDBDU 2011.95 (Bhagamandala) were collected from open secondary forest; BNHS 5863 (Thalakaveri), BNHS 5866 (Muthodi-Kemmanagundi), and BNHS 5867 (Kottigehara) were collected from partially submerged rocks within streams flowing through closed canopy forest; BNHS 5864 (Coorg), and BNHS 5865 and SDBDU 2011.513 (Bygoor) were collected from disturbed secondary forest streams near coffee plantations.

Hylarana sreeni sp. nov. Sreeni's Golden-backed frog

(Figs 12p-r, 14, 15h-j, 16d-f; Tables 1-2)

Holotype. BNHS 5869, an adult male, Siruvani, Kuddam, Palakkad dist., Kerala state, India, collected by SDB and SG, 18 October 2011.

Paratypes. BNHS 5870, an adult male, Siruvani, Singappara, Palakkad dist., collected SDB and SG, 16 October 2011; BNHS 5871, an adult male, Kaikatti, Nelliyampathy, Palakkad dist., collected by SDB, 28 May 2010; BNHS 5872, an adult male, Thekkady, Idukki dist., collected by SDB and SG, 28 January 2012; BNHS 5873 , an adult male, Glenback estate, Kiriparai, Kanyakumari dist., collected by SDB, 19 November 2008; BNHS 5874, an adult male, Pandimotta, Shendurney WLS, Thiruvananthapuram dist., collected by SDB and Systematics Lab team, 13 September 2011; BNHS 5875 an adult female, Siruvani, Singappara, Palakkad dist., collected by SDB and SG, 16 October 2011; BNHS 5876, an adult female, Parambikulam tiger reserve, Palakkad dist., collected by SDB and Systematics Lab team, 13 August 2011; BNHS 5877, an adult female, Gavi, Pathanamthitta dist., collected by SDB, 10 June 2006; BNHS 5878, an adult female, Chathankod, Thiruvananthapuram dist., collected by SDB and Systematics Lab team, 11 September 2011.

Referred specimens. SDBDU 2012.1831, an adult male, Thekkady, Idukki dist., collected by SDB and SG, 28 January 2012; SDBDU 2011.1257, an adult female, Siruvani, Singappara, Palakkad dist., collected by SDB and SG, 16 October 2011; SDBDU 2004.40352a, an adult female, Chathankod, Thiruvananthapuram dist., collected by SDB, 15 Januray 2004; SDBDU 2004.4553, a sub-adult female, Yercaud, Shevaroy hills, Salem dist., collected by SDB, 3 September 2004; SDBDU 2011.1041, a sub-adult male, Kadalar estate, Munnar, Idukki dist., collected by SDB and Systematics Lab team, 23 September 2011.

Comparison. Hylarana sreeni sp. nov. could not be confused with any species within the Hylarana flavescens group, by the suite of its adult size, male SVL 44.0-52.4 mm, $N=7$, female SVL 64.8-80.1 mm, $N=$ 6 , sub-elliptical snout, granular dorsal skin and second toe webbing below the first tubercle on inside of toe II (Figs 12c, f, i, 1, o, r). For detailed differences with $\mathrm{Hy}$ larana caesari, H. flavescens, H.indica, H. magna and H. montanus see 'Comparison' of those species.

Genetic divergence. Intraspecific genetic variation within populations of Hylarana sreeni was $0.8 \pm 0.6 \%$ (range $0-1.5 \%, N=12$ ) for $16 \mathrm{~S}, 2.3 \pm 1.4 \%$ (range $0-3.6 \%, N=12$ ) for COI and $3.7 \pm 2.2 \%$ (range $0-6.1 \%$, $N=14$ ) for Cytb (Table S2). Based on phylogenetic position, $H$. sreeni is closely related to the members of Hylarana flavescens group (Fig. 4). See Hylarana caesari, $H$. flavescens, $H$. indica, $H$. magna and $H$. montanus for comparison with those species.

Description of holotype (Figs 12p-r, 15h-j). Large-sized, moderately robust adult male (SVL 49.5). Head small (HW 15.9, HL 19.5, IFE 9.7, IBE 13.0), longer than 


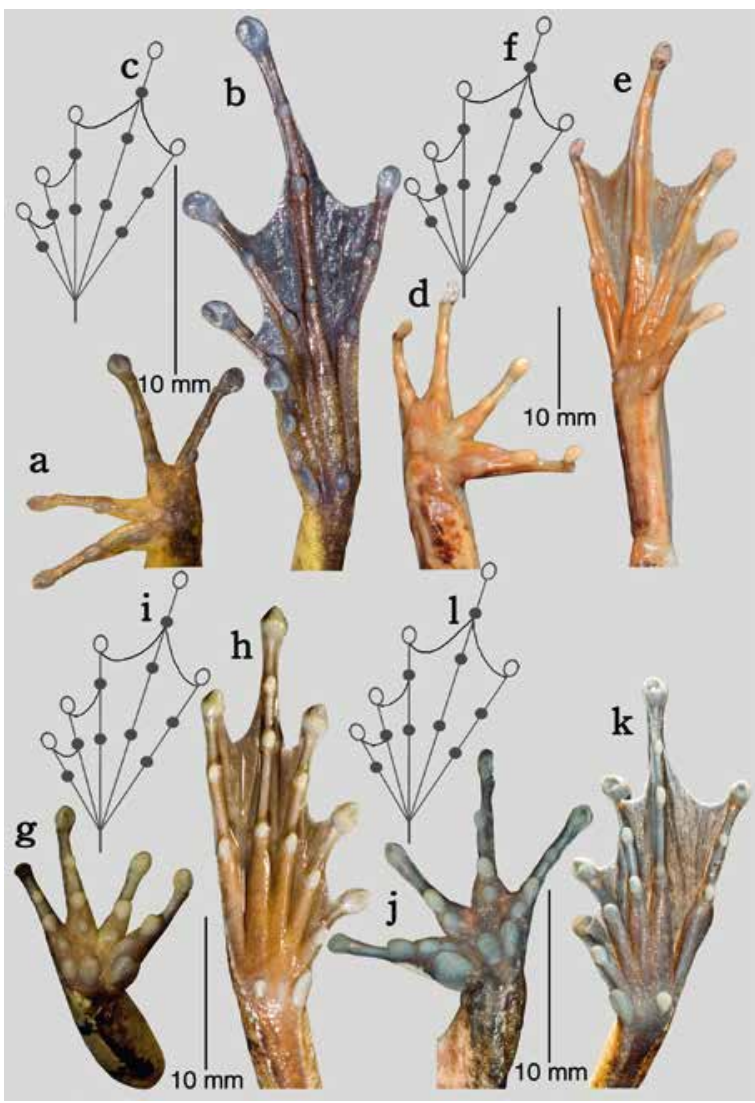

Fig. 18a-l. Ventral view of hand and foot, and schematic illustration of webbing on feet of the Hylarana temporalis group in preservation: a-c. holotype of $H$. serendipi (DZ 1247): a. ventral view of hand, b. ventral view of foot, c. schematic illustration of webbing on feet; d-f. lectotype of Hylorana temporalis (NHM 1947.2.3.5 [ex BMNH 53.7.19.11]): d. ventral view of hand, e. ventral view of foot, f. schematic illustration of webbing on feet; g-i. referred specimen of Hylarana temporalis (DZ 1046): g. ventral view of hand, $h$. ventral view of foot, i. schematic illustration of webbing on feet; $\mathrm{j}-1$. referred specimen of H.temporalis (DZ 1151): j. ventral view of hand, $\mathrm{k}$. ventral view of foot, 1 . schematic illustration of webbing on feet.

wide, flat above; snout sub-elliptical in dorsal and ventral view, rounded in lateral view, slightly protruding, its length (SL 8.6) longer than horizontal diameter of eye (EL 5.7); loreal region vertical and concave with rounded canthus rostralis; interorbital space flat, wider (IUE 4.5) than upper eyelid (UEW 4.4) and narrower than internarial distance (IN 5.0); distance between back of eye (IBE 13.0) 1.3 times the distance between front of eye (IFE 9.7); nostril oval with flap of skin laterally, closer to tip of snout (NS 3.1) than eye (EN 4.7); tympanum (TYD 4.4) 77\% of eye diameter (EL 5.7); tympanum-eye distance (TYE 1.5); pineal ocel- lus present, between anterior border of eye; vomerine ridge present, bearing small teeth, with an angle of $50^{\circ}$ to body axis, as close to choanae as to each other; tongue moderately large, emarginated. Forelimbs moderately short and thin; forelimb (FAL 10.0) shorter than hand length (HAL 13.8); fingers long, finger length formula $\mathrm{I}=\mathrm{II}<\mathrm{IV}<\mathrm{III}$, finger tips with obtusely pointed discs and dorsoventrally compressed, with lateroventral grooves, moderately wide compared to finger width $\left(\mathrm{FD}_{\mathrm{I}} 0.9, \mathrm{FW}_{\mathrm{I}} 0.5 ; \mathrm{FD}_{\text {II }} 1.1, \mathrm{FW}_{\text {II }} 0.4 ; \mathrm{FD}_{\text {III }}\right.$ $\left.1.3, \mathrm{FW}_{\mathrm{III}} 0.4 ; \mathrm{FD}_{\mathrm{IV}} 1.2, \mathrm{FW}_{\mathrm{IV}} 0.5\right)$; dermal fringe present; subarticular tubercles prominent, oval, single, all present; two oval distinct palmar tubercles moderately developed; a distinct supernumerary tubercle at base of each finger. Hindlimbs relatively long and thin; thigh length (TL 25.2) shorter than shank (SHL 28.4), and subequal to foot (FOL 25.3); relative digit lengths $\mathrm{I}<\mathrm{II}<\mathrm{III}<\mathrm{V}<\mathrm{IV}$; toe tips with obtusely pointed discs and dorsoventrally compressed, with lateroventral grooves, rather wide compared to toe width $\left(\mathrm{TD}_{\mathrm{I}} 1.2\right.$, $\mathrm{TW}_{\text {I }} 0.7 ; \mathrm{TD}_{\text {II }} 1.4, \mathrm{TW}_{\text {II }} 0.6 ; \mathrm{TD}_{\text {III }} 1.5, \mathrm{TW}_{\text {III }} 0.7 ; \mathrm{TD}_{\text {IV }}$ 1.5, $\mathrm{TW}_{\mathrm{IV}} 0.6 ; \mathrm{TD}_{\mathrm{V}} 1.2, \mathrm{TW}_{\mathrm{V}} 0.6$ ); webbing present, rather medium: I1-2II1-2+III1-2+IV2-1V; dermal ridge along toe $\mathrm{V}$ present; subarticular tubercles rather prominent, oval, all present; inner metatarsal tubercles distinct and rather short; outer metatarsal tubercles rounded, rather prominent.

Skin of snout and between eyes shagreened and sparsely granular; side of head shagreened to granular; upper eyelids granular; anterior and posterior part of dorsum granular with horny spinules; upper and lower parts of flanks rather shagreened to sparsely glandular; dorsolateral folds that extend from the posterior corner of the eye to the entire body length on both sides, well developed with horny spinules (Figs 5, 15h, j); dorsal part of forelimb shagreened, thigh sparsely granular, tibia and tarsus granular with well developed longitudinal horny spinules; anal region prominently granular; toe $\mathrm{V}$ with dermal fringe having granular projections from the base of $\mathrm{V}$ toe to knee; distinct rictal gland posterior to corner of mouth; distinct humeral glands; ventral part of throat smooth; anterior part of belly shagreened, posterior part of belly shagreened; posterior part of thigh granular.

Colour in preservation (Figs $15 \mathrm{~h}-\mathrm{j}$ ). Dorsal surface greyish-brown, lower flank light brown; tympanic area light greyish-brown, tympanum light brown; upper lip with greyish-white stripe continuing through rictal gland to above arm insertion; forelimbs, dorsal parts of thigh, tibia and foot light greyish-brown with grey 
spots, anterior part of thigh reticulated with light greyish-brown patches on dark grey background; throat and margin of throat greyish-white; chest and belly greyish-white; ventral parts of thigh, tibia and foot light yellowish-brown; webbing dark grey with minute specks. Colour in life (Fig. 16d). Dorsal parts bronze coloured; lower flank light brown; tympanic area light greyish-brown, tympanum light brown; upper lip with yellowish-white stripe continuing through rictal gland to above arm insertion; forelimbs, dorsal parts of thigh, tibia and foot light brown with brown spots; anterior part of thigh reticulated with light yellowishbrown patches on light grey background; throat and margin of throat greyish-white; chest and belly greyish-white; ventral parts of thigh, tibia and foot greyishwhite; webbing dark grey with minute specks.

Variation. See Table 2 for morphometric data from seven adult males and six adult females. BNHS 5874: dorsum dark grey with scattered feeble blackish-grey spots, prominent blackish-grey cross-bands on both fore and hind limbs; BNHS 5873: posterior surface of abdomen slightly granular and ventral surface of thighs, tibia and forelimb margins with prominent dark grey spots; SDBDU 2012.1831: sides of snout and loreal region with spinular projections; BNHS 5871: dorsum with blackish-grey spots, chest and belly dark greyish-brown with minute dark brown spots.

Secondary sexual characters. Males: Single oval shaped nuptial pad on finger I present, cream-coloured; two vocal sacs faintly visible externally as loose skin on the posterior lateral side of the throat; humeral gland weakly developed, positioned laterally on the preaxial side of the upper forelimb. Females (BNHS 5875): ova white, pigmented on pole (diameter 1.3-1.9 mm, $N=14$ ).

Etymology. The species is named 'sreeni' after Dr. K. $\mathrm{V}$. Sreenivasan, as a token of appreciation for him being a constant source of inspiration and support to SDB's research over the past two decades.

Distribution. Hylarana sreeni is one of the more widely distributed Hylarana species in the southern Western Ghats states of Kerala and Tamil Nadu, and found at elevations between $100-1500 \mathrm{~m}$ asl. The present study reports this species from Chathankod, Pandimotta, Gavi, Thekkady, Munnar, Nelliyampathy, Parambikulam, and Siruvani, in Kerala, and Kiriparai in Tamil Nadu. This species was also found in the Shevaroy hills (Yercaud), in the Eastern Ghats (Fig. 14, Table 1).
Habitat and natural history. Hylarana sreeni was predominantly found in primary and secondary forest habitats, in perennial fast flowing streams, usually perched on rocks, or on the banks of the streams. During the breeding season, egg laying was observed in shallow peripheral parts of the streams.

Hylarana temporalis group. This group can be distinguished from other peninsular Indian-Sri Lankan $\mathrm{Hy}$ larana groups by the following suite of characters: small to large-sized adult (male, SVL 30-69 mm; female, SVL 42-80 mm), body slender to robust; dorsolateral folds moderately or well developed (Fig. 5); finger and toes dorsoventrally compressed with obtusely pointed discs (Fig. 6); fourth toe webbing extends beyond the second subarticular tubercle on the outside of toe IV; endemic to Sri Lanka. In a phylogenetic framework, Hylarana temporalis group can be characterised as the most inclusive clade that contains a Sri Lankan radiation (Hylarana serendipi $\mathrm{sp}$. nov. $+H$. temporalis) and none of the Indian radiations (Fig. 4).

Hylarana serendipi sp. nov.

Sri Lankan Golden-backed frog

(Figs 17a-c, 18a-c, 19a-b, 20; Tables 1-2)

Holotype. DZ 1247, an adult male, Kudawa, Sinharaja, Ratnapura dist., Sri Lanka, collected by MM and others, 25 June 2013.

Paratypes. DZ 1146, DZ 1233, DZ 1235, DZ 1248, four adult males, DZ 1144-1145, DZ 1234, three adult females, collected along with holotype.

Comparison. Hylarana serendipi sp. nov. could not be confused with Hylarana temporalis, the only other species in the Hylarana temporalis group, due to its smaller adult size. It differs from $H$. temporalis by its smaller snout-vent size, male SVL 30.1-36.9, $N=5$; female SVL 42.5-43.6, $N=3$ (vs. larger, male SVL 48.1$68.1, N=13$; female SVL 63.5-79.4, $N=8$ ); body slender (vs. robust); absence of supertympanic ridge (vs. presence) (Figs 17c, f, i). Hylarana serendipi is not closely related to any of the Western Ghats species, however due to a long history of its misidentification with $H$. aurantiaca, we provide a comparison with the latter. Hylarana serendipi differs from $H$. aurantiaca by its relatively larger adult size (male, SVL 30.1-36.9, $N=5$; female, SVL 42.5-43.6, $N=3$ ) (vs. smaller, male, SVL 27.1-31.7 mm, $N=9$; female, SVL 37.9, $N$ $=1$ ); dorsal skin granular with scattered spinules (vs. 

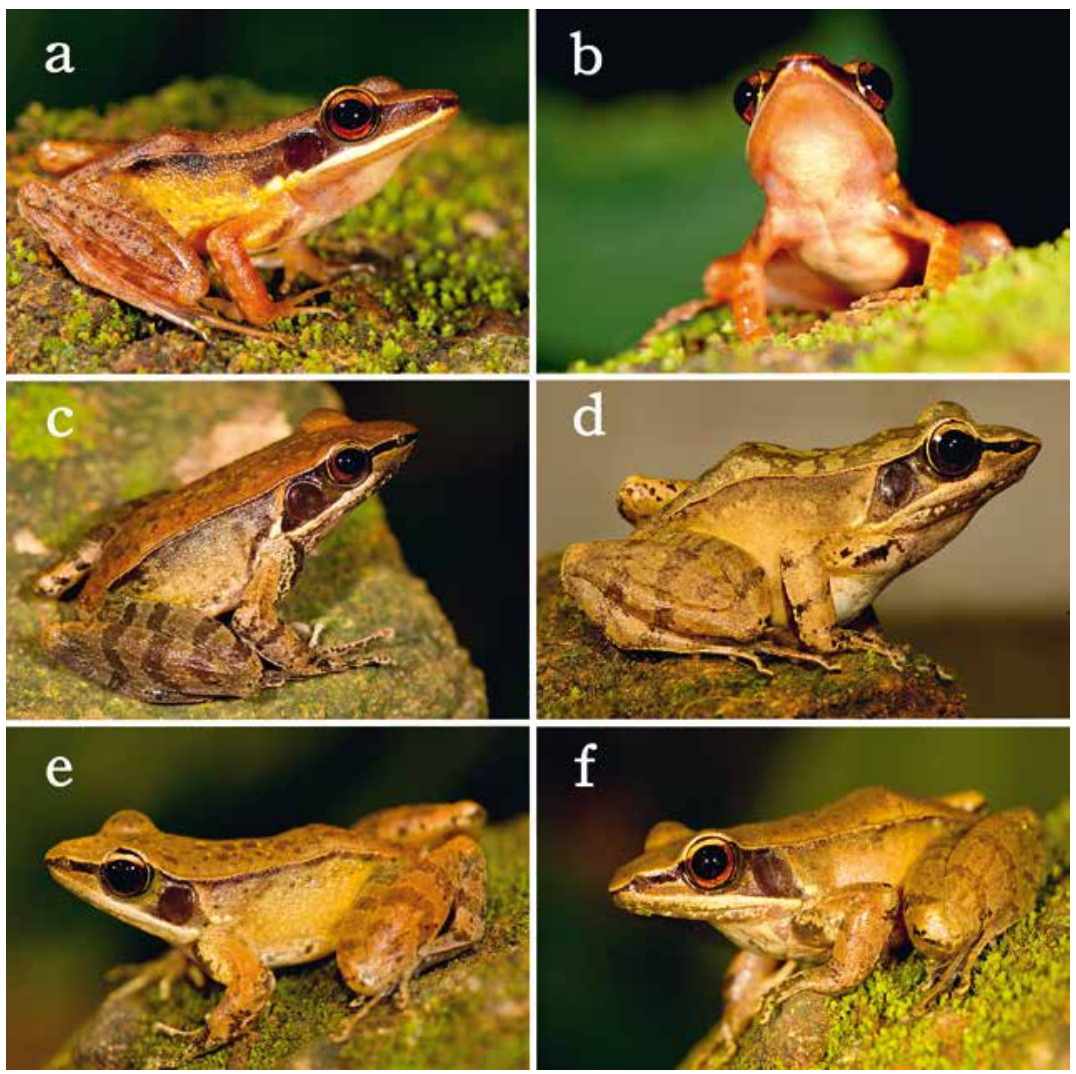

Fig. 19a-f. Hylarana temporalis group in life: a-b. holotype of $H$. serendipi (DZ 1247, male), from Kudawa, Sinharaja, Ratnapura: a. dorsolateral view, b. front view; c-f. H. temporalis: c. dorsolateral view (DZ 1092, male), from Hemmathagama, Kegalle, d. dorsolateral view (DZ 1046, male), from Sarasavi Oya, Peradeniya, e. dorsolateral view (DZ 1153, male), from Panwila, f. dorsolateral view (DZ1151, male), from Udadumbara (Photos: SD Biju). dorsal skin shagreened); subarticular tubercles prominent on toes (vs. weakly developed); third toe webbing extends up to the disc on the outside (vs. extends just beyond the first subarticular tubercle) (Figs 8b-c, $18 \mathrm{~b}-\mathrm{c})$.

Genetic divergence. Intraspecific genetic variation within populations of Hylarana serendipi was $0.1 \pm$ $0.1 \%$ (range $0-0.2 \%, N=3$ ) for $16 \mathrm{~S}, 0.9 \pm 0.5 \%$ (range $0.3-1.2 \%, N=3$ ) for $\mathrm{COI}$ and $1.8 \%(N=2)$ for Cytb. Based on phylogenetic position, H. serendipi is closely related to $H$. temporalis (Fig. 4) from which it differs by an average genetic divergence of $10.5 \pm 0.1 \%$ (range $10.4-10.6 \%, N=14$ ) for $16 \mathrm{~S}, 18.1$ $\pm 0.2 \%$ (range $17.8-18.5 \%, N=18$ ) for COI and 23.8 $\pm 0.6 \%$ (range $23.0-25.0 \%, N=18$ ) for Cytb. Since $H$. serendipi was long misidentified as $H$. aurantiaca from India, the present study compared the two species, and found a very high genetic divergence of $13.8 \pm 0.2 \%$ (range $13.6-14.2 \%, N=10$ ) for $16 \mathrm{~S}, 18.8$ $\pm 0.1 \%$ (range $18.7-19 \%, N=18$ ) for $\mathrm{COI}$ and $23.3 \pm$ $0.5 \%$ (range $22.8-23.9 \%, N=10$ ) for Cytb (Tables SI-S3).
Description of holotype (Figs 17a-c, 18a-c). Smallsized, moderately slender adult male (SVL 36.9). Head small (HW 11.5, HL 14.8, IFE 6.3, IBE 9.3), longer than wide, flat above; snout sub-elliptical in dorsal and ventral view, rounded in lateral view, protruding, its length (SL 6.7) longer than horizontal diameter of eye (EL 4.9); loreal region acute and concave with rounded canthus rostralis; interorbital space flat, equal (IUE 3.2) to upper eyelid (UEW 3.2) and subequal to internarial distance (IN 3.6); distance between back of eye (IBE 9.3) 1.5 times the distance between front of eye (IFE 6.3); nostril oval, closer to tip of snout (NS 2.0) than eye (EN 4.2); tympanum (TYD 3.5) $71 \%$ of eye diameter (EL 4.9); tympanum-eye distance (TYE 0.8); pineal ocellus present, between anterior border of eye; vomerine ridge present, bearing small teeth, with an angle of $40^{\circ}$ to body axis, as close to choanae as to each other; tongue moderately large, emarginated. Forelimbs moderately short and thin; forelimb (FAL 7.1) shorter than hand length (HAL 11.1), finger length formula $\mathrm{I}<\mathrm{II}<\mathrm{IV}<\mathrm{III}$, finger tips dorsoventrally compressed with obtusely pointed discs and lateroventral groove, moderately wide compared to finger width $\left(\mathrm{FD}_{\mathrm{I}} 0.7\right.$, 
$\mathrm{FW}_{\mathrm{I}} 0.4 ; \mathrm{FD}_{\text {II }} 1.0, \mathrm{FW}_{\text {II }} 0.5 ; \mathrm{FD}_{\text {III }} 1.2, \mathrm{FW}_{\text {III }} 0.6 ; \mathrm{FD}_{\text {IV }}$ 1.0, $\mathrm{FW}_{\mathrm{IV}} 0.6$ ); dermal fringe present; subarticular tubercles weakly developed, oval, single, all present; prepollex distinct, oval; two oval palmar tubercles weakly developed; a weakly developed supernumerary tubercle on base of each finger. Hindlimbs relatively long and thin; thigh length (TL 16.3) shorter than shank (SHL 19.1), and foot (FOL 18.2); relative digit lengths $\mathrm{I}<\mathrm{I}$ $<\mathrm{III}<\mathrm{V}<\mathrm{IV}$; toe tips dorsoventrally compressed with obtusely pointed discs and lateroventral grooves, rather wide compared to toe width $\left(\mathrm{TD}_{\mathrm{I}} 0.8, \mathrm{TW}_{\mathrm{I}} 0.5\right.$; $\mathrm{TD}_{\text {II }} 1.1, \mathrm{TW}_{\text {II }} 0.6 ; \mathrm{TD}_{\text {III }} 1.5, \mathrm{TW}_{\text {III }} 0.5 ; \mathrm{TD}_{\text {IV }} 1.3, \mathrm{TW}_{\text {IV }}$ $\left.0.5 ; \mathrm{TD}_{\mathrm{V}} 0.9, \mathrm{TW}_{\mathrm{V}} 0.4\right)$; webbing present, rather medium: I1 $1 / 5^{-}-2^{+} I I 1-2 I I I 1-2^{+} I V 2-1 V$; dermal ridge along toe $\mathrm{V}$ present, subarticular tubercles rather prominent, oval, all present; inner metatarsal tubercles distinct and rather short; outer metatarsal tubercles rounded, rather prominent.

Skin of snout, between eyes, side of head and anterior part of dorsum granular, more prominently granular on upper eyelids; posterior part of back and upper part of flanks granular; lower part of flanks rather smooth; dorsolateral folds that extend from the posterior corner of the eye to the entire body length on both sides, moderately developed (Figs 5, 17a, c); dorsal part of forelimb smooth, thigh, tibia and tarsus with glandular warts in longitudinal lines bearing horny spinules; distinct rictal gland posterior to corner of mouth; flat indistinct humeral glands; ventral part of throat smooth, anterior part of belly shagreened, posterior part of belly and thigh shagreened.

Colour in preservation (Figs 17a-c). Dorsum light brown in colour; lower flanks dark grey with black speckles; tympanic area dark grey; upper lip with white stripe continuing through rictal gland to above arm insertion; dorsolateral folds light brown; forelimbs, dorsal parts of thigh, tibia and foot light brown coloured; throat and margin of throat greyish-white; chest and belly greyish-white; ventral parts of thigh, tibia and foot light brownish-white; webbing dark grey with minute specks. Colour in life (Figs 19a-b). Dorsum uniform reddish-brown with black specks; tympanum and surrounding area dark brown; upper lip with white stripe continuing through yellowishwhite rictal gland to above arm insertion; iris reddishbrown with golden specks and dark patches on either side; flanks light yellowish-grey; limbs dorsally light brown with light grey cross-bands; ventral side white, throat and limbs light grey, feet and webbing dark grey.
Variation. See Table 2 for morphometric data from five adult males and three adult females. DZ 1235: dorsum dark brown in life, turned dark grey in preservation with prominent cross-bands on both hind and forelimbs; throat and chest dark grey in life, turns light grey in preservation.

Secondary sexual characters. Males: Single oval shaped nuptial pad on finger I present, cream-coloured; two vocal sacs faintly visible externally on the posterior lateral side of the throat; humeral gland weakly developed, positioned laterally on the preaxial side of the upper forelimb. Females (DZ 1145): ova white, pigmented on pole (diameter 0.7-0.9 mm, $N=10$ ).

Etymology. The species is named after an ancient name for Sri Lanka, the country of its type locality. The English word serendipity, for which the contemporary meaning is 'a fortunate discovery or an event by chance', has its earliest roots in Sanskrit, where Sri Lanka was referred to as Swavarnadveepa, and later modified by Persian merchants as Serendip. The species epithet serendipi is a noun in the genitive case.

Distribution. Hylarana serendipi is so far known only from the type locality Kudawa, Sinharaja World Heritage Site in Ratnapura dist. of Sri Lanka (Fig. 20, Table 1).

Habitat and natural history. The primary habitat type in Sinharaja World Heritage Site is broadly regarded as tropical lowland evergreen forest (Gunatilleke and Gunatilleke, 1985). The species was found on the banks of streams and in marshy areas, which were under forest cover, where it was relatively abundant during the breeding season (May-August). These marshy areas are covered with a thick layer of leaf litter. All of the type series was collected between 19:00-23:30 h.

Remarks. This species was historically considered to be conspecific with the Indian species Hylarana aurantiaca (Dutta and Manamendra-Arachchi, 1996). For more about taxonomic history see 'Remarks' under H. aurantiaca.

Hylarana temporalis (Günther, 1864)

Günther's Golden-backed frog

(Figs 17d-i, 18d-1, 19c-f, 20; Tables 1-2)

Original name and description. Hylorana temporalis Günther, 1864. The Reptiles of British India, Ray 


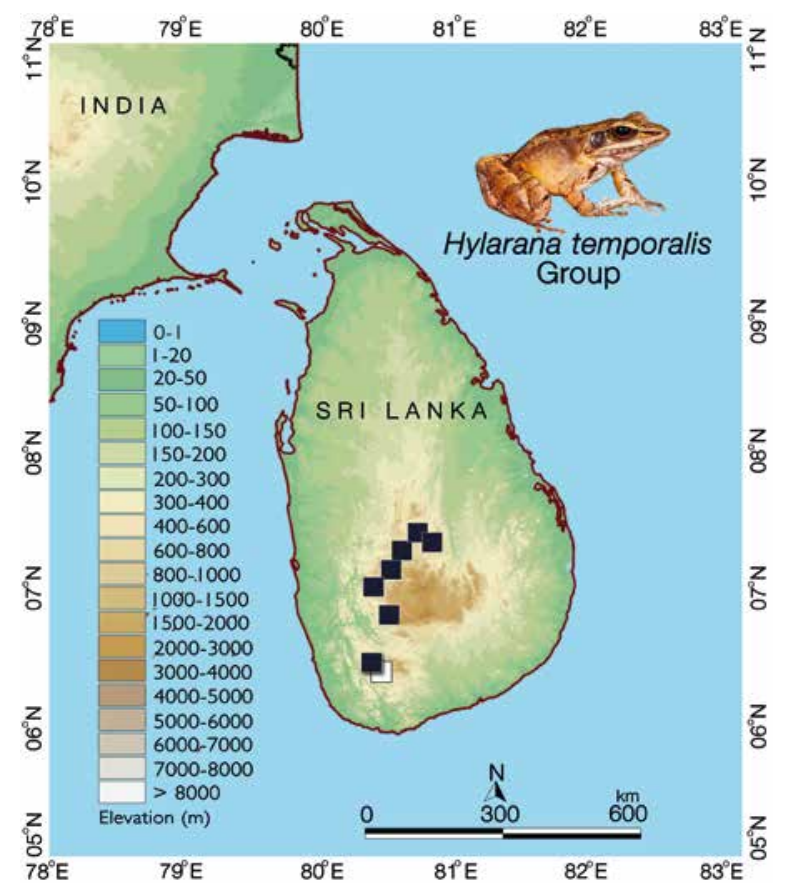

Fig. 20. Geographic distribution of two species of the Hylarana temporalis group in Sri Lanka. Open square = Hylarana serendipi ; closed square $=$ Hylarana temporalis . Coordinates are provided in Table 1 .

Society by Hardwicke, 427. Lectotype. By present designation, NHM 1947.2.2.5, an adult female, SVL 76.5 $\mathrm{mm}$, collected by Mr Cumings. Type locality. 'Ceylon' (= Sri Lanka). Current status of specific name. Valid name, as Hylarana temporalis (Günther, 1864).

Referred specimens. NHM 1947.2.29.47 and NHM 1947.2.2.6, two adult males, 'Ceylon', collected by $\mathrm{Mr}$ Cumings; NHM 1947.2.29.46 (ex BMNH 58.10.15.5), an adult female, 'Ceylon', collected by Mr Cumings; DZ 1092-1094, three adult males, DZ 1095, an adult female, Hemmathagama, Kegalle dist., collected by MM and others, 19 February 2013; DZ 1141-1142, two adult males, Kudawa, Sinharaja, Ratnapura dist., collected by MM and NW, 20 March 2013; DZ 1150-1152, three adult males, Udadumbara, Kandy dist., collected by MM and others, 18 February 2013; DZ 1046, an adult male, DZ 1047, an adult female, Kevunkahata Ela, Peradeniya, Kandy dist., collected by MM and others, 17 February 2013; DZ 1246, an adult male, DZ 1197, DZ 1240-1242, four adult females, Sarasavi Oya, Peradeniya, Kandy dist., collected by MM and others, 26 April 2013; DZ 1153, an adult male, Panwila, Kandy dist., collected by MM and others, 18 February 2013;
DZ 1116, a sub-adult, Kithulgala, Kegalle dist., collected by MM and others, 4 March 2013.

Comments. The original description does not mention the number of specimens in the type series (Günther, 1864). The present study found seven specimens, which we regard as syntypes, BMNH 52.2.19.43-44, BMNH 53.7.19.11, BMNH 58.10.15.5-6, BMNH 58.10.15 and BMNH 58.10.18, in the Natural History Museum, London, from 'Ceylon' (= Sri Lanka), collected by Cumings. Dutta (1997) lists nine specimens, whereas Dutta and Manamendra-Arachchi (1996) list six, both citing these aforementioned museum numbers with punctuation errors. In order to stabilize the nomenclatural status of this species, we designate one of the syntypes as the lectotype. Since no specimen was specifically described in more detail in the original description, we chose an adult female as the lectotype.

There was further confusion with regards to the specimen number of the lectotypified syntype, since the specimen numbers of syntypes differ between the specimen tags, jar labels and NHM register information. The specimen number according to the specimen tag is NHM 1947.2.3.5, however the jar label states NHM 1947.2.2.5 (ex BMNH 53.7.9.11). The museum register provides no resolution to the incongruences of numbers, by providing only the former number BMNH 53.7.19.11, which again differs from that provided on the specimen jar. The present study follows the specimen number on the specimen tag, since it is considered here to be more reliable.

Comparison. Hylarana temporalis could not be confused with Hylarana serendipi sp. nov., the only species of the Hylarana temporalis group to which it is closely related, due to its larger adult size (Figs 17a, d, g). See $H$. serendipi for comparison with that species. Hylarana temporalis has long been believed to occur throughout the Western Ghats of India and Sri Lanka (see 'Remarks' section) due to misidentifications of other species. However, H. temporalis differs from all the members of the Western Ghats by the presence of a rather distinct supratympanic ridge (vs. absent on all the Western Ghats species) (Figs 17f, i, 19c-f).

Genetic divergence. Intraspecific genetic variation within populations of Hylarana temporalis was $0.1 \pm$ $0.1 \%$ (range $0-0.2 \%, N=7$ ) for $16 \mathrm{~S}, 0.3 \pm 0.2 \%$ (range $0-0.7 \%, N=9$ ) for COI and $0.5 \pm 0.4 \%$ (range $0-1.3 \%$, $N=10$ ) for Cytb. Based on phylogenetic position, $H$. 
temporalis is closely related only to $H$. serendipi (Fig. 4). See $H$. serendipi for comparison with that species. Since $H$. temporalis was believed to occur throughout western India and Sri Lanka, the present study compared H.temporalis with $H$. montanus, its closest relative from India based on phylogenetic position, and found a very high genetic divergence of $11.7 \pm 0.1 \%$ (range 11.5-11.9\%, $N=42$ ) for $16 \mathrm{~S}, 20.2 \pm 0.3 \%$ (range $19.7-20.9 \%, N=54$ ) for COI and $22.8 \pm 0.4 \%$ (range 22.1-24.2\%, $N=72$ ) for Cytb (Tables S2-S3).

Description of lectotype (Figs 17d-f, 18d-f). Mediumsized, robust species, adult female (SVL 76.1). Head moderately large (HW 26.2, HL 28.7, IFE 13.5, IBE 19.7), longer than wide, flat above; snout oval from dorsal view, square (due to poor preservation) from lateral view, slightly protruding, its length (SL 11.6) longer than horizontal diameter of eye (EL 9.8); loreal region acute and concave with angular canthus rostralis; interorbital space flat, wider (IUE 6.9) than upper eyelid (UEW 5.9) and narrower than internarial distance (IN 7.6); nostril oval with flap of skin laterally, closer to tip of snout (NS 5.1) than eye (EN 6.5); tympanum (TYD 6.5) 66\% of eye diameter (EL 9.8); tympanum-eye distance (TYE 2.8); pineal ocellus absent; vomerine ridge present, bearing numerous small teeth, with an angle of $45^{\circ}$ to body axis, as close to choanae as to each other, longer than distance between them; tongue large, emarginated, bearing no median lingual process. Forelimbs moderately long and thin; forelimb (FAL 15.8) shorter than hand length (HAL 19.7); fingers rounded without lateral fringes, finger length formula II $<\mathrm{I}<\mathrm{IV}<\mathrm{III}$, finger tips dorsoventrally compressed with obtusely pointed discs and lateroventral groove, moderately wide compared to finger width $\left(\mathrm{FD}_{\mathrm{I}} 2.0, \mathrm{FW}_{\mathrm{I}} 1.2 ; \mathrm{FD}_{\mathrm{II}} 1.4, \mathrm{FW}_{\mathrm{III}} 1.2 ; \mathrm{FD}_{\mathrm{III}} 1.8\right.$, $\left.\mathrm{FW}_{\text {III }} 1.3 ; \mathrm{FD}_{\mathrm{IV}} 1.9, \mathrm{FW}_{\text {IV }} 1.2\right)$; subarticular tubercles very prominent, oval, single, all present; prepollex distinct, oval, two oval distinct palmar tubercles; a distinct supernumerary tubercle on base of each finger. Hindlimbs relatively long and thin; thigh length (TL 38.6) shorter than shank (SHL 40.5), and longer than foot (FOL 37.3); relative digit lengths $\mathrm{I}<\mathrm{II}<\mathrm{III}=\mathrm{V}<\mathrm{IV}$; toe tips dorsoventrally compressed with nearly pointed discs and lateroventral grooves, rather wide compared to toe width $\left(\mathrm{TD}_{\mathrm{I}} 2.0, \mathrm{TW}_{\mathrm{I}} 1.2 ; \mathrm{TD}_{\mathrm{II}} 2.2, \mathrm{TW}_{\mathrm{II}} 1.2 ; \mathrm{TD}_{\mathrm{III}}\right.$ $\left.2.3, \mathrm{TW}_{\text {III }} 1.2 ; \mathrm{TD}_{\mathrm{IV}} 2.2, \mathrm{TW}_{\mathrm{IV}} 1.2 ; \mathrm{TD}_{\mathrm{V}} 2.1, \mathrm{TW}_{\mathrm{V}} 1.2\right)$; webbing moderate: I1-2II1-2III1-2+IV2-1V; dermal ridge along toe $\mathrm{V}$ absent; subarticular tubercles prominent, oval, all present; inner metatarsal tubercles ovoid and short; outer metatarsal tubercles rounded, prominent; supernumerary tubercles absent; tarsal tubercles absent.
Skin of dorsal and lateral surfaces of head, anterior part of back, limbs and ventral surfaces smooth; posterior dorsum, flanks and ventral thighs weakly granular; dorsolateral folds that extend from the posterior corner of the eye to the entire body length on both sides weakly prominent; supratympanic ridge present (Fig. 17f); rictal gland present at the corner of the mouth; moderately small gland above the insertion of the forelimb, humeral glands absent.

Colour in preservation (Figs 17d-f). Dorsal surface greyish-brown; lower flanks light grey; tympanic area light grey, tympanum brown; upper lip with grey stripe continuing through rictal gland to above arm insertion; dorsolateral folds dark grey; forelimbs, dorsal parts of thigh, tibia and foot light brown, anterior part of thigh light brown with grey patches, cross-bands are weakly formed; throat and margin of throat light brown colored; chest and belly light brown; ventral parts of thigh and tibia light grey; foot and webbing light grey. Colour in life (DZ 1046) (Fig. 19d). Dorsal surface light brown with large greenish-brown patches; lower flanks light brown; tympanic area brown; upper lip with yellowish-white stripe continuing through rictal gland to above arm insertion; forelimbs, dorsal parts of thigh, tibia and foot light brown with grey spots, dark grey cross-bands; throat and margin of throat white with black flecks; chest and belly offwhite; ventral parts of thigh, tibia and foot greyishwhite with black spots; webbing dark grey with minute specks; iris lower half dark brown and upper half golden brown.

Variation. See Table 2 for morphometric data from 13 adult males and eight adult females. Considerable variation in life also reflected in preserved specimens. DZ 1092: dorsum light reddish-brown with irregular light grey and light brown spots, a distinct dark brown stripe from tip of snout to anterior corner of eye, chest and throat light brown with yellowish-brown marbling in life (Fig. 19c), dorsum turned grey in preservation; DZ 1153 and DZ 1151: dorsum light golden brown with light brown spots in life (Figs 19e-f), turned greyishbrown in preservation; DZ 1197: dorsum dark brown, throat, chest and belly grey in preservation; DZ 1242 and DZ 1047: dorsum brown, throat, chest and belly light brown with grey marbling in preservation.

Secondary sexual characters. Male: Single oval shaped nuptial pad on finger I present, cream-coloured; two vocal sacs faintly visible externally on the poste- 


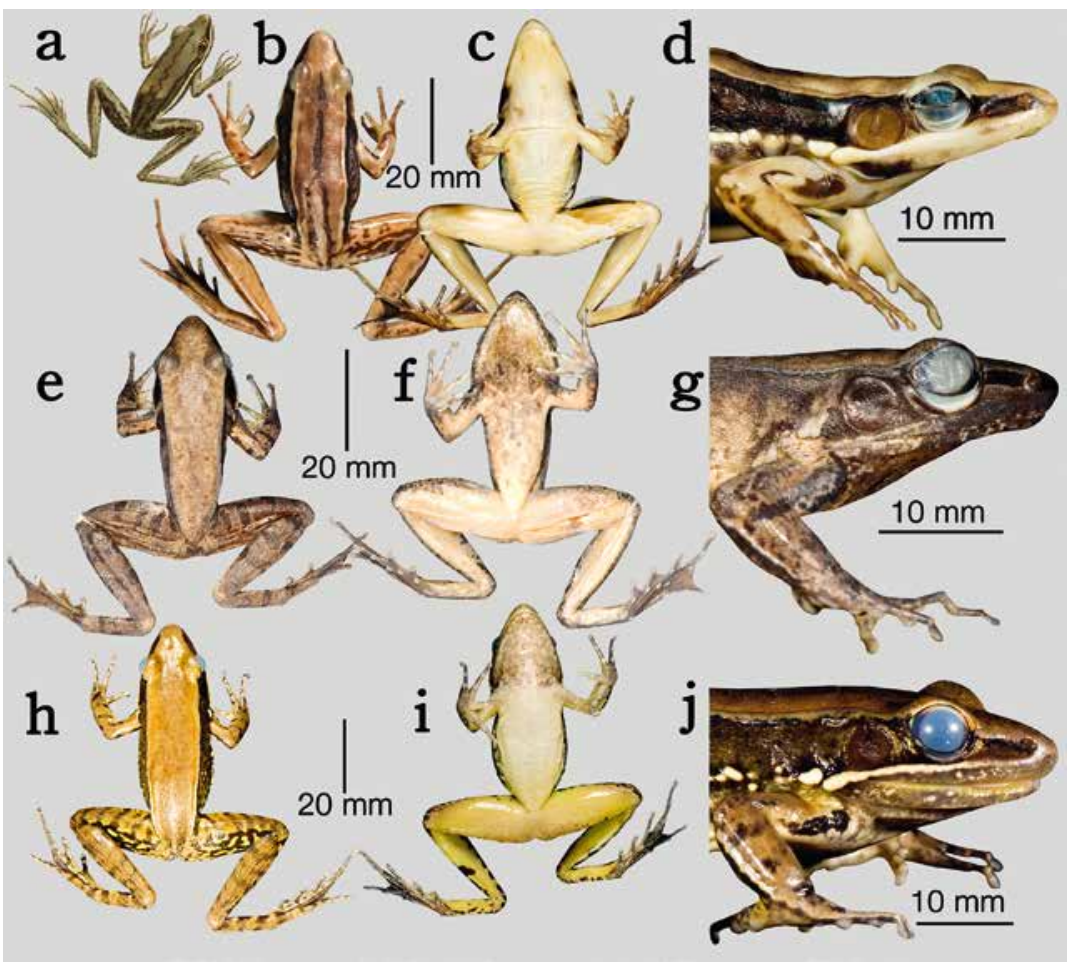

Fig. 21a-j. Hylarana gracilis: a. Rana gracilis an illustration that appeared along with the original description (Gravenhorst, 1829, Plate VIII, Figure III); b-j. dorsal view, ventral view and lateral view of head of Hylarana gracilis in preservation: b-d. referred specimen (DZ 1049): b. dorsal view, c. ventral view, d. lateral view of head, e-g. referred specimen (DZ 1080): e. dorsal view, f. ventral view, g. lateral view of head, h-j. referred specimen (DZ 1081): h. dorsal view, i. ventral view, j. lateral view of head. rior lateral side of the throat; humeral glands weakly developed, positioned laterally on the preaxial side of the upper forelimb. Female (DZ 1047): ova white, pigmented on pole (diameter 1.3-1.7 mm, $N=20$ ).

Distribution. This species is known only from Sri Lan$\mathrm{ka}$, at elevations between 40-1850 m asl. We observed this species from Kandy dist. (Kevunkahata Ela, Peradeniya; Sarasavi Oya, Peradeniya; Panwila, Wattegama; Udadumbara, Hunnasgiriya), Kegalle dist. (Kithulgala and Hemmathagama), Nuwara Eliya dist. (Morey estate, Sri Pada [Adam's Peak]), and Ratnapura dist. (Kudawa, Sinharaja) (Fig. 20, Table 1).

Habitat and natural history. This species was studied from various habitats ranging from highly disturbed lowland wayside streams, to evergreen primary forest on mountains. Two individuals were collected from emergent boulders in a forest stream. When approached they immediately jumped into the water and were observed to remain under water for about $10 \mathrm{~min}$. The breeding season starts from August-May, when males were found calling from 18:00-23:00 h, however, individuals of this species were not found in streams during the mid-monsoon when rains are heaviest.
Hylarana temporalis prefers rocky boulder strewn streams, either forested or non-forested. It is not found in marshy areas under forest cover, which at Sinharaja World Heritage Site was occupied by Hylarana serendipi. Egg clutches consisting of 800-1200 slightly green coloured eggs were found in peripheral rocky pools along these stream. Tadpoles have mouths situated ventroterminally, and are found both in the main streams and rocky pools.

Remarks. This species was also often misidentified. It was originally described from Sri Lanka and frequently reported from the Indian mainland (e.g. Boulenger, 1920; Inger et al., 1985; Daniel and Sekar, 1989; Dutta and Manamendra-Arachchi, 1996; Dutta, 1997; Chanda, 2002; Daniels, 2005; Reshmy et al., 2010, 2011). Biju (2001) raised doubts about the identity of Indian populations, discussed the large amount of intraspecific variations, and suggested a revision of the species. Our study presents strong phylogenetic and morphological support confirming that this taxon is endemic to Sri Lanka and resolves a long standing taxonomic confusion.

Hylarana malabarica group. This group can be distinguished from other peninsular Indian-Sri Lankan 
Hylarana groups, by the following suite of characters: medium-sized adult (male, SVL 44-70 mm; female, SVL 47-70 mm) body slender to robust; dorsolateral folds moderately or well developed (Fig. 5); finger discs without lateroventral grooves and tips rounded (Fig. 6); fourth toe webbing does not extend beyond the second subarticular tubercle on either side; distinct rictal gland posterior to corner of mouth; tympanic area dark brownish-black; groin reticulated light grey or dark brown, with yellow or grey patches. In a phylogenetic framework, Hylarana malabarica group can be characterised as the most basal clade of all other members of the Western Ghats + Sri Lanka Hylarana radiation. The Hylarana malabarica group contains one Sri Lankan and one radiation from the Western Ghats $(H$. gracilis $+H$. malabarica), but none of the other Indian and Sri Lankan radiations (Fig. 4).

Hylarana gracilis (Gravenhorst, 1829)

Gravenhorst's Golden-backed frog

(Figs 21a-j, 22a-c, 23a-f, 24; Tables 1-2)

Original name and description. Rana gracilis Gravenhorst, 1829. Deliciae Musei Zoologici Vratislaviensis, Fasciculus primus, continens Chelonios et Batrachia, Leopold Voss, Leipzig, 45.

Holotype. Figured in Table VIII, Figure III (Gravenhorst, 1829). Type locality. Sri Lanka. Current status of specific name. Valid name, as Hylarana gracilis (Gravenhorst, 1829).

Referred specimens. DZ 1049-1051, three adult males, Nachchaduwa, Anuradhapura dist., collected by MM and others, 17 February 2013; DZ 1107-1108, two adult males, DZ 1109, an adult female, Karawaddana, Thorayaya, Kurunegala dist., collected by MM and others, 5 March 2013; DZ 1156, an adult male, Ganemulla, Gampaha dist., collected by MM and NW, 18 February 2013; DZ 1163-1166, four adult males, Hiyare, Galle dist., collected by MM and others, 24 February 2013; DZ 1080 an adult male, DZ 1081 an adult female, Kotagala, Nuwara Eliya dist., collected by MM and others, 16 February 2013; DZ 1173 , an adult male, Udawatta Kele, Kandy dist., collected by MM and others, 1 March 2013.

Comments. Rana gracilis was described by Gravenhorst (1829) with a brief description, citing an illustration (Fig. 21a) that was not associated with a mentioned voucher specimen. Presumably, Gravenhorst (1829) did not preserve a voucher specimen and only cited an illustration. Though the original description does not state the type locality, it was subsequently restricted to 'Sri Lanka' (Dutta and Manamendra-Arachchi, 1996) or 'Ceylon' (Dutta, 1997). The present study considers the original illustration as the holotype and finds that it appears to be morphologically similar to some Sri Lankan populations of Hylarana currently regarded as Hylarana gracilis. This species is, however, quite variable especially with regards to colour and skin texture, so we identified the population from Nachchaduwa, Anuradhapura (DZ 1049) (Fig. 21b) as typical for the species, since its markings are almost identical to the original illustration.

Comparison. Hylarana gracilis is a unique member of the Hylarana malabarica group from Sri Lanka and hence could not be confused with any Sri Lankan members of this genus. It differs from H. malabarica, the sole member of this group from Indian mainland, by its dorsal skin light brown to light reddish-brown (vs. brightly coloured, dark orangish-brown or dark reddish-brown); dorsal parts of shank with glandular folds and sparse horny spinules (vs. without glandular folds and horny spinules); posterior parts of thigh faintly reticulated (vs. dorsal parts of thigh, shank and foot slightly black, strikingly different from dorsal colour, and with prominent reticulations); third toe webbing extending up to the first subarticular tubercle on the inside (vs. just above the second subarticular tubercle).

Some colour morphs (Figs 23a-f) of this species could be superficially confused with Hylarana serendipi sp. nov. and H. temporalis from Sri Lanka, however $H$. gracilis differs from $H$. serendipi by its large adult male snout-vent size, SVL 44.7-53.4 mm, $N=12$ (vs. smaller, SVL 30.1-36.9 mm, $N=5$ ), finger discs weakly developed and rounded (vs. relatively well developed and nearly pointed), fourth toe webbing extending up to the second subarticular tubercle on the outside (vs. extending beyond the second subarticular tubercle) and fifth toe webbing extending beyond the second subarticular tubercle on the inside (vs. extending up to the disc) (Figs 18b-c, 22b-c); differs from $H$. temporalis by its relatively smaller adult male, SVL 44.7-53.4 mm, $N=12$ (vs. large, SVL 48.1-68.1 mm, $N$ $=13$ ) and absence of supratympanic ridge (vs. presence) (Figs 17f, i, 21d).

Genetic divergence. Intraspecific genetic variation within populations of Hylarana gracilis was $0.4 \pm$ $0.3 \%$ (range $0-0.9 \%, N=7$ ) for $16 \mathrm{~S}, 0.5 \pm 0.3 \%$ (range $0-1.0 \%, N=7$ ) for COI and $1.2 \pm 0.9 \%$ (range $0-2.4 \%$, 


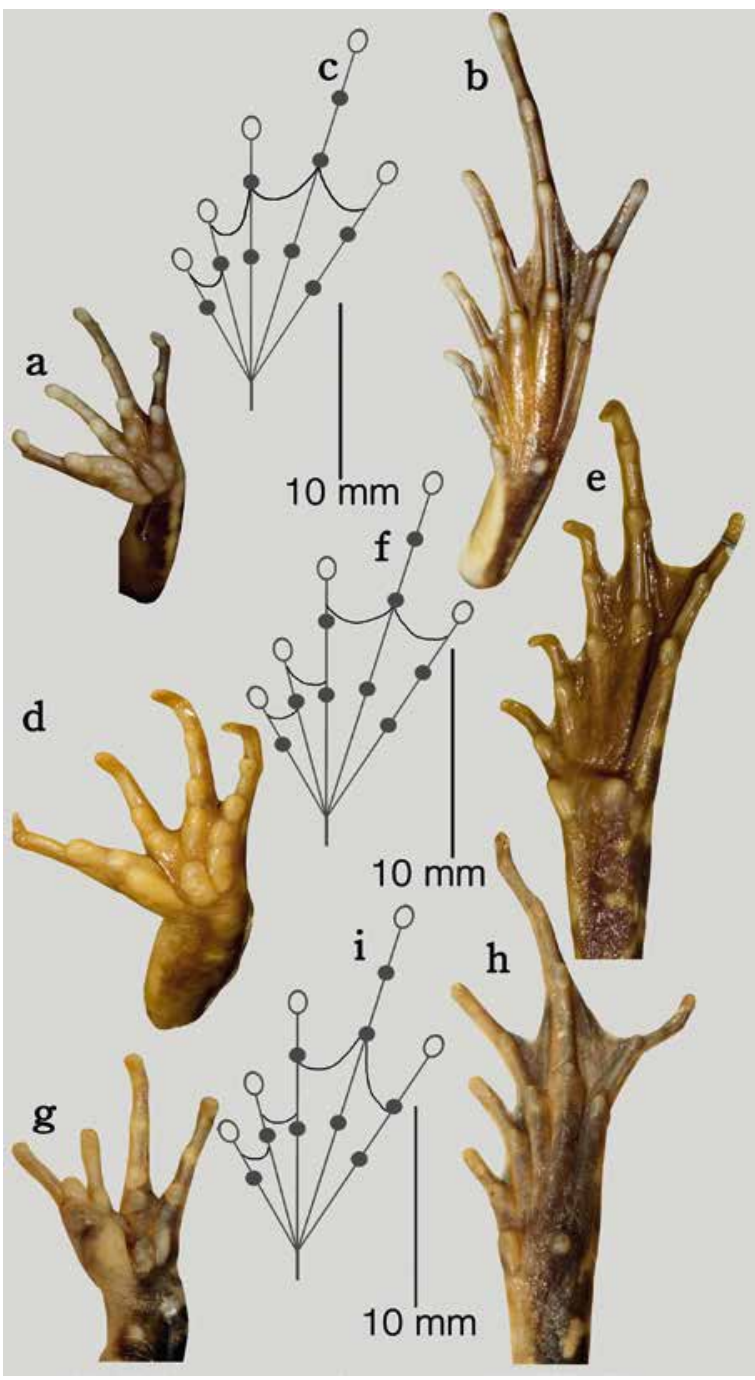

Fig. 22a-i. Ventral view of hand and foot, and schematic illustration of webbing on feet of the Hylarana malabarica group in preservation: a-c. referred specimen of $H$. gracilis (DZ 1049): a. ventral view of hand, $b$. ventral view of foot, c. schematic illustration of webbing on feet; d-f. referred specimen of $H$. malabarica (BNHS 1059): d. ventral view of hand, e. ventral view of foot, f. schematic illustration of webbing on feet; g-i. referred specimen of $H$. malabarica haplogroup 1 (BNHS 5880): g. ventral view of hand, h. ventral view of foot, i. schematic illustration of webbing on feet.

$N=7$ ) for Cytb. Based on phylogenetic position, $H$. gracilis is closely related to the Indian mainland species H. malabarica (Fig. 4). However, it differs from H. malabarica by $8.3 \pm 0.3 \%$ (range $8.0-8.8 \%, N=7$ ) for $16 \mathrm{~S}, 14.4 \pm 0.2 \%$ (range $14.3-14.9 \%, N=7$ ) for COI and $18.4 \pm 0.3 \%$ (range 18.0-18.7\%, $N=7$ ) for Cytb. Since $H$. gracilis could be superficially confused with some morphs of $H$. serendipi and $H$. temporalis, genetic divergence was compared with those species; differs from $H$. serendipi by average genetic divergence of $11.9 \pm 0.3 \%$ (range 11.6-12.3\%, $N=14$ ) for $16 \mathrm{~S}, 18.5 \pm 0.3 \%$ (range $18.0-19.2 \%, N=21$ ) for COI and $26.8 \pm 0.7 \%$ (range $25.8-27.9 \%, N=21$ ) for Cytb, and from H.temporalis by $9.7 \pm 0.3 \%$ (range $9.4-10.1 \%$, $N=49$ ) for $16 \mathrm{~S}, 20.2 \pm 0.2 \%$ (range 19.7-20.7\%, $N=63$ ) for COI and $26.5 \pm 0.4 \%$ (range $25.6-27.4 \%, N=63$ ) for Cytb (Tables S2-S3).

Description of DZ 1049 (Figs 21b-d, 22a-c). Mediumsized, moderately slender adult male (SVL 51.9). Head moderate (HW 15.8, HL 20.6, IFE 7.2, IBE 10.8), longer than wide, flat above; snout subovoid in dorsal and ventral view, rounded in lateral view, slightly protruding, its length (SL 8.6) longer than horizontal diameter of eye (EL 6.0); loreal region acute and concave with rounded canthus rostralis; interorbital space flat, wider (IUE 4.5) than upper eyelid (UEW 3.7) and subequal to internarial distance (IN 4.8); distance between back of eye (IBE 10.8) 1.5 times the distance between front of eye (IFE 7.2); nostril oval, closer to tip of snout (NS 2.8) than eye (EN 4.7); tympanum (TYD 5.8) $97 \%$ of eye diameter (EL 6.0); tympanum-eye distance (TYE 1.3); pineal ocellus present, between anterior border of eye; vomerine ridge present, bearing small teeth, with an angle of $50^{\circ}$ to body axis, as close to choanae as to each other; tongue moderately large, emarginated. Forelimbs moderately short and thin; forelimb (FAL 9.4) shorter than hand length (HAL 14.1); fingers short, finger length formula $\mathrm{I}<\mathrm{II}<\mathrm{IV}<\mathrm{III}$, tip of all fingers rounded, without lateroventral groove, slightly wide compared to finger with $\left(\mathrm{FD}_{\mathrm{I}} 1.1, \mathrm{FW}_{\mathrm{I}} 0.9 ; \mathrm{FD}_{\mathrm{II}} 0.8\right.$, $\mathrm{FW}_{\text {II }} 0.6 ; \mathrm{FD}_{\text {III }} 1.0, \mathrm{FW}_{\text {III }} 0.7 ; \mathrm{FD}_{\text {IV }} 1.0, \mathrm{FW}_{\text {IV }} 0.6$ ); dermal fringe present; subarticular tubercles prominent, oval, single, all present; prepollex distinct, oval; two oval prominent palmar tubercles well developed; a well developed supernumerary tubercle on base of each finger. Hindlimbs relatively long and thin; thigh length (TL 27.4) shorter than shank (SHL 29.8), and foot (FOL 32.4); relative digit lengths $\mathrm{I}<\mathrm{II}<\mathrm{III}<\mathrm{V}<\mathrm{IV}$; tips of all toes rounded with small discs possessing lateroventral grooves, rather wide compared to toe width $\left(\mathrm{TD}_{\mathrm{I}} 0.8\right.$, $\mathrm{TW}_{\text {I }} 0.6 ; \mathrm{TD}_{\text {II }} 0.9, \mathrm{TW}_{\text {II }} 0.7 ; \mathrm{TD}_{\text {III }} 1.0, \mathrm{TW}_{\text {III }} 0.8 ; \mathrm{TD}_{\text {IV }}$ $\left.0.9, \mathrm{TW}_{\mathrm{IV}} 0.8 ; \mathrm{TD}_{\mathrm{V}} 0.8, \mathrm{TW}_{\mathrm{V}} 0.7\right)$; webbing present, rather medium: I1 +2 III-2III2-3IV3-1 $1 / 2 \mathrm{~V}$; dermal ridge along toe $\mathrm{V}$ present, subarticular tubercles rather prominent, oval, all present; inner metatarsal tubercles distinct and rather short; outer metatarsal tubercles rounded, rather prominent. 
Skin of snout, between eyes, sides of head and anterior part of dorsum shagreened, posterior part of back, upper and lower part of flanks shagreened and sparsely granular; dorsolateral folds that extend from the posterior corner of the eye to the entire body length on both sides, well developed (Figs 5, 21b, d); dorsal part of forelimbs smooth; thigh, tibia and tarsus without glandular warts and horny spinules; distinct rictal glands posterior to corner of mouth; flat indistinct humeral glands; discontinuous glands up to groin; ventral part of throat and anterior part of belly smooth, posterior part of belly and thigh shagreened and sparsely granular.

Colour in preservation (Figs 21b-d). Dorsum light brown with one dark brown broad stripe from the anterior part of body (from between the eyes) up to the vent, a second dark brown stripe from posterior half of dorsum up to the vent; lower flanks light grey with black speckles; tympanum light brown; upper flanks dark brown; upper lip with white stripe continuing through rictal gland to above arm insertion; dorsolateral folds dark brown; forelimbs, dorsal parts of thigh, tibia and foot light brown with scattered dark brown patches, two dark brown lines on tibia from knee to the foot; posterior parts of thigh having irregular dark brown reticulations on light brown background; throat and margin of throat greyish-white; chest and belly greyish-white; ventral parts of thigh, tibia and foot light brownish-white; webbing light grey. Colour in life (Fig. 23a). Dorsum uniformly light brown with two black stripes; tympanum light brown; flanks dark brown; groin yellowish-grey; upper lip with white stripe continuing through rictal gland to above arm insertion; iris posterior half reddish-brown and anterior half golden brown; dorsal surface of limbs light brown with black spots and longitudinal lines (on tibia); ventral surface white; throat and limbs light grey; feet and webbing dark grey.

Variation. See Table 2 for morphometric data from 12 adult males and two adult females. A considerable variation in colour, markings, skin texture and webbing in three different populations: DZ 1049-1051 from Nachchaduwa, Anuradhapura is considered as typical because these match the cited illustrations along with the original description; DZ 1051, DZ 1107, DZ 1108, DZ 1156 (Fig. 23d): dorsum shagreened with short spinular projections; DZ 1050, DZ 1108, DZ 1156: discontinuous dorsal stripes; DZ 1080 (Fig. 23b)-1081 (Fig. 23e), DZ 1173: uniform dorsal colour (light brown in life, turned dark grey in preservation) with or without black longitudinal stripe, lighter brown flank compared to the typical population from Nachchaduwa, Anuradhapura, and prominent cross-bands on limbs; DZ 1080: lack of continues glands on lateral side, white patches weakly developed, chest and throat darker; DZ 1163 (Fig 23f, on left)-1166: uniform dorsal colour (dark brown in life, turned dark grey in preservation) with or without black longitudinal stripe; DZ 1164 (Fig. 23f, on right): dorsum uniform dark brown in life, turned dark grey in preservation with minute specks throughout, lateral glands absent, flank light brown in life, light grey in preservation.

Secondary sexual characters. Males: Single oval shaped nuptial pad on finger I present, cream-coloured; two vocal sacs faintly visible externally on the posterior lateral side of the throat; humeral glands weakly developed, positioned laterally on the preaxial side of the upper forelimb. Females (DZ 1109): ova white, pigmented on pole (diameter 1.0-1.3 mm, $N=20$ ).

Distribution. Hylarana gracilis is widely distributed in Sri Lanka. The present study recorded this species from Nachchaduwa, (Anuradhapura dist.), Ganemulla (Gampaha dist.), Kotagala (Nuwara Eliya dist.), Udawatta Kele (Kandy dist.), Karawaddana (Kurunegala dist.) and Hiyare (Galle dist.), at elevations between 28-1250 $\mathrm{m}$ asl (Fig. 24, Table 1).

Habitat and natural history. The primary habitat of this species is open wetland areas both in urban and secondary forest, but is not associated with flowing streams. All of the animals collected during this study were located after sunset by their advertisement call, typically heard between 19:30-22:30 h. This species also calls during the daytime, usually well hidden, and extremely difficult to locate. Bottom dwelling tadpoles have an anteroventral mouth.

Hylarana malabarica (Tschudi, 1838)

Malabar Fungoid Frog (Chari, 1962)

(Figs 22d-i, 23g-h, 24, 25a-f; Tables 1-2)

Original name and description. Rana malabarica Tschudi, 1838. Classification der Batrachier mit Berücksichtigung der fossilen Thiere dieser Abtheilung der Reptilien, Neuchâtel, Petitpierre, 40. Lectotype. By present designation, MNHN 4440, an adult female, 

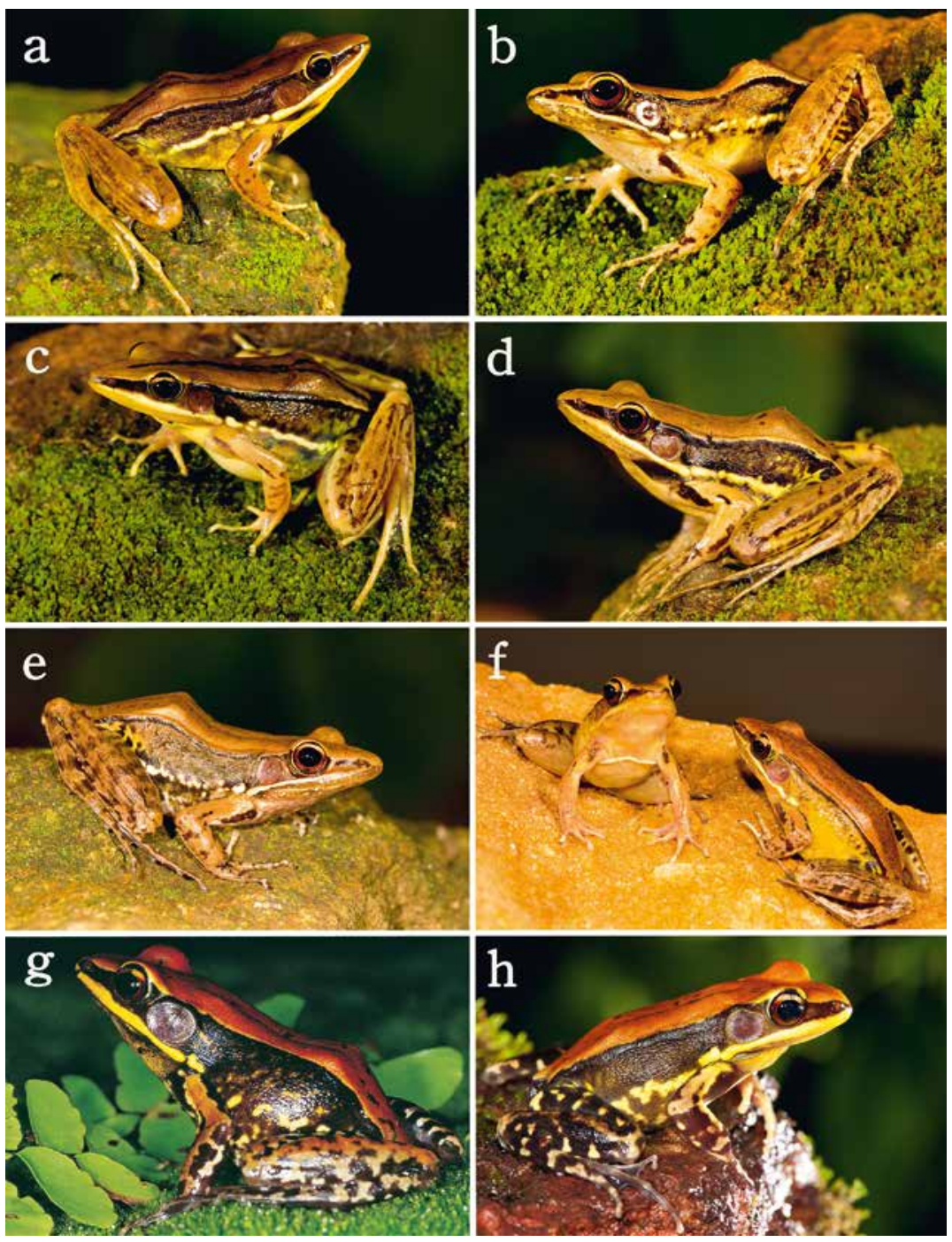

Fig. 23a-h. Hylarana malabarica group in life: a-f. Hylarana gracilis, a. dorsolateral view of referred specimen (DZ 1049, male), from Nachchaduwa, Anuradhapura, b. dorsolateral view of referred specimen (DZ 1080, male), from Kotagala, Nuwara Eliya, c. dorsolateral view of referred specimen (DZ 1109, female) from Karawaddana, Kurunegala, d. dorsolateral view of referred specimen (DZ 1156, male) from Ganemulla, Gampaha, e. dorsolateral view of referred specimen (DZ 1081, female) from Kotagala, Nuwara Eliya, f. front view (on left, DZ 1163, male) and dorsolateral view (on right, DZ 1164, male), referred specimens from Hiyare, Galle; g. Hylarana malabarica, dorsolateral view of referred specimen (BNHS 5879, female), from Meladoor, Thrissur; h. H. malabarica haplogroup 1, dorsolateral view of referred specimen (BNHS 5880, male), from Amboli, Sindhudurg (Photos: SD Biju).
SVL $69.1 \mathrm{~mm}$. Type locality. 'Malabar', India. Current status of specific name. Valid name, as Hylarana malabarica (Tschudi, 1838).

Referred specimens. Hylarana malabarica: BNHS 1059, an adult male and BNHS 1056, an adult female, Edanad, Kasaragod dist., collected by P.B. Shekar, in March 1962; SDBDU 2002.584, an adult female, Mannuthy, Thrissur dist, collected by SDB, 21 June 2002; BNHS 5879, an adult female, Meladoor, Thrissur dist., collected by SDB, 7 July 2003. Hylarana malabarica haplogroup 1: BNHS 5880 and BNHS 5883, two adult males, Amboli, Sindhudurg dist. Maharashtra state, collected by SDB and SG, 30 July 2012; BNHS 58815882 and SDBDU 2013.2373, three adult males, Amboli, Sindhudurg dist., Maharashtra state, collected by
SDB and SG, 5 July 2013; BNHS 5884 and SDBDU 2011.31, two adult males, Kachigebailu, Shimoga dist., Karnataka state, collected by SDB, 10 June 2011; SDBDU 2011.1100a, a sub-adult, Bhimashankar, Pune dist., Maharashtra, collected by SDB, 9 October 2011; SDBDU 2011.596, a sub-adult, Amarkantak, Anuppur dist., Madhya Pradesh, collected by SDB and Systematics Lab team, 23 August 2011.

Other material studied. Hylarana malabarica: BNHS 1031, Cannanore (= Kannur), Kannur dist.; BNHS 1053, Pullampora, Calicut, Kozhikode dist., collected by K.G. Adiyodi, in November 1960; BNHS 2124, Tellicherry (= Thalassery), Kannur dist., collected by Harchekar, 3 March 1973; BNHS 2146, Nilambur, Malappuram dist., collected by Whitakar, 
in 1971; BNHS 2191-2202, Begur, Mananthavady (= Mānantoddy), Wayanad dist., collected by P.B.S./Mahadik, 29 April 1975; BNHS 1051, Manalur, Palni Hills, Dindigul dist., collected by Br. Navarro. Hylarana malabarica haplogroup 1: BNHS 1043, Kanheri caves, Mumbai dist., collected by H. Abdulali; BNHS 1060, Koyna Nagar, Satara dist., collected by P.W. Soman; BNHS 4083, Amboli, Sindhudurg dist., collected by Varad Giri and V. Hedge; BNHS 1036, Ratnagiri, Ratnagiri dist., collected by Kirtikar; BNHS 1052, Khandala, Pune dist., collected by Br. Navarro; BNHS 2402, Matheran, Raigad dist., collected by I.D. Khehimkar; BNHS 4025, Phansad Wildlife Sanctuary, Raigad dist., collected by Varad Giri; BNHS 4008, Tansa WLS, Thane dist., collected by V. Giri and V. Patil.; BNHS 1997, Goa, collected by H. Abdulali.

Comments. This species was described by Tschudi (1838) from 'Malabar', India and subsequently reported from throughout the Western Ghats, central India (Dutta, 1997; Chanda, 2002; Daniels, 2005) and Meghalaya in Northeast India (Chanda, 2002). Padhye et al. (2012) discussed genetic variability in six populations of Hylarana malabarica from Maharashtra in the Western Ghats and regarded them as a complex of species due to considerable morphological and genetic differences.

We studied populations from northern parts of the Western Ghats (states of Maharashtra and Karnataka), together with new collections from Meladoor, Kerala (within the limits of one of the type localities, 'Malabar', in the southern Western Ghats). The populations sampled from northern parts of the Western Ghats (Amboli and Kachigebailu), referred to as Hylarana malabarica haplogroup 1 , were genetically different from the Hylarana malabarica typical (from Meladoor). We observed significant (3.8\% for $16 \mathrm{~S}$ ) or even considerable (3.2\% for COI and 6.3\% for Cytb) genetic variation between the two populations (Table S3), however, adequate morphological differences were not found to allow recognition of a new species in this complex, perhaps due to insufficient sampling. Therefore, the present study does not designate $H$. malabarica haplogroup 1 as a new species. More extensive surveys in the entire range of $H$. malabarica are essential to understand the real diversity in this taxon.

The original description of Rana malabarica was based on six specimens (Guibé, 1950). SDB examined the specimens present in MNHN collection, MNHN 771 and MNHN 4440 from 'Malabar', and MNHN 4439 from 'Bengale'. Considering that the syntype series consists of specimens apparently collected from the opposite limits of this 'species' geographic range, and recognizing that two distinct genetic haplogroups are now known, we hereby designate MNHN 4440 (an adult female, SVL $69.1 \mathrm{~mm}$ ) from 'Malabar' as lectotype (Fig. 25a) in order to stabilize the nomenclatural status of this taxon.

Pairwise genetic divergence has been discussed in the 'Genetic divergence' section, and morphological differences in the 'Variation' section of this species.

Comparison. As a unique species Hylarana malabarica could not be confused with other members of the Hylarana malabarica group, by the combination of its strikingly bright dorsal colouration both in life (Fig. 23 ) and in preservation (Figs 21, 25). See Hylarana gracilis for more specific comparison with that species.

Genetic divergence. Intraspecific genetic variation within populations of Hylarana malabarica could not be calculated since the present study recorded a single specimen of this species from Meladoor (part of the type locality 'Malabar'). However, populations of this species from northern parts of the Western Ghats, i.e. Hylarana malabarica haplogroup 1, were found to differ considerably and showed intraspecific genetic variation of $0.2 \pm 0.2 \%$ (range $0-0.4 \%, N=3$ ) for $16 \mathrm{~S}$, $0.2 \pm 0.1 \%$ (range $0.2-0.3 \%, N=3$ ) for COI and $1.0 \pm$ $0.7 \%$ (range $0.2-1.5 \%, N=3$ ) for Cytb; differed from the typical population by genetic divergence of $3.8 \pm$ $0.1 \%$ (range $3.7-3.9 \%, N=3$ ) for $16 \mathrm{~S}, 3.2 \pm 0.1 \%$ (range $3.1-3.3 \%, N=3$ ) for COI and $6.3 \pm 0.7 \%$ (range 5.9$7.0 \%, N=3$ ) for Cytb (Table S3). Based on phylogenetic position, $H$. malabarica is closely related to $H y$ larana gracilis from Sri Lanka (Fig. 4). See Hylarana gracilis for comparison with that species.

Description of lectotype (Fig. 25a). Medium-sized, slender to robust mature female (SVL 69.1). Head small (HW 22.2, HL 26.8, IFE 11.8, IBE 17.3), longer than wide, flat above; snout subovoid in dorsal and ventral view, rounded in lateral view, slightly protruding, its length (SL 9.8) longer than horizontal diameter of eye (EL 4.6); loreal region acute and concave with rounded canthus rostralis; interorbital space flat, subequal (IUE 5.7) to upper eyelid (UEW 5.8); distance between back of eye (IBE 17.3) 1.5 times the distance between front of eye (IFE 11.8); nostril oval, closer to tip of snout (NS 3.4) than eye (EN 5.3); eye diameter (EL 4.6) $83 \%$ of tympanum (TYD 5.5); tympanum-eye distance (TYE 


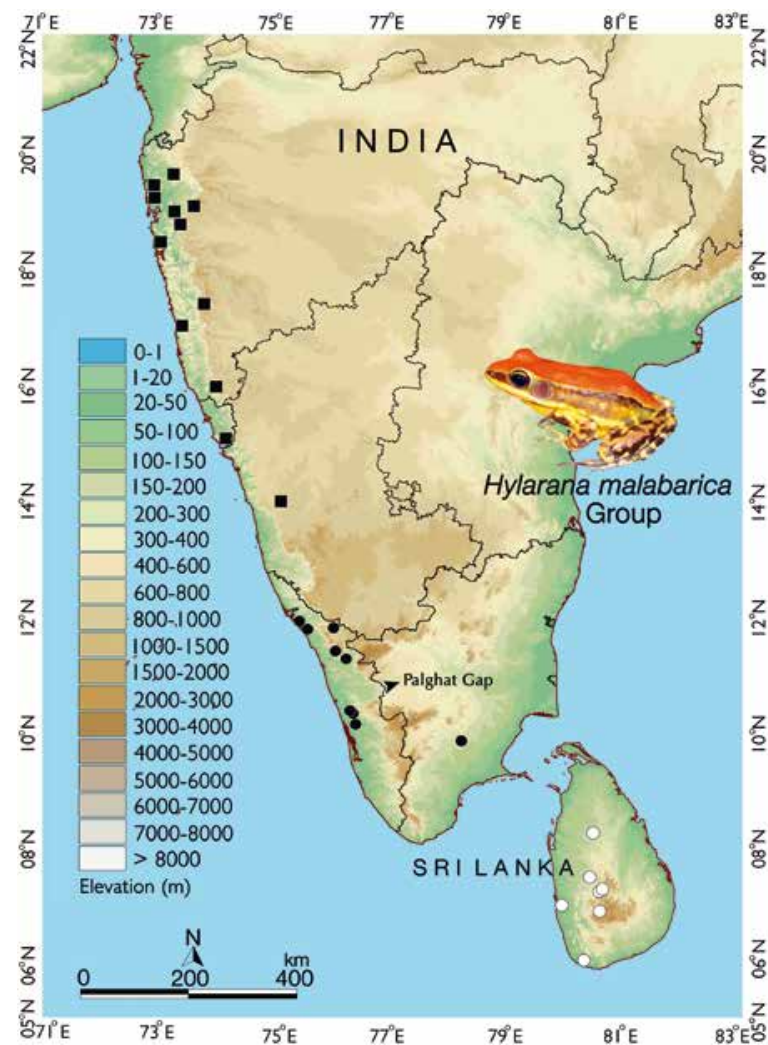

Fig. 24. Geographic distribution of the Hylarana malabarica group in Sri Lanka and the Western Ghats. Open circle $=H y$ larana gracilis, closed circle $=$ Hylarana malabarica , closed square = Hylarana malabarica haplogroup 1. Coordinates are provided in Table 1.

2.0); pineal ocellus present, between anterior border of eye; vomerine ridge present, bearing small teeth, with an angle of $40^{\circ}$ to body axis, as close to choanae as to each other, tongue moderately large, emarginated. Forelimbs moderately short and thin; forelimb (FAL 13.9) shorter than hand length (HAL 17.7); finger length formula $\mathrm{I}<\mathrm{II}<\mathrm{IV}<\mathrm{III}$, tip of all fingers rounded, without lateroventral groove, slightly wide compared to finger width $\left(\mathrm{FD}_{\mathrm{I}} 1.1, \mathrm{FW}_{\mathrm{II}} 0.9 ; \mathrm{FD}_{\mathrm{II}} 0.8, \mathrm{FW}_{\mathrm{II}} 0.6\right.$; $\mathrm{FD}_{\text {III }} 1.0, \mathrm{FW}_{\text {III }} 0.7 ; \mathrm{FD}_{\text {IV }} 1.0, \mathrm{FW}_{\text {IV }} 0.6$ ); subarticular tubercles prominent, oval, single, all present; prepollex distinct, oval; two oval prominent palmar tubercles well developed. Hindlimbs relatively long and thin; thigh length (TL 28.7) shorter than shank (SHL 32.7), and foot (FOL 32.5); relative digit lengths $\mathrm{I}<\mathrm{II}<\mathrm{III}<\mathrm{V}<\mathrm{IV}$; tips of all toes rounded without lateroventral grooves, slightly wide compared to toe width $\left(\mathrm{TD}_{\mathrm{I}} 0.8, \mathrm{TW}_{\mathrm{I}} 0.6 ; \mathrm{TD}_{\text {II }} 0.9, \mathrm{TW}_{\mathrm{II}} 0.6 ; \mathrm{TD}_{\text {III }} 1.0, \mathrm{TW}_{\text {III }}\right.$ $\left.0.8 ; \mathrm{TD}_{\mathrm{IV}} 0.9, \mathrm{TW}_{\mathrm{IV}} 0.8 ; \mathrm{TD}_{\mathrm{V}} 0.8, \mathrm{TW}_{\mathrm{V}} 0.7\right)$; webbing present, rather medium: $\mathrm{I1}^{+}-2^{+} \mathrm{II} 1^{2} / 3^{-}-2^{2} / 3 \mathrm{III} 1^{2} / 3-3 \mathrm{IV} 3-2-\mathrm{V}$; dermal ridge along toe $\mathrm{V}$ present, subarticular tubercles rather prominent, oval, all present; inner metatarsal tubercles distinct and rather short; outer metatarsal tubercles rounded, rather prominent.

Skin of snout, between eyes, sides of head and anterior part of dorsum shagreened; posterior part of back, upper and lower parts of flanks shagreened and sparsely granular; dorsolateral folds that extend from the posterior corner of the eye to the entire body length on both sides, moderately developed (Figs 5, 25a); dorsal surface of forelimbs smooth; thigh, tibia and tarsus shagreened and sparsely glandular; distinct rictal gland posterior to corner of mouth; ventral surface of throat smooth, anterior parts of belly shagreened, posterior part of belly and thigh granular.

Colour in preservation (Fig. 25a). Dorsum greyishbrown with light brown spots, lower flanks light brownish-black with creamy-white speckles; tympanum light brown; upper flanks light brown; upper lip with white stripe continuing through rictal gland to above arm insertion; dorsal part of forelimbs light brown with scattered greyish-brown markings; thigh dark brown coloured with scattered light greyishbrown patches; throat and margin of throat greyishwhite; chest and belly greyish-white; ventral parts of thigh, tibia and foot light brownish-white. Colour in life (BNHS 5879) (Fig. 23g). Dorsum uniform reddishbrown with two black spots; tympanum light brown; flanks dark blackish-brown, groin dark brownishblack with light yellow patches; upper lip with yellow stripe continuing through yellow rictal gland to above arm insertion; iris posterior half reddish-brown and anterior half golden brown; limbs dorsally light brown with black spots; ventral side of throat and belly light grey; limbs light grey; feet and webbing dark grey.

Description of BNHS 5880 (Figs 22g-i, 25e-f). Medium-sized, slender adult male (SVL 55.1). Head moderately large, (HW 19.3, HL 20.5, IFE 9.1, IBE 13.6), longer than wide, flat above; snout subovoid in dorsal and ventral view, rounded in lateral view, protruding, its length (SL 8.7) longer than horizontal diameter of eye (EL 5.5); loreal region acute and concave with rounded canthus rostralis; interorbital space flat, wider (IUE 4.6) than upper eyelid (UEW 4.4) and narrower than internarial distance (IN 4.9); distance between back of eye (IBE 13.6) 1.5 times the distance between front of eye (IFE 9.1); nostril closer to tip of snout (NS 3.0) than eye (EN 4.3); tympanum (TYD 5.6) nearly 
equal to eye diameter (EL 5.5); tympanum-eye distance (TYE 1.0); pineal ocellus present, between anterior border of eye; vomerine ridge present, bearing small teeth, with an angle of $45^{\circ}$ to body axis, as close to choanae as to each other; tongue moderately large, emarginated. Forelimbs short and thin; forelimb (FAL 12.4) shorter than hand length (HAL 15.3); fingers long, finger length formula II $<\mathrm{I}<\mathrm{IV}<\mathrm{III}$, tips of all fingers rounded, without lateroventral groove; dermal fringe absent; subarticular tubercles rather prominent, oval, single, all present; two oval distinct palmar tubercles well developed; a distinct supernumerary tubercle on base of each finger (Fig. 22g). Hindlimbs relatively long; thigh length (TL 25.9) shorter than shank (SHL 25.8), and shorter to foot (FOL 26.3); relative digit lengths $\mathrm{I}<\mathrm{II}<\mathrm{III}<\mathrm{V}<\mathrm{IV}$; tips of all toes rounded without lateroventral grooves; webbing present, rather medium: $\mathrm{I}^{1} /{ }_{2}-2+\mathrm{II}^{2} /{ }_{3}-2^{4} / \mathrm{III} 2-3 \mathrm{IV} 3-2 \mathrm{~V}$; dermal ridge along toe $\mathrm{V}$ absent, subarticular tubercles rather prominent, oval, all present; inner metatarsal tubercles distinct and rather short; outer metatarsal tubercles rounded, rather prominent; supernumerary tubercles absent; tarsal tubercles absent.

Skin of snout, between eyes, sides of head shagreened, anterior part of dorsum finely shagreened to sparsely granular, posterior part of back finely glandular; upper parts of flank finely granular; dorsolateral folds that extend from the posterior corner of the eye to the entire body length on both sides, moderately developed (Figs 5, 25e-f); dorsal parts of thigh, shank and foot weakly glandular; distinct rictal gland posterior to corner of mouth; humeral glands prominent; ventral part of throat slightly granular, lower part of belly and posterior parts of thigh granular.

Colour in preservation (Figs 25e-f). Dorsum brownish-orange; lower flanks dark grey with light yellow spots; tympanic area dark brownish-black; upper lip with white stripe continuing through rictal gland to above arm insertion; dorsal part of forelimbs creamywhite with grey cross-bands; dorsal parts of thigh, tibia and foot black with white patches; throat and margin of throat, chest and belly creamy-white; ventral part of throat, chest and belly greyish-white; hands and ventral parts of tibia and foot light grey with black spots; webbing dark grey with minute specks. Colour in life (BNHS 5880) Fig. 23h). Dorsum dark brownishorange; lower flanks dark brownish-black with yellow spots; tympanic area dark brownish-black; upper lip with yellowish-white stripe continuing through yellow coloured rictal gland to above arm insertion; dorsal part of forelimbs light yellowish-brown with brown cross-bands; dorsal parts of thigh, tibia and foot dark brownish-black with yellow reticulation; throat and margin of throat yellowish-white with black flecks; chest and belly whitish-yellow; ventral parts of thigh, tibia and foot grey with light grey spots; webbing dark grey with minute specks; iris reddish-brown.

Variation. See Table 2 for morphometric data from eight adult males (one H. malabarica + seven H. malabarica haplogroup 1) and four adult females (H. malabarica). SDBDU 2011.31: Dorsum dark brownish-orange with scattered dark brown spots; upper and lower flanks granular, ventral surface with prominent dark grey patches mosaicked with creamy-white colour, ventral parts of thigh, tibia and foot light brownishblack with creamy-yellow reticulations; BNHS 5883, dorsum light brownish-orange with irregular black spots; BNHS 5882 and BNHS 5884, dorsal parts of back brownish-orange dorsum with scattered spots; $H$. malabarica haplogroup 1 differs from the typical by its third toe webbing up to the first subarticular tubercle on the outside (vs. extending well beyond the first subarticular tubercle) and fifth toe webbing up to the first subarticular tubercle on the inside (vs. extending beyond the first subarticular tubercle).

Secondary sexual characters. Males: Single oval shaped nuptial pad on finger I present, cream-coloured; two vocal sacs faintly visible externally on the posterior lateral side of the throat; humeral glands weakly developed, positioned laterally on the preaxial side of the upper forelimb. Females (SDBDU 2002.584): ova white, pigmented on pole (diameter 0.7-1.0 mm, $N=20$ ).

Distribution. We collected this species from Meladoor and Mannuthy in Thrissur dist., Kerala state. This study identified other distribution records by morphological examination of museum specimens from Kerala: Edanad, Kasaragod dist; Cannanore (= Kannur), Kannur dist.; Tellicherry (= Thalassery), Kannur dist.; Pullurampara, Kozhikode dist.; Nilambur, Malappuram dist.; Mananthavady (= Mānantoddy), Wayanad dist.; Tamil Nadu: Manalur, Palni Hills, Dindigul dist.; Karanataka: Manipal, Udupi dist. Hylarana malabarica haplogroup 1 has so far been found to occur in northern Karnataka (Kachigebailu), Maharashtra (Amboli, Bhimashankar and Tungareshwar WLS) and Madhya Pradesh (Amarkantak). Other distribution records based on morphological examination of museum specimens include: Kanheri Caves (Mumbai dist.), 


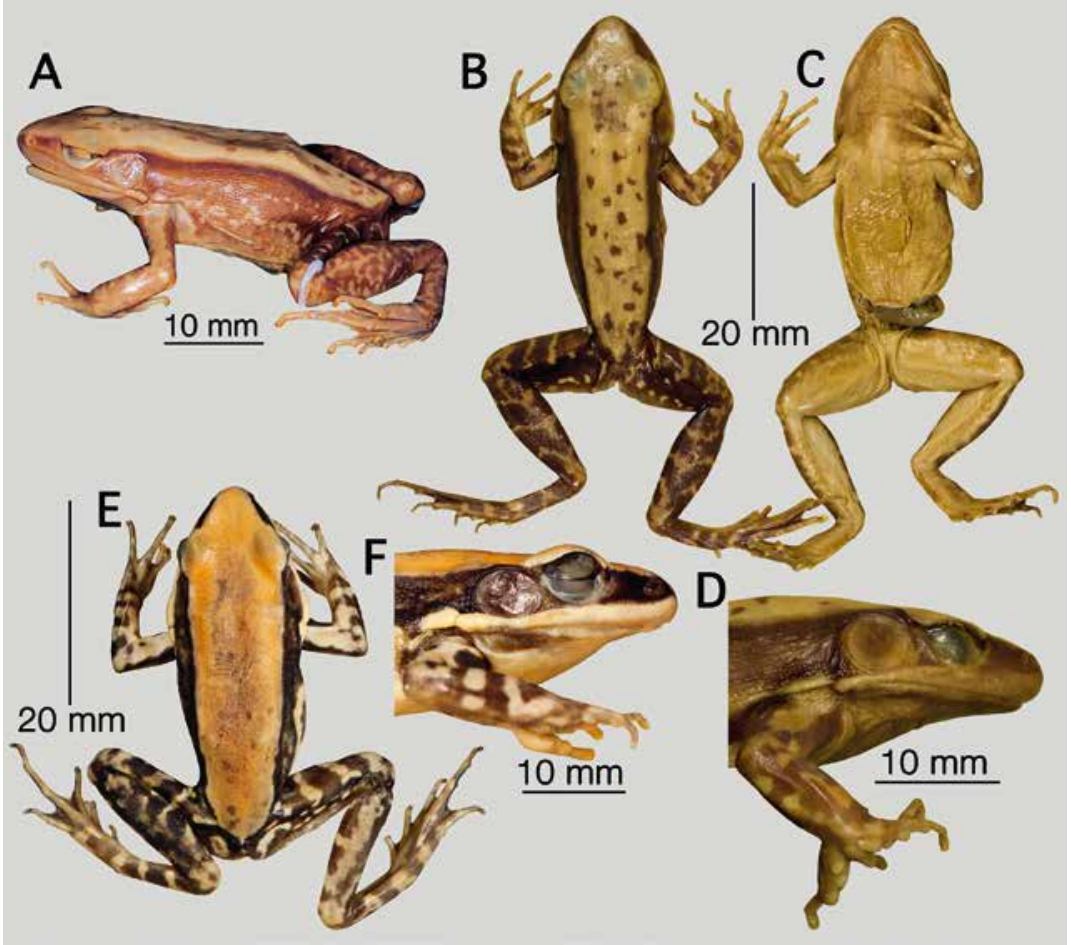

Fig. 25a-f. Hylarana malabarica: a. dorsolateral view of lectotype of Rana malabarica $(=$ Hylarana malabarica $)$ (MNHN 4440); b-d. referred specimen of H. malabarica (BNHS 1059): b. dorsal view, c. ventral view, d. lateral view of head; e-f. referred specimen of $H$. $m a$ labarica haplogroup 1 (BNHS 5880): e. dorsal view, f. lateral view of head.
Khandala (Pune dist.), Matheran and Phansad WLS (Raigad dist.), Ratnagiri (Ratnagiri dist.), Koyna Nagar (Satara dist.), Tansa WLS (Thane dist.) and Goa (Fig. 24, Table 1). Species identification for SDBDU 2011.596 from Madhya Pradesh was confirmed by molecular data, and the distribution table includes this record (Fig. 4).

Habitat and natural history. The present study reports Hylarana malabarica from disturbed habitats, mainly in human inhabited areas. Specimens were collected between 18:00-21:00 $\mathrm{h}$ from a permanent water body near a paddy field or roadside man-made pond. Popula- tions of $H$. malabarica haplogroup 1 were also mostly studied from disturbed habitats, including wayside streams (BNHS 5880-5883), and secondary forest (BNHS 5884 and SDBDU 2011.31). Individuals of this species were found both in temporary (BNHS 58805883) and permanent water bodies (BNHS 5884 and SDBDU 2011.31), often associated with floating vegetation, but none were found in fast flowing streams. We found individuals aggregating near water bodies immediately after monsoon showers. Males called continuously after sunset until approximately 23:00 h. During the dry season this species could not be found in areas where they were abundant during the monsoons season. 


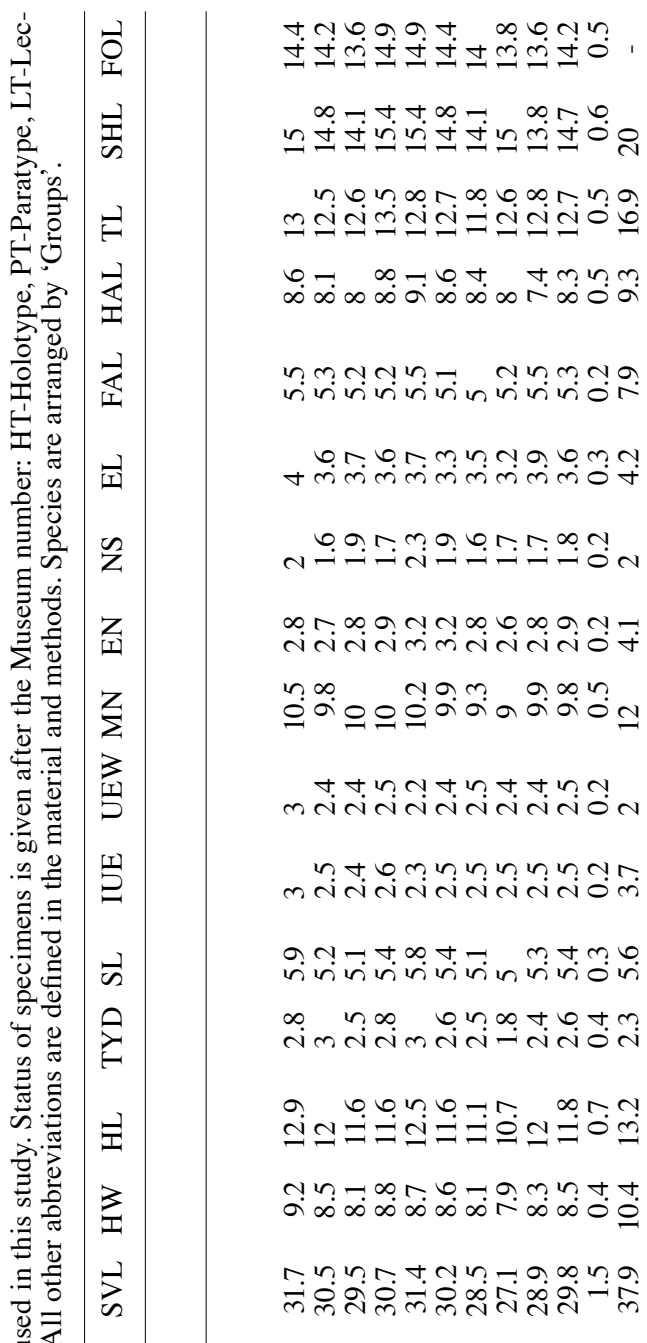

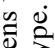

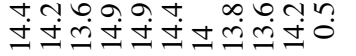

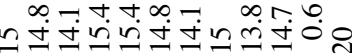

in 0 in $\infty \mathrm{N} \infty 6 \infty \mathrm{n}$ in

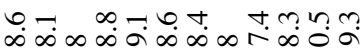

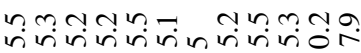

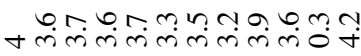
n

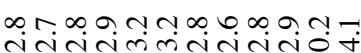

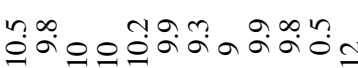

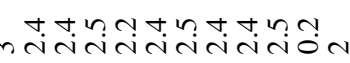

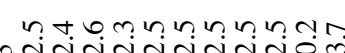
유

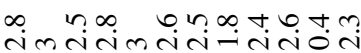

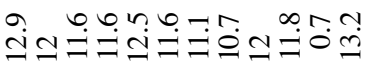
ํำ

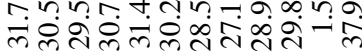

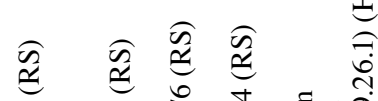

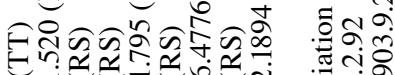 च-

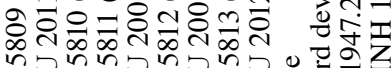

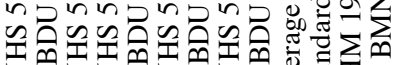

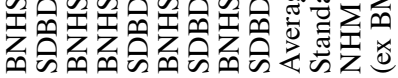

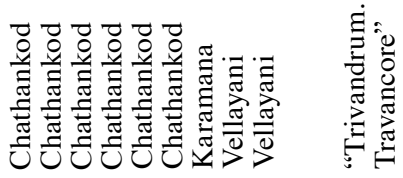

$\Sigma \Sigma \Sigma \Sigma \Sigma \Sigma \Sigma \Sigma \Sigma \quad$ I

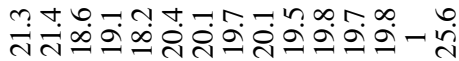

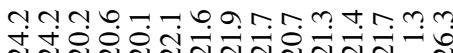
$\infty$ - $m m+\infty n n a n$ in

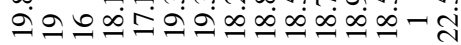

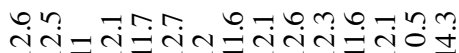

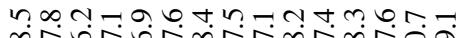

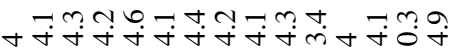

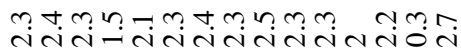

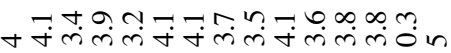
Noba Nabna

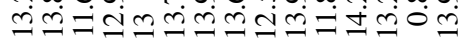

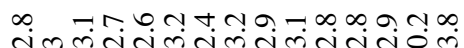
감ำ

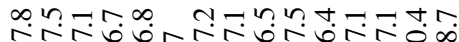

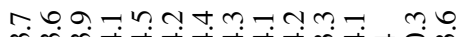

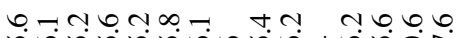
ํํำำ m

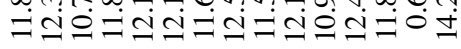
भ



$\Sigma \Sigma \Sigma \Sigma \Sigma \Sigma \Sigma \Sigma \Sigma \Sigma \Sigma \Sigma \Sigma$

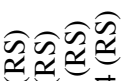

EFEFEFEO

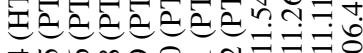

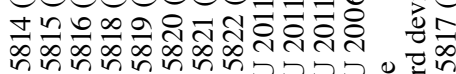
. ํㅗㅇ

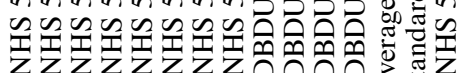

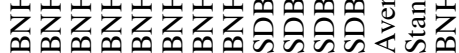
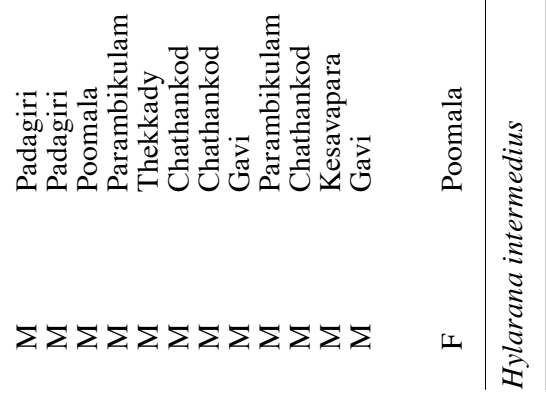

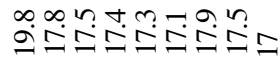

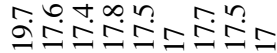

mon $a$ in an

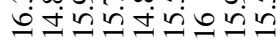

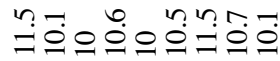

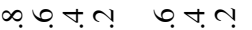
0.000 ด

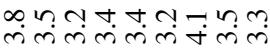

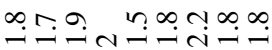

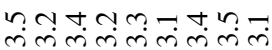

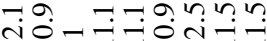

กับ

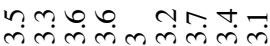

n

ก- m

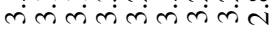

$0, m-a, 0, \pi$

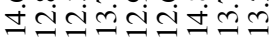

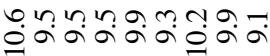

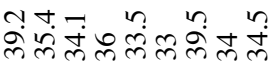

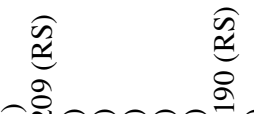

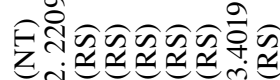

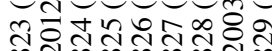

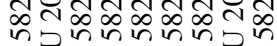

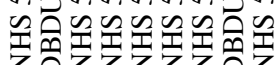

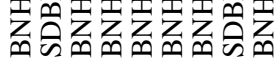

$\exists=\stackrel{ }{\exists}$

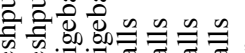

बे

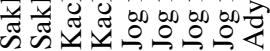

$\Sigma \Sigma \Sigma \Sigma \Sigma \Sigma \Sigma \Sigma \Sigma$ 
- Thagagontr

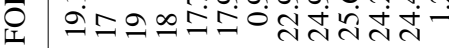

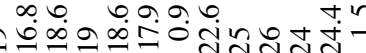

-

\&

\

在

-

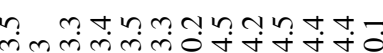

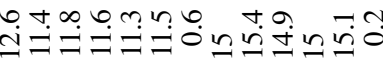

3

聍

龱

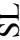

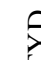

$\nexists$

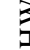

is

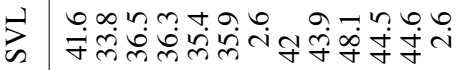
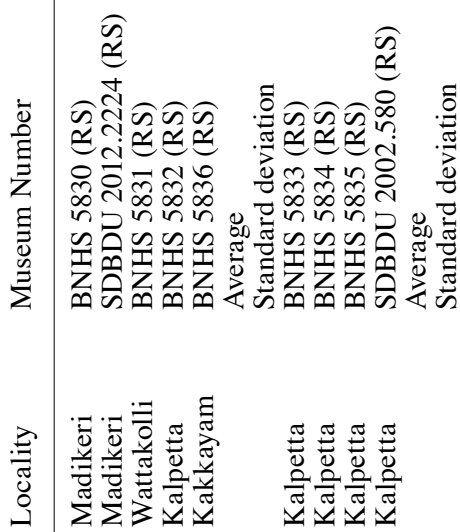

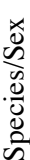

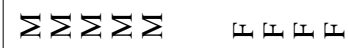

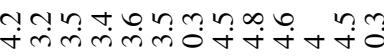

تேำ

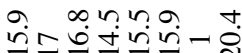

an $\infty+m a m$

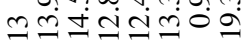

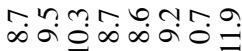

$m \infty n \infty \infty, \infty, \infty$ vivio $\dot{0}$ in

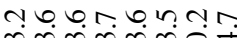

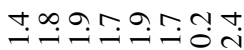

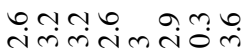
ån

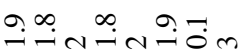

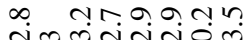
or $\infty-6 \operatorname{lom} \infty$ vivinivio

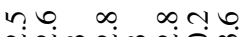
$m \infty \infty$. ㄸำำำ

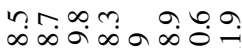

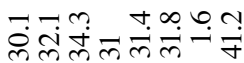
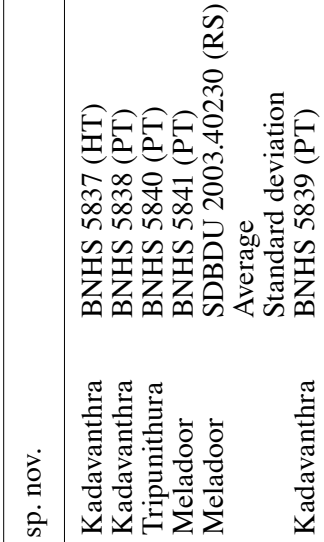

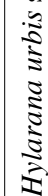

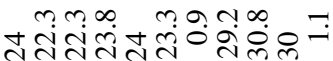
nto badnct.

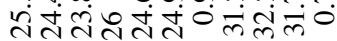

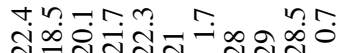
n⿻m

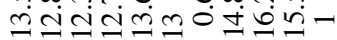

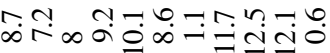

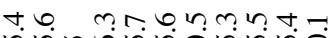
rivino in irio in inio

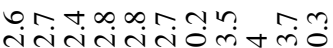

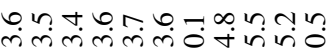
n $+\infty-\infty-\infty$ n N N 어ำ约向

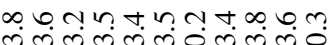

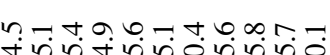

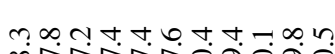

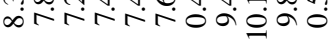

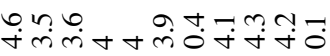

ㄴ.t.

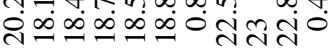

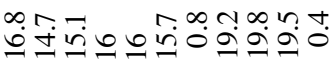

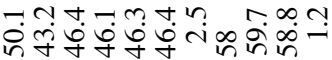
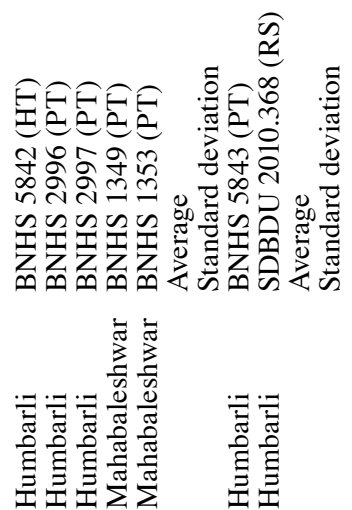

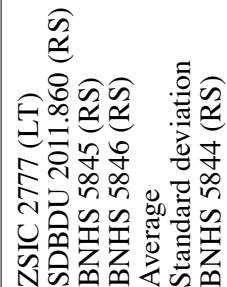

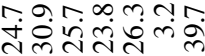

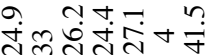

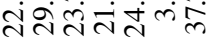

$\infty \infty, a-a r$ ํํำํํ்

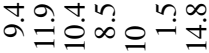

ก

nก- ทnन

लंभिलmं

๓ฺ̣

ㄱ. $\operatorname{no} \infty$

ㅂํํำด ำ่

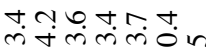

no n

mก tin

응 $\infty$

min

ก

ำ่ำ่ำ่

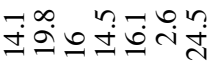

ทำㅇำ

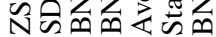

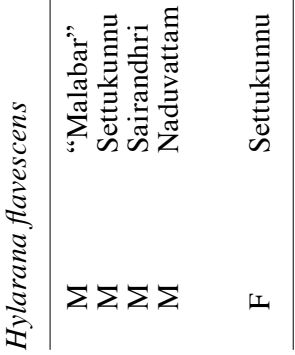

Nin

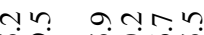




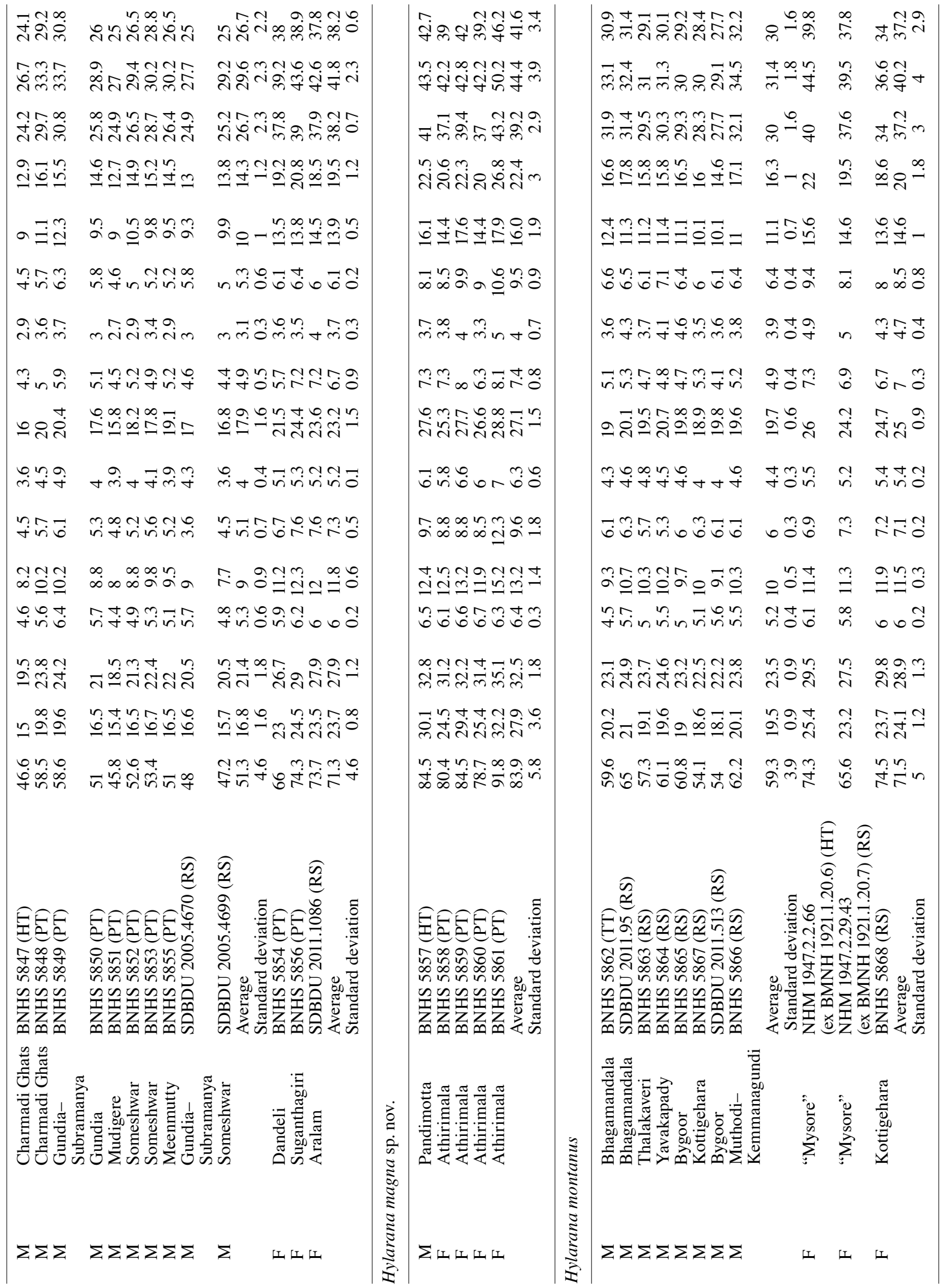



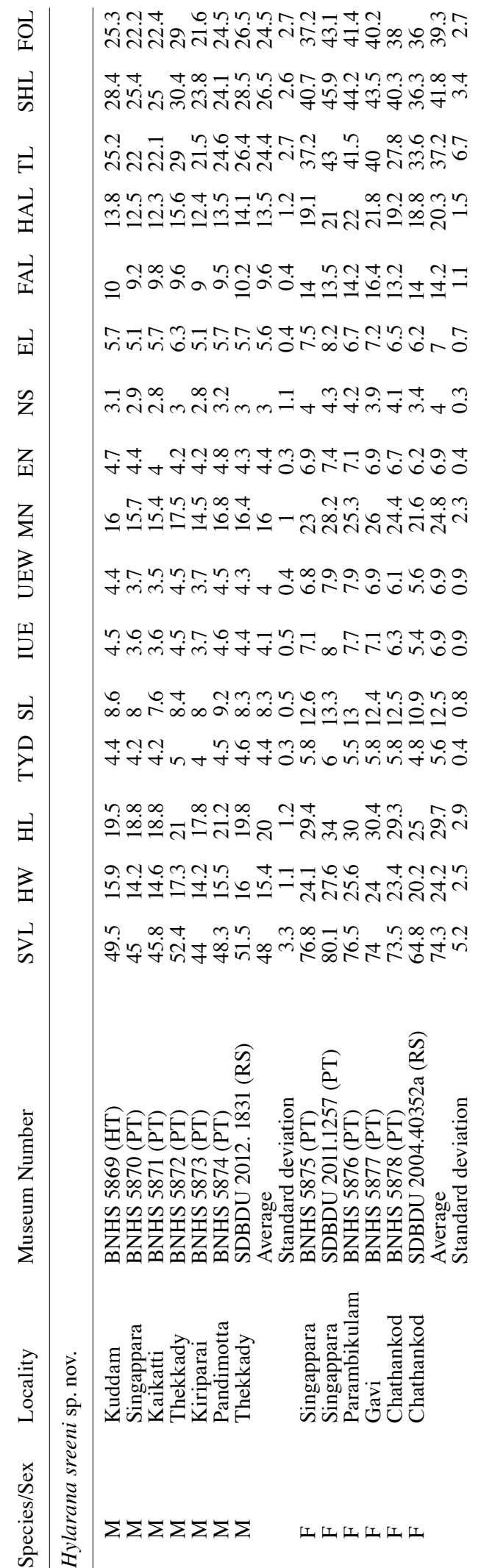

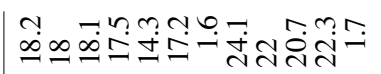

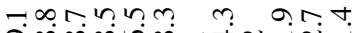

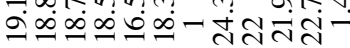

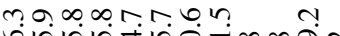

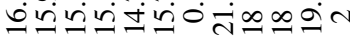

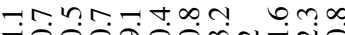
$\exists \circ 00000 \dot{0}$

-

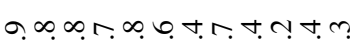

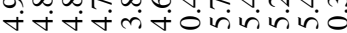

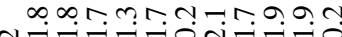

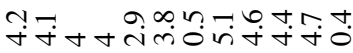

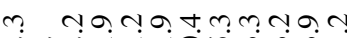
ำบำำตำ-

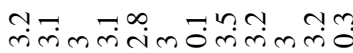

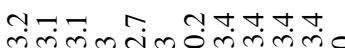
ํำ $n+t n \infty m m i \infty+6 \mathrm{C}$

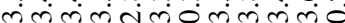

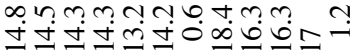

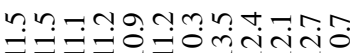

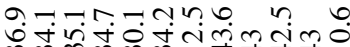
mmmmm
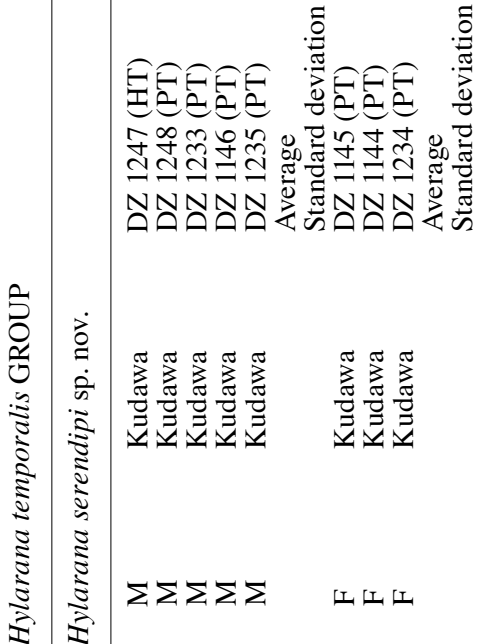

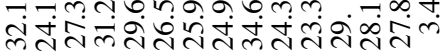

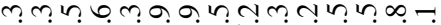

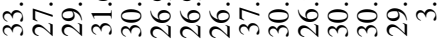

$m \infty+m+0 m m \infty m \sim a-m n$

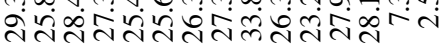

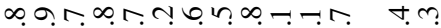

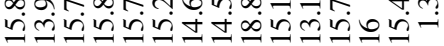

ำดेतู

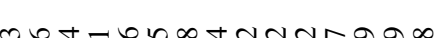
ن

$m a+r m-7+\infty \infty \infty m 0$

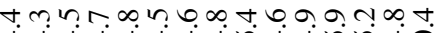

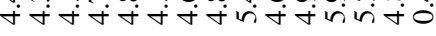

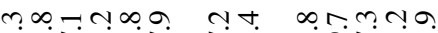

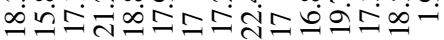

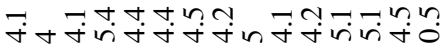
भु+

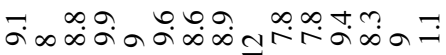

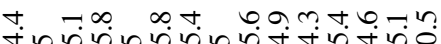

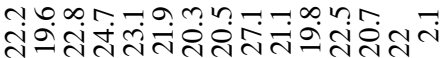
$-\infty 0$ ar ammomtn

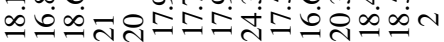

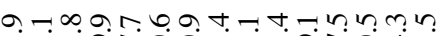

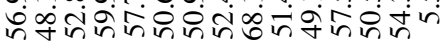

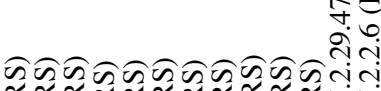

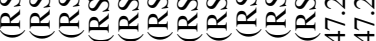

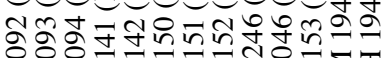

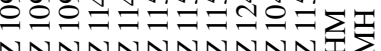

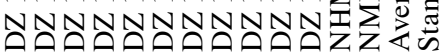

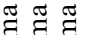

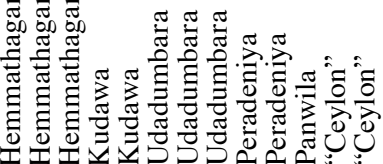




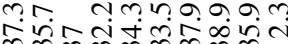
mintor

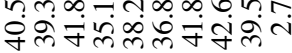
o. anon tan mं लिखं N-t.

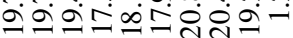

$\infty m \infty$, $\infty$, ம்

ă मำ

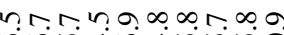
6ं

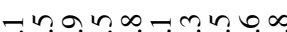

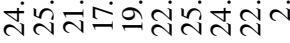

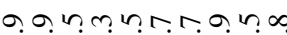
जि ดัก 브큼ํํำำ nกल

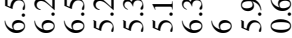

No.

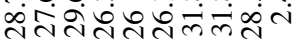

ㄱa mกtস

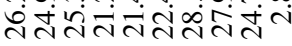

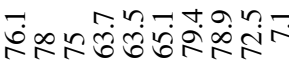

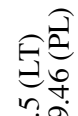

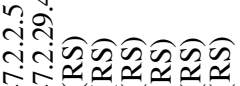
.

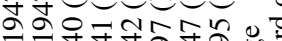

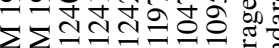

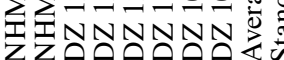

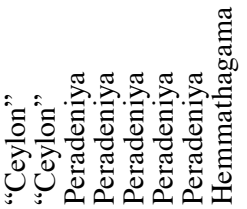

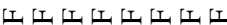

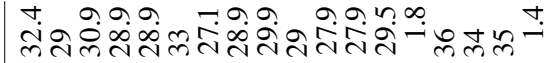

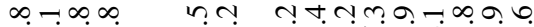

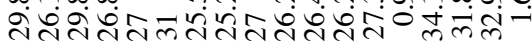

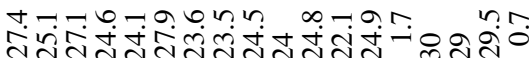
-n $\infty$ N Not

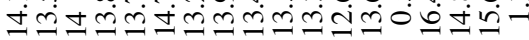

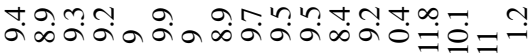

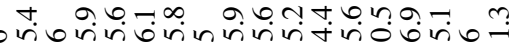
$\infty \infty \infty$ m तं तं

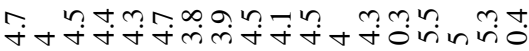
m- - ำ

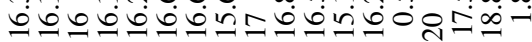

r.

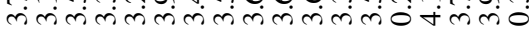

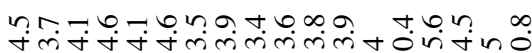

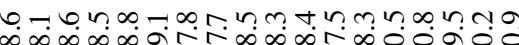
$\infty+a n$ nnnnn

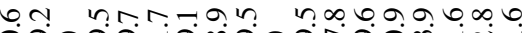

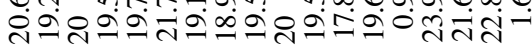

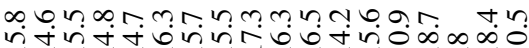
a

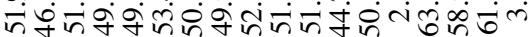

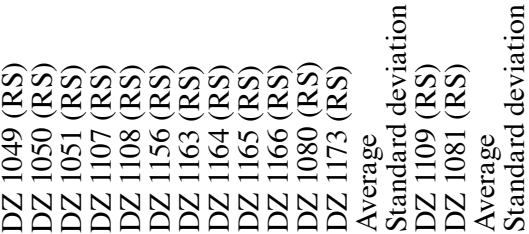

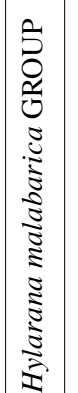

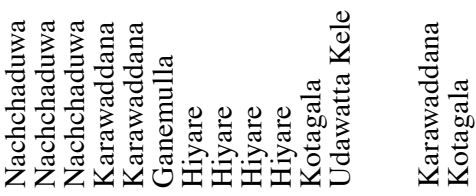

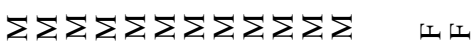

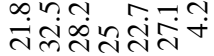
$\operatorname{nindanm}$

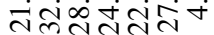

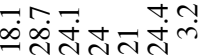
ํํำำำง

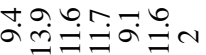
부요

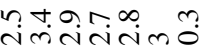

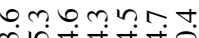

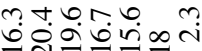
n),$\infty$ o. $\forall \dot{+} \dot{\theta}+\dot{0}$

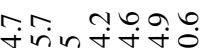

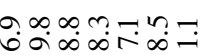
는

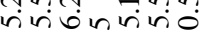

$\infty$ a a inn बेंतें

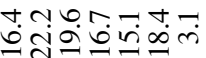

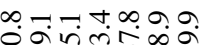

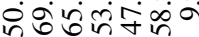

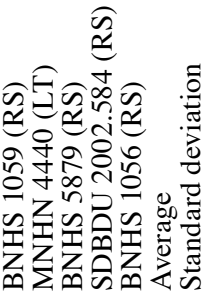

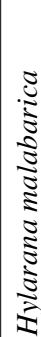

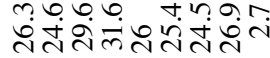
$\infty-\pi$ anntand

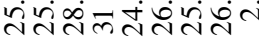
$a m-\infty$ in no bin

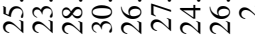
m ก ก ก

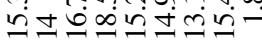

tang

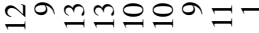

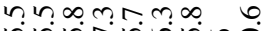
nivitionio

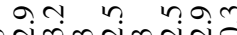
mmandmun

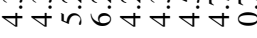

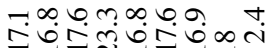

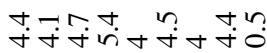

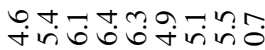

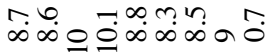

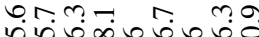

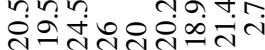

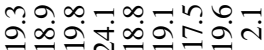

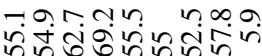

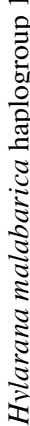


SI 1. List of sequences used in the study for intra and interspecific pairwise comparisons, barcoding and molecular phylogeny of Hylarana species.

Present study

Hylarana aurantiaca

Hylarana flavescens

Hylarana gracilis

Hylarana indica sp. nov.

Hylarana intermedius

Hylarana magna sp. nov.

Hylarana malabarica

Hylarana malabarica haplogroup 1

Hylarana montanus
Collection Locality Voucher No.

BNHS 5811

BNHS 5812

SDBDU 2011.520

SDBDU 2006.309

SDBDU 2006.4776

SDBDU 2011.277

BNHS 5813

SDBDU 2004.4527

BNHS 5842

SDBDU 2004.4510b

SDBDU 2010.361

BNHS 5820

BNHS 5821

BNHS 5822

SDBDU 2011.1169

BNHS 5815

SDBDU 2006.4845a

SDBDU 2006.4845b

SDBDU 2011.540

BNHS 5818

BNHS 5817

BNHS 5819

BNHS 5846

BNHS 5844

BNHS 5845

SDBDU 2011.1228

DZ 1164

DZ 1156

DZ 1107

DZ 1080

DZ 1049

DZ 1050

DZ 1173

SDBDU 2008.419

BNHS 5855

SDBDU 2011.1086

BNHS 5848

BNHS 5854

SDBDU 2005.4670

BNHS 5850

SDBDU 2011.49

SDBDU 2003.1446

BNHS 5851

BNHS 5852

BNHS 5856

SDBDU 2011.1407

SDBDU 2011.203

BNHS 5825

BNHS 5836

BNHS 5832

BNHS 5830

BNHS 5823

SDBDU 2011.216

BNHS 5831

BNHS 5861

SDBDU 2002.2050

SDBDU 2008.1929

BNHS 5857

SDBDU 2012.899

BNHS 5879

SDBDU 2011.596

BNHS 5880

SDBDU 2011.1100a

SDBDU 2011.31

SDBDU 2011.95

BNHS 5862

BNHS 5865

Acc. No

$16 \mathrm{~S}$

KM068907

KM068908

KM068909

KM068910

KM068911

KM068912

KM068913

KM068914

KM068915

KM068916

KM068917

KM068918

KM068919

KM068920

KM068921

KM068922

KM068923

KM068924

KM068925

KM068926

KM068927

KM068928

KM068929

KM068930

KM068931

KM068932

KM068933

KM068934

KM068935

KM068936

KM068937

KM068938

KM068939

KM068940

KM068941

KM068942

KM068943

KM068944

KM068945

KM068946

KM068947

KM068948

KM068949

KM068950

KM068951

KM068952

KM068953

KM068954

KM068955

KM068956

KM068957

KM068958

KM068959

KM068960

KM068961

KM068962

KM068963

KM068964

KM068965

KM068966

KM068967

KM068968

KM068969

KM068970

KM068971

KM068972

KM068973
COI

KM069014

KM069015

KM069016

KM069017

KM069018

KM069019

KM069020

KM069021

KM069022

KM069023

KM069024

KM069025

KM069026

KM069027

KM069028

KM069029

KM069030

KM069031

KM069032

KM069033

KM069034

KM069035

KM069036

KM069037

KM069038

KM069039

KM069040

KM069041

KM069042

KM069043

KM069044

KM069045

KM069046

KM069047

KM069048

KM069049

KM069050

KM069051

KM069052

KM069053

KM069054

KM069055

KM069056

KM069057

KM069058

KM069059

KM069060

KM069061

KM069062

KM069063

KM069064

KM069065

KM069066

KM069067

KM069068

KM069069

KM069070

KM069071

KM069072

KM069073

KM069074

KM069075

KM069076

KM069077

KM069078

KM069079

KM069080
CytB

KM069122

KM069123

KM069124

KM069125

KM069126

KM069127

KM069128

KM069129

KM069130

KM069131

KM069132

KM069133

KM069134

KM069135

KM069136

KM069137

KM069138

KM069139

KM069140

KM069141

KM069142

KM069143

KM069144

KM069145

KM069146

KM069147

KM069148

KM069149

KM069150

KM069151

KM069152

KM069153

KM069154

KM069155

KM069156

KM069157

KM069158

KM069159

KM069160

KM069161

KM069162

KM069163

KM069164

KM069165

KM069166

KM069167

KM069168

KM069169

KM069170

KM069171

KM069172

KM069173

KM069174

KM069175

KM069176

KM069177

KM069178

KM069179

KM069180

KM069181

KM069182

KM069183

KM069184

KM069185

KM069186

KM069187

Rag1

KM069227 


\begin{tabular}{|c|c|c|c|c|c|c|}
\hline & Yavakapady & BNHS 5864 & KM068974 & KM069081 & KM069188 & - \\
\hline & Kottigehara & SDBDU 2011.64 & KM068977 & KM069084 & KM069191 & - \\
\hline \multirow[t]{3}{*}{ Hylarana serendipi sp. nov. } & Kudawa & DZ 1144 & KM068979 & KM069086 & KM069193 & KM069248 \\
\hline & Kudawa & DZ 1145 & KM068980 & KM069087 & KM069194 & - \\
\hline & Kudawa & DZ 1146 & KM068981 & KM069088 & - & - \\
\hline \multirow{8}{*}{ Hylarana sreeni sp. nov. } & Chathankod & BNHS 5878 & KM068983 & KM069091 & KM069197 & - \\
\hline & Gavi & BNHS 5877 & KM068984 & KM069092 & KM069198 & - \\
\hline & Glenback estate & BNHS 5873 & KM068985 & KM069093 & KM069199 & - \\
\hline & Kadalar estate & SDBDU 2011.1041 & KM068986 & KM069094 & KM069200 & - \\
\hline & Kuddam & BNHS 5869 & KM068987 & KM069095 & KM069201 & KM069249 \\
\hline & Singappara & BNHS 5870 & KM068992 & KM069100 & KM069206 & - \\
\hline & Yercaud & SDBDU 2004.4553 & KM068993 & KM069101 & KM069207 & - \\
\hline & Thekkady & BNHS 5872 & KM068994 & KM069102 & KM069208 & KM069252 \\
\hline \multirow[t]{9}{*}{ Hylarana temporalis } & Hemmathagama & DZ 1092 & KM068995 & KM069103 & KM069209 & - \\
\hline & Hemmathagama & DZ 1095 & KM068996 & KM069104 & KM069210 & - \\
\hline & Kithulgala & DZ 1116 & KM068997 & KM069105 & KM069211 & - \\
\hline & Panwila & DZ 1153 & KM068998 & KM069106 & KM069212 & KM069253 \\
\hline & Peradeniya & DZ 1046 & KM068999 & KM069107 & KM069213 & - \\
\hline & Kudawa & DZ 1141 & KM069000 & KM069108 & KM069214 & KM069254 \\
\hline & Kudawa & DZ 1142 & KM069001 & KM069109 & KM069215 & - \\
\hline & Udadumbara & DZ 1150 & KM069002 & KM069110 & KM069216 & KM069255 \\
\hline & Udadumbara & DZ 1151 & KM069003 & KM069111 & KM069217 & - \\
\hline Hylarana cf. leptoglossa & Manipur & SDBDU 2007.93 & KM069011 & KM069119 & KM069224 & KM069259 \\
\hline Hylarana cf. tytleri & Tripura & SDBDU 2009.421 & KM069012 & KM069120 & KM069225 & KM069260 \\
\hline \multicolumn{7}{|l|}{ GenBank } \\
\hline Hylarana baramica & Malaysia & NCBI GenBank & EU604178 & - & - & EF088265 \\
\hline Hylarana cubitalis & Thailand & NCBI GenBank & - & - & - & EF088267 \\
\hline Hylarana erythraea & Borneo & NCBI GenBank & AY322294 & - & - & DQ347219 \\
\hline Hylarana faber & Cambodia & NCBI GenBank & - & - & - & EF088269 \\
\hline Hylarana guentheri & Vietnam1, China2 & NCBI GenBank & AY3222871 & JN7008212 & - & - \\
\hline Hylarana latouchii & Taiwan1, China2 & NCBI GenBank & AB0588801 & JN7008142 & EU0349261 & - \\
\hline Hylarana maosonensis & Vietnam & NCBI GenBank & EU754859 & - & - & EF088274 \\
\hline Hylarana nicobariensis & Java, Indonesia & NCBI GenBank & DQ347332 & - & - & DQ347274 \\
\hline Hylarana nigrovittata & Vietnam1, China2, Laos3 & NCBI GenBank & AF2852171 & JN7008132 & - & EF0882763 \\
\hline \multicolumn{7}{|l|}{ Out group } \\
\hline Clinotarsus curtipes & Karnataka & SDBDU 2011.42 & KM069013 & KM069121 & KM069226 & KM069261 \\
\hline Lankanectes corrugatus & Sri Lanka & NCBI GenBank & AF215393 & - & - & AY571653 \\
\hline
\end{tabular}




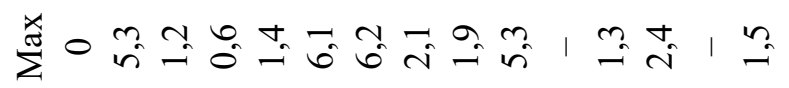

蛋

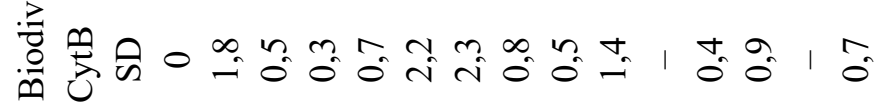

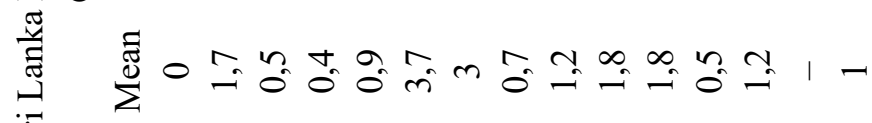

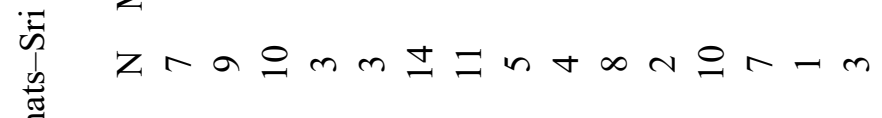
]ुำ

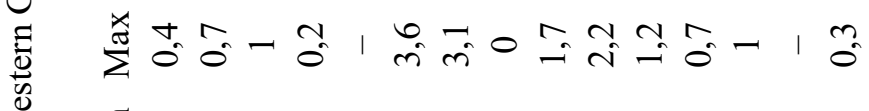
ह 50000100000 3001 है 高

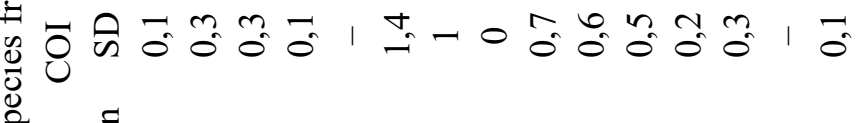
瑳 zoa am I Z t thmar-m

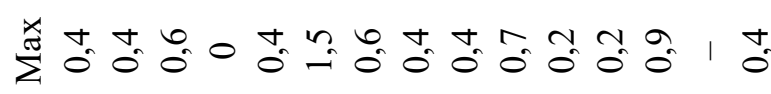
声 000000000000010

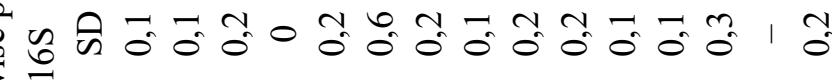

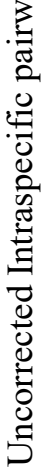

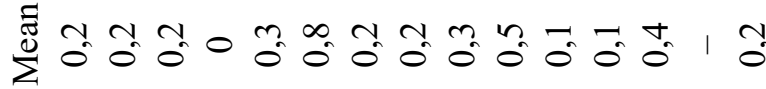
Zun a om $n$ Iattrmnn बิ

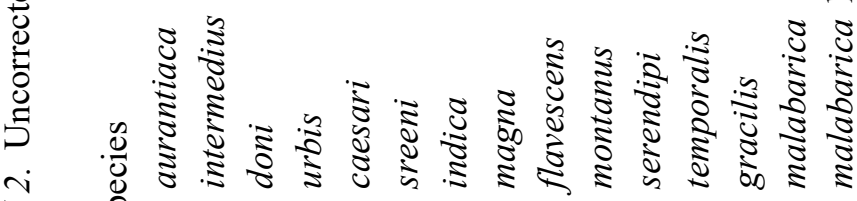

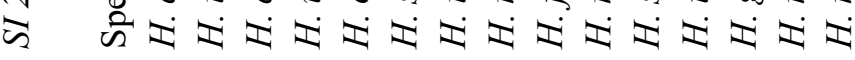




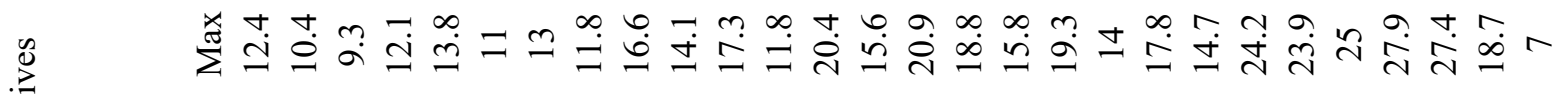

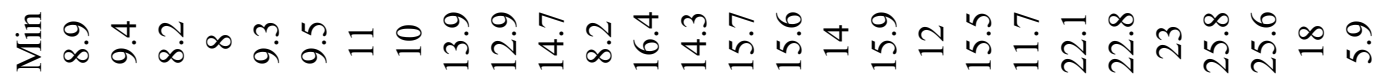

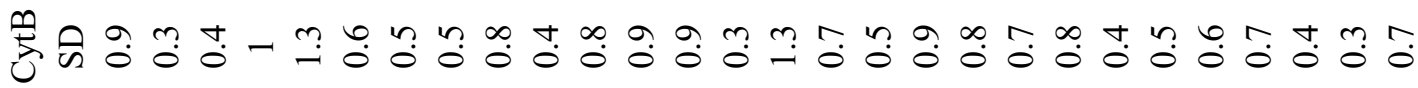
焉

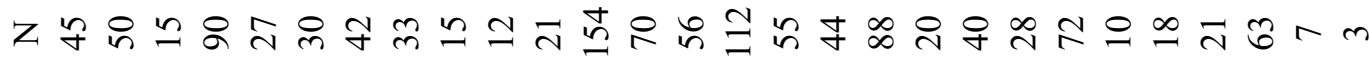

豖

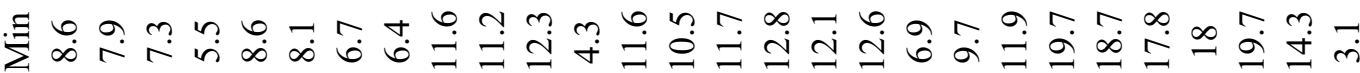

券

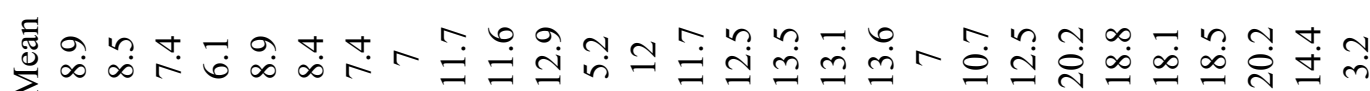

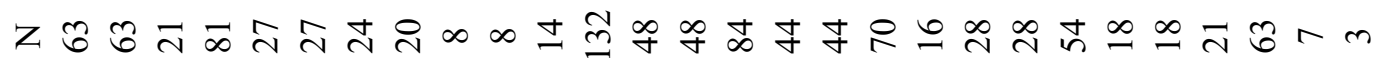

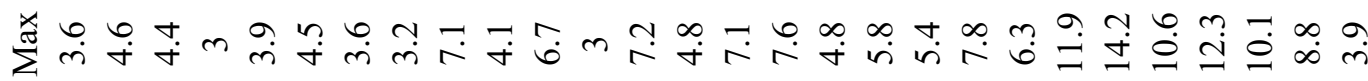

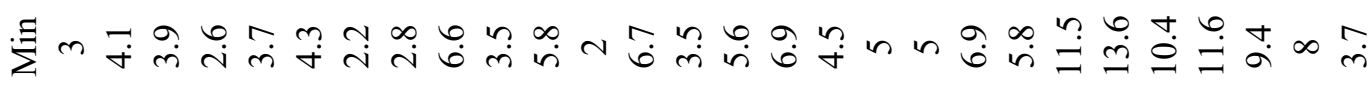

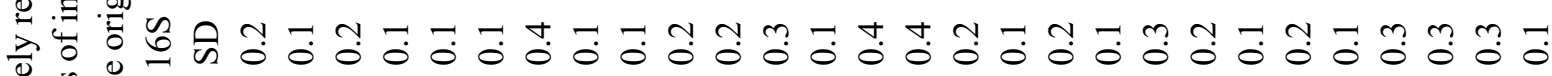
응

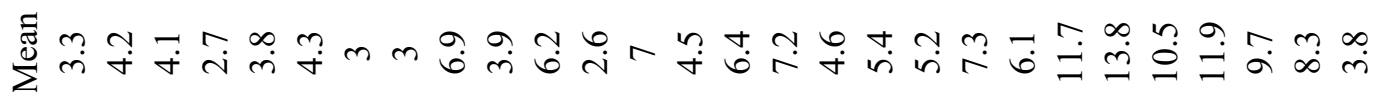

